\title{
Prevention of diabetes through lifestyle intervention
}

Citation for published version (APA):

Drummen, M. (2019). Prevention of diabetes through lifestyle intervention: effects on liver fat and brain .

[Doctoral Thesis, Maastricht University]. Gildeprint Drukkerijen. https://doi.org/10.26481/dis.20190124md

Document status and date:

Published: 01/01/2019

DOI:

10.26481/dis.20190124md

Document Version:

Publisher's PDF, also known as Version of record

\section{Please check the document version of this publication:}

- A submitted manuscript is the version of the article upon submission and before peer-review. There can be important differences between the submitted version and the official published version of record.

People interested in the research are advised to contact the author for the final version of the publication, or visit the DOI to the publisher's website.

- The final author version and the galley proof are versions of the publication after peer review.

- The final published version features the final layout of the paper including the volume, issue and page numbers.

Link to publication

\footnotetext{
General rights rights.

- You may freely distribute the URL identifying the publication in the public portal. please follow below link for the End User Agreement:

www.umlib.nl/taverne-license

Take down policy

If you believe that this document breaches copyright please contact us at:

repository@maastrichtuniversity.nl

providing details and we will investigate your claim.
}

Copyright and moral rights for the publications made accessible in the public portal are retained by the authors and/or other copyright owners and it is a condition of accessing publications that users recognise and abide by the legal requirements associated with these

- Users may download and print one copy of any publication from the public portal for the purpose of private study or research.

- You may not further distribute the material or use it for any profit-making activity or commercial gain

If the publication is distributed under the terms of Article $25 \mathrm{fa}$ of the Dutch Copyright Act, indicated by the "Taverne" license above, 


\section{PREVENTION OF DIABETES THROUGH LIFESTYLE INTERVENTION}

- Effects on Liver fat and Brain -

Mathijs Drummen 


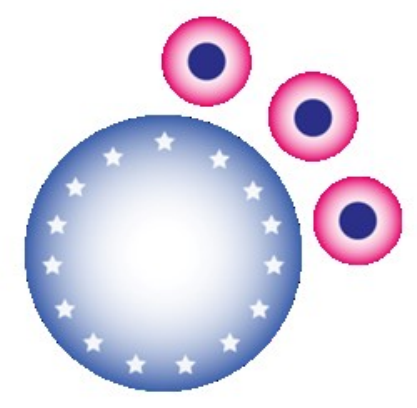

The study presented in this thesis was performed within the NUTRIM School of Nutrition and Translational Research in Metabolism and was supported by the $7^{\text {th }}$ Framework Programme of the European Commission.

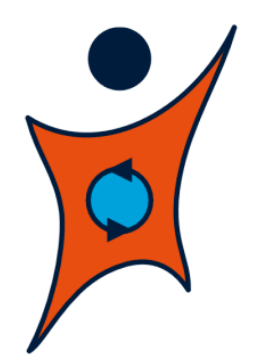

COVER DESIGN:

LAYOUT:

PRINTED AND PUBLISHED BY: Gildeprint

ISBN:

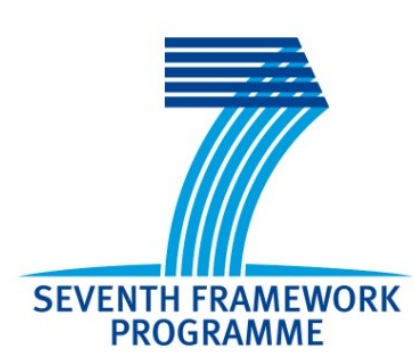

Roel Olieslagers

Mathijs Drummen

978-94-6323-481-8

CM. Drummen, 2018, the Netherlands

No parts of this thesis may be reproduced or transmitted in any form or by any means without the permission of the author or, when appropriate, of the publishers of the publications. 


\title{
PREVENTION OF DIABETES THROUGH LIFESTYLE INTERVENTION
}

\section{- Effects on Liver fat and Brain .}

\author{
PROEFSCHRIFT \\ ter verkrijging van de graad van doctor aan de Universiteit Maastricht, \\ op gezag van de Rector Magnificus, Prof. Dr. Rianne M. Letschert, \\ volgens het besluit van het College van Decanen \\ in het openbaar te verdedigen \\ op donderdag 24 januari 2019 om 10:00 uur
}

door

Mathijs Drummen

Geboren op 11 april 1989 te Heerlen 


\section{PROMOTOR}

Prof. dr. M.S. Westerterp-Plantenga

CO-PROMOTOR

Dr. T.C. Adam

Dr. A.C.E Vreugdenhil

\section{ASSESSMENT COMMITTEE}

Prof. dr. P. Schrauwen (chair)

Prof. dr. A. Masclee

Prof. dr. H. Preissl

Prof. dr. D. Tomé

Prof. dr. R. Goebel 


\section{TABLE OF CONTENTS}

\section{CHAPTER 1: General introduction}

CHAPTER 2: PREVIEW: PREVention of diabetes through lifestyle Intervention and population studies in Europe and around the World. Design, methods and baseline participant description of an adult cohort enrolled into a 3-year randomised clinical trial

CHAPTER 3: Objectively measured physical activity and sedentary time are associated with cardio-metabolic risk factors in adults with pre-diabetes: The PREVIEW study

CHAPTER 4: Dietary protein and energy balance in relation to obesity and co-morbidities

CHAPTER 5: Insulin Resistance, Weight and Behavioral Variables as Determinants of Brain Reactivity to Food Cues - a PREVIEW Study

CHAPTER 6: Men and women respond differently to rapid weight loss: Metabolic outcomes of a multi-centre intervention study after a low-energy diet in 2500 overweight, individuals with pre-diabetes (PREVIEW)

CHAPTER 7: Long-term effects of increased protein intake after weight loss on intrahepatic lipid content and implications for insulin sensitivity - a PREVIEW study

CHAPTER 8: Associations of brain reactivity to food cues with weight loss, protein intake and dietary restraint during the PREVIEW intervention

CHAPTER 9: Associations with grey matter volume and cortical thickness in the PREVIEW study

CHAPTER 10: General discussion

SUMMARY

SAMENVATTING

VALORIZATION

ACKNOWLEGDEMENTS

LIST OF PUBLICATIONS

ABOUT THE AUTHOR 

CHAPTER 1

General Introduction 
The increasing prevalence in type-2 diabetes (T2D), driven by changes in lifestyle and environment, has also increased the surge to find optimal strategies for T2D prevention. Clinical trials have shown that lifestyle interventions are the most effective tool in the prevention of T2D and they should be directed at individuals with the highest risk (1). Obesity is one of the strongest risk factors for developing T2D (2) and merely being overweight imposes a three-fold increased risk of T2D (3). One of the hallmarks of both obesity and T2D is increased insulin resistance (4), but exact mechanisms by which obesity links with insulin resistance remain unknown. Enlargement of lipid depots have been associated with insulin resistance (5) and especially when visceral adipose tissue depots expand, odds of insulin resistance increase (6).

Reducing insulin resistance and T2D risk can be achieved by losing body weight. Modest weight reduction of 5 to 10 percent was shown to already lead to clinically relevant health benefits, including the amelioration of insulin resistance (7). Weight loss occurs when energy expenditure exceeds energy intake and while this is relatively simple to achieve for a short period, long-term weight loss has proven to be very difficult to maintain (8). To this end, lifestyle interventions have been directed at establishing long-term body weight loss $(9,10)$. Within these interventions, different dietary lifestyle regimes have been evaluated throughout the years and recently a high protein/low GI diet vs low protein/high GI diet has been suggested to yield supreme results for long-term weight loss (11). Based on the association between increased body weight and T2D development, a high-protein /low GI diet may thus be effective for the prevention of T2D development (12). It remains unclear whether high protein diets have additional effects on insulin resistance beyond effects on body weight management (CHAPTER 4). Protein may affect underlying mechanisms that could influence metabolic parameters irrespective of body weight. Based on short-term studies there may be protein-specific effects on intrahepatic lipid content and brain activation, which aid in the prevention of T2D (CHAPTER 7 and 8). Moreover, combining high-protein intake with lower glycaemic index (GI)/glycaemic load (GL) has been suggested to be the optimal diet for prevention of T2D. International guidelines already include recommendations for lower GI foods (13), but long-term effects of lower GI foods on the prevention of T2D have not been tested in large trials.

Other important lifestyle components are physical activity and exercise. Increasing physical activity may be a potent strategy to reduce T2D risk. Increased physical activity was shown to increase insulin sensitivity (14) and an exercise intervention led to a decrease in the incidence of T2D over a 6-year period compared to a control group (15).

In this perspective, The PREVIEW-study (Prevention of Diabetes through Lifestyle Intervention and Population Studies in Europe and around the World), has been initiated. The PREVIEW-study is a multi-centre trial to determine effects of a lifestyle intervention on T2D development in individuals with pre-diabetes (CHAPTER 2) and started in 2013. The multi-centre trial was performed in eight centers including Maastricht University in Maastricht, the Netherlands.

Pre-diabetes was defined as having impaired fasting glucose and/or impaired glucose tolerance in combination with overweight/obesity, in accordance with the American Diabetes Association 
(ADA) criteria (16). Individuals with pre-diabetes present a highly vulnerable group with up to 70 percent of the individuals eventually developing diabetes (17).

The PREVIEW-study started with an eight-week low energy diet to establish body weight loss (CHAPTER 6), followed by a lifestyle intervention with four intervention arms, differing in physical activity and dietary programs. Physical activity programs of the PREVIEW intervention consisted of two groups differing in physical activity intensities. While it is know that physical activity is able to increase insulin sensitivity (14), it is unknown whether altering physical activity intensity or duration may have differential effects on insulin resistance and T2D development (CHAPTER 3).

Dietary programs of the PREVIEW intervention consisted of two groups differing in protein intake and GI/GL. Increasing protein intake has been recommended to achieve weight loss and especially to maintain body-weight after weight loss (18). Body-weight management may be improved by increased protein intake via increased satiety and energy expenditure and decreased body-fat percentage (CHAPTER 4). A reduction in body-fat percentage during energy restriction corresponds with a reduction in fat mass and sparing of fat-free mass and thereby limits the reduction of energy expenditure. Especially a reduction in ectopic fat mass relative to total bodyfat mass has been related to improved metabolic health, including insulin resistance (19). Intrahepatic lipid accumulation has been suggested as both a cause and consequence of insulin resistance (20). Short-term studies showed that protein supplementation was able to reduce intrahepatic lipid content $(21,22)$. Intrahepatic lipid content can be quantified using magnetic resonance spectroscopy (MRS) (23). Using MRS, metabolites can be non-invasively identified within tissues based on their resonance frequency. Proton $\left({ }^{1} \mathrm{H}\right)$-MRS can be specifically used to quantify lipid accumulation in the liver. During the PREVIEW-study, ${ }^{1} \mathrm{H}-\mathrm{MRS}$ was used to determine long-term effects of weight loss and weight maintenance with increased protein intake on intrahepatic lipid content and its implications for insulin resistance (CHAPTER 7).

The difficulties of achieving long-term body weight maintenance are partly explained by decreased compliance to dietary guidelines, which is therefore also an important issue within the three year intervention of the PREVIEW-study. A reduction in compliance may be caused by a reduced rewarding value of food in response to lower levels of energy intake (24-26). Alterations in brain reward activity may overrule the homeostatic control of energy balance, leading to increased food intake and weight (re)gain (27). Neuroimaging studies have identified brain regions involved in food-reward processing. Especially the mesolimbic pathway has been associated with reward and motivation and consists of dopaminergic neurons originating in the ventral tegmental area projecting to the nucleus accumbens, striatum and prefrontal cortex (28, 29). The mesolimbic pathway interacts with pathways associated with emotion and cognitive control to modulate activity of homeostatic brain regions and regulate eating behavior (30). Protein supplementation was shown to alter the brain reward response and hence may improve long-term weight management (31). Furthermore, converging evidence suggests that brain reward activity is affected by insulin resistance (CHAPTER 5) (32). This may also explain differences found in food-reward related brain activation between individuals with T2D or obesity and healthy individuals $(24,33)$. Functional magnetic resonance imaging (fMRI) was used to measure brain reactivity to food cues during the PREVIEW-study (CHAPTER 8). The technique 
that was used to determine brain activity was blood oxygen level dependent imaging, which utilizes the differential magnetic properties of de-oxygenated and oxygenated hemoglobin. In response to neuronal activation, the ratio between de-oxygenated and oxygenated hemoglobin changes leading to changes in signal intensity.

Changes in body weight and insulin resistance during The PREVIEW-study may also lead to differences in brain structure (CHAPTER 9). Grey matter volume and cortical thickness have reportedly been reduced in individuals with obesity and T2D $(34,35)$. Grey matter comprises neuronal cell bodies, dendrites and glial cells and its volume has been shown to decrease with aging and in neurodegenerative diseases $(36,37)$. Grey matter volume is a function of both cortical surface area and cortical thickness and in past years especially the latter has been posed as a relevant marker of brain functionality (38). However, while the relationships between cortical thickness, grey matter volume and brain function are far from clear, even less is known about the dynamic properties of these variables.

In this thesis, the effects of a lifestyle intervention with increased protein intake to prevent diabetes were studied. This included effects on body weight, body composition and insulin resistance, with special focus for the role of intrahepatic lipid content and brain reward system. The studies in this thesis present data of the complete PREVIEW-cohort including the Maastricht cohort and of sub-studies performed solely in the Maastricht cohort. Studies are presented in temporal order of data collection, beginning with a general description of the methods, followed by reports on baseline, and lastly intervention related results. 


\section{REFERENCES}

1. Ahmad LA, Crandall JP. Type 2 Diabetes Prevention: A Review. Clinical Diabetes 2010;28(2):53-9

2. Guh DP, Zhang W, Bansback N, Amarsi Z, Birmingham CL, Anis AH. The incidence of co-morbidities related to obesity and overweight: a systematic review and meta-analysis. BMC Public Health 2009;9:88.

3. Weinstein AR, Sesso HD, Lee IM, Cook NR, Manson JE, Buring JE, Gaziano JM. Relationship of physical activity vs body mass index with type 2 diabetes in women. Jama 2004;292(10):1188-94.

4. Al-Goblan AS, Al-Alfi MA, Khan MZ. Mechanism linking diabetes mellitus and obesity. Diabetes, Metabolic Syndrome and Obesity: Targets and Therapy 2014;7:587-91.

5. Hocking S, Samocha-Bonet D, Milner KL, Greenfield JR, Chisholm DJ. Adiposity and insulin resistance in humans: the role of the different tissue and cellular lipid depots. Endocrine reviews 2013;34(4):463-500.

6. McLaughlin T, Lamendola C, Liu A, Abbasi F. Preferential fat deposition in subcutaneous versus visceral depots is associated with insulin sensitivity. J Clin Endocrinol Metab 2011;96(11):E1756-60.

7. Blackburn G. Effect of degree of weight loss on health benefits. Obesity research 1995;3 Suppl 2:211s-6s.

8. Wing RR, Phelan S. Long-term weight loss maintenance. Am J Clin Nutr 2005;82(1 Suppl):222s-5s.

9. Tuomilehto J, Lindstrom J, Eriksson JG, Valle TT, Hamalainen H, Ilanne-Parikka P, Keinanen-Kiukaanniemi S, Laakso M, Louheranta A, et al. Prevention of type 2 diabetes mellitus by changes in lifestyle among subjects with impaired glucose tolerance. The New England journal of medicine 2001;344(18):1343-50.

10. Li G, Zhang P, Wang J, Gregg EW, Yang W, Gong Q, Li H, Li H, Jiang Y, An Y, et al. The long-term effect of lifestyle interventions to prevent diabetes in the China Da Qing Diabetes Prevention Study: a 20-year follow-up study. Lancet 2008;371(9626):1783-9.

11. Larsen TM, Dalskov SM, van Baak M, Jebb SA, Papadaki A, Pfeiffer AF, Martinez JA, Handjieva-Darlenska T, Kunesova $M$, Pihlsgard $M$, et al. Diets with high or low protein content and glycemic index for weight-loss maintenance. The New England journal of medicine 2010;363(22):2102-13.

12. Liu AY, Silvestre MP, Poppitt SD. Prevention of type 2 diabetes through lifestyle modification: is there a role for higher-protein diets? Advances in nutrition 2015;6(6):665-73.

13. Buyken AE, Mitchell P, Ceriello A, Brand-Miller J. Optimal dietary approaches for prevention of type 2 diabetes: a life-course perspective. Diabetologia 2010;53(3):406-18.

14. Duncan GE, Perri MG, Theriaque DW, Hutson AD, Eckel RH, Stacpoole PW. Exercise training, without weight loss, increases insulin sensitivity and postheparin plasma lipase activity in previously sedentary adults. Diabetes Care 2003;26(3):557-62.

15. Pan XR, Li GW, Hu YH, Wang JX, Yang WY, An ZX, Hu ZX, Lin J, Xiao JZ, Cao HB, et al. Effects of diet and exercise in preventing NIDDM in people with impaired glucose tolerance. The Da Qing IGT and Diabetes Study. Diabetes Care 1997;20(4):537-44.

16. 2. Classification and Diagnosis of Diabetes:Standards of Medical Care in Diabetes-2018. Diabetes Care 2018;41(Supplement 1):S13-S27.

17. Tabák AG, Herder C, Rathmann W, Brunner EJ, Kivimäki M. Prediabetes: a high-risk state for diabetes development. Lancet. 2012;379(9833):2279-90.

18. Westerterp-Plantenga MS, Lejeune MP, Nijs I, van Ooijen M, Kovacs EM. High protein intake sustains weight maintenance after body weight loss in humans. Inter J Obes and related metabolic disorders : journal of the International Association for the Study of Obesity 2004;28(1):57-64.

19. Fabbrini E, Magkos F, Mohammed BS, Pietka T, Abumrad NA, Patterson BW, Okunade A, Klein S. Intrahepatic fat, not visceral fat, is linked with metabolic complications of obesity. Proc Nat/ Acad Sci USA 2009;106(36):15430-5.

20. Valenti L, Bugianesi E, Pajvani U, Targher G. Nonalcoholic fatty liver disease: cause or consequence of type 2 diabetes? Liver Internationa/2016;36(11):1563-79.

21. Bortolotti M, Maiolo E, Corazza M, Van Dijke E, Schneiter P, Boss A, Carrel G, Giusti V, Le KA, Quo Chong $D G$, et al. Effects of a whey protein supplementation on intrahepatocellular lipids in obese female patients. Clinical nutrition 2011;30(4):494-8.

22. Theytaz F, Noguchi Y, Egli L, Campos V, Buehler T, Hodson L, Patterson BW, Nishikata N, Kreis R, Mittendorfer $B$, et al. Effects of supplementation with essential amino acids on intrahepatic lipid concentrations during fructose overfeeding in humans. Am J Clin Nutr 2012;96(5):1008-16.

23. Szczepaniak LS, Nurenberg P, Leonard D, Browning JD, Reingold JS, Grundy S, Hobbs HH, Dobbins RL. Magnetic resonance spectroscopy to measure hepatic triglyceride content: prevalence of hepatic steatosis in the general population. Am J Physiol Endocrinol Metab 2005;288(2):E462-8. 
24. Chechlacz M, Rotshtein P, Klamer S, Porubska K, Higgs S, Booth D, Fritsche A, Preissl H, Abele H, Birbaumer $\mathrm{N}$, et al. Diabetes dietary management alters responses to food pictures in brain regions associated with motivation and emotion: a functional magnetic resonance imaging study. Diabetologia 2009;52(3):524-33.

25. Cameron JD, Goldfield GS, Cyr MJ, Doucet E. The effects of prolonged caloric restriction leading to weightloss on food hedonics and reinforcement. Physio/ Behav 2008;94(3):474-80.

26. Stice E, Burger K, Yokum S. Caloric Deprivation Increases Responsivity of Attention and Reward Brain Regions to Intake, Anticipated Intake, and Images of Palatable Foods. NeuroImage 2013;67:322-30.

27. Berthoud HR. Homeostatic and non-homeostatic pathways involved in the control of food intake and energy balance. Obesity (Silver Spring) 2006;14 Suppl 5:197s-200s.

28. Wise RA. Brain Reward Circuitry: Insights from Unsensed Incentives. Neuron 2002;36(2):229-40.

29. Sanchez-Lasheras C, Konner AC, Bruning JC. Integrative neurobiology of energy homeostasis-neurocircuits, signals and mediators. Frontiers in neuroendocrinology 2010;31(1):4-15.

30. Berthoud HR. Metabolic and hedonic drives in the neural control of appetite: Who's the boss? Curr Opin Neurobio/2011;21(6):888-96.

31. Leidy HJ, Ortinau LC, Douglas SM, Hoertel HA. Beneficial effects of a higher-protein breakfast on the appetitive, hormonal, and neural signals controlling energy intake regulation in overweight/obese, "breakfast-skipping," late-adolescent girls. Am J Clin Nutr 2013;97(4):677-88.

32. Adam TC, Tsao S, Page KA, Hu H, Hasson RE, Goran MI. Insulin sensitivity and brain reward activation in overweight Hispanic girls: a pilot study. Pediatr Obes 2015;10(1):30-6.

33. Pursey KM, Stanwell P, Callister RJ, Brain K, Collins CE, Burrows TL. Neural Responses to Visual Food Cues According to Weight Status: A Systematic Review of Functional Magnetic Resonance Imaging Studies. Frontiers in Nutrition 2014;1.

34. Raji CA, Ho AJ, Parikshak NN, Becker JT, Lopez OL, Kuller LH, Hua X, Leow AD, Toga AW, Thompson PM. Brain structure and obesity. Hum Brain Mapp 2010;31(3):353-64.

35. Moran C, Beare R, Phan TG, Bruce DG, Callisaya ML, Srikanth V. Type 2 diabetes mellitus and biomarkers of neurodegeneration. Neurology 2015;85(13):1123-30.

36. Hafkemeijer A, Altmann-Schneider I, de Craen AJM, Slagboom PE, van der Grond J, Rombouts SARB. Associations between age and gray matter volume in anatomical brain networks in middle-aged to older adults. Aging Cel/2014;13(6):1068-74.

37. Seeley WW, Crawford RK, Zhou J, Miller BL, Greicius MD. Neurodegenerative diseases target large-scale human brain networks. Neuron 2009;62(1):42-52.

38. Winkler AM, Kochunov P, Blangero J, Almasy L, Zilles K, Fox PT, Duggirala R, Glahn DC. Cortical thickness or grey matter volume? The importance of selecting the phenotype for imaging genetics studies. NeuroImage 2010;53(3):1135-46. 


\section{CHAPTER 2}

PREVIEW: PREVention of diabetes through lifestyle Intervention and population studies in Europe and around the World.

Design, methods and baseline participant description of an adult cohort enrolled into a 3year randomised clinical trial

M. Fogelholm, T. M. Larsen, M. Westerterp-Plantenga, I. Macdonald, J. Alfredo Martinez Hernandez, N. Boyadjieva, S. Poppitt, W. Schlicht, G. Stratton, J. Sundvall, T. Lam, E. Jalo, P.Christensen, M. Drummen, E. Simpson, S. Navas-Carretero, T. Handjieva-Darlenska, R. Muirhead, M. P. Silvestre, D. Kahlert, L. Pastor-Sanz, J. BrandMiller and A. Raben

Published in:

Nutrients (2017) 


\section{ABSTRACT}

Type-2 diabetes (T2D) is one of the fastest growing chronic diseases worldwide. The PREVIEW project has been initiated to find the most effective lifestyle (diet and physical activity) for the prevention of T2D, in overweight and obese participants with increased risk for T2D. The study is a 3-y multi-centre, $2 \times 2$ factorial, randomised controlled. The impact of a high-protein, lowglycaemic index (GI) vs. moderate protein, moderate-GI diet in combination with moderate or high-intensity physical activity on the incidence of T2D and related clinical end-points is investigated. The intervention started with a 2-month 8-week weight reduction using a lowcalorie diet, followed by a randomised 34-month weight maintenance phase comprising 4 treatment arms. Eight intervention centres are participating (Denmark, Finland, United Kingdom, the Netherlands, Spain, Bulgaria, Australia, New Zealand). Data from blood specimens, urine, faeces, questionnaires, diaries, body composition assessments and accelerometers are collected at months $0,2,6,12,18,24$ and 36. In total, 2,326 adults were recruited. Mean age was 51.6 (SD 11.6) years, $67 \%$ were women. PREVIEW is to date the largest, multinational trial to address prevention of $\mathrm{T} 2 \mathrm{D}$ in pre-diabetic adults through diet and exercise intervention. The final participant will complete the intervention in March, 2018. 


\section{INTRODUCTION}

Type-2 diabetes (T2D) is a disease associated with serious comorbidities, including microvascular (retinopathy, nephropathy, neuropathy) and macrovascular (cardiovascular) events (1). The estimated global prevalence is approximately $8 \%$ and a prediction suggests that this will increase by $55 \%$ up to the year $2035(2,3)$. An important risk factor for T2D is obesity (BMI $>30 \mathrm{~kg} / \mathrm{m} 2)$ predicting a more than 10 -fold increase in incidence compared to normal weight (4). Weight gain during adulthood is also a independent risk factor for T2D (5), as are genetic inheritance, unhealthy dietary habits and insufficient physical activity (6-8).

Long-term studies have shown benefits of a lifestyle intervention (diet and exercise), on T2D incidence in China (9), USA (10) and Finland (11). Lifestyle change (diet, physical activity, weight loss) may reduce the incidence of T2D by $28 \%-59 \%$ (12). The American Diabetes Prevention Program (DPP) (13), the Finnish Diabetes Prevention Study (DPS) (14) and the Chinese Da Qing Diabetes Prevention Study (15) were all designed to produce weight loss by prescribing a highcarbohydrate $(\mathrm{CHO})$ ( $>50$ percent of energy $(\mathrm{E} \%)$ from $\mathrm{CHO}$ ), low-fat $(<30 \mathrm{E} \%)$ diet approach which reflected the understanding of a prudent diet 20 years ago. No attention was paid to glycaemic index (GI) per se, and to date no studies have investigated the role of GI for prevention of type-2 diabetes. Other dietary prescriptions that produce significant and sustainable weight loss may also be effective in T2D prevention. Current international recommendations include lower ranges for $\mathrm{CHO}$ intake (16) and a recommendation to choose lower GI foods (17). A combination of lower $\mathrm{CHO}$ (45 E\%), higher protein together with lower GI might be the optimal diet for prevention of T2D (18), perhaps related to sustained weight loss as shown in medium term trials (19). To date these hypotheses have not been tested in large trials of long duration (20).

The program for physical activity in the trials described above followed the international public health recommendations, that is, a total of approximately 150 minutes per week of moderateintensity aerobic activities or 75 minutes of vigorous intensity activity $(10,14)$. A question, not examined in earlier studies, is whether the metabolic responses are different between higher- and lower-intensity exercise programs. Moderate-intensity exercise relies relatively more on fat oxidation, whereas vigorous-intensity exercise relies more on $\mathrm{CHO}$ oxidation and use of intramuscular substrates (21). Houmard et al. found that total exercise time, not intensity or exercise energy expenditure, was associated with the greatest improvement of insulin sensitivity in obese participants (22). However, the hypothesis that physical activity with different intensity levels may differentially affect T2D prevention has yet to be tested in any large-scale intervention.

Since obesity is a strong risk factor for T2D, any successful prevention program should be able to prevent weight regain in individuals after a significant weight loss. The high heterogeneity of dietary intervention design prevents firm conclusions being drawn regarding preferred macronutrient composition (23). Notably a recent multi-centre trial 'DiOGenes' (Diet, Obesity and Genes) identified a higher-protein, moderate-CHO and low-GI diet as superior to other diets of varying macronutrient composition in preventing weight regain over six months (19) and in a smaller subset over 12 months (24), after 2 months of rapid weight loss. 
Despite the evidence that a lifestyle program combining prudent diet, increased physical activity and weight loss reduces the risk for T2D in susceptible individuals (12), important details remain unanswered. These include the long-term effects and sustainability of diets higher in protein with a lower glycaemic load, combined with the effects of higher intensity exercise. The present paper describes PREVention of diabetes through lifestyle Intervention and population studies in Europe and around the World (PREVIEW), a large multi-centre international randomised controlled trial in adults designed to answer these questions.

\section{METHODS}

\section{Aims of the study}

The aim is to determine the effects and interactions of two diets and two physical activity programmes on the prevention of T2D in overweight, pre-diabetic adults, who have undergone a short period of significant weight loss. Our primary hypothesis is that a higher protein, lower $\mathrm{CHO} /$ low GI diet (based on the DiOGenes study(19)) will be superior in preventing T2D when compared with a moderate protein, higher $\mathrm{CHO} /$ moderate GI diet (based on the DPS and DPP studies $(10,14))$. We also hypothesise that high-intensity physical activity will be superior compared to moderate-intensity physical activity (25).Each participant receives one of the two dietary programs, and one of the two physical activity programs, thus we have four groups (high protein diet and high-intensity physical activity; moderate protein diet and high-intensity physical activity; high protein diet and moderate-intensity physical activity; moderate-protein diet and moderate-intensity physical activity). The majority of outcomes will be analysed by using these four arms. The primary endpoint and statistical power calculations are based on a two-arm design (diets compared against each other).

\section{Primary and secondary endpoints}

The primary endpoint is incidence of T2D in high vs. moderate protein diet measured over a 36month intervention period, based on the WHO criteria (26) of either (i) OGTT with fasting plasma glucose FPG $>7.0 \mathrm{mmol} / \mathrm{l}$ and/or 2 -h post prandial ( $75 \mathrm{~g}$ glucose load) plasma glucose $\geq 11.1$ $\mathrm{mmol} / \mathrm{l}$, or (ii) T2D diagnosed by a medical doctor between the Clinical Investigation Days (CID) of PREVIEW, by using random plasma glucose $\geq 11.1 \mathrm{mmol} / \mathrm{L}$ in the presence of symptoms of diabetes, OGTT or glycated hemoglobin (HbAlc). Asymptomatic individuals with a single abnormal value will have to repeat the test within 2-4 weeks to confirm the T2D diagnosis. The secondary endpoints include changes in HbAlc, body weight, BMI, waist, and thigh circumference, body composition, insulin sensitivity, including Matsuda Index (27), glucose tolerance assessed by area under the curve during OGTT, blood pressure, serum lipids, C-reactive protein, liver enzymes, perceived quality of life and work ability, habitual well-being, sleep, chronic stress, and subjective appetite sensations. Other endpoints assessed by sub-group studies include liver fat content using magnetic resonance imaging (MRI) and proton magnetic resonance spectroscopy (H-MRS); colorectal cancer risk assessed from faecal markers; gut microbiome community assessment from faecal collections; maximal oxygen uptake capacity (VO2 max); urine metabolite profiles using metabolomic techniques and food reward outcomes. 


\section{Study setting and design}

The PREVIEW intervention study for adult participants has eight study sites: University of Copenhagen (Denmark), University of Helsinki (Finland), University of Maastricht (The Netherlands), University of Nottingham (UK), University of Navarra (Spain), Medical University of Sofia (Bulgaria), University of Sydney (Australia) and University of Auckland (New Zealand). The 36-month intervention consists of two phases (FIGURE 1): a 2-month period of rapid weight reduction achieved using a commercial low-calorie diet (about $800 \mathrm{kcal} /$ day), followed by a 34month randomised lifestyle (diet and physical activity) intervention phase for weight loss maintenance.

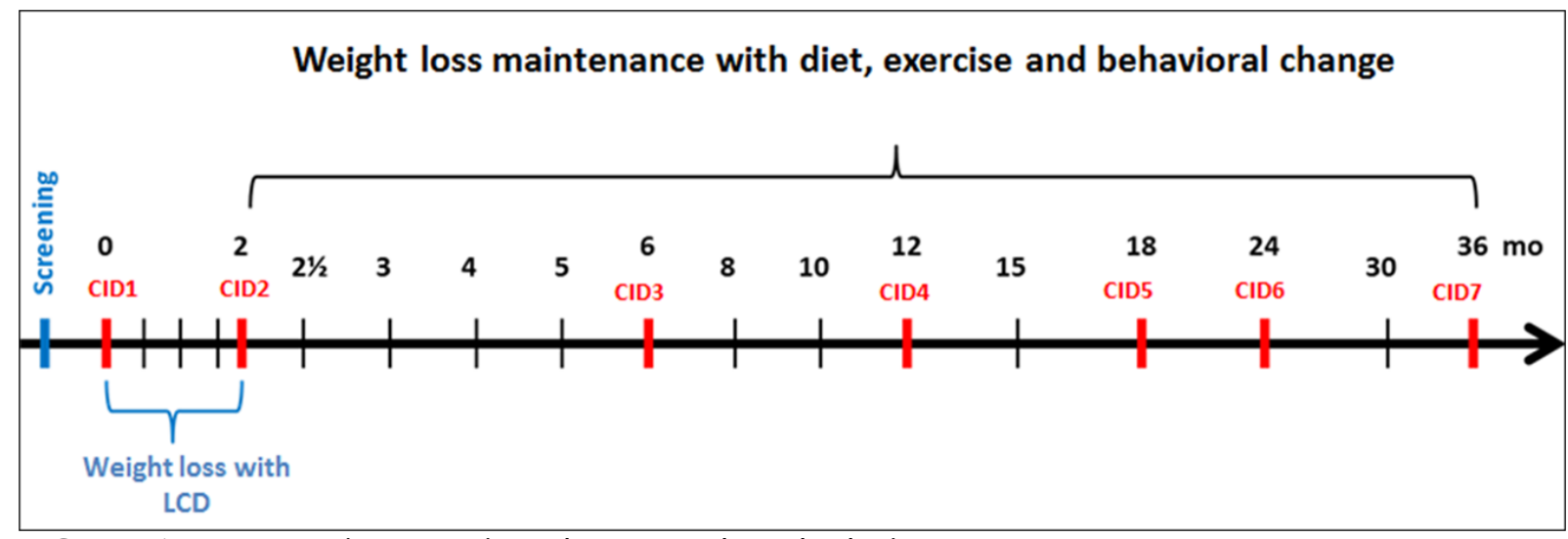

FIGURE 1. PREVIEW intervention: the general study design

Clinical investigation days (CID) are conducted throughout the intervention, from CID1 (baseline) to CID7 (end of trial). At CID visits, anthropometry, blood tests and questionnaires are performed and collection of completed diet records, accelerometers, and 24-h urine samples is done. Adverse (AE) and serious adverse events (SAE) and concomitant medications are recorded. In addition, a total of 17 group visits, leaded by instructors, are held throughout the trial to support lifestyle modification. The CID assessments and group visits are conducted within University settings or associated Clinics. Participants follow the diet and physical activity counselling advice in a "real-life" setting without daily supervision from researchers.

\section{Participants, recruitment and randomisation}

The inclusion criteria were: age 25 - 70 years (from mid 2013 to mid 2014 individuals aged 25-45 and 55-70 years were enrolled, and from mid 2014 onwards additionally age-group 45-54 years); BMI > $25 \mathrm{~kg} / \mathrm{m} 2$; pre-diabetes confirmed by an OGTT using ADA criteria (13): (i) IFG, with venous plasma glucose concentration of $5.6-6.9 \mathrm{mmol} / \mathrm{l}$ when fasted, and/or (ii) IGT, with venous plasma glucose concentration of $7.8-11.0 \mathrm{mmol} / \mathrm{l}$ at $2 \mathrm{~h}$ after oral administration of standard 75 g glucose dose, and fasting plasma glucose $<7.0 \mathrm{mmol} / \mathrm{l}$. The main exclusion criteria were T2D, and any illness and/or medication with known or potential effect on compliance (e.g. unable to follow the physical activity program) or the main outcomes. A complete list of inclusion and exclusion criteria is presented as Supplementary Table 1. 
TABLE 1. Description of the PREVIEW dietary interventions

Higher protein $\left(25 \mathrm{E} \%^{\mathrm{a}}\right)$

Moderate protein (15 E\%)

Moderate carbohydrate (45 E\%)

Higher carbohydrate (55 E\%)

Low $\mathrm{GI}^{\mathrm{b}}(\leq 50)$ diet

Medium GI ( $\geq 56)$ diet

\begin{tabular}{|c|c|c|}
\hline $\begin{array}{l}\text { Comparison between } \\
\text { the groups }\end{array}$ & $\begin{array}{l}\text { - Protein intake higher } \\
\text { - Carbohydrate intake lower } \\
\text { - GI lower }\end{array}$ & $\begin{array}{l}\text { - Protein intake lower } \\
\text { - } \quad \text { Carbohydrate intake higher } \\
\text { - } \quad \text { GI medium }\end{array}$ \\
\hline $\begin{array}{l}\text { Food items with } \\
\text { increased use (relative } \\
\text { to the other group) }\end{array}$ & $\begin{array}{l}\text { - Whole-grain cereals with low GI } \\
\text { - Pasta } \\
\text { - Low-fat dairy products } \\
\text { - Poultry } \\
\text { - Fish } \\
\text { - Legumes }\end{array}$ & $\begin{array}{l}\text { Whole-grain cereals with } \\
\text { moderate/high GI, e.g. bread } \\
\text { - Potatoes, sweet potatoes, } \\
\text { couscous, rice } \\
\text { - Bananas }\end{array}$ \\
\hline Similar use & $\begin{array}{l}\text { - } \text { Most fruits and vegetables } \\
\text { - } \text { Vegetable oils, margarine } \\
\text { - } \text { Red meat (decreased in both) } \\
\text { - } \quad \text { Sugar-sweetened beverages (dec }\end{array}$ & ed in both) \\
\hline
\end{tabular}

Participants were recruited using multiple methods across the eight study sites, e.g., newspaper advertisements, newsletters, radio and television advertisements/interviews, and direct contact with primary and occupational health care providers. Interested individuals were contacted for the pre-screening. In the interview, inclusion and exclusion criteria were queried, including the Finnish Diabetes Risk Score (28) assessment. Potential participants were given written and oral information. Signed informed consent was required prior to commencement of laboratory screening. The laboratory screening comprised measurements of weight, height, resting blood pressure, electrocardiography (in those aged 55 y or more), and an OGTT. A fasting blood sample was collected from the ante-cubital vein for later assessment of full inclusion and exclusion criteria, whilst glucose concentration was immediately analysed at each study site (HemoCue ${ }^{\mathrm{TM}}$, Angelholm, Sweden; Reflotron ${ }^{\mathrm{TM}}$, Roche diagnostics, Switzerland; or EML105 Radiometer, Copenhagen). Participants were then given a standard glucose drink (75 g glucose, dissolved in $300 \mathrm{ml}$ water), which they had to take within 3-5 minutes, and a second venous blood sample was collected after $2 \mathrm{~h}$. No other food or drinks or smoking were allowed and participants were required to remain sedentary during the test. The 0 and $2 \mathrm{~h}$ glucose concentration were used to identify those with pre-diabetes. Potentially eligible participants had fasting blood samples analysed to assess safety with haemoglobin, creatinine and alanine (ALT)/aspartate transaminase (AST). Upon confirmation of eligibility, participants were enrolled into the trial and randomised to one of the four treatment groups. Randomisation was stratified by gender and age group (25$45,46-54$ and $55-70 \mathrm{y}$ ), and sequentially assigned from each stratum to different interventions, 
hence, securing an even distribution of gender and age group over the four intervention arms in each centre.

\section{Low-calorie diet (LCD)}

The trial started with a 2-month (8-wk) weight reduction program using a commercial LCD, with a requirement to lose $>8 \%$ initial body weight in order to continue to the weight maintenance phase. The LCD consisted of $3.4 \mathrm{MJ}(800 \mathrm{kcal}), 15-20 \mathrm{E} \%$ fat, $35-40 \mathrm{E} \%$ protein ( $84 \mathrm{~g}$ protein) and 45-50 E\% CHO. The daily diet comprised of $4 \times 40 \mathrm{~g}$ Cambridge Weight Plan ${ }^{\circledR}$ meal replacement sachets (Cambridge Weight Plan Ltd, UK), three of which were dissolved in $250 \mathrm{ml}$ low fat milk or similar lactose-free alternatives and one in $250 \mathrm{ml}$ water. Energy-free drinks were permitted. Moreover, a maximum of $400 \mathrm{~g}$ of non-starchy, low $\mathrm{CHO}$ vegetables such as lettuce, asparagus, broccoli, celery, cucumber, mushrooms, radish, tomato and watercress could be consumed. During the LCD, participants attended group visits at weeks 2, 4, 6, 8. Body weight, $A E, S A E$ and concomitant medications were recorded, LCD sachets dispensed, and dietary and behavioural instructions given. No specific instructions on physical activity were given during the LCD weightreduction phase. Upon completion of the two months (CID2), participants who failed to reach the target weight reduction (i.e. $>8 \%$ of initial body weight) were excluded from the intervention.

\section{Weight maintenance phase: intervention diets}

The two intervention diets are described in TABLE 1. The moderate protein (MP) diet is based on the DPS-dietary advice (14) aiming to reach a moderate protein (15 E\%) and higher $\mathrm{CHO}$ (55 E\%) macronutrient distribution with at least moderate dietary GI $(>56)$, following current recommendations for prevention of T2D (17). The (HP) diet has a higher protein (25 E\%) and moderate $\mathrm{CHO}(45 \mathrm{E} \%)$ distribution with lower dietary $\mathrm{GI}(<50)$, based on the most successful weight-loss maintenance diet in the DiOGenes study (19). Protein intake is higher and CHO intake is lower than the recommended range for prevention of T2D $(16,17)$. Both intervention diets are moderate in fat (30 E\%) and the target macronutrient profile and food choices are supported by evidence for prevention of weight gain and/or T2D $(8,23)$. Notably, increased intake of sugar-rich foods or refined grains is not encouraged as a means to reach the higher $\mathrm{CHO}$ level, nor is increased consumption of red meat encouraged within the higher protein diet. The diets are consumed ad libitum with respect to energy, with no provision of an individual target for daily energy intake. Self-monitoring of total energy consumption is not required. However, participants are instructed about controlling portion sizes of specific food types in order to achieve the macronutrient and GI prescriptions, and in self-monitoring and adjustment of portion sizes in general, in order to maintain their body weight loss. They are also encouraged to follow a regular meal pattern. Additional weight reduction is allowed, but without anything other than adherence to the maintenance diet and physical activity regimens. The participants are given examples of daily eating plans with foods in appropriate proportions to reflect the macronutrient and GI requirements of the two interventions. A food-exchange list assists in self-selected variety, whilst preserving the required macronutrient and GI levels. Cooking books (one for each diet) with recipes suitable for all countries were specifically prepared for PREVIEW. 


\section{Weight maintenance phase: physical activity programmes}

The trial has two physical activity interventions with a similar target for energy expenditure $(>4.2$ $\mathrm{MJ} / \mathrm{wk}>1000 \mathrm{kcal} / \mathrm{wk})$, comprising high-intensity $(\mathrm{HI})$ exercise or moderate-intensity (MI) exercise, as shown in TABLE 2. Measured heart-rate using a heart-rate monitor or wrist palpation, and/or perceived exertion using the Borg scale (29) are the principal methods of controlling the intensity. The participants may choose from several exercise options with similar level of metabolic turnover (energy expenditure divided by resting metabolic rate, i.e. MET values). The specific advice is based on the U.S. Centers for Disease Control and Prevention (CDC) recommendations of $75 \mathrm{~min}$ high-intensity $(\mathrm{HI})$ or $150 \mathrm{~min}$ moderate-intensity (MI) physical activity weekly (30). We developed a leaflet and other written instruction materials for the two PA groups. Physical activity is generally not supervised by the PREVIEW team, but participants are allowed to join supervised exercise groups of their own choice. A critical issue in PREVIEW is that many participants may be morbidly obese (BMI>40) and therefore their ability to cope with a high-intensity exercise program is likely to be limited and even risky. We addressed this point during the recruitments by specifically asking about perceived competence in coping with our program, and by ECG in all volunteers aged $>55$ years. Moreover, significant weight reduction ( $>8 \%$ of baseline body weight) during the first 2 months' LCD period will simultaneously decrease also the cardiovascular risks. The flexibility of our exercise program (only target energy expenditure is specified, the modes of exercise are due to the participant) is also likely to improve safety and adherence.

\section{Group visits and the behavioural modification program}

Group visits (8-12 individuals), are conducted throughout the three year intervention to deliver the behaviour modification information in relation to diet and physical activity (31). There are 17 group visits, each 1-2 hours, with decreasing frequency as the trial progresses. The behaviour modification programme is developed based on theories and evidence from health psychology and behaviour change (32-34). For example, participants' beliefs about the consequences of behaviour (i.e. outcome expectancies), their intention to change their behaviour in the long run, and their belief in their ability to achieve the behaviour change goals (self-efficacy) are relevant predictors of successful behaviour change. Counsellors may apply respective behaviour change techniques (35) that are scheduled to common stages of behaviour change (36). At the beginning of the weight-maintenance phase (i.e. month 2), the participants are instructed on how to plan, to start and to follow the physical activity programme. In the group sessions, the participants are also instructed on basic principles of increasing physical activity and in motivational and selfregulative behaviour techniques to overcome barriers to exercise and behaviour modification. Stretching and home-based muscle-conditioning exercises are also supervised in a group-based session accompanied with written educational material (31). 
TABLE 2. Description of the physical activity interventions

\begin{tabular}{|c|c|c|}
\hline & $\begin{array}{l}\text { High-intensity } \\
\text { physical activity (HI) }\end{array}$ & $\begin{array}{l}\text { Moderate-intensity physical } \\
\text { activity (MI) }\end{array}$ \\
\hline Heart rate & $76-90 \% \mathrm{HRmax}^{\mathrm{a}}$ or $61-80 \% \mathrm{HRR}^{\mathrm{b}}$ & $60-75 \%$ HRmax or $45-60 \%$ HRR \\
\hline $\begin{array}{l}\text { Examples of activities } \\
\text { (these may vary depending } \\
\text { on the fitness level of the } \\
\text { participant) }\end{array}$ & $\begin{array}{l}\text { - } \text { Bicycling, vigorous effort } \\
\text { - } \quad \text { Strenuous ball games } \\
\text { - } \quad \text { Aerobics with very vigorous } \\
\text { - } \text { effort, e.g. with extra weights } \\
\text { - Jogging }>8 \mathrm{~km} / \mathrm{h} \\
\text { - } \quad \text { Swimming, vigorous effort } \\
\text { - Cross-country skiing }\end{array}$ & $\begin{array}{l}\text { - } \text { Bicycling, moderate effort } \\
\text { - } \quad \text { Leisurely ball games } \\
\text { - } \text { Most conditioning exercises } \\
\text { (aerobic, power yoga, etc.) } \\
\text { - Brisk walking }(4-6 \mathrm{~km} / \mathrm{h}) \\
\text { - Swimming, recreational } \\
\text { - }\end{array}$ \\
\hline Weekly duration (in total) & at least $75 \mathrm{~min}$ & at least $150 \mathrm{~min}$ \\
\hline $\begin{array}{l}\text { Recommended weekly } \\
\text { frequency }\end{array}$ & $2-3$ times & $3-5$ times \\
\hline Daily duration (guideline) & $25-40 \mathrm{~min}$ & $\begin{array}{l}30-50 \text { min (may be broken down } \\
\text { into shorter sessions) }\end{array}$ \\
\hline
\end{tabular}

Additional exercises

- Muscle conditioning exercises, by using own weight: twice weekly at home, 15-20 min per session.

- Stretching: twice weekly, 15-20 min per session

\footnotetext{
${ }^{a}$ HRmax $=$ max heart rate, defined as 220 - age (220 in children under $16 \mathrm{y}$ )

${ }^{\mathrm{b}} \mathrm{HRR}=$ heart rate reserve, defined as the difference between measured resting $\mathrm{HR}$ and estimated HRmax
}

\section{Collection of data and description of analyses}

Data are collected from biological specimens (blood, urine, faecal), self-administered records and questionnaires, and an activity-monitoring device (Actigraph GT3X accelerometer) (see TABLE 3 with a description of timing). The CID's are scheduled for a specific week and the aim is to make the measurements as precisely as scheduled. To accommodate as complete a data collection as possible we allow the following visit windows: month $2:-3$ to +5 days; month $6: \pm 1$ weeks; month 12: \pm 2 weeks; the remaining measurement points: \pm 4 weeks. Blood samples are initially stored locally at $-80^{\circ} \mathrm{C}$, then transported and analysed centrally at the National Institution for Health and Welfare (THL) in Helsinki, Finland. Diet records are analysed at each site using local food composition data and software. If available, local GI data for individual food items are used, and when not available, generic global GI data are used. Accelerometer data are downloaded at local sites, and collated and analysed centrally at the Swansea University, Wales, UK. All questionnaires used in PREVIEW were prepared in English, then translated into the local language in Finland, Denmark, The Netherlands, Spain and Bulgaria using authorized translators. A second authorized translator then back-translated the local versions to English, with this iterative process repeated until a final version of sufficient quality was obtained. 


\section{Data management}

All data are stored in a central project database at the University of Copenhagen. The central database ensures standardized handling and storing of data and the possibility for easy extraction and delivery of data both within and after the official project period (2013-2018). Currently, the database receives input from four data sources on a regular basis: 1) All immediate data measured (e.g. anthropometrics, blood glucose) and interviewed (e.g. use of medication) during the CID's and entered into OpenClinica server (electronic Case Report Form); 2) Data on socialcognitive determinants of behaviour, on cultural and socio-demographic as well as socioeconomic components are collected by the Questionnaire Delivery Platform (QDP), designed for PREVIEW by NetUnion. The participants enter their own data into the QDP. A paper version of the questionnaires is also available. 3) Physical activity is reported using the Baecke inventory, and an electronic Physical Activity Log (PAL), designed by Swansea University, University of Stuttgart, and implemented by NetUnion. 4) The Central Lab at the National Institute for Health and Welfare (THL) enters all laboratory analyses into the data hub. Data from analyses of the ActiGraph data accelerometers, from food diaries and from the maximal oxygen uptake (VO2max) analyses are imported from all sites.

\section{Governance and quality management}

The intervention trial is led by Prof. Fogelholm at the University of Helsinki, in collaboration with the project coordinator, Prof. Raben at the University of Copenhagen. In this large, international multi-centre trial, we are collaborating intensively to ensure data collection of high quality and consistency of the intervention across all sites. Specific working groups were formed with relevant site representatives. The purpose of these working groups is to discuss and agree on questions related to dietary topics, physical activity, data management, and other methodological and medical issues. During the recruitment phase, principal investigators from each centre participated in a monthly teleconference, which continues at regular intervals throughout the intervention.The core personnel for each site meet annually at a 3-day General Assembly for the full PREVIEW consortium. PREVIEW has a website (http://previewstudy.com/) with both public access and restricted area for the PREVIEW researchers.An electronic trial master file with relevant documents has been designed and is maintained by the University of Copenhagen within the private part of the PREVIEW website. All written study material is uploaded and made available at the PREVIEW website private area, including the protocol and amendments, standard operation procedures (SOPs), and instruction materials for the intervention subjects, in order ensure that comparable methods are followed across individual sites. The SOPs are reviewed and revised as needed and also new SOPs are prepared, if necessary. Representatives from each intervention site participated in two training sessions, each of $2-3$ days duration, in 2013. One session focussed on the main study protocol, the CID protocols and all outcome measurements (University of Copenhagen),. The other session focused on instructor training in group counselling (behaviour change) methods (University of Stuttgart). Attendees then trained their local staff. 
TABLE 3. Overview of data collection methods at different Clinical Investigation Days (CID) in PREVIEW Outcome Data collection method Assessment time-points (month)

\begin{tabular}{|c|c|c|c|c|c|c|c|c|}
\hline & & $\begin{array}{c}0 \\
\text { CID1 }\end{array}$ & $\begin{array}{c}2 \\
\text { CID2 }\end{array}$ & $\begin{array}{c}6 \\
\text { CID3 }\end{array}$ & $\begin{array}{c}12 \\
\text { CID4 }\end{array}$ & $\begin{array}{c}18 \\
\text { CID5 }\end{array}$ & $\begin{array}{c}24 \\
\text { CID6 }\end{array}$ & $\begin{array}{c}36 \\
\text { CID7 }\end{array}$ \\
\hline $\begin{array}{l}\text { Glucose tolerance/ } \\
\text { diagnosis of T2D }\end{array}$ & $\begin{array}{l}75 \text { g Oral Glucose } \\
\text { Tolerance Test }\end{array}$ & - & & - & - & & - & - \\
\hline $\begin{array}{l}\text { Blood chemistry } \\
\text { (lipid metabolism, } \\
\text { glucose metabolism, } \\
\text { inflammation markers, } \\
\text { etc.) }\end{array}$ & $\begin{array}{l}\text { Fasting venous blood } \\
\text { specimen }\end{array}$ & - & - & - & - & - & - & - \\
\hline Urinary nitrogen & 24-h urine collection & - & & - & . & & - & . \\
\hline $\begin{array}{l}\text { Risk markers for colon } \\
\text { cancer (e.g. Short } \\
\text { Chain Fatty Acids) }\end{array}$ & 3-d faecal collection ${ }^{a}$ & - & - & - & - & - & - & - \\
\hline Gut microbiota & Faecal spot sample $^{a}$ & . & & & . & & & \\
\hline $\begin{array}{l}\text { Weight, height, BMI } \\
\text { and anthropometrics }\end{array}$ & $\begin{array}{l}\text { Weight; height (week } 0 \\
\text { and 156); waist and hip } \\
\text { circumference }\end{array}$ & - & - & - & - & - & - & - \\
\hline Body composition & $\begin{array}{l}\text { Body composition by } \\
\text { DXA, BodPod or } \\
\text { Bioelectrical impedance } \\
\text { (BIA) }\end{array}$ & - & - & - & - & & - & - \\
\hline $\begin{array}{l}\text { Blood pressure and } \\
\text { resting heart rate }\end{array}$ & $\begin{array}{l}\text { Resting blood pressure } \\
\text { and heart rate }\end{array}$ & - & - & - & - & - & . & - \\
\hline $\begin{array}{l}\text { Nutrient intakes, } \\
\text { dietary GI and food } \\
\text { consumption }\end{array}$ & 4-d food record & - & & - & - & & - & - \\
\hline Physical activity & $\begin{array}{l}\text { 7-d accelerometer, 7-d } \\
\text { physical activity log, } \\
\text { Baecke questionnaire }\end{array}$ & - & & - & - & & - & - \\
\hline $\begin{array}{l}\text { Maximal oxygen } \\
\text { uptake }\end{array}$ & $\begin{array}{l}\mathrm{VO}_{2} \text { max test by } \\
\text { ergometer or treadmill }\end{array}$ & - & & - & & & - & \\
\hline $\begin{array}{l}\text { Psycho-social } \\
\text { mediators and } \\
\text { moderators health } \\
\text { behaviour }\end{array}$ & $\begin{array}{l}\text { Several questionnaires } \\
\text { (listed with references } \\
\text { in Supplementary Table } \\
2 \text { (online only)) }\end{array}$ & - & - & - & - & & - & - \\
\hline Eating behaviour & $\begin{array}{l}\text { Three Factor Eating } \\
\text { Questionnaire (TFEQ) }\end{array}$ & - & - & - & - & & - & . \\
\hline Sleeping & $\begin{array}{l}\text { Epworth Sleepiness } \\
\text { Scale (ESS), Pittsburgh } \\
\text { Sleep Quality Index } \\
\text { (PSQI) }\end{array}$ & - & - & - & - & & - & - \\
\hline Stress and mood & $\begin{array}{l}\text { Perceived Stress Scale } \\
\text { (PSS), Profile of Mood } \\
\text { Scale (POMS) }\end{array}$ & - & - & - & - & & - & - \\
\hline
\end{tabular}




\section{Statistical power and basic analyses}

The anticipated 3-y incidence of T2D in the PREVIEW trial is $21 \%$, based on data from the Finnish DPS and US DPP $(10,11)$. The power calculation was derived for comparison of the two dietary interventions (HP vs. MP). It was hypothesized that a risk reduction of one quarter (1/4) in the MP group would reduce the incidence of T2D incidence from $21 \%$ to $16 \%$, and that a risk reduction of one half $(1 / 2)$ in the HP group would reduce the incidence of T2D from $21 \%$ to $10.5 \%$. Consequently, the sample size required to detect this difference in T2D incidence (16\% vs. 10.5\%) was at least 649 per diet group or 1,298 participants in total (for a two-sided comparison with a power $(1-\beta)$ of $80 \%$ and $p<.05)$, with a $10 \%$ drop-out during the first 10 months from month 2 (CID2) onwards and another 20\% drop-out between months 12 (CID4) and 36 (CID7). Thus, the number of participants needed for the intervention was 1,802. To allow an estimated drop-out of $25 \%$ as a result of failure to lose $>8 \%$ of initial body weight during the 2 -month LCD period, the number of participants required to be enrolled into PREVIEW was initially estimated to be 2,403 . The primary data are analysed statistically using the principle of 'intention-to-treat' (ITT cohort) and also as a completers' cohort. A 'completer' is defined as a participant who has remained in the trial for the full three year intervention period, or who has been diagnosed with T2D before the end of the intervention. The primary outcome in the adults' trial is incidence of T2D. For statistical analysis assessing the effect of the two diets on the T2D is 'Semi-parametric Cox proportional hazards regression model'. Missing data are addressed using hot-deck imputation. Missing covariate information is addressed using multiple imputation. Sensitivity analyses (e.g. complete-case analyses without drop-outs) will be carried out to assess if censoring was informative or non-informative. For statistical analysis of the continuous secondary outcomes (e.g. blood chemistry, anthropometrics, etc.) a 'linear mixed model' is used. For the categorical outcomes (e.g. sex, educational attainment, proportion of subjects maintaining a defined weight loss, etc.), the type of statistical analysis is 'logistic' or 'ordinal mixed-effects model'. The parameter of interest is the difference in odds ratio between the intervention groups. Although the main statistical analyses will be done by using the entire cohort, one of the most important stratified analyses will use an age-group (e.g. above and below 65 years) stratification. By comparing older against younger participants we might get new insight on whether dietary protein content in this respect has different effects on, e.g., body composition, weight and clinical variables.

\section{Ethical issues}

The study protocol and amendments were reviewed and approved by local Human Ethics Committees at all study sites. The work of PREVIEW is carried out in full compliance with the relevant requirements of the latest version of the Declaration of Helsinki (59th WMA General Assembly, Seoul, Korea, October 2008), and the ICH-GCP, The International Conference on Harmonisation ( $\mathrm{ICH}$ ) for Good Clinical Practice to the extent that this is possible and relevant. All participants provided written informed consent prior to commencing screening procedures in clinic. All information obtained during the trial is handled according to local regulations and the European Directive 95/46/CE (directive on protection of individuals with regard to the processing 
of personal data and on the free movement of such data). The trial is registered with ClinicalTrials.gov, NCT01777893.

\section{RESULTS}

As PREVIEW is an on-going trial, only results obtained from participant screening and baseline phases are presented here. Screening was conducted from June 2013 to February 2015. On average, $35 \%$ of the pre-screened individuals were eligible for the laboratory screening. Further, $43 \%$ of the screened participants were found to be eligible for the trial. In total, 2,326 overweight, pre-diabetic adults were enrolled and randomised into the trial. This was $97 \%$ of the original prespecified target (FIGURE 2). Approximately half of the participants were $55-70$ years at baseline (TABLE 4).

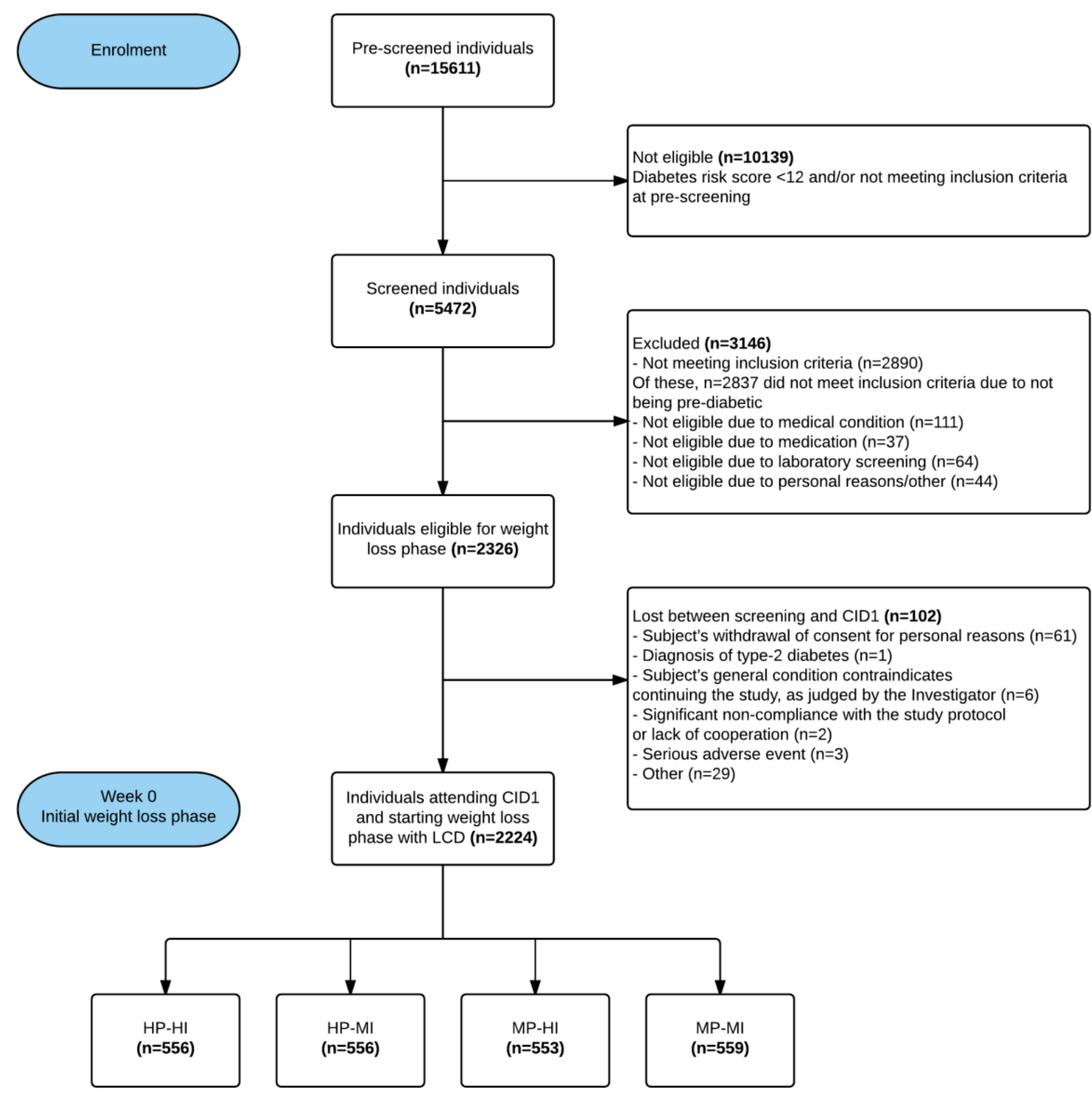

FIGURE 2. PREVIEW intervention: the subjects' flow-chart 
Baseline characteristics from blood biochemistry and anthropometric assessments are shown assigned to each intervention group in TABLE 5. The basic characteristics of the groups are similar. A notable feature of the participants is that the mean baseline fasting glucose concentration was approximately at the mid of the eligibility range, whereas the mean 2-h glucose concentration was at the lower cut-off point. According to the OGTT laboratory data, 1389 (62\%) of all participants had increased fasting glucose at baseline, 506 (23\%) had impaired glucose tolerance and 286 (13\%) had both of these pre-diabetic indicators. At baseline (CID1), 25 participants (1\%) - who all had been diagnosed with pre-diabetes at screening - were not diagnosed with pre-diabetes anymore. The prevalence of pre-diabetes described above were not significantly different between the four study groups.

TABLE 4. Number and age distribution of participants recruited for the PREVIEW intervention trial

$$
\text { Pre- Age Age Age }
$$

screened Screened Randomised Men Women 25-45 yrs 46-54 yrs 55-70 yrs Mean age

\begin{tabular}{llllllllll} 
Site & $(\mathrm{n})$ & $(\mathrm{n})$ & $(\mathrm{n})$ & $(\mathrm{n})$ & $(\mathrm{n})$ & $(\mathrm{n})$ & $(\mathrm{n})$ & $(\mathrm{n})$ & $\mathrm{yrs}(\mathrm{SD})$ \\
\hline UCPH & 2061 & 908 & 379 & 159 & 220 & 86 & 62 & 233 & $54.2(10.9)$ \\
HEL & 1269 & 633 & 289 & 88 & 201 & 39 & 33 & 221 & $58.2(8.9)$ \\
UM & 675 & 553 & 203 & 94 & 109 & 42 & 17 & 145 & $56.6(10.0)$ \\
UNOTT & 3914 & 979 & 264 & 102 & 162 & 95 & 42 & 133 & $51.6(12.0)$ \\
UNAV & 1740 & 732 & 307 & 93 & 214 & 145 & 82 & 93 & $47.5(10.6)$ \\
MU & 1190 & 488 & 368 & 87 & 281 & 190 & 7 & 158 & $47.8(12.0)$ \\
UNSYD & 3108 & 595 & 195 & 56 & 139 & 59 & 36 & 102 & $53.0(10.8)$ \\
UOA & 1654 & 584 & 321 & 77 & 244 & 156 & 47 & 103 & $47.0(11.4)$ \\
Total & 15,611 & 5,472 & 2,326 & 756 & 1,570 & 812 & 326 & 1,188 & $51.6(11.6)$ \\
\hline
\end{tabular}

Abbreviations for study sites: UCPH = University of Copenhagen (Denmark); HEL = University of Helsinki (Finland); UM = Maastricht University (The Netherlands); UNOTT = University of Nottingham (UK); UNAV = University of Navarra (Spain); MU = Medical University of Sofia (Bulgaria); UNSYD = University of Sydney (Australia); UOA = University of Auckland (New Zealand).

\section{DISCUSSION}

To our knowledge, PREVIEW is the first trial of its kind comparing two potentially effective interventions, a novel higher protein/low GI diet vs. current best practice moderate protein, higher $\mathrm{CHO} /$ moderate $\mathrm{GI}$ diet, in order to determine whether there is a more efficient lifestyle strategy to prevent T2D. Moreover, previous studies have neither used an effective weight-loss phase by LCD as a start of the intervention, nor a multi-country design.

Our inclusion criteria for "pre-diabetes" differed from the Finnish DPS. Here, IGT was an unconditional requirement without limits for IFG (14). In the US DPP, both IGT and IFG were required (37) and the lower limit for IFG was $5.3 \mathrm{mmol} / \mathrm{l}$ (vs. $5.6 \mathrm{mmol} / \mathrm{l}$ in PREVIEW). It is unclear if the differences in diagnostic criteria between these studies have any major effects on the outcome.

In addition to the diagnostic cut-offs per se, also the distribution of results within the diagnostic criteria (i.e., above the lower and below the upper cut-off points) may have an effect on the outcome (38). In PREVIEW, a majority of the subjects were eligible due to higher fasting blood 
glucose, rather than impaired glucose tolerance (higher 2-h value). A small proportion (1\%) was not diagnosed anymore with pre-diabetes at baseline. This may be explained by change of method (HemoCue ${ }^{\mathrm{TM}}$ or Reflotron ${ }^{\mathrm{TM}}$ at screening, laboratory assessment at baseline), to normal day-to-day variance in the assessed variables, or to change in lifestyle after being accepted as a participant to PREVIEW. For future studies of T2D prevention, a single measurement of HbA1c, which is becoming standard clinical practice in many countries may save both time and costs (39). Still, there remains some controversy as to the utility of $\mathrm{HbAlc}$ when compared with standard OGTT as a diagnostic tool (40).

TABLE 5. Number of participants, age, anthropometric results, blood chemistry and blood pressure for all intervention groups, assessed at baseline (CID1) before weight reduction. The results are shown as mean $( \pm S D)$.

\begin{tabular}{|c|c|c|c|c|}
\hline & \multicolumn{2}{|c|}{$\begin{array}{l}\text { HP: Higher protein ( } 25 \mathrm{E} \%) \\
\text { Moderate carbohydrate (45 E\%) } \\
\text { Low GI ( } \leq 50) \text { diet }\end{array}$} & \multicolumn{2}{|c|}{$\begin{array}{l}\text { MP: Moderate protein (15 E\%) } \\
\text { Higher carbohydrate (55 E\%) } \\
\text { Medium GI }(\geq 56) \text { diet }\end{array}$} \\
\hline & $\begin{array}{l}\text { Moderate-intensity } \\
\text { physical activity }\end{array}$ & $\begin{array}{l}\text { High-intensity } \\
\text { physical activity }\end{array}$ & $\begin{array}{l}\text { Moderate-intensity } \\
\text { physical activity }\end{array}$ & $\begin{array}{l}\text { High-intensity } \\
\text { physical activity }\end{array}$ \\
\hline No. (men/women) & $556(184 / 372)$ & $556(177 / 379)$ & $559(180 / 379)$ & $553(179 / 374)$ \\
\hline Age, years & $51.6 \pm 11.5$ & $51.8 \pm 11.7$ & $51.4 \pm 11.2$ & $51.4 \pm 11.8$ \\
\hline \multicolumn{5}{|l|}{ Anthropometrics } \\
\hline Height, $\mathrm{cm}$ & $168 \pm 9$ & $168 \pm 9$ & $168 \pm 9$ & $168 \pm 10$ \\
\hline Weight, kg & $99.3 \pm 20.8$ & $100.6 \pm 21.0$ & $101.6 \pm 22.6$ & $98.7 \pm 20.9$ \\
\hline Body Mass Index, $\mathrm{kg} / \mathrm{m}^{2}$ & $35.1 \pm 6.5$ & $35.6 \pm 6.7$ & $35.7 \pm 6.6$ & $35.0 \pm 6.4$ \\
\hline Waist circumference, $\mathrm{cm}$ & $109.6 \pm 15.2$ & $111.0 \pm 15.3$ & $111.1 \pm 15.4$ & $109.6 \pm 14.5$ \\
\hline Hip circumference, $\mathrm{cm}$ & $117.6 \pm 14.5$ & $118.8 \pm 14.8$ & $119.2 \pm 13.9$ & $117.8 \pm 13.8$ \\
\hline Body fat (\% of weight) & $43.0 \pm 7.5$ & $43.5 \pm 7.5$ & $43.5 \pm 7.9$ & $43.1 \pm 7.8$ \\
\hline \multicolumn{5}{|c|}{ Blood chemistry and blood pressure } \\
\hline f P-glucose, $\mathrm{mmol} / \mathrm{I}$ & $6.2 \pm 0.8$ & $6.2 \pm 0.6$ & $6.2 \pm 0.7$ & $6.2 \pm 0.8$ \\
\hline $2 \mathrm{hP}$-glucose, $\mathrm{mmol} / \mathrm{l}$ & $7.8 \pm 2.3$ & $7.7 \pm 2.25$ & $7.5 \pm 2.2$ & $7.7 \pm 2.1$ \\
\hline fP-insulin, mU/L & $13.6 \pm 7.9$ & $14.0 \pm 8.7$ & $13.2 \pm 7.7$ & $13.1 \pm 7.2$ \\
\hline $\mathrm{HbA} 1 \mathrm{c}, \mathrm{mmol} / \mathrm{mol}$ & $36.6 \pm 3.9$ & $36.8 \pm 3.9$ & $36.7 \pm 4.2$ & $36.7 \pm 4.0$ \\
\hline Cholesterol, mmol/l & $5.2 \pm 1.0$ & $5.1 \pm 1.0$ & $5.3 \pm 1.0$ & $5.1 \pm 1.0$ \\
\hline LDL cholesterol, mmol/l & $3.3 \pm 0.9$ & $3.2 \pm 0.8$ & $3.3 \pm 0.9$ & $3.2 \pm 0.8$ \\
\hline HDL cholesterol, mmol/l & $1.3 \pm 0.3$ & $1.3 \pm 0.3$ & $1.3 \pm 0.3$ & $1.3 \pm 0.3$ \\
\hline Triglycerides, mmol/l & $1.5 \pm 0.8$ & $1.5 \pm 0.7$ & $1.5 \pm 0.9$ & $1.5 \pm 0.8$ \\
\hline CRP, mg/l & $5.3 \pm 6.3$ & $6.0 \pm 8.7$ & $5.2 \pm 5.1$ & $5.1 \pm 7.5$ \\
\hline Systolic BP, mmHg & $128.5 \pm 15.6$ & $129.7 \pm 16.2$ & $128.7 \pm 16.3$ & $129.3 \pm 15.5$ \\
\hline Diastolic BP, mmHg & $78.2 \pm 10.9$ & $77.6 \pm 11.2$ & $78.4 \pm 11.5$ & $78.3 \pm 10.7$ \\
\hline
\end{tabular}

$\mathrm{GI}=$ glycaemic index; $\mathrm{BP}=$ blood pressure

PREVIEW is a much larger trial than both the Finnish DPS $(n=522)(11)$ and Chinese Da Qing study $(n=577)(9)$, although smaller than the DPP $(n=3,234)(10)$. However, in the DPP a third of the participants received 'Metformin' in addition to dietary advice, hence the number of participants without medical treatment, but adhering to lifestyle intervention (diet and physical activity) was 2,161 which is similar to PREVIEW. Of the above interventions, the geographical and 
ethnic variation is greatest in PREVIEW. The age-range of participants in DPP and DPS was 33-67 years, slightly narrower than in PREVIEW, but the mean age of participants is similar across the studies (50-55 years). The large proportion of older participants in PREVIEW, (> 55 years), was expected since the risk for T2D increases with age (2), and due to the growing health consciousness of this age group, many of whom are retired and have the time to participate in a demanding intervention. The smaller proportion of middle age-adults is also explained by later initiation of recruitment in this age group, compared with younger and older participants. In general, finding an adequate number of pre-diabetic subjects was a real challenge in most countries, given the "hidden" status of this condition. Thus, recruitment took about 3 times as long as planned from the beginning of the project.

One major challenge in PREVIEW is related to adherence to the diet and physical activity programs. The HP-diet is novel and, with the higher protein content, also somewhat outside the current boundaries of nutritional guidelines $(41,42)$. Whether the HP diet results in better adherence than the MP diet with high $\mathrm{CHO}$ and whole-grain cereal intakes is one of the key interests in PREVIEW. Nutrient intakes and food consumption patterns will be assessed in PREVIEW by repeated 4- $d$ diet-records. The poor accuracy of dietary assessment is well known (43), but it is expected that the difference in dietary protein and $\mathrm{CHO}$ intakes should be sufficiently large to be detected using this method. Moreover, protein intake is verified using $24 \mathrm{~h}$ urinary nitrogen excretion (44).

It may be more difficult to create a verifiable difference for GI than for protein-to-CHO ratio. Whilst GI values of foods have been shown to provide a good summary of postprandial glycaemia (45), difficulties in attributing GI values to foods for which there are no validated data available may add to variability (46), particularly in a multi-centre intervention such as PREVIEW. In DiOGenes, the reported observed difference in mean dietary GI was small (56 vs. 60 units) (19) which increases the requirements of precision.

The physical activity intervention in PREVIEW is not a supervised training programme. Participants are expected to integrate activity into their daily lives and use local opportunities to achieve their goals. To improve adherence, there is flexibility with the type of activities chosen. A combination of measures of physical activity is used to analyse the compliance to the type of intervention and our methods allow a description of activities that were used to achieve this. It is probable that the HI-program will be more challenging in the long-term. Warming-up, cooling-down, muscular conditioning exercises and stretching are carefully explained to the participants in order to decrease the risk for injuries. It should be noted that the HI-program in PREVIEW is not highintensity interval-training (HIIT). While there are some data on potential benefits from HIIT on cardiovascular function and glucose metabolism (47), we considered the data on feasibility and long-term maintenance of this kind of training still too limited.

In addition to good compliance of the programmes, keeping the drop-out rate as low as possible will be challenging. Frequent contact with the research staff is one way to reduce the drop-out rate. However, PREVIEW has been planned to study how behavioural change is realized under 'real life' conditions, and hence the fading visit design where group visits are infrequent during 
years ' 2 ' and ' 3 ' of the intervention. Adherence is encouraged through a number of practices, including use of specific behaviour change techniques (31), such as implementation intentions, or Facebook groups, one for each randomised group, to promote attendance at group visits and CIDs. In addition, the sites can also conduct general information lectures and/or physical activity sessions and/or send a newsletter to the participants, once or twice a year.

Compared to DPS and DPP studies, a particular feature of PREVIEW is related to the different settings in which the intervention is conducted, including not only genetic background, but also attitudes, norms, and socio-economic features. Although the participating countries are welldeveloped, considerable variations exist, e.g., regarding food attitudes and habits, as well as traditions of practicing physical activity.

The unique feature in the PREVIEW intervention is the direct comparison of two potentially efficacious diet and physical activity intervention programs. Hence, PREVIEW has a clear potential to identify a recommended optimal diet and physical activity programme to prevent T2D, a programme which is also suitable across different countries. It is also possible, however, that PREVIEW data will demonstrate that there are several, equally efficacious alternatives. Clearly, both answers are important from a public health viewpoint. 


\section{SUPPLEMENTARY MATERIALS}

The following are available online at www.mdpi.com/link, Table S1: Inclusion and exclusion criteria in the PREVIEW screening, Table S2: Questionnaires on moderators, mediators, behaviour and social environment.

\section{ACKNOWLEDGEMENTS}

This study has received grants from the EU 7th Framework Programme (FP7-KBBE-2012), grant agreement no. 312057; the New Zealand Health Research Council, grant no. 14/191; and the NHMRC-EU Collaborative Grant, Australia. All LCD products were provided by Cambridge Weight Plan ${ }^{\circledR}$, UK. This sponsorship is highly appreciated. We want to acknowledge particularly the following medical and scientific experts, who have helped us in building up the study: Prof. Arne Astrup (Copenhagen, Denmark), Prof. Stephen Collagiuri (Sydney, Australia), Prof. Peter Mansell (Nottingham, UK) and the PREVIEW Scientific Advisory Board, Prof. Louise Dye (Leeds, UK), Prof. Richard L. Atkinson (Richmond, Virginia, USA), Prof. Boyd Swinburn (Melbourne, Australia), Prof. Lauren Lissner, (Göteborg, Sweden) and Ms. Grethe Andersen (Copenhagen, Denmark). Moreover, we want to acknowledge the great staff who has worked and is working for PREVIEW, e.g. study nurses, lab technicians, nutritionists, physical activity experts, trainees, post and pregraduate students, involved in the recruitment of all participants and in planning and initiating the weight-reduction phase and intervention.

\section{AUTHOR CONTRIBUTIONS}

A.R., J.B, and M.F. were responsible for the initial study conception. T.M.L., M.W., I.M., J.A.M., S.P., W.S., G.S., J.S., T.L., T.H., D.K., J.B. and A.R. were involved in development of the study design. All authors, but particularly E.J., P.C., M.D., E.S., S.N., N.B., R.M., M.S. and L.P. were involved in the development of the practical implementation of the study. M.F. wrote the draft version of the manuscript and all authors were involved in critically revising the paper. All authors have also seen and accepted the submitted version.

\section{CONFLICTS OF INTEREST}

The authors declare no conflict of interest. The founding sponsors had no role in the design of the study; in the collection, analyses, or interpretation of data; in the writing of the manuscript, and in the decision to publish the results. 


\section{REFERENCES}

1. American Diabetes Association. Standards of medical care in diabetes--2011. Diabetes Care 2011, 34 Suppl 1, S11-S61.

2. Guariguata L, Whiting DR, Hambleton I, Beagley J, Linnenkamp U, Shaw JE., Global estimates of diabetes prevalence for 2013 and projections for 2035. Diabetes Res Clin Pract 2014,103(2),137-149.

3. Tamayo T, Rosenbauer J, Wild SH, Spijkerman AMW, Baan C, Forouhi NG, Herder C, Rathmann W, Diabetes in Europe: an update. Diabetes Res Clin Pract 2014, 103(2), 206-217.

4. Guh DP, Zhang W, Bansback N, Amarsi Z, Birmingham CL, Anis AH. The incidence of co-morbidities related to obesity and overweight: a systematic review and meta-analysis. BMC Public Health 2009, 9, 88.

5. Morimoto Y, Schembre SM, Steinbrecher A, Erber E, Kolonel LN, Maskarinec G. Ethnic differences in weight gain and diabetes risk: the Multiethnic Cohort Study. Diabetes Metab 2011, 37(3), 230-236.

6. Aune D, Norat T, Leitzmann M, Tonstad S, Vatten LJ. Physical activity and the risk of type 2 diabetes: a systematic review and dose-response meta-analysis. Eur J Epidemio/2015;30(7):529-542.

7. Bhupathiraju SN, Tobias DK, Malik VS, Pan A, Hruby A, Manson JE, Willett WC, Hu FB. Glycemic index, glycemic load, and risk of type 2 diabetes: results from 3 large US cohorts and an updated meta-analysis. Am J Clin Nutr 2014, 100(1), 218-232.

8. Ley SH, Hamdy O, Mohan V, Hu FB. Prevention and management of type 2 diabetes: dietary components and nutritional strategies. Lancet 2014, 383(9933):1999-2007.

9. Li G, Zhang P, Wang J, An Y, Gong Q, Gregg EW, Yang W, Zhang B, Shuai Y, Hong J, et al. Cardiovascular mortality, all-cause mortality, and diabetes incidence after lifestyle intervention for people with impaired glucose tolerance in the Da Qing Diabetes Prevention Study: a 23-year follow-up study. Lancet Diabetes Endocrino/ 2014, 2(6), 474-480.

10. Knowler WC, Barrett-Connor E, Fowler SE, Hamman RF, Lachin JM, Walker EA, et al. Reduction in the incidence of type 2 diabetes with lifestyle intervention or metformin. N Eng/ J Med 2002, 346(6), 393-403.

11. Tuomilehto J, Lindström J, Eriksson JG, Valle TT, Hämäläinen $H$, Ilanne-Parikka P, Keinänen-Kiukaanniemi $S$, Laakso M, Louheranta A, Rastas $M$, et al. Prevention of type 2 diabetes mellitus by changes in lifestyle among subjects with impaired glucose tolerance. N Eng/J Med 2001, 344(18), 1343-1350.

12. Walker KZ, O'Dea K, Gomez M, Girgis S, Colagiuri R, Diet and exercise in the prevention of diabetes. $J$ Hum Nutr Diet Off J Br Diet Assoc 2010, 23(4), 344-352.

13. Mayer-Davis EJ, Sparks KC, Hirst K, Costacou T, Lovejoy JC, Regensteiner JG, Hoskin MA, Kriska AM, Bray GA, Diabetes Prevention Program Research Group. Dietary intake in the diabetes prevention program cohort: baseline and 1-year post randomization. Ann Epidemio/2004, 14(10), 763-772.

14. Eriksson J, Lindström J, Valle $T$, Aunola $S$, Hämäläinen $H$, Ilanne-Parikka $P$, Keinänen-Kiukaanniemi $S$, Laakso $M$, Lauhkonen $M$, Lehto $P$, et al. Prevention of Type II diabetes in subjects with impaired glucose tolerance: the Diabetes Prevention Study (DPS) in Finland. Study design and 1-year interim report on the feasibility of the lifestyle intervention programme. Diabetologia 1999, 42(7), 793-801.

15. Pan XR, Li GW, Hu YH, Wang JX, Yang WY, An ZX, Hu ZX, Lin J, Xiao JZ, Cao HB, et al. Effects of diet and exercise in preventing NIDDM in people with impaired glucose tolerance. The Da Qing IGT and Diabetes Study. Diabetes Care 1997, 20(4), 537-544.

16. Mann JI, De Leeuw I, Hermansen K, Karamanos B, Karlström B, Katsilambros N, Riccardi G, Rivellese AA, Rizkalla S, Slama G, et al. Evidence-based nutritional approaches to the treatment and prevention of diabetes mellitus. Nutr Metab Cardiovasc Dis 2004, 14(6), 373-394.

17. Ajala O, English P, Pinkney J. Systematic review and meta-analysis of different dietary approaches to the management of type 2 diabetes. Am J Clin Nutr 2013, 97(3), 505-16.

18. Buyken $A E$, Mitchell $P$, Ceriello A, Brand-Miller, J. Optimal dietary approaches for prevention of type 2 diabetes: a life-course perspective. Diabetologia 2010, 53(3), 406-418.

19. Larsen TM, Dalskov S-M, van Baak M, Jebb SA, Papadaki A, Pfeiffer AFH, Martinez JA, HandjievaDarlenska $T$, Kunešová $M$, Pihlsgård $M$, et al. Diets with high or low protein content and glycemic index for weight-loss maintenance. N Eng/ J Med 2010, 363(22), 2102-2113.

20. Astrup A, Raben A, Geiker N. The role of higher protein diets in weight control and obesity-related comorbidities. Int J Obes 2015, 39(5), 721-726.

21. Romijn JA, Coyle EF, Sidossis LS, Gastaldelli A, Horowitz JF, Endert E, Wolfe RR. Regulation of endogenous fat and carbohydrate metabolism in relation to exercise intensity and duration. Am J Physio/ 1993, 265(3 Pt 1), E380-E391.

22. Houmard JA, Tanner CJ, Slentz CA, Duscha BD, McCartney JS, Kraus WE. Effect of the volume and intensity of exercise training on insulin sensitivity. J App/ Physio/2004, 96(1), 101-6. 
23. Fogelholm M, Anderssen S, Gunnarsdottir I, Lahti-Koski M. Dietary macronutrients and food consumption as determinants of long-term weight change in adult populations: a systematic literature review. Food Nutr Res 2012, 56.

24. Aller EEJG, Larsen TM, Claus H, Lindroos AK, Kafatos A, Pfeiffer A, Martinez JA, Kunesova M, Stender S et al. Weight loss maintenance in overweight subjects on ad libitum diets with high or low protein content and glycemic index: the DIOGENES trial 12-month results. Int J Obes 2014, 38(12), 1511-1517.

25. Watt MJ, Heigenhauser GJ, Spriet LL. Effects of dynamic exercise intensity on the activation of hormonesensitive lipase in human skeletal muscle. J Physio/2003, 547(Pt 1), 301-308.

26. WHO: Definition and diagnosis of diabetes mellitus and intermediate hyperglycaemia. WHO, http://www.who.int/diabetes/publications/diagnosis_diabetes2006/en/

27. Matsuda $M$, DeFronzo RA. Insulin sensitivity indices obtained from oral glucose tolerance testing: comparison with the euglycemic insulin clamp. Diabetes Care 1999, 22(9), 1462-1470.

28. Silventoinen K, Pankow J, Lindström J, Jousilahti P, Hu G, Tuomilehto J. The validity of the Finnish Diabetes Risk Score for the prediction of the incidence of coronary heart disease and stroke, and total mortality. Eur J Cardiovasc Prev Rehabil 2005, 12(5), 451-458.

29. Borg GA, Psychophysical bases of perceived exertion. Med Sci Sports Exerc 1982, 14(5), 377-381.

30. 2008 Physical Activity Guidelines for Americans, http://www.health.gov/paguidelines/guidelines/

31. Kahlert D, Unyi-Reicherz A, Stratton G, Larsen TM, Fogelholm M, Raben A, Schlicht W. PREVIEW Behavior Modification Intervention Toolbox (PREMIT): A Study Protocol for a Psychological Element of a Multicenter Project. Front Psycho/2016, 7, 1136.

32. Michie S, Abraham C, Whittington C, McAteer J, Gupta S. Effective techniques in healthy eating and physical activity interventions: a meta-regression. Health Psycho/ 2009, 28(6), 690-701.

33. Greaves CJ, Sheppard KE, Abraham C, Hardeman W, Roden M, Evans PH, Schwarz P, IMAGE Study Group. Systematic review of reviews of intervention components associated with increased effectiveness in dietary and physical activity interventions. BMC Public Health 2011, 11, 119.

34. Olander EK, Fletcher H, Williams S, Atkinson L, Turner A, French DP. What are the most effective techniques in changing obese individuals' physical activity self-efficacy and behaviour: a systematic review and metaanalysis. Int J Behav Nutr Phys Act 2013, 10, 29.

35. Michie S, Richardson M, Johnston M, Abraham C, Eccles MP, Cane J, Wood CE. The behavior change technique taxonomy ( $v 1$ ) of 93 hierarchically clustered techniques: building an international consensus for the reporting of behavior change interventions. Ann Behav Med 2013, 46(1), 81-95.

36. Prochaska JO, DiClemente CC. Stages of change in the modification of problem behaviors. Prog Behav Modif 1992, 28, 183-218.

37. The Diabetes Prevention Program: baseline characteristics of the randomized cohort. The Diabetes Prevention Program Research Group. Diabetes Care 2000, 23(11), 1619-1629.

38. Edelstein SL, Knowler WC, Bain RP, Andres R, Barrett-Connor EL, Dowse GK, Haffner SM, Pettitt DJ, Sorkin JD, Muller DC, et al. Predictors of progression from impaired glucose tolerance to NIDDM: an analysis of six prospective studies. Diabetes 1997, 46(4), 701-710.

39. Saudek CD, Herman WH, Sacks DB, Bergenstal RM, Edelman D, Davidson MB. A new look at screening and diagnosing diabetes mellitus. J Clin Endocrinol Metab 2008, 93(7), 2447-53.

40. Malkani S, Mordes JP. Implications of using hemoglobin A1C for diagnosing diabetes mellitus. Am J Med 2011, 124(5), 395-401.

41. Nordic Nutrition Recommendations Project Group. Nordic Nutrition Recommendations 2012. Integrating nutrition and physical activity. 5th ed. Copenhagen: Nordic Council of Ministers, 2014. (Nord 2014).

42. Dietary Guidelines for Americans. Available from: http://www.cnpp.usda.gov/DietaryGuidelines

43. Dhurandhar NV, Schoeller D, Brown AW, Heymsfield SB, Thomas D, Sørensen TIA, Speakman, JR, Jeansonne $M$, Allison DB, Energy Balance Measurement Working Group.. Energy balance measurement: when something is not better than nothing. Int J Obes 2015, 39(7), 1175-1176

44. Corella D, Ordovás JM. Biomarkers: background, classification and guidelines for applications in nutritional epidemiology. Nutr Hosp 2015, 31 Suppl 3, 177-188.

45. Brand-Miller JC, Petocz P, Denyer G. Glycemic index, postprandial glycemia, and the shape of the curve in healthy subjects: analysis of a database of more than 1,000 foods. Am J Clin Nutr 2009, 89(1), 97-105.

46. Whelan WJ, Hollar D, Agatston A, Dodson HJ Tahal DS. The glycemic response is a personal attribute. IUBMB Life 2010, 62(8), 637-641.

47. Ramos JS, Dalleck LC, Tjonna AE, Beetham KS, Coombes JS. The impact of high-intensity interval training versus moderate-intensity continuous training on vascular function: a systematic review and meta-analysis. Sports Med 2015, 45(5), 679-692. 


\section{CHAPTER 3}

Objectively measured physical activity and sedentary time are associated with cardiometabolic risk factors in adults with pre-diabetes: The PREVIEW study

N. Swindell, K. Mackintosh, M. McNarr, J. W. Stephens, D. Sluik, M. Fogelholm, M. Drummen, I. MacDonald, J. Alfredo Martinez, T. Handjieva-Darlenska, S. Poppitt, J. Brand-Miller, T. M. Larsen, A. Raben and G. Stratton

Published in:

Diabetes Care (2018) 


\section{ABSTRACT}

\section{Objective}

The aim of the present cross-sectional study was to examine the association between physical activity (PA), sedentary time (ST) and cardio-metabolic risk in adults with pre-diabetes.

\section{Design and Methods}

Participants ( $n=2,326 ; 25-70$ years, $67 \%$ female) from eight countries with a body mass index (BMI) $>25 \mathrm{~kg} \cdot \mathrm{m}^{-2}$, impaired fasting glucose (IFG; 5.6-6.9 $\mathrm{mmol} \cdot \mathrm{I}^{-1}$ ) and/or impaired glucose tolerance (IGT; 7.8-11.0 mmol. $\mathrm{I}^{-1}$ at $2 \mathrm{hr}$ ) participated. Seven-day accelerometry objectively assessed PA levels and sedentary time.

\section{Results}

Multiple linear regression revealed that moderate-to-vigorous physical activity (MVPA) was negatively associated with homeostatic model assessment of insulin resistance (HOMA-IR) (standardized $\beta=-0.078[-0.128,-0.027]$ ), waist circumference (WC); $\beta=-0.177[-0.122,-0.134]$ ), fasting insulin $(\beta=-0.115[-0.158,-0.072])$, 2 -hour glucose $(\beta=-0.069[-0.112,-0.025])$, triglycerides $(\beta=-0.091[-0.138,-0.044])$ and $C$-reactive protein (CRP; $\beta=-0.086[-0.127,-0.045])$. Sedentary time was positively associated with HOMA-IR $(\beta=0.175[0.114,0.236])$, WC $(\beta=0.215[0.026,0.131])$, fasting insulin $(\beta=0.155[0.092,0.219])$, triglycerides $(\beta=0.106 \quad[0.052,0.16]), \quad \operatorname{CRP} \quad(\beta=0.106$ $[0.39,0.172])$, systolic blood pressure (BP) $\beta=0.078[0.026,0.131])$ and diastolic $B P(\beta=0.106$ [0.39,0.172]). Associations reported between total $P A$ (counts.minute ${ }^{-1}$ ) and all risk factors were comparable or stronger than MVPA; HOMA-IR $(\beta=-0.151[-0.194,-0.107]), W C(\beta=-0.179[-0.224,-$ $0.134])$, fasting insulin $(\beta=-0.139[-0.183,-0.096])$, 2 -hour glucose $(\beta=-0.088[-0.131,-0.045])$, triglycerides $(\beta=-0.117[-0.162,-0.071])$ and $C R P(\beta=-0.104[-0.146,-0.062])$.

\section{Conclusions}

In adults with pre-diabetes, objectively measured PA and ST were associated with cardiometabolic risk markers. Total PA was at least as strongly associated with cardio-metabolic risk markers as MVPA, which may imply that the accumulation of total PA over the day is as important as achieving the intensity of MVPA. 


\section{INTRODUCTION}

The global prevalence of diabetes among adults has almost quadrupled since 1980 to 422 million cases in 2014 and expected to continue to grow (1). This dramatic rise in prevalence is largely due to the increase in type 2 diabetes which accounts for the majority of all diagnosed cases in adults (1). Changes in lifestyle factors such as sedentary behaviour, insufficient PA, dietary choices and excess weight are important contributors in the development of type 2 diabetes (2). Physical activity plays an important role, independent of weight, in the prevention of type 2 diabetes through its effect on insulin resistance (3). Physical activity leads to the translocation of GLUT-4 transporters to the plasma membrane increasing glucose uptake into skeletal muscle (4). Sedentary time has also been associated with insulin resistance and fasting triglyceride levels, independent of PA and obesity (5). Sedentary time is thought to affect carbohydrate metabolism by decreasing muscle GLUT-4 concentrations while also reducing lipoprotein lipase (LPL) activity and triglycerides clearance $(6,7)$. Light activity is also associated with cardio-metabolic health and, together with sedentary time, occupies the majority of waking hours (8). Indeed, light-intensity activity substantially contributes to overall daily energy expenditure and may also mean spending less time in sedentary behaviours.

Many studies reporting associations between PA, ST and cardio-metabolic risk factors are limited by the self-reported measures of PA and ST $(9,10)$ which are susceptible to reporting and recall bias. In the limited number that have used objective measures of PA, investigations of international samples measured concurrently with the same protocol are lacking, little consistency exists with regards to the devices, wear time criteria, intensity cut points or epoch lengths used, thereby limiting the ability to make comparisons between these studies. Furthermore, despite those with pre-diabetes being at the highest risk of developing type-2 diabetes and representing the population at which many lifestyle interventions are targeted, few studies have described the relationship between PA and insulin resistance in this population.

Typically, epidemiological research assessing the effect of PA and ST on cardio metabolic risk factors has been conducted in the general population $(8,11,12)$. The few studies conducted in high risk populations have included participants based on a risk score questionnaire (5), family history of type 2 diabetes $(9,13)$ or participants diagnosed with diabetes and pre-diabetes have been combined (14). Consequently, physical characteristic and metabolic parameters of study participants varied substantially. As a result, it is unclear to what extent reported associations could be inferred to individuals with pre-diabetes.

Therefore, the purpose of this study was to quantify the relationship between objectively measured PA and ST with cardio metabolic health and risk of diabetes.

\section{METHODS}

\section{Participants and setting}

A detailed account of the PREVention of diabetes through lifestyle Intervention and population studies in Europe and around the World (PREVIEW) project has been published elsewhere (15). 
Participants were recruited into the PREVIEW project between June 2013 and February 2015. The PREVIEW study is a large multi-national diabetes prevention intervention being conducted at eight study sites: University of Copenhagen (Denmark), University of Helsinki (Finland), University of Maastricht (The Netherlands), University of Nottingham (UK), University of Navarra (Spain), Medical University of Sofia (Bulgaria), University of Sydney (Australia) and University of Auckland (New Zealand).

Participants were selected through an internet-based pre-screening tool or telephone interview using the Finnish Diabetes Risk Score (16). A total of 15,611 individuals were contacted for prescreening. Potential participants were sent a written description of the trial, given verbal information at the study site and signed informed consent prior to a laboratory screening. The laboratory screening was attended by 5,472 participants and included assessment of body mass, stature, resting blood pressure (BP), and a 2-hour OGTT (17). Glucose concentrations were analysed at each study site (HemoCue ${ }^{\mathrm{TM}}$, Angelholm, Sweden; Reflotron ${ }^{\mathrm{TM}}$, Roche diagnostics, Switzerland; or EML105 Radiometer, Copenhagen) to identify people with pre-existing diabetes.

At the end of this process, 2,326 participants met the following inclusion criteria and found eligible to take part in the study: age $25-70$ years; BMI $>25 \mathrm{~kg} / \mathrm{m}^{2}$; pre-diabetes confirmed at OGTT. Pre-diabetes was defined, in line with WHO/IDF and ADA criteria (17), as either (i) IFG, with venous plasma glucose concentration of $5.6-6.9 \mathrm{mmol} \cdot \mathrm{I}^{-1}$ and/or (ii) IGT, with venous plasma glucose concentration of $7.8-11.0 \mathrm{mmol} \cdot \mathrm{I}^{-1}$ at 2 hours and fasting plasma glucose $<7.0 \mathrm{mmo} \cdot \mathrm{I}^{-1}$. Participants were free of pre-existing type 2 diabetes, and any illness and/or medication with potential effect on compliance or the outcomes of the study.

\section{Measurements and procedures}

\section{Physical activity}

Participants wore an ActiSleep+ (ActiGraph LLC, Pensacola, FL) accelerometer attached to an elastic waist belt worn over the right mid-axillary line. The ActiSleep+ was worn $24 \mathrm{~h} \cdot \mathrm{day}^{-1}$ for seven consecutive days, removing only for water-based activities. The principal output from the ActiSleep + is an activity count, which represents raw accelerations that have been rescaled and filtered. Activity counts were collected at $100 \mathrm{~Hz}$ and aggregated to 60 -second epochs (18). Sleep time was determined using a fully-automated algorithm developed for use in 24-hour waist-worn accelerometer protocols. The algorithm produces estimates of nocturnal sleep period that are compared to an expert visual inspection of accelerometer trace (19). After the removal of nocturnal sleep episodes, participants were included in the analyses if they wore the monitor for $\geq 10$ hours on $\geq 4$ days (18) including 1 weekend day (20). Mean activity count during valid wear time (counts.minute ${ }^{-1}$, CPM) has been shown to correlate well with total activity energy expenditure measured by the doubly labelled water technique (21) and was used as an indicator of total PA volume $(18,28)$. Troiano cut points $(18)$ were used to determine time (minutes.day ${ }^{-1}$ ) spent at different intensity categories (Sedentary $<100$, moderate $<2,020$ and vigorous $<5,999$ counts per minute). Moderate and vigorous activity were summed to obtain moderate to vigorous physical activity (MVPA). 


\section{Cardio-metabolic risk factors}

In all study centres, standardized procedures were followed and measurements were performed by trained personnel. Self-administered questionnaires, accelerometer data and fasting blood samples, were collected at baseline. Blood was drawn from the vein in the antecubital fossa after fasting ( $>10$ hours). Blood samples were initially stored locally at $-80^{\circ} \mathrm{C}$, then transported and analysed centrally at the National Institution for Health and Welfare (THL) in Helsinki, Finland where they were analysed for insulin, $\mathrm{HbA}_{1 c}$, glucose, high sensitivity $\mathrm{C}$-reactive protein (hs-CRP), total cholesterol, triglycerides, HDL-cholesterol (HDL-C) and LDL-cholesterol (LDL-C) concentrations. Insulin resistance was calculated using the homeostasis model assessment for insulin resistance, HOMA-IR using the equation: HOMA-IR= Fasting insulin $\left(\mathrm{mU} \cdot \mathrm{I}^{-1}\right) \times$ Fasting glucose $\left(\mathrm{mmol} \cdot \mathrm{l}^{-1}\right.$ ) / 22.5. HOMA-IR has been validated against the gold standard hyperinsulinemic-euglycemic clamp technique (23). Total adiposity was assessed by dual energy X-ray absorptiometry (DEXA) in four (Copenhagen, Nottingham, Sydney and Auckland), bioelectrical impedance in 3 (Helsinki, Sofia, and Navarra) and with Bodpod (Maastricht.) in one site. Self-administered questionnaires assessed general and socio-economic variables, including ethnicity, educational status and household income.

\section{Statistical analysis}

Descriptive statistics (mean $\pm S D$ ) were calculated for continuous variables and frequencies (\%) for categorical variables. Two-fifths of the participants had a missing value on at least one variable, HOMA-IR was missing in $7.8 \%$ of all cases, while $17 \%$ of values were missing for the accelerometer values (CPM, MVPA, and sedentary time). Multiple imputation with fully conditional specification model, (Markov chain Monte Carlo) was used to impute missing values. All variables were included in the imputation and all variables with skewed distribution were $\log _{10}$ or square root transformed prior to imputation (24). Ten multiple imputed data sets were generated and pooled estimates were reported. Due to their positively skewed distribution, HDL-C, triglycerides hs-CRP, and waist circumference were logarithmically transformed $\left(\log _{10}\right)$ while HOMA-IR was square root transformed. Separate multiple linear regression models were performed to test the independent association between MVPA, CPM and ST with cardio-metabolic health markers (HOMA-IR, fasting insulin, FPG, $2 \mathrm{~h}$ glucose, $\mathrm{HbA}_{1 c}$, waist circumference, triglycerides, total $\mathrm{C}, \mathrm{HDL}-$ C and LDL-C-) and CRP while adjusting for potential confounders. Model 1 was adjusted for age, sex, ethnicity (Caucasian, Asian, Black, Arabic, Hispanic or other), smoking (daily, less than weekly, no smoker), accelerometer wear time, intervention centre, sleep duration, body fat\%, education level (no formal education, primary/junior school, secondary school, secondary vocational education, higher vocational education or university education) and household income (less than $£ 9360, £ 9360-£ 12,479.99, £ 12,480-£ 15,599.99, £ 15,600-£ 18,719.99, £ 18,720-£ 22,879.99$, $£ 22,880-£ 27,559.99, £ 27,560-£ 32,759.99, £ 32,760-£ 41,079.99, £ 41,080-£ 53,559.99, £ 53,560$ or more per year). Model 2 was additionally adjusted for ST while MVPA was the main exposure variables or for MVPA when ST was the main exposure variable. Sex, age $(<45.9,46-54.9,>55$ years), BMI and intervention centre differences in the associations between MVPA, sedentary time, or CPM and each cardio-metabolic risk factor were tested for by adding interaction terms to the model. A variance inflation factor $<4$ confirmed that multicollinearity was not a concern (25). 
Square root and log-transformations were directly compared across cardio-metabolic markers, and results of linear regression analysis presented as standardised beta coefficients. Data were analysed using the Statistical Package for the Social Sciences version 22.0 (SPSS Inc., Chicago, IL, USA) and alpha was set to $p<.05$.

TABLE 1 Descriptive, metabolic and physical activity characteristics of 2,326 pre-diabetic adults from the PREVIEW study

\begin{tabular}{|c|c|c|}
\hline Characteristics & Female $(n=1570)$ & Male $(n=755)$ \\
\hline Age (years) & $51.6 \pm 11.6$ & $53.5 \pm 11.6$ \\
\hline Height (m) & $1.64 \pm 0.07$ & $1.77 \pm 0.07$ \\
\hline Weight (kg) & $95.88 \pm 20.33$ & $108.87 \pm 20.98$ \\
\hline $\mathrm{BMI}\left(\mathrm{kg} \cdot \mathrm{m}^{<}\right)$ & $35.70 \pm 6.76$ & $34.55 \pm 6.01$ \\
\hline Fat (\%) & $46.45 \pm 5.85$ & $36.67 \pm 6.92$ \\
\hline Waist (cm) & $107.7 \pm 14.6$ & $116.8 \pm 14.5$ \\
\hline Systolic BP (mmHg) & $126.98 \pm 5.88$ & $133.10 \pm 14.8$ \\
\hline Diastolic BP (mmHg) & $77.07 \pm 11.15$ & $80.88 \pm 9.96$ \\
\hline Fasting insulin $\left(\left.\mathrm{mU} \cdot\right|^{-1}\right)$ & $12.53 \pm 6.54$ & $14.03 \pm 6.68$ \\
\hline Fasting plasma glucose $\left(\left.\mathrm{mmol} \cdot\right|^{-1}\right)$ & $6.08 \pm 0.67$ & $6.33 \pm 0.66$ \\
\hline $2 \mathrm{~h}$ plasma glucose $\left(\mathrm{mmol} \cdot \mathrm{I}^{-1}\right)$ & $7.64 \pm 2.21$ & $7.73 \pm 2.24$ \\
\hline $\mathrm{HbA}_{1 \mathrm{c}}\left(\left.\mathrm{mmol} \cdot\right|^{-1}\right)$ & $36.61 \pm 4.03$ & $36.73 \pm 4.06$ \\
\hline $\mathrm{HbA}_{1 \mathrm{c}}(\%)$ & $5.50 \pm 0.37$ & $5.51 \pm 0.37$ \\
\hline HOMA-IR & $3.44 \pm 1.90$ & $4.00 \pm 2.01$ \\
\hline Triglycerides $\left(\left.\mathrm{mmol} \cdot\right|^{-1}\right)$ & $1.45 \pm 0.77$ & $1.62 \pm 0.82$ \\
\hline Total cholesterol $\left(\mathrm{mmol} \cdot \mathrm{I}^{-1}\right)$ & $5.25 \pm 0.99$ & $5.03 \pm 0.97$ \\
\hline HDL-cholesterol $\left(\mathrm{mmol} \cdot \mathrm{I}^{-1}\right)$ & $1.33 \pm 0.29$ & $1.15 \pm 0.23$ \\
\hline LDL-cholesterol $\left(\mathrm{mmol} \cdot \mathrm{I}^{-1}\right)$ & $3.28 \pm 0.84$ & $3.16 \pm 0.85$ \\
\hline $\operatorname{CRP}(\mathrm{mg} / \mathrm{l})\left(\mathrm{mg} \cdot \mathrm{l}^{-1}\right)$ & $4.81 \pm 4.02$ & $3.46 \pm 3.35$ \\
\hline \multicolumn{3}{|l|}{ Accelerometer Variables } \\
\hline Waking wear Time (minutes.day ${ }^{-1}$ ) & $933.10 \pm 83.85$ & $928.40 \pm 83.37$ \\
\hline Sleep (minutes.day ${ }^{-1}$ ) & $474.69 \pm 80.26$ & $471.83 \pm 85.16$ \\
\hline Sedentary (minutes.day ${ }^{-1}$ ) & $579.46 \pm 91.76$ & $617.54 \pm 98.06$ \\
\hline Light (minutes.day ${ }^{-1}$ ) & $320.84 \pm 82.62$ & $280.12 \pm 78.20$ \\
\hline Moderate (minutes.day ${ }^{-1}$ ) & $25.30 \pm 6.88$ & $30.33 \pm 20.33$ \\
\hline MVPA (minutes.day ${ }^{-1}$ ) & $26.18 \pm 17.03$ & $31.58 \pm 20.62$ \\
\hline CPM (counts.minute ${ }^{-1}$ ) & $294.30 \pm 96.77$ & $297.98 \pm 17.28$ \\
\hline \multicolumn{3}{|l|}{ Ethnicity } \\
\hline Caucasian (\%) & 86.02 & 89.9 \\
\hline Asian (\%) & 2.66 & 2.71 \\
\hline Black (\%) & 1.82 & 1.2 \\
\hline Arabic (\%) & 0.2 & 0.3 \\
\hline Hispanic (\%) & 2.33 & 1.38 \\
\hline Other (\%) & 6.61 & 4.25 \\
\hline \multicolumn{3}{|l|}{ Smoking } \\
\hline Yes (Daily) \% & 10.72 & 9.57 \\
\hline Sometimes (less than weekly) (\%) & 3.3 & 2.93 \\
\hline No (\%) & 85.98 & 87.48 \\
\hline
\end{tabular}




\section{TABLE 1 continued}

\begin{tabular}{|c|c|c|}
\hline Education & Female $(n=1570)$ & Male $(n=755)$ \\
\hline No formal education (\%) & 0.5 & -- \\
\hline Primary/junior school (\%) & 2.1 & 2.8 \\
\hline Secondary school (\%) & 15.1 & 14.2 \\
\hline Secondary vocational education (\%) & 17.7 & 19.2 \\
\hline Higher vocational education (\%) & 16.4 & 18.6 \\
\hline University education & 40.5 & 35.6 \\
\hline Other & 7.6 & 9.7 \\
\hline \multicolumn{3}{|l|}{ Household income per year (\%) } \\
\hline less than $£ 9360$, (\%) & 8.8 & 5.3 \\
\hline$£ 9360-£ 12,479.99(\%)$ & 5.8 & 2.9 \\
\hline$£ 12,480-£ 15,599.99(\%)$ & 5.1 & 2.5 \\
\hline$£ 15,600-£ 18,719.99(\%)$ & 6.5 & 3.5 \\
\hline$£ 18,720-£ 22,879.99(\%)$ & 5.7 & 4.6 \\
\hline$£ 22,880-£ 27,559.99(\%)$ & 8.1 & 5.9 \\
\hline$£ 27,560-£ 32,759.99(\%)$ & 10.6 & 8.1 \\
\hline$£ 32,760-£ 41,079.99(\%)$ & 11.2 & 10.9 \\
\hline$£ 41,080-£ 53,559.99(\%)$ & 13.4 & 14.2 \\
\hline$£ 53,560$ or more (\%) & 24.9 & 42 \\
\hline
\end{tabular}

\section{RESULTS}

TABLE 1 displays the descriptive physical and biochemical characteristics of the 2,326 participants (32\% male, age $52.2 \pm 11.5$ years). Waking accelerometer wear time was $928.40 \pm 83.37$ and $933.10 \pm 83.85$ minutes/day for men and women respectively. Mean ST was $617.54 \pm 98.06$ for men and $579.46 \pm 91.76 \mathrm{~min} /$ day for women. Mean MVPA was $31.58 \pm 20.62 \mathrm{~min} /$ day for men and $26.18 \pm 17.03 \mathrm{~min} /$ day for women. Only $50 \%$ of participants met the recommended guidelines of 30 minutes of MVPA per day (26). TABLES 2, 3 and 4 show the standardized regression coefficients of CPM, MVPA, and ST with the cardio metabolic risk factors.

\section{Counts per minute}

TABLE 2 shows the standardized regression coefficients of CPM, with the cardio metabolic risk factors. After adjusting for age, sex, ethnicity, smoking, accelerometer wear time, intervention centre, sleep duration, body fat\%, education level and household income, CPM had significant inverse associations with HOMA-IR, waist circumference, fasting insulin, 2-hour glucose, triglycerides and CRP and a positive association with HDL-cholesterol.

TABLE 3 shows the standardized regression coefficients for MVPA with the cardio metabolic risk factors. In model 1, adjusted for age, sex, ethnicity, smoking, accelerometer wear time, intervention centre, sleep duration, body fat\%, education level and household income, MVPA was significantly and negatively associated with HOMA-IR, waist circumference, fasting insulin, $2 \mathrm{~h}$ glucose, triglycerides and (RP), and positively associated with HDL-cholesterol. After adjusting for 
ST in model 2, the association with HDL-cholesterol was lost. Associations with other biochemical factors were slightly attenuated but all remained significant.

TABLE 2 Standardized $\beta$ coefficients for associations between total physical activity (counts minute ${ }^{-1}$ ) and cardio metabolic risk factor

\begin{tabular}{|c|c|c|c|c|}
\hline Characteristics & B & 95\% Confidence interval & $\mathbf{p}$ & $\mathbf{R}^{\mathbf{2}}$ \\
\hline Waist $(\mathrm{cm})$ & -0.179 & $(-0.224,-0.134)$ & & 0.21 \\
\hline Systolic BP (mmHg) & -0.033 & $(-0.074,0.007)$ & & 0.19 \\
\hline Diastolic BP (mmHg) & -0.020 & $(-0.057,0.017)$ & & 0.34 \\
\hline Fasting insulin $\left(\left.\mathrm{mU} \cdot\right|^{-1}\right)$ & -0.139 & $(-0.183,-0.096)$ & $m$ & 0.13 \\
\hline Fasting glucose $\left(\mathrm{mmol} \cdot \mathrm{I}^{-1}\right)$ & -0.028 & $(-0.074,0.018)$ & & 0.16 \\
\hline 2-h plasma glucose $\left(\mathrm{mmol} \cdot \mathrm{I}^{-1}\right)$ & -0.088 & $(-0.131,-0.045)$ & $\pi \times x$ & 0.11 \\
\hline $\mathrm{HbA1c}(\%)$ & -0.049 & $(-0.098,-0.001)$ & & 0.13 \\
\hline HOMA-IR & -0.151 & $(-0.194,-0.107)$ & $m$ & 0.13 \\
\hline Triglycerides $\left(\left.\mathrm{mmol} \cdot\right|^{-1}\right)$ & -0.117 & $(-0.162,-0.071)$ & $m$ & 0.08 \\
\hline Total cholesterol $\left(\mathrm{mmol} \cdot \mathrm{I}^{-1}\right)$ & -0.007 & $(-0.053,0.038)$ & & 0.10 \\
\hline $\mathrm{HDL}\left(\mathrm{mmol} \cdot \mathrm{I}^{-1}\right)$ & 0.088 & $(0.048,0.129)$ & $m$ & 0.19 \\
\hline $\operatorname{LDL}\left(\mathrm{mmol} \cdot \cdot^{-1}\right)$ & 0.002 & $-0.045,0.049)$ & & 0.06 \\
\hline $\operatorname{CRP}\left(\left.\mathrm{mg} \cdot\right|^{-1}\right)$ & -0.104 & $(-0.146,-0.062)$ & $m$ & 0.21 \\
\hline
\end{tabular}

Adjusted for age, sex, ethnicity, smoking, household income, education level, body fat\%, wear time, sleep time and intervention centre. ${ }^{*} \mathrm{P}<0.05 ;{ }^{* * \mathrm{P}}<0.01 ;{ }^{* * *} \mathrm{P}<0.001$

\section{MVPA}

\section{Sedentary time}

TABLE 4 shows the standardized regression coefficients for ST with the cardio metabolic risk factors. In model 1 , adjusted for age, sex, ethnicity, smoking, accelerometer wear time, intervention centre, sleep duration, body fat\%, education level and household income, ST was positively associated with waist circumference, systolic BP, diastolic BP, mean arterial pressure, fasting insulin, $2 \mathrm{~h}$ glucose, HOMA-IR, triglycerides and CRP, and negatively associated HDL. After adjusting for MVPA in model 2, associations with 2-hour plasma glucose were no longer significant. Fasting plasma glucose, total cholesterol and LDL-cholesterol were not associated with any of our exposure variables. Two-way interactions indicate that associations between MVPA and fasting insulin were greater in the older age group (table 3). We did not observe any significant sex, centre, or BMI interactions between measures of PA or ST and any cardio metabolic risk factors.

\section{CONCLUSIONS}

This study investigated the associations between objectively measured PA and ST and metabolic variables in a worldwide sample of overweight and obese adults (BMI $>25 \mathrm{~kg} / \mathrm{m}^{2}$ ) with prediabetes confirmed through an OGTT (27). To our knowledge this is the first international investigation of associations between objectively measured PA and ST with cardio-metabolic risk factors in a population that exclusively meet the criteria for pre-diabetes (IFG 5.6-6.9 or IGT 7.8-11 $\left(\mathrm{mmol} \cdot \mathrm{I}^{-1}\right)$. Previous studies conducted in high risk populations have included participants based on a risk score questionnaire (5), family history of type 2 diabetes $(9,13)$ or participants with diabetes and pre-diabetes have been combined (14). Consequently, physical characteristics and 
metabolic parameters reported in these studies varied substantially from the present study. In our population of participants with pre-diabetes, MVPA was negatively associated with HOMA-IR, waist circumference, fasting insulin, $2 \mathrm{~h}$ glucose, triglycerides and CRP after accounting for potential confounders, sleep duration and sedentary time.

TABLE 3 Standardized $\beta$-coefficients for associations between MVPA (min.day ${ }^{-1}$ ) and cardiometabolic risk factors

\begin{tabular}{|c|c|c|c|c|}
\hline Characteristics & B & $95 \% \mathrm{Cl}$ & $\mathbf{p}$ & $\mathbf{R}^{2}$ \\
\hline \multicolumn{5}{|l|}{ Model 1} \\
\hline Waist $(\mathrm{cm})$ & -0.177 & $(-0.122,-0.134)$ & $x \times \pi$ & 0.20 \\
\hline Systolic BP (mmHg) & -0.005 & $(-0.047,0.083)$ & & 0.19 \\
\hline Diastolic BP (mmHg) & -0.007 & $(-0.044,0.031)$ & \multirow[b]{2}{*}{$n n$} & 0.34 \\
\hline Fasting insulin $\left(\mathrm{mU} \cdot \mathrm{l}^{-1}\right)$ & -0.115 & $(-0.158,-0.072)$ & & 0.12 \\
\hline Fasting glucose $\left(\mathrm{mmol} \cdot \mathrm{I}^{-1}\right)$ & -0.028 & $(-0.072,0.017)$ & \multirow[b]{2}{*}{$x \times$} & 0.16 \\
\hline $2 \mathrm{~h}$ plasma glucose $\left(\mathrm{mmol} \cdot \mathrm{I}^{-1}\right)$ & -0.069 & $(-0.112,-0.025)$ & & 0.11 \\
\hline $\mathrm{HbA}_{1 c}(\%)$ & -0.046 & $(-0.096,0.004)$ & \multirow[b]{2}{*}{$\cdots$} & 0.13 \\
\hline HOMA-IR & -0.122 & $(-0.166,-0.078)$ & & 0.12 \\
\hline Triglycerides $\left(\left.\mathrm{mmol} \cdot\right|^{-1}\right)$ & -0.091 & $(-0.138,-0.044)$ & $m$ & 0.08 \\
\hline Total cholesterol $\left(\mathrm{mmol} \cdot \mathrm{I}^{-1}\right)$ & -0.010 & $(-0.056,0.035)$ & & 0.10 \\
\hline $\mathrm{HDL}\left(\mathrm{mmol} \cdot \mathrm{I}^{-1}\right)$ & 0.055 & $(0.009,0.101)$ & - & 0.18 \\
\hline $\operatorname{LDL}\left(\left.\mathrm{mmol} \cdot\right|^{-1}\right)$ & 0.002 & $(-0.044,0.048)$ & & 0.06 \\
\hline $\operatorname{CRP}\left(\left.\mathrm{mg} \cdot\right|^{-1}\right)$ & -0.086 & $(-0.127,-0.045)$ & $\pi \pi \pi$ & 0.26 \\
\hline \multicolumn{5}{|l|}{ Model 2} \\
\hline Waist (cm) & -0.127 & $(-0.173,-0.081)$ & $\pi \pi \pi$ & 0.22 \\
\hline Systolic BP (mmHg) & 0.020 & $(-0.026,0.067)$ & & 0.20 \\
\hline Diastolic BP $(\mathrm{mmHg})$ & 0.011 & $(-0.03,0.053)$ & \multirow{2}{*}{ n } & 0.35 \\
\hline Fasting insulin $\left(\mathrm{mU} \cdot \mathrm{I}^{-1}\right)$ main effect & -0.078 & $(-0.127,-0.03)$ & & 0.13 \\
\hline 25-45.9 years(reference) & - & - & - & - \\
\hline $46.0-54.9$ years & 0.025 & $(-0.120,0.170)$ & \multirow[b]{2}{*}{ * } & 0.13 \\
\hline $55.0-71$ years & -0.098 & $(-0.195,-0.001)$ & & 0.13 \\
\hline Fasting glucose $\left(\mathrm{mmol} \cdot \mathrm{l}^{-1}\right)$ & -0.014 & $(-0.063,0.035)$ & \multirow[b]{2}{*}{ ^ } & 0.17 \\
\hline $2 \mathrm{~h}$ plasma glucose $\left(\mathrm{mmol} \cdot \mathrm{I}^{-1}\right)$ & -0.053 & $(-0.1,-0.006)$ & & 0.11 \\
\hline $\mathrm{HbA}_{1 \mathrm{c}}(\%)$ & -0.036 & $(-0.095,0.023)$ & \multirow[b]{2}{*}{ n } & 0.13 \\
\hline HOMA-IR & -0.080 & $(-0.129,-0.031)$ & & 0.14 \\
\hline Triglycerides $\left(\mathrm{mmol} \cdot \mathrm{l}^{-1}\right)$ & -0.067 & $(-0.117,-0.017)$ & “ & 0.08 \\
\hline Total cholesterol $\left(\mathrm{mmol} \cdot \mathrm{I}^{-1}\right)$ & -0.013 & $(-0.064,0.037)$ & \multirow[b]{4}{*}{ ^ } & 0.10 \\
\hline $\mathrm{HDL}\left(\left.\mathrm{mmol} \cdot\right|^{-1}\right)$ & 0.028 & $(-0.081,0.383)$ & & 0.19 \\
\hline $\operatorname{LDL}\left(\mathrm{mmol} \cdot \cdot^{-1}\right)$ & 0 & $(-0.053,0.052)$ & & 0.06 \\
\hline $\operatorname{CRP}\left(\mathrm{mmol} \cdot \cdot^{-1}\right)$ & -0.061 & $(-0.108,-0.015)$ & & 0.27 \\
\hline
\end{tabular}

Model 1 adjusted for age, sex, ethnicity, smoking, household income, education level, body fat\%, wear time, sleep time, and intervention centre. Model 2 additionally adjusted for $S T$. ${ }^{*} P<0.05$; ${ }^{* * P}<0.01$; $* * * P<0.001$

Our study also demonstrated that total PA volume (counts.minute ${ }^{-1}$ ) at least as strongly associated with the aforementioned risk factors as MVPA. Before controlling for sedentary time in model 2, total PA volume also accounts for greater variance in cardio-metabolic risk factors than MVPA. Hence, it appears that in this population although both are significant, the accumulation of total PA over a day is a stronger indicator of insulin resistance and some related cardio metabolic risk factors than MVPA. 
TABLE 4 Standardized $\beta$-coefficients for associations between ST (min.day ${ }^{-1}$ ) and cardiometabolic risk factors

\begin{tabular}{|c|c|c|c|c|}
\hline Characteristics & $B$ & $95 \% C I$ & $\boldsymbol{p}$ & $R^{2}$ \\
\hline \multicolumn{5}{|l|}{ Model 1} \\
\hline Waist (cm) & 0.215 & $(0.146,0.267)$ & 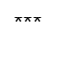 & 0.21 \\
\hline Systolic BP (mmHg) & 0.078 & $(0.026,0.131)$ & ^ & 0.20 \\
\hline Diastolic BP (mmHg) & 0.057 & $(0.007,0.106)$ & \multirow{2}{*}{$\times \approx x$} & 0.35 \\
\hline Fasting insulin $\left(\mathrm{mU} \cdot \mathrm{I}^{-1}\right)$ & 0.155 & $(0.092,0.219)$ & & 0.13 \\
\hline Fasting glucose $\left(\mathrm{mmol} \cdot \mathrm{I}^{-1}\right)$ & 0.052 & $-0.004,0.108)$ & \multirow[b]{2}{*}{ ^ } & 0.17 \\
\hline $2 \mathrm{~h}$ plasma glucose $\left(\mathrm{mmol} \cdot \mathrm{I}^{-1}\right)$ & 0.072 & $(0.015,0.129)$ & & 0.11 \\
\hline $\mathrm{HbA}_{1 c}(\%)$ & 0.047 & $(-0.022,0.117)$ & \multirow[b]{2}{*}{$m$} & 0.13 \\
\hline HOMA-IR & 0.175 & $(0.114,0.236)$ & & 0.13 \\
\hline Triglycerides $\left(\left.\mathrm{mmol} \cdot\right|^{-1}\right)$ & 0.106 & $(0.052,0.16)$ & $m n$ & 0.08 \\
\hline Total cholesterol $\left(\mathrm{mmol} \cdot \mathrm{l}^{-1}\right)$ & -0.006 & $(-0.062,0.051)$ & \multirow[b]{2}{*}{$m$} & 0.10 \\
\hline $\mathrm{HDL}\left(\left.\mathrm{mmol} \cdot\right|^{-1}\right)$ & -0.103 & $(-0.165,-0.042$ & & 0.19 \\
\hline $\operatorname{LDL}\left(\left.\mathrm{mmol} \cdot\right|^{-1}\right)$ & -0.007 & $(-0.062,0.048)$ & & 0.06 \\
\hline $\operatorname{CRP}\left(\left.\mathrm{mg} \cdot\right|^{-1}\right)$ & 0.106 & $(0.039,0.172)$ & œ & 0.26 \\
\hline \multicolumn{5}{|l|}{ Model 2} \\
\hline Waist (cm) & 0.165 & $(0.109,0.221)$ & \multirow{2}{*}{$\begin{array}{l}m \\
x \times\end{array}$} & 0.22 \\
\hline Systolic BP (mmHg) & 0.086 & $(0.028,0.143)$ & & 0.20 \\
\hline Diastolic BP $(\mathrm{mmHg})$ & 0.061 & $(0.006,0.116)$ & \multirow{2}{*}{${ }_{\pi \times}^{\pi}$} & 0.35 \\
\hline Fasting insulin $\left(\mathrm{mU} \cdot \mathrm{I}^{-1}\right)$ main effect & 0.126 & $(0.055,0.198)$ & & 0.13 \\
\hline Fasting glucose $\left(\mathrm{mmol} \cdot \mathrm{l}^{-1}\right)$ & 0.047 & $(-0.014,0.108)$ & & 0.17 \\
\hline $2 \mathrm{~h}$ plasma glucose $\left(\mathrm{mmol} \cdot \mathrm{I}^{-1}\right)$ & 0.053 & $(-0.009,0.114)$ & & 0.11 \\
\hline $\mathrm{HbA}_{1 \mathrm{c}}(\%)$ & 0.034 & $(-0.045,0.113)$ & \multirow[b]{2}{*}{$m$} & 0.13 \\
\hline HOMA-IR & 0.145 & $(0.077,0.213)$ & & 0.14 \\
\hline Triglycerides $\left(\left.\mathrm{mmol} \cdot\right|^{-1}\right)$ & 0.08 & $(0.023,0.138)$ & $\approx \pi$ & 0.08 \\
\hline Total cholesterol $\left(\mathrm{mmol} \cdot \mathrm{I}^{-1}\right)$ & -0.011 & $(-0.074,0.052)$ & \multirow[b]{2}{*}{ x } & 0.10 \\
\hline $\mathrm{HDL}\left(\left.\mathrm{mmol} \cdot\right|^{-1}\right)$ & -0.093 & $(-0.163,-0.022)$ & & 0.19 \\
\hline $\operatorname{LDL}\left(\left.\mathrm{mmol} \cdot\right|^{-1}\right)$ & -0.007 & $(-0.069,0.055)$ & \multirow[b]{2}{*}{ - } & 0.06 \\
\hline $\operatorname{CRP}\left(\left.\mathrm{mmol} \cdot\right|^{-1}\right)$ & 0.083 & $(0.01,0.156)$ & & 0.27 \\
\hline
\end{tabular}

Model 1 adjusted for age, sex, ethnicity, smoking, household income, education level, body fat\%, wear time, sleep time, and intervention centre. Model 2 additionally adjusted for MVPA. ${ }^{*} \mathrm{P}<0.05 ;{ }^{* *} \mathrm{P}<0.01$; $* * * P<0.001$

Previous studies in populations with a family history of diabetes and newly diagnosed diabetes, have shown that total energy expenditure spent on PA (14), counts.minute ${ }^{-1}$ (13) and MVPA (9) were negatively associated with waist circumference, fasting serum triglycerides, systolic BP, fasting plasma glucose, fasting plasma insulin, HOMA-IR and a clustered metabolic risk score. In agreement with our findings, Ekelund et al (13), reported that total counts.day ${ }^{-1}$ was more strongly associated with clustered risk and individual cardio metabolic risk factors than MVPA. In the general population, Balkau and colleagues (22) reported associations between MVPA and total PA with insulin resistance using the gold standard clamp technique for determining insulin sensitivity. However, after adjusting for total PA, associations with MVPA were lost (22). These findings, in keeping with the present study would support the hypothesis that the accumulation of total PA volume accounts for greater variance in insulin resistance and some related cardio metabolic risk factors than MVPA. 
The present study also demonstrated that after controlling for confounders, ST is positively associated with waist circumference, systolic BP, diastolic BP, fasting insulin, HOMA-IR, triglycerides, CRP, and HDL-cholesterol independent of time spent in MVPA. In agreement with our findings, Henson et al (5) reported positive associations between ST, 2 hour plasma glucose, triglycerides and HDL-cholesterol, independent total PA in a population at risk of type 2 diabetes (5). Similarly, positive associations between ST, waist circumference, insulin, HOMA-IR, and HDLcholesterol were reported in an older sample with newly diagnosed type-2 diabetes (28). There is a lack of consensus on the role of ST in pathology of cardio metabolic risk factors. Some authors have reported that once total energy expenditure is taken into account the association between ST and cardio-metabolic health are lost. These findings suggest that ST reduces total energy expenditure by displacing other activities that are more energy costly $(22,29)$. Other investigators have found that the mechanism linking ST to glucose metabolism and metabolic health differ from those of PA and may be related to static posture and unloading of large skeletal muscle groups when seated $(7,30)$ Sedentary time is thought to affect glucose homeostasis and lipid metabolism by reducing muscle GLUT-4 content and insulin-stimulated glucose uptake (6) while also reducing LPL activity leading to impaired triglyceride and HDL cholesterol metabolism (7).

Further, light activity is associated with marked improvements in cardio-metabolic health (8) while interventions have shown that replacing ST with postural changes such as standing or light ambulatory activity can improve glycaemic control to a greater extent than structured exercise of the same energy cost (31). In the present analysis, sedentary time was associated with HDL cholesterol however, associations between MVPA and HDL cholesterol were lost after controlling for ST. Similarly, ST was positively associated with systolic and diastolic blood pressure independent of MVPA while no association was found between CPM or MVPA with either blood pressure variable. Associations between PA, ST and blood pressure variables reported by observation studies have been inconsistent $(8,12,14)$. However, experimental studies in overweight/obese populations have suggested that a reduction of sedentary time and the interruption of prolonged sedentary bouts with light or moderate activity are associated with improved systolic and diastolic blood pressure (32).

While physical activity guidelines continue to focus on participation in MVPA (26), our data demonstrated that in a population with pre-diabetes, total volume of PA was as strongly associated with cardio-metabolic health as MVPA. The implications of this finding may be important considering the levels of PA in this population. Light activity may be more readily adopted by individuals with pre-diabetes particularly if they are physically inactive, overweight/obese, or reluctant to engage in structured exercise (31).

The lack of associations observed for all exposure variables with fasting glucose is consistent with previous research $(5,8)$. This finding reflects the fact that the PA predominantly affects peripheral insulin sensitivity, which is responsible for lowering blood glucose levels after an OGTT when most of the glucose is taken up by skeletal muscle (33).

The strengths of this study are the implementation of a $24 \mathrm{~h}$ accelerometer wear time protocol that resulted in a greater mean waking wear time ( 15.5 hours) than many studies of a similar 
nature $(5,18,28)$. Longer monitoring duration provides greater reliability of average activity estimates. This approach also allowed an objective assessment of sleep time using an algorithm to detect sleep onset and wake time from a $24 \mathrm{~h}$ waist worn accelerometer trace (19) This allowed the study team to control for the confounding effects of sleep on cardio metabolic risk factors (34).

Type 2 diabetes is high on public health agendas with attention on the prevention or delay of diabetes onset and the management of cardio metabolic risk factors $(35,36)$. National and international guidelines focus on first identifying high-risk individuals and second controlling modifiable risk factors such as body weight, diet, ST and PA, through targeted interventions $(37,38)$. This study provides new evidence of associations between PA and ST with cardio metabolic markers in a population to which the results are most applicable.

Whilst this study has numerous strengths it is also important to acknowledge its limitations. First, the cross-sectional design does not allow insight into the direction of causality between each exposure variable and markers of cardio metabolic health and, although we controlled for many potential confounding factors, we did not account for dietary intake or alcohol consumption which may have influenced our results. Secondly, although accelerometers offer more robust assessments of PA than self-report (39), they are not without limitation. Hip worn accelerometers capture most movement during locomotion, but cannot account for upper body movement, movement that occurs during activities such as cycling or weight lifting (40) or distinguish between light intensity activities such as sitting and standing. Furthermore, the accelerometer is removed during water-based activities and contact sports. Therefore, PA may be underestimated. Given the fixed nature of accelerometer-derived variables (sleep, light activity ST and MVPA) as proportions of wake time, time spent in behaviours within the day are inherently collinear; every increase in time spent in one behaviour unavoidably causes a decrease in the time spent in one or a combination of the other behaviours. Thus, it is not possible to include all subcomponents of the day (sleep, sedentary, light activity, MVPA) in a regression model without violating collinearity assumptions. Consequently, in the present study it is not possible to say with certainty that the positive associations observed between cardio-metabolic risk factors and ST are truly independent and not, in fact, negative associations with light activity. Finally, participants in this study were voluntary recruits to a lifestyle intervention from the 8 study sites worldwide with approximately $50 \%$ of the study sample were between 55-70 years. Whilst this may limit the applicability of the current findings to the older age-range, it is this group who are at greater risk of type 2 diabetes and are perhaps more likely to participate in such interventions given their greater availability of time to those still in employment.

In conclusion, this study provides new evidence that in a large diverse population of adults with pre-diabetes, objective measures of PA and ST are associated with markers of cardio metabolic health. Furthermore, associations with total PA volume are stronger than MVPA. Taken together, these findings suggest that replacing ST with light activity may provide practical approach to improve cardio-metabolic health in a population with low engagement in MVPA. 


\section{ACKNOWLEDGEMENTS}

The authors acknowledge particularly the medical and scientific experts, who helped in building up the study, Arne Astrup (University of Copenhagen, Denmark), Stephen Colagiuri (University of Sydney, Australia), Peter Mansell (University of Nottingham U.K.), and the PREVIEW Scientific Advisory Board, Louise Dye (University of Leeds, U.K.), Richard L. Atkinson (Virginia Commonwealth University), Boyd Swinburn (University of Auckland, New Zealand; Deakin University, Melbourne, Australia), Lauren Lissner (University of Göteborg, Sweden), and Grethe Andersen (Danish Agriculture \& Food Council, Copenhagen, Denmark). Furthermore, the authors acknowledge the great staff working on PREVIEW around the world for their phenomenal efforts in recruitment and in the running of the project. The authors are especially grateful for the participants for volunteering their time to the study.

\section{FUNDING}

PREVIEW received grants from the EU Seventh Framework Programme (FP7-KBBE-2012), grant no. 312057; the New Zealand Health Research Council, grant no. 14/191; and the NHMRC-EU Collaborative Grant, Australia. Dietary products were provided by Cambridge Weight Plan, Corby, U.K.

\section{DUALITY OF INTEREST}

I.M. is an International Life Sciences Institute Europe member of the Dietary Carbohydrates Task Force and a member of the expert group on "Efficacy Markers of Diabetes Risk" and expert group on "Carbohydrate-Based Recommendations as a Basis for Dietary Guidelines: A Scientific Review." In all cases, travel and subsistence are paid but not attendance fees. I.M. received honorarium as part of the Nature Publishing Group (Springer Nature) and as Editor of the International Journal of Obesity. I.M. has had research travel and accommodation reimbursed for a Nestle Research Centre Consultancy for Nutrition in the Life Cycle (honorarium paid to the University of Nottingham). I.M. received honorarium from Mars Incorporated-Waltham Centre for Pet Nutrition for providing peer-review of pet nutrition research (amount received per annum less than $£ 5,000$ ). I.M. has had travel and subsistence costs reimbursed by Mars UK/Europe as a Member of Nutrition Advisory Board and Health and Wellbeing Committee (honorarium paid to the University of Nottingham). I.M. has had travel and subsistence costs reimbursed as an Ikea Member of the Science and Health Committee (honorarium paid to the University of Nottingham). S.D.P. holds the Fonterra Chair in Human Nutrition at the University of Auckland. J.B.-M. is the President of the Glycemic Index Foundation, Director of the Sydney University Glycemic Index Research Service, and the author of books about the glycemic index of foods. No other potential conflicts of interest relevant to this article were reported.

\section{AUTHOR CONTRIBUTIONS}

N.S. conducted analysis and wrote the manuscript. K.M. was involved in the study conception, PA analyses, and editing of the manuscript. M.M. was involved in the study conception, analyses, and editing of the manuscript. J.W.S. assisted in the preparation of the manuscript and study design. 
D.S. advised on analysis and preparation of the manuscript. M.F. was the principle investigator of the Helsinki site and was involved in conception of the study and editing of the manuscript. M.D. was an investigator of the Maastricht University site and participated in editing of the manuscript. I.M. was principle investigator of the Nottingham site and was involved in conception of the study and editing of the manuscript. J.A.M. was principle investigator of the Navarra site and was involved in editing of the manuscript. T.H.-D. was principle investigator of the Sofia site and was involved in the design of the study, recruitment and implementation of the trial, data interpretation, and approval of the manuscript. S.D.P. was principle investigator of the Auckland site and participated in editing of the manuscript. J.B.-M. was principal investigator of the Sydney site and was involved in editing of the manuscript. T.M.L. was principal investigator of the Copenhagen site and involved in editing of the manuscript. A.R. was the project coordinator of PREVIEW and was involved in the conception of the study and editing of the manuscript. G.S. contributed to study design and conception, supervision of PA analyses, and editing of the manuscript. N.S., K.M., M.M., and G.S. formed the writing group. G.S. is the guarantor of this work and, as such, had full access to all the data in the study and takes responsibility for the integrity of the data and the accuracy of the data analysis 


\section{REFERENCES}

1. Risk NCD, Collaboration F. Worldwide trends in diabetes since 1980: a pooled analysis of 751 populationbased studies with 4.4 million participants. Lancet 2016;387(10027):1513-30.

2. Lee I-M, Shiroma EJ, Lobelo F, Puska P, Blair SN, Katzmarzyk PT. Impact of Physical Inactivity on the World's Major Non-Communicable Diseases. Lancet 2012;380(9838):219-29.

3. Duncan GE, Perri MG, Theriaque DW, Hutson AD, Eckel RH, Stacpoole PW. Exercise training, without weight loss, increases insulin sensitivity and postheparin plasma lipase activity in previously sedentary adults. Diabetes Care 2003;26(3):557-62.

4. Holloszy JO. Exercise-induced increase in muscle insulin sensitivity. J Appl Physiol. 2005;99(1):338-43.

5. Henson J, Yates T, Biddle SJH, Edwardson CL, Khunti K, Wilmot EG, et al. Associations of objectively measured sedentary behaviour and physical activity with markers of cardiometabolic health. Diabetologia 2013;56(5):1012-20.

6. Megeney LA, Neufer PD, G.L. D. Effects of muscle activity ad fiber composition on glucose transport ad GLUT4. Am J Clin Nutr 1993;264:E583--593.

7. Bey L, Hamilton MT. Suppression of skeletal muscle lipoprotein lipase activity during physical inactivity : a molecular reason to maintain daily low-intensity activity. J Physio/2003;673-82.

8. Healy GN, Wijndaele K, Dunstan DW, Shaw J, Salmon J, Zimmet P, et al. Objectively measured sedentary time, physical activity, and metabolic risk. Diabetes Care 2008;31(2):369-711.

9. Ekelund U, Brage S, Griffin SJ, Wareham NJ. Objectively Measured Moderate- and Vigorous-Intensity Physical Activity but Resistance in High-Risk Individuals. Diabetes Care 2009;32(6):1081-6.

10. Rosique-Esteban N, Díaz-López A, Martínez-González MA, Corella D, Goday A, Martínez JA, et al. Leisuretime physical activity, sedentary behaviors, sleep, and cardiometabolic risk factors at baseline in the PREDIMED-PLUS intervention trial: A cross-sectional analysis. PLoS One 2017;12(3):e0172253.

11. Nelson RK, Horowitz JF, Holleman RG, Swartz AM, Strath SJ, Kriska AM, et al. Daily physical activity predicts degree of insulin resistance: a cross-sectional observational study using the 2003-2004 National Health and Nutrition Examination Survey. Int J Behav Nutr Phys Act 2013;10(1):10.

12. Knaeps S, Lefevre J, Wijtzes A, Charlier R, Mertens E, Bourgois JG. Independent Associations between Sedentary Time, Moderate-To-Vigorous Physical Activity, Cardiorespiratory Fitness and Cardio-Metabolic Health: A Cross-Sectional Study. PLoS One 2016;11(7):1-13.

13. Ekelund U, Griffin SJ, Wareham NJ. Physical activity and metabolic risk in individuals with a family history of type 2 diabetes. Diabetes Care 2007;30(2):337-42.

14. Hamasaki H, Noda M, Moriyama S, Yoshikawa R, Katsuyama H, Sako A, et al. Daily Physical Activity Assessed by a Triaxial Accelerometer Is Beneficially Associated with Waist Circumference, Serum Triglycerides, and Insulin Resistance in Japanese Patients with Prediabetes or Untreated Early Type 2 Diabetes. J Diabetes Res 2015;2015:526201.

15. Raben A, Fogelholm M, Feskens $E$, Westerterp-Plantenga M, Schlicht W, Brand-Miller J. PREVention of diabetes through lifestyle Intervention and population studies in Europe and around the World. On behalf of the PREVIEW consortium. Obes Facts 2013:6(Suppl. 1):194.

16. Silventoinen $K$, Pankow J, Lindstrom J, Jousilahti P, Hu G, Tuomilehto J. The validity of the Finnish Diabetes Risk Score for the prediction of the incidence of coronary heart disease and stroke, and total mortality. Eur J Cardiovasc Prev Rehabil 2005;12(5):451-8.

17. WHO/IDF. Definition and diagnosis of diabetes mellitus and intermediate hyperglycemia : report of a WHO/IDF consultation. 2006.

18. Troiano RP, Berrigan D, Dodd KW, Masse LC, Tilert T, Mcdowell M. Physical activity in the United States measured by accelerometer. Med Sci Sports Exerc 2008;40(1):181-8.

19. Tudor-locke C, Barreira T V, Schuna JM, Mire E, Katzmarzyk PT. Fully automated waist - worn accelerometer algorithm for detecting children' s sleep period time separate from 24 - hour physical activity or sedentary behaviors. App/ Physiol Nutr Metab 2014;39(225):53-7.

20. Aadland $E$, Ylvisåker E. Reliability of objectively measured sedentary time and physical activity in adults. PLoS One 2015;10(7):1-13.

21. Rabinovich RA, Louvaris Z, Raste $Y$, Langer D, Van Remoortel H, Giavedoni S, et al. Validity of physical activity monitors during daily life in patients with COPD. Eur Respir J. 2013;42(5):1205-15.

22. Balkau B, Mhamdi L, Oppert J, Nolan J. Physical activity and insulin sensitivity the RISC study. Diabetes 2008;57(October):2613-8.

23. Wallace TM, Levy JC, Matthews DR. Use and abuse of HOMA modeling. Diabetes Care. 2004;27(6):1487-95. 
24. Sterne JAC, White IR, Carlin JB, Spratt M, Royston P, Kenward MG, et al. Multiple imputation for missing data in epidemiological and clinical research: potential and pitfalls. BMJ 2009;338.

25. Field A. Discovering Statistics Using SPSS. 3rd ed. Vol. 81, International Statistical Review 2013. 169-170 p.

26. WHO. Global recommendations on physical activity for health. 2010.

27. Diagnosis and classification of diabetes mellitus. Diabetes Care 2011;34(SUPPL.1).

28. Cooper AR, Sebire S, Montgomery AA, Peters TJ, Sharp DJ, Jackson N, et al. Sedentary time, breaks in sedentary time and metabolic variables in people with newly diagnosed type 2 diabetes. Diabetologia 2012;55(3):589-99.

29. Maher C, Olds T, Mire E, Katzmarzyk PT. Reconsidering the sedentary behaviour paradigm. PLoS One 2014;9(1).

30. Peddie MC, Bone JL, Rehrer NJ, Skeaff CM, Gray AR, Perry TL. Breaking prolonged sitting reduces postprandial glycemia in healthy, normal-weight adults: A randomized crossover trial. Am J Clin Nutr 2013;98(2):358-66.

31. Dempsey PC, Owen N, Yates TE, Kingwell BA, Dunstan DW. Sitting Less and Moving More: Improved Glycaemic Control for Type 2 Diabetes Prevention and Management. Curr Diab Rep 2016;16(11).

32. Dempsey P, Sacre J, Owen N, Straznicky N, Cohen N, Kingwell B, et al. Interrupting prolonged sitting reduces resting blood pressure in adults with type 2 diabetes. Hear Lung Circ. 2015;24(12):S127-8.

33. Færch K, Borch-Johnsen K, Holst JJ, Vaag A. Pathophysiology and aetiology of impaired fasting glycaemia and impaired glucose tolerance: Does it matter for prevention and treatment of type 2 diabetes? Diabetologia 2009;52(9):1714-23.

34. Knutson KL. Sleep duration and cardiometabolic risk: a review of the epidemiologic evidence. Best Pr Res Clin Endocrinol Metab 2010;24(5):731-43.

35. Richardson E, Zaletel J, Nolte E. National Diabetes Plans in Europe What lessons are there for the prevention and control of chronic diseases in Europe? On behalf of Joint Action CHRODIS.

36. International Diabetes Federation. Global Diabetes Plan 2011-2021. Vasa. 2011;1-20.

37. Paulweber P. Lindstrom, J. Lalic, N. M. Greaves, C. J. McKee, M. Kissimova-Skarbek, K. Liatis, S. Cosson, E. Szendroedi, J. Sheppard, K. E. Charlesworth, K. Felton, A. -M. Hall, M. Rissanen, A. Tuomilehto, J. Schwarz, P. E. Roden, M.CA Writing Grp IMAGE BV. A European Evidence-Based Guideline for the Prevention of Type 2 Diabetes. Horm Metab Res 2010;42:3-36.

38. Chatterton $\mathrm{H}$, Younger $\mathrm{T}$, Fischer $\mathrm{A}$, Khunti K. Risk identification and interventions to prevent type 2 diabetes in adults at high risk: summary of NICE guidance. BMJ 2012;345(jul12 3):e4624-e4624.

39. Prince S, Adamo K, Hamel M, Hardt J, Gorber S, Tremblay M. A comparison of direct versus self-report measures for assessing physical activity in adults: a systematic review. Int J Behav Nutr Phys Act 2008;5(1):56.

40. Welk G. Physical Activity Assessments for Health-related Research. Vol. 1. Human Kinetics, 2002. 269 p. 


\section{CHAPTER 4}

\section{Dietary protein and energy balance in relation to obesity and co-morbidities}

M. Drummen, L. Tischmann, B. Gatta-Cherifi, T. Adam and M. Westerterp-Plantenga

Published in:

Frontiers in Endocrinology (2018) 


\section{ABSTRACT}

Dietary protein is effective for body-weight management, in that it promotes satiety, energy expenditure, and changes body-composition in favor of fat-free body mass. With respect to body-weight management, the effects of diets varying in protein differ according to energy balance. During energy restriction, sustaining protein intake at the level of requirement appears to be sufficient to aid body weight loss and fat loss. An additional increase of protein intake does not induce a larger loss of body weight, but can be effective to maintain a larger amount of fatfree mass. Protein induced satiety is likely a combined expression with direct and indirect effects of elevated plasma amino acid and anorexigenic hormone concentrations, increased diet-induced thermogenesis, and ketogenic state, all feed-back on the central nervous system. The decline in energy expenditure and sleeping metabolic rate as a result of body weight loss is less on a highprotein than on a medium-protein diet. In addition, higher rates of energy expenditure have been observed as acute responses to energy-balanced high-protein diets. In energy balance, high protein diets may be beneficial to prevent the development of a positive energy balance, whereas low-protein diets may facilitate this. High protein-low carbohydrate diets may be favorable for the control of IHTG in healthy humans, likely as a result of combined effects involving changes in protein and carbohydrate intake. Body weight loss and subsequent weight maintenance usually shows favorable effects in relation to insulin sensitivity, although some risks may be present. Promotion of insulin sensitivity beyond its effect on body-weight loss and subsequent bodyweight maintenance seems unlikely. In conclusion, higher-protein diets may reduce overweight and obesity, yet whether high-protein diets, beyond their effect on body-weight management, contribute to prevention of increases in NAFDL, type 2 diabetes and cardiovascular diseases is inconclusive. 


\section{INTRODUCTION}

The prevalence of obesity and its associated co-morbidities, such as non-alcoholic fatty liver disease (NAFLD), type 2 diabetes and cardiovascular diseases, has increased in a growing number of countries $(1,2)$. Energy intake exceeding energy expenditure results in a chronic positive energy balance, storage of excess energy and subsequent body weight gain (3). Treatment of obesity requires a negative energy balance, which most efficiently and effectively is achieved by applying an energy-restricted diet (4). However, this usually results in increased feelings of hunger and desire to eat, and in a decrease of the feeling of fullness, implying a risk for sustaining a lower energy intake. Body weight loss consists of loss of fat mass and of fat-free mass (FFM); the latter causes a reduction in energy expenditure and a decrease in energy requirement. This vicious cycle may counteract the negative energy balance induced by the energy-restricted diet. Consequently, body weight loss should be paralleled by a reduction in energy intake without changing appetite, and maintenance of energy expenditure by preserving FFM. Both goals can be achieved through an energy-restricted, relatively high-protein diet (5-8). In this review the mechanisms of proteininduced appetite modulation, reward homeostasis, and energy expenditure are highlighted, including possible adverse effects of protein-diets. Finally, the relevance of relatively high-protein diets for treatment or prevention of NAFLD, cardiovascular diseases and type 2 diabetes apart from weight-loss and subsequent weight maintenance are discussed.

\section{SHORT-TERM DIETARY PROTEIN-INDUCED ENERGY HOMEOSTASIS - SATIETY}

Short-term intervention studies using energy-balanced diets with large contrasts in relative protein content have shown that high-protein diets are more satiating than diets lower in protein (9-15). Furthermore, subjects consumed less food during an ad libitum high-protein diet relative to baseline (16), while being similarly satiated and satisfied (16-18). Dietary proteins exert a high satiating effect via different pathways including stimulation of gut hormone secretion, digestion effects, circulating amino-acid levels, energy expenditure, a ketogenic state and possibly gluconeogenesis. Here the gut-brain axis, encompassing signaling from gastrointestinal hormones released in the blood and acting at their brain receptors, conducts signals to the brain deriving from the gastrointestinal system contributing to control of energy intake.

\section{AMINOSTATIC THEORY}

Elevated blood concentrations of amino acids may stimulate satiety signaling in the brain $(13,19$ 23). According to the 'aminostatic theory', serum amino acids that cannot be channelled into protein synthesis directly serve as satiety signals (24). However, the aminostatic theory failed to gain strong support because fasting circulating amino acid levels do not correlate with appetitive sensations and there are non-congruent appetitive responses to protein sources varying in the rate of amino acid appearance. Indirectly, dietary amino acids may act on satiety signaling via receptors in the duodeno-intestinal and hepatoportal regions (25). Depending on the type of amino acid, they increase or decrease the activity of hepatic vagal afferent fibers, innervating satiety centers in the brain (25). The branched-chain amino acids leucine, isoleucine and valine reportedly contribute to satiety, following these mechanisms $(13,19-21,23,25)$. 


\section{ROLE OF ANOREXIGENIC AND OREXIGENIC GUT HORMONES}

The satiety-stimulating effect of protein is partly related to increases in anorexigenic gut hormones, produced in response to peripheral and central detection of amino acids (23, 26-30). They react to elevated protein intake and stimulate vagal activity in brain areas involved in the control of food intake $(23,31,32)$. Concentrations of glucagon-like peptide 1 (GLP-1), cholecystokinin (CCK) and peptide $Y Y$ (PYY) consistently increase in response to high protein intakes $(23,26-30)$. Apart from its effect on anorexigenic hormones, protein intake can also influence orexigenic tone. Therefore, dietary protein consumed in liquid preloads prolongs the postprandial suppression of ghrelin $(33,34)$. This response was not affected by the type of protein consumed (soy, whey, or gluten) and was similarly observed in lean and overweight subject. The ghrelin decrease was also shown during a whey-protein infusion intraduodenally administered with a dose dependent effect $(35,36)$. Cortisol response has also been studied after protein ingestion with a significant decline of serum cortisol within $30 \mathrm{~min}$ after amino-acid ingestion (37). This underlines the general view that amino-acids also stimulate catabolic pathways. In addition, effects of protein on the orexigenic endocannabinoids have to be investigated (38).

\section{POSSIBLE RELATIONS OF CHANGES IN AMINO-ACID CONCENTRATIONS OR GUT HORMONES WITH SATIETY}

Acute amino acid-related effects on satiety, depending on the quality proteins, have been reported. The digestion of 'fast' proteins, such as whey, results in high and early rises of plasma amino acids and appetite hormones (23). The slower digestion and absorption rates of casein result in more prolonged and maintained plasma amino acid and hormone concentrations than those of whey $(13,22,39,40)$. However, at high concentrations, no clear evidence exists for differences in satiating capacity between different types of protein, (11, 21-23, 28, 33, 41-43). The concentrations of certain amino acids have to be above a particular minimum threshold to promote a relatively stronger hunger suppression or greater fullness (23). Indispensible or complete proteins reach these thresholds at lower concentrations than other, dispensible or incomplete proteins. Deficiency of essential amino-acids may lead to suppression of intake of food consisting of incomplete proteins (44). A chemosensor for essential amino acid deficiency is present in the anterior periform cortex (45), signaling brain areas that control food intake (44). Likewise, consumption of an incomplete protein may be detected and result in a signal to stop eating in humans (46). The signal of incomplete proteins is rather a signal of hunger suppression than of satiation or satiety $(23,46)$.

\section{PROTEIN-INDUCED SATIETY AND DIET-INDUCED THERMOGENESIS}

The relationship between protein-induced satiety and diet-induced thermogenesis, or DIT, is explained by increased energy expenditure at rest implying increases in oxygen consumption and body temperature. The feeling of oxygen deprivation is translated into satiety feelings $(12,47)$. A positive relationship between an increase in satiety and at the same time an increase in 24-h DIT has been observed with an energy-balanced high-protein diet $(12,48)$. 


\section{HIGH-PROTEIN LOW-CARBOHYDRATE INDUCED KETOGENIC EFFECT AND GLUCONEOGENESIS}

Fasting $\beta$-hydroxybutyrate concentrations increase in response to a ketogenic high-protein, 'lowcarb' diet compared with an isoenergetic medium-protein, medium-carbohydrate diet (49-51). Increased concentrations of $\beta$-hydroxybutyrate directly affected satiety in a $36 \mathrm{~h}$ study (52). Gluconeogenesis and satiety were increased at a zero carbohydrate, high-protein diet, however, these were unrelated to each other, yet the increased concentration of $\beta$-hydroxybutyrate contributed to satiety in the high-protein diet (53).

In general, in short-term experiments, ad libitum high-protein diets have been observed to sustain appetite at a level comparable to the original diet, despite a lower energy intake. Energyrestricted, high-protein diets produce a sustained lower energy intake compared to diets with lower protein content, without altered appetite and satiety scores (17, 54). Consequently, individuals who consume a high-protein diet in combination with energy-restriction are more satiated and potentially less likely to consume additional calories from foods extraneous to dietary prescription (10).

From short-term experiments we conclude that relatively high-protein diets have the potential to maintain a negative energy balance by sustaining satiety at the level of the original diet $(9,16)$. This strong satiety effect depends partly on the type of dietary protein, and is elicited by a mixture of gut-brain axis effects, such as anorexigenic gut hormones, digestion, amino-acids, ketogenesis, and the increase in diet-induced thermogenesis. Gluconeogenesis did not show a relation with satiety (53).

\section{SHORT-TERM DIETARY PROTEIN-INDUCED REWARD HOMEOSTASIS}

Although dietary protein-induced satiety affects energy intake, it may be dominated by rewarddriven eating behavior $(20,31,55-57)$. Several brain areas that are involved in food reward link high-protein intake with reduced food wanting and thereby act as a mechanism involved in the reduced energy intake following high protein intake (20,31,55-57). A mechanism through which protein acts on brain reward centers involves direct effects of certain amino acids as precursors of the neuropeptides serotonin and dopamine $(31,55)$. A high-protein, low-carbohydrate breakfast vs. a medium-protein, high-carbohydrate breakfast led to reduced reward-related activation in the hippocampus and parahippocampus before dinner $(20,32)$. Furthermore, acute food-choice compensation changed the macronutrient composition of a subsequent meal to offset the protein intervention (56). A compensatory increase in carbohydrate intake was related to a decrease in liking and task-related signaling in the hypothalamus after a high-protein breakfast. After a lowerprotein breakfast, an increase in wanting and task-related signaling in the hypothalamus was related to a relative increase in protein intake in a subsequent meal (56). Protein intake may directly affect the rewarding value of this macronutrient $(56,58)$. Thus limited protein-induced food reward may affect compliance to a long-term protein-diet. 


\section{SHORT-TERM DIETARY PROTEIN-INDUCED ENERGY EXPENDITURE - EFFECTS AND MECHANISMS}

With respect to dietary protein-induced energy expenditure, short-term effects of energybalanced high-protein diets showed higher rates of energy expenditure, especially diet-induced thermogenesis (DIT) $(59,60)$. Mechanisms encompass the ATP required for the initial steps of metabolism, such as protein breakdown, synthesis and storage, and oxidation including urea synthesis. Also gluconeogenesis may take place. Protein storage capacity of the body is limited. Therefore readily metabolic processing is necessary. The magnitude of DIT is determined by the level of energy intake in relation to energy requirement and the type of protein, and is illustrated by the difference between the gross energy value of $22-25 \mathrm{~kJ} / \mathrm{g}$ and the net metabolizable energy of $13 \mathrm{~kJ} / \mathrm{g}$. DIT values for separate proteins are 20 to $30 \%$ of energy intake from protein (61).

Significantly higher dietary protein induced DIT (59), subsequently Sleeping Metabolic Rate (SMR) and Basal Metabolic Rate (BMR) $(12,60)$ was shown in $36 \mathrm{~h}$ respiration chamber studies, in comparison to iso-energetic, iso-volumetric, dietary carbohydrate or fat, composed of normal food items and matched organoleptic properties. Short-term protein- induced increase in DIT is explained by the ATP required for the initial steps of metabolism and oxidation including urea synthesis, while subsequent protein induced increase of SMR is explained by stimulation of protein synthesis and protein turnover. The metabolic efficacy of protein oxidation largely depends on the amino acid composition of the protein (62). A well-balanced amino acid mixture produces a higher thermogenic response than does an amino acid mixture with a lower biological value, explaining why intake of plant proteins or incomplete proteins results in less protein synthesis than does intake of animal protein. Based upon the stoichiometry of amino acid catabolism and urea synthesis, the calculated energy expenditure to produce ATP is ranging from $153 \mathrm{~kJ} / \mathrm{ATP}$ for cysteine, to $99 \mathrm{~kJ} / \mathrm{ATP}$ for glutamate (63). This relative metabolic inefficiency contributes to the higher diet-induced energy expenditure of a high protein meal, which, in turn, has shown to be related to subjective feelings of satiety (48). Gluconeogenesis, as a result of further postprandial amino-acid metabolism also contributes to the protein induced energy expenditure. De novo synthesis of glucose in the liver from gluconeogenic precursors including amino acids is stimulated by a high protein diet in the fed state $(64,65)$, and is an alternative biochemical pathway to cope with postprandial amino acid excess (66). When the protein content of the diet is increased, Phosphoenolpyruvate Carboxylase (PEPCK) that catalyzes the initial conversion of oxaloacetate to phosphoenolpyruvate is up-regulated either in the fasted and in the fed state, whereas glucose 6-phosphatase (G6Pase), that catalyzes the last step of gluconeogenesis is up-regulated in the fasted state and down-regulated in the fed state (64). Although hepatic glycogen stores as well as hepatic gluconeogenesis have been suggested to play a role in the regulation of satiety $(67,68)$, this was not confirmed by a study by Veldhorst et al. (49). However, they showed that gluconeogenesis strongly increased energy expenditure, in that forty-two percent of the increase in energy expenditure after the high-protein diet was explained by the increase in gluconeogenesis. The cost of gluconeogenesis was $33 \%$ of the energy content of the produced glucose (49). 


\section{PROTEIN TURNOVER, PROTEIN BREAKDOWN, AND PROTEIN SYNTHESIS}

Also protein turnover contributes to the high energetic costs of protein metabolism, and protein synthesis. The daily protein turnover of a healthy adult - defined as synthesis plus breakdown-, $300 \mathrm{gram} /$ day, depends on the type of protein, and age. It is high in children, and decreases with older age. Increasing protein intake increases protein turnover by increasing protein synthesis and protein breakdown, and does not necessarily affect protein balance $(69,70)$. Rapidly digested dietary protein results in a stronger increase in postprandial protein synthesis and amino acid oxidation than slowly digested protein $(39,40,71)$.

Acutely, high protein intake stimulates protein synthesis and turnover, and induces a small suppression of protein breakdown (72-74). Prolonged low protein intake may lead to muscle loss due to the lack of precursor amino acid availability for de novo muscle protein synthesis $(75,76)$. Hursel et al. (70) observed that protein turnover was significantly higher after a 12-week highprotein vs. low-protein diet, with significant increases in protein synthesis, protein breakdown, and protein oxidation. Notably, in the fasted state net protein balance was less negative after the low-protein diet compared with the high-protein diet, while in the fed state, protein balance was positive with the high-protein diet, and negative with the low-protein diet (70). Thus protein turnover in the fasted state needs to be distinguished from that in the fed state. The role of protein synthesis and protein breakdown in FFM accretion was discussed by Deutz and Wolfe (77) and Symons et al. (76). The observed maximum response of protein synthesis after a single serving of 20-30 g of dietary protein suggests that additional effects of protein intake on FFM accretion are accounted for by the inhibition of protein breakdown. However, a beneficial reduction of protein breakdown only occurs with acute ingestion of protein $(70,76,78-80)$. The positive protein balance observed at a high-protein diet is due to acute postprandial responses, rather than to the postabsorptive state.

Consumption of a low-protein diet for 12 weeks was not detrimental to young healthy individuals who might have the ability to adapt acutely to this condition (70). The Adaptive Demands model developed by Millward may provide an explanation for the observation that the human body is able to show physiological adaptations to changes in protein intake (81). The model proposes that the metabolic demand for amino acids comprises a fixed component and a variable adaptive component (81). Short-term changes in protein intake are likely within the adaptive range. Adaptations in protein and amino acid metabolism to changes in protein intake largely occur via changes in whole-body protein turnover and amino acid oxidation (82). Changes in amino acid oxidation were reflected as decreased and increased nitrogen excretion in response to the lowand high-protein diets respectively. The activity of enzymes that regulate: 1) transamination, 2) the disposal of the carbon skeletons in intermediary metabolism, and 3) the disposal of nitrogen through the urea cycle increased in response to high protein intake $(83,84)$. Nevertheless, a positive nitrogen balance following high protein intake $(69,82,85,86)$ does not automatically reflect an increase in protein anabolism (87). The capacity of the body to increase amino acid anabolism through an increase in lean body mass is limited (87). Only interventions using diets high in specific indispensable amino acids, such as leucine, might be able to stimulate protein synthesis in specific target groups $(73,88)$. Therefore, transient retention or loss of body nitrogen 
because of a labile pool of body nitrogen may contribute to adaptations in amino acid metabolism in response to changes in protein intake (89). Transient adaptive mechanisms may be distinguished from mechanisms that maintain homeostasis in the body in the longer-term.

\section{LONG-TERM DIETARY PROTEIN EFFECTS DURING ENERGY RESTRICTION, BODY-WEIGHT LOSS AND BODY-WEIGHT MAINTENANCE}

Most long-term studies comparing energy-restricted diets with a relatively high protein content and diets with a normal protein content, within a large range of fat contents, showed independent effects of a high protein intake on body weight reduction (7, 90-93, 93-110), while in other studies the opposite has been observed (111-121). From these studies, a larger reduction in fat mass following relatively high-protein diets was reported by Wycherly et al. (7), Soenen et al. (90), Brinkworth et al, (93) Brinkworth et al. (94), Due et al. (96), Das et al. (112), Foster et al. (107), Frisch et al. (97), Gardner et al. (98), Jesudason et al. (101), Keogh et al. (121), Krebs et al. (119), Layman et al. (102), Mcauley et al. (104), while less reduction in fat mass was reported by Delbridge et al. (113). An energy-restricted high-protein diet in combination with exercise can even increase muscle mass (124). The main reason behind the differences in outcomes of the studies cited, is the difference in dosage of dietary protein (125). If the control, implying an adequate protein intake is sufficiently high, then no differences in body weight effects are expected. If the relatively high protein diet is higher than $1,2 \mathrm{~g} / \mathrm{kg}$ body weight daily, then a fat free mass sparing effect can be expected.

Conclusions from long-term studies comparing relatively high-protein with normal-protein diets differ from those testing relatively high-protein and low-protein diets (5). In the following studies compliance was monitored and confirmed with a quantitative biomarker, such as urinary nitrogen $(5,7,91)$. A relatively high protein diet (in \% of energy) implies a restriction in carbohydrate and fat intake, but no restriction of protein intake (in $\mathrm{g} / \mathrm{d}$ ), thus a protein intake comparable to the original diet. During energy restriction, sustaining protein intake at the level of the minimal requirement $(0.66 \mathrm{~g} / \mathrm{kg}$ body weight daily) appears not to hinder body weight loss and fat loss ( 7 , $91,126)$. An additional increase of protein intake may not induce a larger loss of body weight, but can be effective to maintain a larger amount of $\operatorname{FFM}(7,91,126)$ and limits the reduction of energy expenditure through sparing of FFM $(91,127)$. For example, a 6 -month energy restricted diet with a daily protein intake just above the minimal requirement $(0.8 \mathrm{~g} / \mathrm{kg}$ body weight daily) induced a comparable reduction in body weight to an energy-restricted diet with a daily protein intake well above the minimal requirement ( $1.2 \mathrm{~g} / \mathrm{kg}$ body weight daily) (91). Interestingly, a protein intake of $1.2 \mathrm{~g} / \mathrm{kg}$ body weight daily resulted in a stronger decrease in fat mass and preservation of FFM (91). Dietary protein intake below requirements could lead to less weight loss and a higher risk for body weight regain (6). Increasing the relative protein content of a diet automatically results in a decrease in the relative content of carbohydrate and/or fat, which theoretically could be a factor in triggering the described effects. However, a study by Soenen et al. demonstrated that the effects of a relatively high protein intake on body weight loss and weight maintenance were present independent of a low carbohydrate intake (90), and that low carbohydrate alone, without high protein did not trigger the described effects. 
However, protein diets could have resulted in stronger effects with respect to body weight management, if compliance would have been larger (see section 4). To counteract poor compliance, dietary restraint is necessary (128). In several long term clinical trials with dietary protein, cognitive dietary restraint had increased, implying greater conscious control over food intake $(68,90,91)$. Post hoc analysis of those data shows that the change in the cognitive dietary restraint score was inversely related to the change in body weight. Dietary restraint is associated with brain signaling for reward, indicating a greater control over food intake and implying a greater control over reward as well (129). In general dietary restraint is associated with long-term weight maintenance $(130,131)$.

Taken together, Clifton et al. (125) conclude from a recent meta-analysis that the short-term benefit of higher protein diets persists to a small degree over the long term, depending on dietary compliance.

\section{BODY COMPOSITION}

Older studies, in the perspective of composing meal replacers to be used as energy restricted diets showed strong energy restriction effects on body composition, in relation to the percentage from dietary protein. The protein content of a formula diet was varied from 0 to $50 \mathrm{~g} / \mathrm{d}$ resulting in a protein loss of between 1202 to 91 grams, respectively, over 28 days (132). Loss of fat mass (FM) as a percentage of body weight loss was $43 \%$ with $0 \mathrm{~g} / \mathrm{d}$ protein, and up to $79 \%$ with $50 \mathrm{~g} / \mathrm{d}$ protein (20), indicating a change in body composition including sparing of fat free mass (FFM), due to the amount of protein intake. Similarly, during weight maintenance following weight loss, FFM was preserved, while FM was reduced. Since weight maintenance after weight loss usually implies a slight weight regain, Stock's model can be applied (133). The greatest metabolic efficiency of weight gain is shown when protein intake is $10-15 \%$ of energy and inefficiency is shown with $<5 \%$ and $>20 \%$ of energy from protein. The latter metabolic inefficiency is related to body composition. For $1 \mathrm{~kg}$ of body mass with 60\% FM and 40\% FFM, an additional $30 \mathrm{MJ}$ needs to be ingested, whereas for $1 \mathrm{~kg}$ of only FFM, an additional 50-70 MJ is needed $(133,134)$. This metabolic inefficiency, partly due to sparing FFM promotes dietary protein induced weight maintenance. In addition, preserving FFM, being the main determinant of basal energy expenditure, limits a possible reduction in energy expenditure during weight maintenance. Whitehead et al. showed that during energy-restriction, the decline in total energy expenditure and SMR as a result of body weight loss is less on a high-protein than on a medium-protein diet (135). Even an increase in FFM during a high-protein diet in negative energy balance has been observed (124), although these changes may partly be ascribed to a high protein intake combined with physical activity.

\section{PREVENTION OF OVERWEIGHT: ROLE OF DIETARY PROTEIN IN NEUTRAL ENERGY BALANCE}

If the protein-induced effects on appetite and energy expenditure observed during energy restriction also hold under non-restricted conditions, then, increasing protein intake with a usual diet may prevent overweight and obesity. A 12-week intervention study was performed comparing high-protein ( $30 \%$ of energy from protein) and low-protein ( $5 \%$ of energy from 
protein) diets, in weight stable individuals (136). In this controlled situation, participants were able to sustain the high- and low-protein diets. The low-protein diet facilitated the development of positive energy balance, while the high-protein diet was beneficial to prevent this (136). Correspondingly, small increases in fullness and satiety ratings were observed as acute responses to a high-protein diet in neutral energy balance (1136). In this situation, translation into large changes in energy intake was not possible, because subjects had to maintain their body weight. In the longer term, appetite ratings were returned to the level of the original diet, which suggests that the human body habituates to the satiating effects of high protein intake (136). FFM showed small increases and decreases after a 12-week intervention with high-protein and low-protein diets in energy balance (136). As a consequence, SMR, DIT and total energy expenditure was maintained at the high-protein diet, while it was significantly decreased at the low protein diet. Thus, at a constant body weight, a high-protein diet may protect against the development of a positive energy balance. The consumption of a low-protein diet may increase the risk for the development of a positive energy balance through adaptive thermogenesis (136).

\section{DIETARY PROTEIN AND OVERWEIGHT RELATED CO-MORBIDITIES}

Humans with overweight or obesity may show co-morbidities, such as a nonalcoholic fatty liver disease, type 2 diabetes, or cardiovascular diseases. Whether a high-protein diet may be protective against these co-morbidities, independent of, or in addition to effects of weight loss is still under debate.

\section{NONALCOHOLIC FATTY LIVER DISEASE}

In general, weight loss improves metabolic function $(6,7)$, yet a high protein intake may modulate intrahepatic triglyceride (IHTG) content as well (137-139). In short-term studies, protein supplementation was shown to be associated with reduced hepatic fat (137-139). High ectopic lipid content, especially IHTG content, and not visceral adipose tissue (VAT) volume, is an independent risk factor for these metabolic disturbances (140-142). A 12-week intervention study showed that effects of high- and low-protein diets on IHTG content in weight-stable individuals tended to lower IHTG content after the high protein-low carbohydrate diet compared with the low protein-high carbohydrate diet (127). This suggests that high protein-low carbohydrate diets may be favorable for the control of IHTG in healthy humans. High protein intake stimulates hepatic lipid oxidation due to the high energetic demand for amino acid catabolism and ketogenesis $(5,49)$. Furthermore, hepatic lipid oxidation may be stimulated by an increased bile acid production, a process that may also inhibit lipogenesis (143). Protein-induced glucagon secretion inhibits de novo lipogenesis and stimulates hepatic ketogenesis $(144,145)$. High protein intake may blunt the increase of very low density lipoprotein (VLDL)-TG concentrations induced by carbohydrate intake (146-148). High VLDL-TG concentrations may increase hepatic TG, and subsequently IHTG content (148). The observed trend for a difference in IHTG content between the diets likely is the result of combined effects involving changes in protein and carbohydrate intake. 


\section{TYPE 2 DIABETES}

Relevant diets possibly contributing to the management of type 2 diabetes are low-carbohydrate diets. Those diets often are high-protein diets. A recent systematic review explored the interpretation and effectiveness of a low-carbohydrate diet in the management of type 2 diabetes (149). They suggest that low-carbohydrate diets may improve HbA1c, HDL cholesterol and triglyceride levels. The meta-analyses confirmed statistically significant superiority of the lowcarbohydrate intervention arm in improving $\mathrm{HbA1c}$, HDL cholesterol, triglyceride and systolic blood pressure levels at 1 year. Reducing carbohydrate intake demonstrated a strong superiority over control diets in reducing diabetes medication, which may have diminished the observed effects of a reduced-carbohydrate intake on $\mathrm{HbAlc}$. This review concludes that reducing carbohydrate intake may promote favourable health outcomes in the management of type 2 diabetes in the context of a healthy diet (149). The relation between high-protein intake and type 2 diabetes is still under debate, and results differ depending on study duration and source of protein. Short-term studies have reported favorable effects on glucose homeostasis $(21,150,151)$, while an epidemiological and a long-term study reported an increased risk for type 2 diabetes with increased protein intake (152-154). The increased risk may be dependent on the source of protein. Tian et al. conducted a systematic review and meta-analysis of cohort studies to investigate the association between protein consumption and the risk for type 2 diabetes (155). In this review, they reported an increased relative risk of type 2 diabetes for total protein and animal protein in men and women and a reduced relative risk for plant protein in women.

However, high-protein diets may have some risk regarding insulin sensitivity. An increase in Branched-Chain Amino Acids (BCAAs) seems to be a marker of type 2 diabetes $(156,157)$. Newgard et al. observed in rodents that in the context of a dietary pattern that includes high fat consumption BCAA contributes to the development of obesity-associated insulin resistance. Moreover, Pedersen et al. (158) showed that the serum metabolome of insulin-resistant individuals is characterized by increased levels of BCAAs, which correlate with a human gut microbiome that has an enriched biosynthetic potential for BCAA.

Taken together, when protein diets are applied during energy restriction aiming at weight loss and subsequent weight maintenance, the latter usually shows favorable effects in relation to insulin sensitivity, although some risks may be present. That a higher protein diet would promote insulin sensitivity beyond its effect on body-weight loss and subsequent body-weight maintenance seems unlikely.

\section{CARDIOVASCULAR DISEASES}

Parameters that indicate cardiovascular risks usually change in a favorable direction during body weight loss. The question remains whether the type of diet, especially a protein diet, would affect favorable changes in cardiovascular parameters. Atherosclerosis lies at the root of cardiovascular complications, and the main indicators are the HDL- and LDL cholesterol. Certain proteins may exert a greater effect on blood cholesterol levels than other (159). Possible different effects from vegetable vs animal proteins have been tested. Sacks et al. (160) compared diets enriched in 
casein for 20 days with diets enriched in soy for 20 days. They did not observe significant differences in LDL or HDL cholesterol, neither between lipid profiles or lipid proteins. Other studies, comparing casein and soy diets, did find significant reductions in LDL with the soy diet, compared to the casein diets $(161,162)$, however this did not appear in volunteers with already high cholesterol concentrations (163). In long term weight loss and subsequent weight maintenance studies, it was shown that individuals consuming soy meal replacements showed favorable effects in their cardiovascular profile, e.g. lowering LDL, TG, visceral fat, and systolic blood pressure (164). With respect to blood pressure, a study by Teunissen-Beekman et al. (165) compared postprandial blood pressure-related responses to the ingestion of pea protein, milk protein and egg-white protein. They concluded that lower postprandial blood pressure is not necessarily accompanied by higher NOx, insulin, glucagon or GLP-1 responses, and that dietary protein, especially egg-white protein, may induce a risk for elevated blood pressure (165). Yet, it has been reported that effects of dietary protein depend on age. Tielemans et al. (166) showed that intake of plant protein, but not animal protein, was inversely associated with 5 -year changes in blood pressure level in elderly men. A critical evaluation of the evidence for the effects of milk proteins and their associated peptides on blood pressure and vascular dysfunction, showed that results are inconclusive, while one study clearly reported that main intact milk proteins reduced blood pressure, and whey protein improved measures of arterial stiffness (167). Some epidemiological studies based upon large community cohorts report no overall relationship between protein type and dietary protein sources on coronary heart diseases (168), while another epidemiological study indicated that high red meat intake increases risk for coronary heart disease and stroke, and that poultry, fish and nuts reduced these risks (169, 170). A general systematic review on health effects of protein intake in healthy adults reported that results are inconclusive for a relationship between protein intake and cardiovascular diseases (171), while a recent systematic review concluded that low-carbohydrate diets, that often are high-protein diets may improve HDL cholesterol and triglyceride levels and systolic blood pressure levels at 1 year (149). Taken together, more accurately designed randomized control trials on dietary protein quality and quantity and possible relations with cardiovascular risks are required.

\section{ADVERSE EFFECTS OF PROTEIN-DIETS}

There is a long-held view that high-protein intake might interfere with calcium homeostasis by increasing the acid load. It is hypothesized that this could be partially buffered by bone, subsequently resulting in bone resorption and hypercalciuria (172). In general, protein is a necessary nutrient for bone health (173). Nitrogen intake seems to have a positive effect on calcium balance and consequent preservation of bone mineral content (174). With respect to renal issues, only patients with pre-existing dysfunction appeared to have an increased risk for the development of kidney stones and renal diseases (172). In addition, Jesudason et al. (101) showed that both a medium or higher protein energy restriction diet, inducing body weight loss, normalized renal function in individuals with hyperfiltration. Similarly, Møller et al. (175) showed in a study in volunteers with overweight or obesity and pre-diabetes on a higher protein diet, a significant increase in urinary urea/creatinine ratio and serum urea after one year. There were no associations between increased protein intake and creatinine clearance, estimated glomerular 
filtration rate, urinary albumin/creatinine ratio, or serum creatinine. They found no indication of impaired kidney function after one year with a higher protein intake in pre-diabetic older adults. In the elderly, beneficial health effects of higher-protein intake might outweigh the adverse effects possibly because of the changes in protein metabolism with ageing. In contrast, persistent total protein and amino acid intake below requirements impairs bodily functions leading to higher disease and mortality risks across the lifespan $(176,177)$. Taken together, application of relatively high-protein diets, whereby protein intake is sustained at the original level, does not seem to have any adverse effects in healthy individuals. Although no clear recommendation exists that defines the safe upper limit of protein intake, consumption of up to $1.66 \mathrm{~g} / \mathrm{kg} \mathrm{BW}$ daily has not been associated with increased health risks $(87,122)$. This means that sustaining or slightly increasing protein intake during energy restriction likely poses no adverse effects in healthy individuals. However, protein intake can exceed the suggested safe upper limit. The question arises whether and how and over which time-frame these high intakes of protein would negatively affect health. Recent studies applying medium-term, high-protein interventions in neutral or positive energy balance did not report any adverse effects $(136,178)$. However, the limits of adaptation to high protein intake over the longer term remain to be investigated.

\section{DISCUSSION}

With respect to body-weight management, the effects of diets varying in protein differ according to energy balance. During energy restriction, sustaining protein intake at the level of requirement appears to be sufficient to aid body weight loss and fat loss (FIGURE 1). An additional increase of protein intake does not induce a larger loss of body weight, but can be effective to maintain a larger amount of FFM (FIGURE 1). Protein induced satiety is likely a combined expression with direct and indirect effects of elevated plasma amino acid and anorexigenic hormone concentrations, increased DIT, and a ketogenic state, which all feed-back on the central nervous system (FIGURE 1). Changes in appetite appear most clearly as short-term response to changes in dietary protein content; the human body may habituate to the satiating effects of protein intake in the longer-term. The decline in energy expenditure and sleeping metabolic rate as a result of body weight loss is less on a high-protein than on a normal-protein diet. In addition, higher rates of energy expenditure have been observed as acute responses to energy-balanced high-protein diets (FIGURE 1). In energy balance, high protein diets may be beneficial to prevent the development of a positive energy balance, whereas low-protein diets may facilitate this. Furthermore, high protein, low carbohydrate diets may be favorable for the prevention of metabolic disturbances. During positive energy balance, excess energy intake alone may account for the increase in fat mass. Increases in energy expenditure and FFM may largely be predicted by protein intake.

Whether high-protein diets, beyond their effect on body-weight management, contribute to prevention of increases in NAFDL, type 2 diabetes and cardiovascular diseases is inconclusive (FIGURE 1). High protein-low carbohydrate diets may be favorable for the control of IHTG in healthy humans, likely as a result of combined effects involving changes in protein and carbohydrate intake. When protein diets are applied during energy restriction aiming at weight loss and subsequent weight maintenance, the latter usually shows favorable effects in relation to 
insulin sensitivity, although some risks may be present. That a higher protein diet would promote insulin sensitivity beyond its effect on body-weight loss and subsequent body-weight maintenance seems unlikely. At least high-protein diets do not seem to have adverse effects on these co-morbidities. In conclusion, higher-protein diets may reduce overweight and obesity, yet whether high-protein diets, beyond their effect on body-weight management, contribute to prevention of increases in NAFDL, type 2 diabetes and cardiovascular diseases is inconclusive.

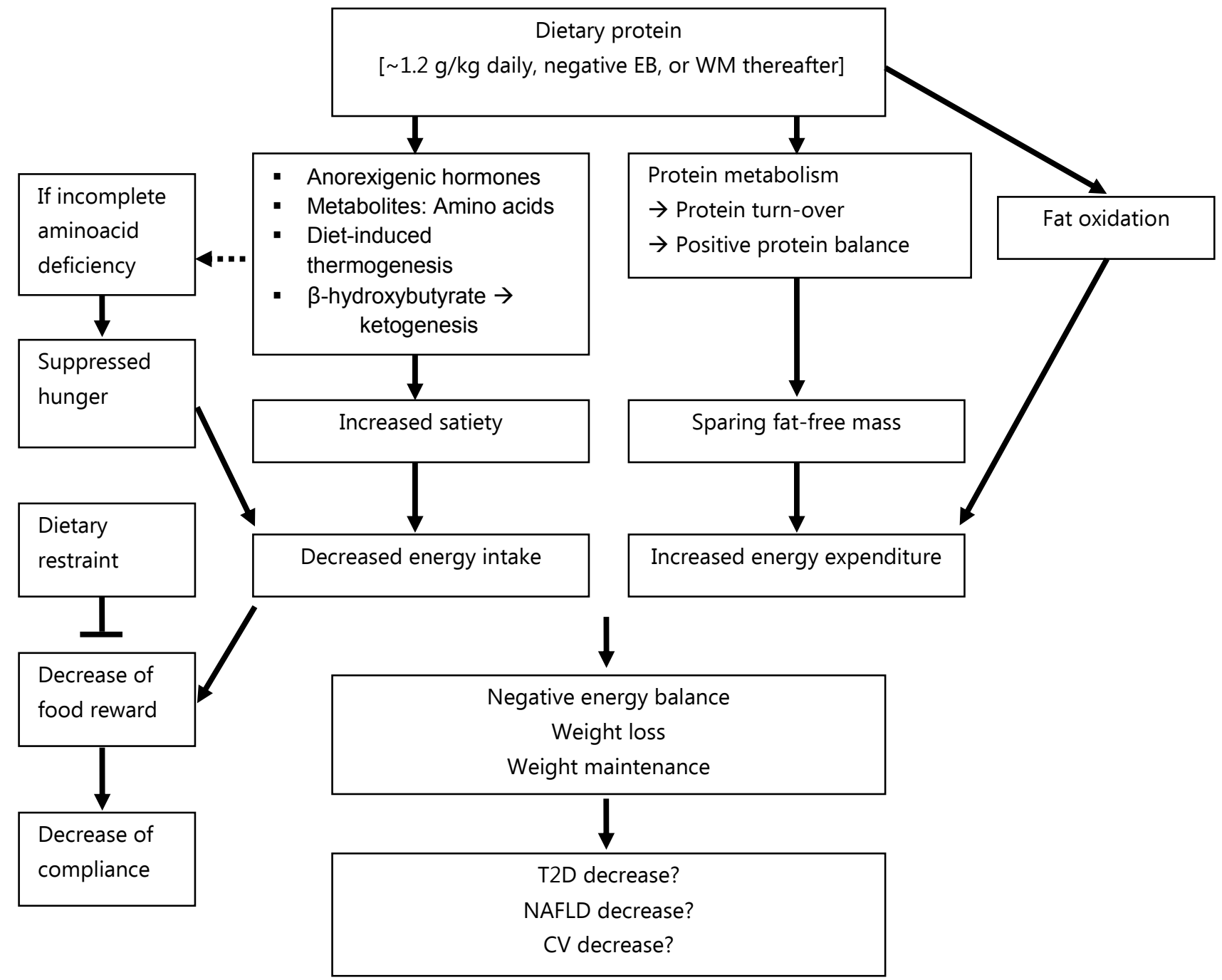

FIGURE 1. Summary of the observations on relatively high protein diets applied during energy restriction or weight maintenance (WM) thereafter. $E B$, energy balance; T2D, type 2 Diabetes; NAFLD, non-alcoholic fatty liver disease; CV, cardiovascular diseases.

\section{AUTHOR CONTRIBUTIONS STATEMENT}

The sections of the manuscript were written by MD, LT, BG-C, TA, and MW-P. The review is partly an update of Westerterp-Plantenga et al. (4) and Westerterp-Plantenga et al.(5).

\section{CONFLICT OF INTEREST STATEMENT}

The authors have no conflict of interest to declare. 


\section{REFERENCES}

1. World Health Organization Obesity and Overweight. Fact Sheet N³11. Version Current March 2013. 2014.

2. Abete I, Astrup A, Martinez JA, Thorsdottir I Zulet MA. Obesity and the metabolic syndrome: role of different dietary macronutrient distribution patterns and specific nutritional components on weight loss and maintenance. Nutr Rev .2010 68:214-31.

3. Westerterp KR. Energy Balance in Motion. New York, NY/Dordrecht/London: Springer; 2013.

4. Westerterp-Plantenga MS, Nieuwenhuizen A, Tome D, Soenen S, Westerterp KR. Dietary protein, weight loss, and weight maintenance. Annu Rev Nutr. 2009 29:21-41.

5. Westerterp-Plantenga MS, Lemmens SG, Westerterp KR. Dietary protein - its role in satiety, energetics, weight loss and health. Br J Nutr. 2012 108:S105-12.

6. Acheson KJ. Diets for body weight control and health: the potential of changing the macronutrient composition. Eur J Clin Nutr. 2013 67:462-6.

7. Wycherley TP, Moran LJ, Clifton PM, Noakes M, Brinkworth GD. Effects of energy-restricted high-protein, low-fat compared with standard-protein, low-fat diets: a meta-analysis of randomized controlled trials. Am J Clin Nutr. 2012 96:1281-98.

8. Leidy HJ, Clifton PM, Astrup A, Wycherley TP, Westerterp-Plantenga MS, Luscombe-Marsh ND, et al. . The role of protein in weight loss and maintenance. Symposium Am J Clin Nutr. 2015 Epub ahead of print.

9. Westerterp-Plantenga MS, Luscombe-Marsh N, Lejeune MPGM, Diepvens K, Nieuwenhuizen A, Engelen MPKJ, et al. Dietary protein, metabolism, and body-weight regulation: dose-response effects. Int J Obesity 2006 30:S16-23.

10. Halton TL, Hu FB. The effects of high protein diets on thermogenesis, satiety and weight loss: a critical review. J Am Coll Nutr. 2004 23:373-85.

11. Bendtsen LQ, Lorenzen JK, Bendsen NT, Rasmussen C Astrup A. Effect of dairy proteins on appetite, energy expenditure, body weight, and composition: a review of the evidence from controlled clinical trials. $A d v$. Nutr. 2013 4:418-38.

12. Lejeune MP, Westerterp KR, Adam TC, Luscombe-Marsh ND, Westerterp-Plantenga MS. Ghrelin and glucagon-like peptide 1 concentrations, 24-h satiety, and energy and substrate metabolism during a highprotein diet and measured in a respiration chamber. Am J Clin Nutr. 2006 83:89-94.

13. Veldhorst MAB, Nieuwenhuizen AG, Hochstenbach-Waelen A, Westerterp KR, Engelen MPKJ, Brummer RJM, et al. . Comparison of the effects of a high- and normal-casein breakfast on satiety, 'satiety' hormones, plasma amino acids and subsequent energy intake. Br J Nutr. 2009 101:295-303.

14. Veldhorst MAB, Nieuwenhuizen AG, Hochstenbach-Waelen A, Westerterp KR, Engelen MPKJ, Brummer RJM, et al. . Effects of high and normal soyprotein breakfasts on satiety and subsequent energy intake, including amino acid and 'satiety' hormone responses. Eur J Nutr 2009 48:92-100.

15. Leidy HJ, Racki EM. The addition of a protein-rich breakfast and its effects on acute appetite control and food intake in 'breakfast-skipping' adolescents. Int J Obes. 2010 34:1125-33.

16. Weigle DS, Breen PA, Matthys CC, Callahan HS, Meeuws KE, Burden VR, et al. . A high-protein diet induces sustained reductions in appetite, ad libitum caloric intake, and body weight despite compensatory changes in diurnal plasma leptin and ghrelin concentrations. Am J Clin Nutr. 2005 82:41-8.

17. Martens EA, Lemmens SG, Westerterp-Plantenga MS. Protein leverage affects energy intake of high-protein diets in humans. Am J Clin Nutr. 2013 97:86-93.

18. Martens EA, Gatta-Cherifi B, Gonnissen HK, Westerterp-Plantenga MS. The potential of a high protein-low carbohydrate diet to preserve intrahepatic triglyceride content in healthy humans. Plos ONE 2014:e109617.

19. Morrison CD, Reed SD, Henagan TM. Homeostatic regulation of protein intake: in search of a mechanism. Am J Physiol Regul Integr Comp Physiol. 2012 302:R917-28.

20. Fromentin G, Darcel N, Chaumontet C, Marsset-Baglieri A, Tome D. Peripheral and central mechanisms involved in the control of food intake by dietary amino acids and proteins. Nutr Res Rev. 2012 25:29-39.

21. Acheson KJ A, Blondel-Lubrano S, Oguey-Araymon M, Beaumont S, Emady-Azar C, Ammon-Zufferey I, et al. Protein choices targeting thermogenesis and metabolism. Am J Clin Nutr. 2011 93:525-34.

22. Hall WL, Millward DJ, Long SJ, Morgan LM. Casein and whey exert different effects on plasma amino acid profiles, gastrointestinal hormone secretion and appetite. Br J Nutr. 2003 89:239-48.

23. Veldhorst MA, Nieuwenhuizen AG, Hochstenbach-Waelen A, van Vught AJ, Westerterp KR, Engelen $M$, et al. Dose-dependent satiating effect of whey relative to casein or soy. Physio/ Behav. 2009 96:675-82.

24. Mellinkoff SM, Frankland M, Boyle D, Greipel M. Relationship between serum amino acid concentration and fluctuations in appetite. J Appl Physiol. (1956) 8:535-8. 
25. Niijima A, Torii K, Uneyama H. Role played by vagal chemical sensors in the hepato-portal region and duodeno-intestinal canal: an electrophysiological study. Chem Senses 2005 30:I178-9.

26. Belza A, Ritz C, Sorensen MQ, Holst JJ, Rehfeld JF, Astrup A. Contribution of gastroenteropancreatic appetite hormones to protein-induced satiety. Am J Clin Nutr. 2013 97:980-9.

27. Diepvens K, Haberer D, Westerterp-Plantenga M. Different proteins and biopeptides differently affect satiety and anorexigenic/orexigenic hormones in healthy humans. Int J Obes. 2008 32:510-8.

28. Juvonen $K R$, Karhunen $L J$, Vuori $E$, Lille $M E$, Karhu $T$, Jurado-Acosta $A$, et al. . Structure modification of a milk protein-based model food affects postprandial intestinal peptide release and fullness in healthy young men. Br J Nutr. 2011 106:1890-8.

29. Karhunen LJ, Juvonen KR, Huotari A, Purhonen AK, Herzig KH. Effect of protein, fat, carbohydrate and fibre on gastrointestinal peptide release in humans. Regul Pept. 2008 149:70-8.

30. Maersk M, Belza A, Holst JJ, Fenger-Gron M, Pedersen SB, Astrup A, et al. . Satiety scores and satiety hormone response after sucrose-sweetened soft drink compared with isocaloric semi-skimmed milk and with non-caloric soft drink: a controlled trial. Eur J Clin Nutr. 2012 66:523-9.

31. Davidenko O, Darcel N, Fromentin G, Tome D. Control of protein and energy intake - brain mechanisms. Eur J Clin Nutr. 2013 6:455-61.

32. Leidy HJ, Ortinau LC, Douglas SM, Hoertel HA. Beneficial effects of a higher-protein breakfast on the appetitive, hormonal, and neural signals controlling energy intake regulation in overweight/obese, "breakfast-skipping," late-adolescent girls. Am J Clin Nutr. 2013 97:677-888.

33. Bowen J, Noakes M, Trenerry C, Clifton PM. Appetite regulatory hormone responses to various dietary proteins differ by body mass index status despite similar reductions in ad libitum energy intake. $J$ Clin Endocrinol Metab. 2006a 91:1477-83.

34. Bowen J, Noakes M, Clifton PM. Energy intake, ghrelin, and cholecystokinin after different carbohydrate and protein preloads in overweight men. J Clin Endocrinol Metab. 2006b 91:2913-9.

35. Giezenaar C, van der Burgh Y, Lange K, Hatzinikolas S, Hausken T, et al. . Effects of substitution, and adding of carbohydrate and fat to whey-protein on energy intake, appetite, gastric emptying, glucose, insulin, ghrelin CCK, and GLP-1 in healthy older men-A Randomized Controlled Trial. Nutrients 2018 10:E113.

36. Giezenaar C, Luscombe-Marsh ND, Hutchison AT, Standfield S, Feinle-Bisset C, Horowitz M, et al. .. Dosedependent effects of randomized intraduodenal whey-protein loads on glucose, gut hormone, and amino acid concentrations in healthy older and younger men. Nutrients 2018 10:E78.

37. Gröschl M, Knerr I, Topf HG, Schmid P, Rascher W, Rauh M. Endocrine responses to the oral ingestion of a physiological dose of essential amino acids in humans. J Endocrinol. 2003 179:237-44.

38. Gatta-Cherifi B, Cota D. New insights on the role of the endocannabinoid system in the regulation of energy balance. Int J Obes. 2016 40:210-9.

39. Boirie $Y$, Dangin M, Gachon P, Vasson MP, Maubois JL, Beaufrere B. Slow and fast dietary proteins differently modulate postprandial protein accretion. Proc Natl Acad Sci USA. 1997 94:14930-5.

40. Dangin $M$, Boirie $Y$, Garcia-Rodenas $C$, Gachon $P$, et al. The digestion rate of protein is an independent regulating factor of postprandial protein retention Am J Physiol Endocrinol Metab. 2001 280:E340-8.

41. Adechian S, Balage M, Remond D, Migné C, Quignard-Boulangé A, Marset-Baglieri A, et al. . Protein feeding pattern, casein feeding, or milk-soluble protein feeding did not change the evolution of body composition during a short-term weight loss program. Am J Physiol Endocrinol Metab. 2012 303:E973-82.

42. Lorenzen J, Frederiksen R, Hoppe C, Hvid R, Astrup A. The effect of milk proteins on appetite regulation and diet-induced thermogenesis. Eur J Clin Nutr. 2012 66:622-7.

43. Pal S, Radavelli-Bagatini S, Hagger M, Ellis V. Comparative effects of whey and casein proteins on satiety in overweight and obese individuals: a randomized controlled trial. Eur J Clin Nutr. 2014 68:980-6.

44. Gietzen DW, Hao S, Anthony TG. Mechanisms of food intake suppressionin indispensable amino acid deficiency. AnnRevNutr. 2007 27:63-78.

45. Leung PM, Rogers QR. Importance of preperiform cortex in food intake respons in rats to amino acids. $A m$ J Physiol. 1971 221:929-35.

46. Hochstenbach-Waelen A, Westerterp-Plantenga MS, Veldhorst MA, Westerterp KR. Single-protein and casein diets affect energy expenditure similarly but substrate balance and appetite differently in adults. $J$ Nutr. 2009 139:2285-92.

47. Westerterp-Plantenga MS, Westerterp KR, Rubbens M, Verwegen CR, Richelet JP, Gardette B. Appetite at "high altitude" [Operation Everest III (Comex- '97)]: a simulated ascent of Mount Everest. J App/ Physiol. 1999 87:391-9. 
48. Westerterp-Plantenga MS, Rolland V, Wilson SA, Westerterp KR. Satiety related to $24 \mathrm{~h}$ diet-induced thermogenesis during high protein/carbohydrate vs high fat diets measured in a respiration chamber. Eur $J$ Clin Nutr. 1999a 53:495-502.

49. Veldhorst MA, Westerterp-Plantenga MS, Westerterp KR. Gluconeogenesis and energy expenditure after a high-protein, carbohydrate-free diet. Am J Clin Nutr 2009d 90:519-26.

50. Coleman MD, Nickols-Richardson SM. Urinary ketones reflect serum ketone concentration but do not relate to weight loss in overweight premenopausal women following a low-carbohydrate/high-protein diet. J Am Diet Assoc 2005 105,608-611.

51. Johnston CS, Tjonn SJ, Swan P, White A, Hutchins H, Sears B. Ketogenic low-carbohydrate diets have no metabolic advantage over nonketogenic low-carbohydrate diets. Am J Clin Nutr. 2006 83:1055-61.

52. Veldhorst MA, Westerterp KR, van Vught AJ, Westerterp-Plantenga MS. Presence or absence of carbohydrates and the proportion of fat in a high-protein diet affect appetite suppression but not energy expenditure in normal-weight human subjects fed in energy balance. Br J Nutr. 2010 104:1395-405.

53. Veldhorst MA, Westerterp KR, Westerterp-Plantenga MS. Gluconeogenesis and protein-induced satiety. $\mathrm{Br}$ J Nutr. 2012 107:595-600.

54. Martens EA, Tan SY, Dunlop MV, Mattes RD, Westerterp-Plantenga MS. Protein leverage effects of beef protein on energy intake in humans. Am J Clin Nutr. 2014 99:1397-406.

55. Journel M, Chaumontet C, Darcel N, Fromentin G, Tome D. Brain responses to high-protein diets. Adv Nutr. 2012 3:322-9.

56. Born JM, Martens MJ, Lemmens SG, Goebel R, Westerterp-Plantenga MS. Protein v. carbohydrate intake differentially affects liking- and wanting-related brain signalling. Br J Nutr. 2013 109:376-81.

57. Lemmens SG, Martens EA, Born JM, Martens MJ, Westerterp-Plantenga MS. Lack of effect of high-protein vs. high-carbohydrate meal intake on stress-related mood and eating behavior. Nutr J 2011 10:136.

58. Griffioen-Roose S, Mars M, Siebelink E, Finlayson G, Tome D, de Graaf C. Protein status elicits compensatory changes in food intake and food preferences. Am J Clin Nutr. 2012 95:32-8.

59. Westerterp KR, Wilson SA, Rolland V. Diet induced thermogenesis measured over $24 \mathrm{~h}$ in a respiration chamber: effect of diet composition. Int J Obes Relat Metab Disord. 1999 23:287-92.

60. Mikkelsen PB, Toubro S, Astrup A. Effect of fat-reduced diets on 24-h energy expenditure: comparisons between animal protein, vegetable protein, and carbohydrate. Am J Clin Nutr. 2000 72:1135-41.

61. Tappy L. Thermic effect of food and sympathetic nervous system activity in humans. Reprod. Nutr. Dev. 1996 36:391-7.

62. Stryer L. 1988. Biochemistry. New York, NY: W.H. Freeman and Company.

63. van Milgen J. Modeling biochemical aspects of energy metabolism in mammals. J Nutr. 2002 132:3195202.

64. Azzout-Marniche D, Gaudichon C, Blouet C, Bos C, Mathe V, Huneau JF, et al. . Liver glyconeogenesis: a pathway to cope with postprandial amino acid excess in high-protein fed rats? Am J Physiol Regul Integr Comp Physiol. 2007 292:R1400-7.

65. Pijls LT, de Vries H, Donker AJ, van Eijk JT. The effect of protein restriction on albuminuria in patients with type 2 diabetes mellitus: a randomized trial. Nephro/ Dial Transplant. 1999 114:1445-53.

66. Koopman R, Saris WH, Wagenmakers AJ, van Loon LJ. Nutritional interventions to promote post-exercise muscle protein synthesis. Sports Med. 2007 37:895-906.

67. McCarty MF. Promotion of hepatic lipid oxidation and gluconeogenesis as a strategy for appetite control. Med Hypotheses 1994 42:215-25.

68. Westerterp-Plantenga MS, Lejeune MPGM, Nijs I, van Ooijen M, Kovacs EMR. High protein intake sustains weight maintenance after body weight loss in humans. Int J Obes. 2004 28:57-64.

69. Pannemans DL, Halliday D, Westerterp KR, Kester AD. Effect of variable protein intake on whole-body protein turnover in young men and women. Am J Clin Nutr. 1995 61:69-74.

70. Hursel R, Martens EA, Gonnissen HK, Hamer HM, Senden JM, van Loon LJ, et al. . Prolonged adaptation to a high carbohydrate-low protein diet does not lead to a more negative whole-body protein balance when compared with a high protein-low carbohydrate diet. PLOS ONE. 2015 10:e0137183.

71. Dangin $M$, Boirie $Y$, Guillet $C$, Beaufrere B. Influence of the protein digestion rate on protein turnover in young and elderly subjects. J Nutr. 2002 132:3228S-33S.

72. Tang JE, Phillips SM. Maximizing muscle protein anabolism: the role of protein quality. Curr Opin Clin Nutr Metab Care 2009 12:66-71.

73. van Loon $\sqcup$. Leucine as a pharmaconutrient in health and disease. Curr Opin Clin Nutr Metab Care 2012 15:71-7. 
74. Gilbert JA, Bendsen NT, Tremblay A, Astrup A. Effect of proteins from different sources on body composition. Nutr Metab Cardiovasc Dis. 2011 21(Suppl. 2):B16-31.

75. Dideriksen K, Reitelseder S, Holm L. Influence of amino acids, dietary protein, and physical activity on muscle mass development in humans. Nutrients 2013 5:852-76.

76. Symons TB, Sheffield-Moore M, Wolfe RR, Paddon-Jones D. A moderate serving of high-quality protein maximally stimulates skeletal muscle protein synthesis in young and elderly subjects. J Am Diet Assoc. 2009 109:1582-6.

77. Deutz NE, Wolfe RR. Is there a maximal anabolic response to protein intake with a meal? Clin Nutr. 2013 32:309-13.

78. Greenhaff PLLG, Karagounis N, Peirce EJ, Simpson M, Hazell R, et al. Disassociation between the effects of amino acids and insulin on signaling, ubiquitin ligases, and protein turnover in human muscle. Am J Physiol Endocrinol Metab. 2008 295:E595-604.

79. Flakoll PJ, Kulaylat M, Frexes-Steed M, Hourani H, Brown LL, Hill JO, et al. . Amino acids augment insulin's suppression of whole body proteolysis. Am J Physiol. 1989 257: E839-47.

80. Louard RJ, Barrett EJ, Gelfand RA. Overnight branched-chain amino acid infusion causes sustained suppression of muscle proteolysis. Metabolism 1995 44:424-9.

81. Millward DJ. An adaptive metabolic demand model for protein and amino acid requirements. $B r J \mathrm{Nutr}$. 2003 90:249-60.

82. Tome D, Bos C. Dietary protein and nitrogen utilization. J Nutr. 2000 130:1868S-1873S.

83. Harper AE, Miller RH, Block KP. Branched-chain amino acid metabolism. Annu Rev Nutr. 1984 4:409-54.

84. Harper AE. Some recent developments in the study of amino acid metabolism. Proc Nutr Soc. 1983 42:437-49.

85. Garlick PJ, McNurlan M, Patlak CS. Adaptation of protein metabolism in relation to limits to high dietary protein intake. Eur J Clin Nutr. 199953 (Suppl. 1):S34-43.

86. Price GM, Halliday D, Pacy PJ, Quevedo MR, Millward DJ. Nitrogen homeostasis in man: influence of protein intake on the amplitude of diurnal cycling of body nitrogen. Clin Sci. 1994 86:91-102.

87. Millward DJ. Identifying recommended dietary allowances for protein and amino acids: a critique of the 2007 WHO/FAO/UNU report. Br J Nutr. 2012a2 108(Suppl. 2):S3-21.

88. Millward DJ. Knowledge gained from studies of leucine consumption in animals and humans. J Nutr. 22012b 142:2212S-9S.

89. Munro HN. General Aspects of the Regulation of Protein Metabolism by Hormones. New York, NY: Academic Press, 1964

90. Soenen S, Bonomi AG, Lemmens SG, Scholte J, Thijssen MA, et al. Relatively high-protein or 'low-carb' energy-restricted diets for body weight loss and body weight maintenance? Phys Behav. 2012 107:374/80.

91. Soenen S, Martens EA, Hochstenbach-Waelen A, Lemmens SG, Westerterp-Plantenga MS. Normal protein intake is required for body weight loss and weight maintenance, and elevated protein intake for additional preservation of resting energy expenditure and fat free mass. J Nutr. 2013 143:591-6.

92. Larsen TM, Dalskov SM, van Baak M, Jebb SA, Papadaki A, Pfeiffer AF, et al. . Diets with high or low protein content and glycemic index for weight-loss maintenance. N Eng/ J Med. 2010 363,2102-13.

93. Brinkworth GD, Noakes M, Parker B, Foster P, Clifton PM. Longterm effects of advice to consume a highprotein, low-fat diet, rather than a conventional weight-loss diet, in obese adults with type 2 diabetes: oneyear follow-up of a randomised trial. Diabetologia 2004a 47:1677-86.

94. Brinkworth GD, Noakes M, Keogh JB, Luscombe ND, Wittert GA, Clifton PM. Long-term effects of a highprotein, low-carbohydrate diet on weight control and cardiovascular risk markers in obese hyperinsulinemic subjects. Int J Obes Relat Metab Disord. 2004b 28:661-70.

95. Clifton PM, Keogh JB, Noakes M. Long-term effects of a high-protein weight-loss diet. Am J Clin Nutr. 2008 87:23-9.

96. Due A, Toubro S, Skov AR, Astrup A. Effect of normal-fat diets, either medium or high in protein, on body weight in overweight subjects: a randomised 1-year trial. Int J Obes Relat Metab Disord. 2004 28:1283-90.

97. Frisch S, Zittermann A, Berthold HK, Götting C, Kuhn J, Kleesiek K, et al. . A randomized controlled trial on the efficacy of carbohydrate-reduced or fat-reduced diets in patients attending a telemedically guided weight loss program. Cardiovasc Diabetol. 2009 18:8-36.

98. Gardner CD, Kiazand A, Alhassan S, Kim S, Stafford RS, Balise RR, et al. . Comparison of the Atkins, Zone, Ornish, and LEARN diets for change in weight and related risk factors among overweight premenopausal women: the A TO Z Weight Loss Study: a randomized trial. J Am Med Assoc. 2007 297:969-77.

99. Griffin HJ, Cheng HL, O'Connor HT, Rooney KB, Steinbeck KS. Higher protein diet for weight management in young overweight women:a 12-month randomized controlled trial. Diabetes Obes Metab. 2013.15:572-5 
100. Iqbal N, Vetter ML, Moore RH, Chittams JL, Dalton-Bakes C et al. Effects of a low-intensity intervention that prescribed a low-carbohydrate vs a low-fat diet in obese, diabetic participants. Obesity 2010 18:1733-8.

101. Jesudason DR, Pedersen E, Clifton PM. Weight-loss diets in people with type 2 diabetes and renal disease: a randomized controlled trial of the effect of different dietary protein amounts. Am J Clin Nutr. 2013 98:494501.

102. Layman DK, Evans EM, Erickson D, Seyler J, et al. A moderate-protein diet produces sustained weight loss and long-term changes in body composition and blood lipids in obese adults. J Nutr. 2009 139:514-21.

103. Lim SS, Noakes M, Keogh JB, Clifton PM. Long-term effects of a low carbohydrate, low fat or high unsaturated fat diet compared to a no-intervention control. Nutr Metab Cardiovasc Dis. 2010 20:599-607.

104. McAuley KA, Smith KJ, Taylor RW, McLay RT, Williams SM, Mann JI. Long-term effects of popular dietary approaches on weight loss and features of insulin resistance. Int J Obes. 2006 30:342-9.

105. Sacks FM, Bray GA, Carey VJ, Smith SR, Ryan DH, Anton SD, et al. . Comparison of weight-loss diets with different compositions of fat, protein, and carbohydrates. N Eng/ J Med. 2009 360:859-73.

106. Stern L, Iqbal N, Seshadri P, Chicano KL, Daily DA, McGrory J, et al. . The effects of low-carbohydrate versus conventional weight loss diets in severely obese adults: one-year follow-up of a randomized trial. Ann Intern Med. 2004 140:778-85.

107. Foster GD, Wyatt HR, Hill JO, McGuckin BG, Brill C, Mohammed BS, et al. . A randomized trial of a lowcarbohydrate diet for obesity. N Eng/ J Med. 2003 348:2082-90.

108. Davis NJ, Tomuta N, Schechter C, Isasi CR, Segal-Isaacson CJ, Stein D, et al. . Comparative study of the effects of a 1-year dietary intervention of a low- carbohydrate diet versus a low-fat diet on weight and glycemic control in type 2 diabetes. Diabetes Care 2009 32:1147-52.

109. Shai I, Schwarzfuchs D, Henkin Y, Shahar DR, Witkow S, Greenberg I, et al. . Weight loss with a lowcarbohydrate, Mediterranean, or low-fat diet. N Engl J Med. 2008 359:229-41.

110. Larsen RN, Mann NJ, Maclean E, Shaw JE. The effect of high-protein, low- carbohydrate diets in the treatment of type 2 diabetes:na 12 month randomised controlled trial. Diabetologia 2011 54:731-40.

111. Dansinger ML, Gleason JA, Griffith JL, Schaefer EJ. Comparison of the Atkins, Ornish, weight watchers, and zone diets for weight loss and heart disease risk reduction: a randomized trial. J Am Med Assoc. 2005 293:43-53.

112. Das SK, Gilhooly CH, Golden JK, Pittas AG, Fuss PJ, Cheatham RA, et al. . Long-term effects of 2 energyrestricted diets differing in glycemic load on dietary adherence, body composition, and metabolism in CALERIE: a 1-y randomized controlled trial. Am J Clin Nutr. 2007 85:1023-30.

113. Delbridge EA, Prendergast LA, Proietto J. One-year weight maintenance after significant weight loss in healthy overweight and obese subjects: does diet composition matter? Am J Clin Nutr. 2009 90:1203-14.

114. Dyson PA, Beatty S, Matthews DR. An assessment of low-carbohydrate or low-fat diets for weight loss at 2 year's follow-up. Diabet Med. 2010 27,363-364.

115. Foster GD, Wyatt HR, Hill JO, Makris AP, Rosenbaum DL, et al. . Weight and metabolic outcomes after 2 years on a low-carbohydrate versus low-fat diet: a randomized trial. Ann Intern Med. 2010 153:147-57.

116. Guldbrand H, Dizdar B, Bunjaku B, Lindstrom T, Fredrikson M, et al. . 2012. In type 2 diabetes, randomisation to advice to follow a low- carbohydrate diet transiently improves glycaemic control compared with advice to follow a low-fat diet producing a similar weight loss. Diabetologia 55:2118-27.

117. Keogh JB, Luscombe-Marsh ND, Noakes M, Clifton PM. 2007. Long-term weight maintenance and cardiovascular risk factors are not different following weight loss on carbohydrate-restricted diets high in either monounsaturated fat or protein in obese hyperinsulinaemic men and women. Br J Nutr. 97:405-10.

118. Klemsdal TO, Holme I, Nerland H, Tonstad S. Effects of a low glycemic load diet versus a low-fat diet in subjects with and without the metabolic syndrome. Nutr Metab Cardiovasc Dis. 2010 20:195-201.

119. Krebs JD, Elley CR, Parry-Strong A, Lunt H, Drury PL, Bell DA, et al. . The Diabetes Excess Weight Loss (DEWL) Trial: a randomised controlled trial of high-protein versus high-carbohydrate diets over 2 years in type 2 diabetes. Diabetologia 2012 55:905-14.

120. Sukumar D, Ambia-Sobhan H, Zurfluh R, Schlussel Y, Stahl TJ, Gordon CL, et al. . Areal and volumetric bone mineral density and geometry at two levels of protein intake during caloric restriction: a randomized, controlled trial. J Bone Miner Res 2011 26:1339-48.

121. Keogh JB, Brinkworth GD, Clifton PM. Effects of weight loss on a low-carbohydrate diet on flow-mediated dilatation, adhesion molecules and adiponectin. Br J Nutr. 2007 98:852-859.

122. Joint WHO/FAO/UNU Expert Consultation. Protein and amino acid requirements in human nutrition. World Health Organ Tech Rep Ser. 2007 1-265.

123. Brinkworth GD, Noakes M, Buckley JD, Keogh JB, Clifton PM. Longterm effects of a very-low-carbohydrate weight loss diet compared with an isocaloric low-fat diet after 12 mo. Am J Clin Nutr. 2009 90:23-32. 
124. Josse AR, Atkinson SA, Tarnopolsky MA, Phillips SM. Increased consumption of dairy foods and protein during diet- and exercise-induced weight loss promotes fat mass loss and lean mass gain in overweight and obese premenopausal women. J Nutr. 2011 141:1626-34.

125. Clifton PM, Condo D, Keogh JB. Long term weight maintenance after advice to consume low carbohydrate, higher protein diets-a systematic review and meta-analysis. Nutr Metabol Cardiovasc Dis. 2014 24:224-35.

126. Krieger JW, Sitren HS, Daniels MJ, Langkamp-Henken B. Effects of variation in protein and carbohydrate intake on body mass and composition during energy restriction: a meta-regression 1. Am J Clin Nutr. 2006 83:260-74.

127. Martens EA, Westerterp-Plantenga MS. Protein diets, body weight loss and weight maintenance. Curr Opin Clin Nutr Metab Care 2014 17:75-9.

128. Stunkard AJ, Messick S. The three-factor eating questionnaire to measure dietary restraint, disinhibition and hunger. J Psychosom Res. 1985 29:71-83.

129. Born JM, Lemmens SG, Martens MJ, Formisano E, Goebel R, Westerterp-Plantenga MS. Differences between liking and wanting signals in the human brain and relations with cognitive dietary restraint and body mass index. Am J Clin Nutr. 2011 94:392-403.

130. Vogels N, Diepvens K, Westerterp-Plantenga MS. Predictors of long-term weight maintenance. Obes Res. 2005 13:2162-8.

131. Vogels N, Diepvens K, Westerterp-Plantenga MS. Successful long-term weight maintenance: a 2-year follow-up. Obesity 2007 15:1258-66.

132. Ditschuneit HH. Ergebnisse ambulante Adipositastherapie mit verschiedenen proteïnereichen Diaeten. Ergebnisse der Adipositasforschung. Erlangen: Perimed Fachbuch-Verlagsgesel/schaft 1984:p171-178.

133. Stock MJ. Gluttony and thermogenesis revisited. Int J Obes. 1999 23:1105-17.

134. Pullar JD, Webster AJF. The energy cost of fat and protein disposition in the rat. Br J Nutr. (1977) 37:355-63.

135. Whitehead JM, McNeill G, Smith JS. The effect of protein intake on 24-h energy expenditure during energy restriction. Int J Obes Relat Metab Disord. 1996 20:727-32.

136. Martens EA, Gonnissen HK, Gatta-Cherifi B, Janssens PL, Westerterp-Plantenga MS. Maintenance of energy expenditure on high-protein vs. high-carbohydrate diets at a constant body weight may prevent a positive energy balance. Clin Nutr. 2015 34:968-75.

137. Bortolotti M, Kreis R, Debard C, Cariou B, Faeh D, Chetiveaux M, Ith M, et al. . High protein intake reduces intrahepatocellular lipid deposition in humans. Am J Clin Nutr. 2009. 90:1002-10.

138. Bortolotti M, Maiolo E, Corazza M, Van Dijke E, Schneiter P, Boss A, et al. . Effects of a whey protein supplementation on intrahepatocellular lipids in obese female patients. Clin Nutr. 2011 30:494-8.

139. Theytaz F, Noguchi Y, Egli L, Campos V, Buehler T, Hodson L, et al. . Effects of supplementation with essential amino acids on intrahepatic lipid concentrations during fructose overfeeding in humans. Am J Clin Nutr. 2012 96:1008-16.

140. Lettner A, Roden M. Ectopic fat and insulin resistance. Curr Diab Rep. 2008:8:185-91.

141. Fabbrini E, Magkos F, Mohammed BS, Pietka T, Abumrad NA, Patterson BW, et al. . Intrahepatic fat, not visceral fat, is linked with metabolic complications of obesity. Proc Natl Acad Sci USA. 2009 106:15430-5.

142. Magkos F, Fabbrini E, Mohammed BS, Klein S. Increased whole-body adiposity without a concomitant increase in liver fat is not associated with augmented metabolic dysfunction. Obesity 2010. 18:1510-5.

143. Watanabe M, Houten SM, Wang L, Moschetta A, Mangelsdorf DJ, Heyman RA, et al. . Bile acids lower triglyceride levels via a pathway involving FXR, SHP, and SREBP-1c. J Clin Invest. 2004 113:1408-18.

144. Gannon MC, Nuttall JA, Damberg G, Gupta V, Nuttall FQ. Effect of protein ingestion on the glucose appearance rate in people with type 2 diabetes. J Clin Endocrinol Metab. 2001 86:1040-7.

145. Torres N, Tovar AR. The role of dietary protein on lipotoxicity. Nutr Rev. 2007 65:S64-68.

146. Hudgins LC, Hellerstein M, Seidman C, Neese R, Diakun J, Hirsch J. Human fatty acid synthesis is stimulated by a eucaloric low fat, high carbohydrate diet. J Clin Invest. 1996 97:2081-91.

147. Hudgins LC, Hellerstein MK, Seidman CE, Neese RA, Hirsch J. Relationship between carbohydrate-induced hypertriglyceridemia and fatty acid synthesis in lean and obese subjects. J Lipid Res. 2000 41:595-604.

148. Schwarz JM, Neese RA, Turner S, Dare D, Hellerstein MD. Short-term alterations in carbohydrate energy intake in humans. Striking effects on hepatic glucose production, de novo lipogenesis, lipolysis, and wholebody fuel selection. J Clin Invest. 1995) 96:2735-43.

149. Huntriss $R$, Campbell $M$, Bedwell $C$. The interpretation and effect of a low-carbohydrate diet in the management of type 2 diabetes: a systematic review and meta-analysis of randomised controlled trials. Eur J Clin Nutr. 2018 72:311-25.

150. Promintzer M, Krebs M. Effects of dietary protein on glucose homeostasis. Curr Opin Clin Nutr Metab Care 2006 9:463-8. 
151. Pal S, Ellis V, Dhaliwal S. Effects of whey protein isolate on body composition, lipids, insulin and glucose in overweight and obese individuals. Br J Nutr. 2010 104:716-23.

152. Sluijs I, van der ADL, Beulens JW, Spijkerman AM, Ros MM, der Schouw YT. Ascertainment and verification of diabetes in the EPIC-NL study. Neth J Med. 2010 68:333-9. Erratum in: Neth J Med. $201068: 342$

153. Sluijs I, van der Schouw YT, van der ADL, Spijkerman AM, Hu FB, et al. . Carbohydrate quantity and quality and risk of type 2 diabetes in EPIC- NL study. Am J Clin Nutr. 2010 92:905-11.

154. Linn T, Santosa B, Grönemeyer D, Aygen S, Scholz N, Busch M, et al. . Effect of long-term dietary protein intake on glucose metabolism in humans. Diabetologia 2000 43:1257-65.

155. Tian S, Xu Q, Jiang R, Han T, Sun C, Na L. Dietary protein consumption and the risk of type 2 diabetes: a systematic review and meta-analysis of cohort studies. Nutrients 2017 6:9.

156. Newgard CB, An J, Bain JR, Stevens RD, et al. A branched-chain amino acid-related metabolic signature that differentiates obese and lean humans and contributes to insulin resistance. Cell Metab. 2009 9:311-326.

157. Lynch CJ, Adams SH. Branched-chain amino acids in metabolic signalling and insulin resistance. Nat Rev Endocrinol. 2014 10:723-36.

158. Pedersen HK, Gudmundsdottir V, Nielsen HB, Hyotylainen T, Nielsen T, Jensen BA, et al. . Human gut microbes impact host serum metabolome and insulin sensitivity. Nature 2016 535:376-81.

159. Vega-Lopez S, Lichtenstein AH. Dietary protein type and cardiovascular disease risk factors. Prev Cardiol. 2005 8:31-40.

160. Sacks FM, Breslow JL, Wood PG, Kass EH. Lack of an effect of dairy protein (casein) and soy protein on plasma cholesterol of strict vegetarians. An experiment and a critical review J Lipid Res. 1983 24:1012-20.

161. Van Raaij JMA, Katan MB, Hautvast JGAJ, Hermus RJJ. Effects of casein versus soy protein diets on serum cholesterol and lipoproteins in young healthy volunteers. Am J Clin Nutr. 1981 34:1261-71.

162. Meinhertz H, Nilausen K, Faergemen O. Effects of dietary proteins on plasma lipoprotein levels in normal subjects: interaction with dietary cholesterol. J Nutr Sci Vitaminol. 1990 36:S157-S164.

163. Crouse JR, Morgan T, Terry JG, Ellis J, Vitolins M, Burke GL. A randomized trial comparing the effect of casein with that of soy protein comntaining varying amounts of isoflavones on plasma concentrations of lipids and lipoproteins. Arch Intern Med. 1999 159:2070-6

164. Anderson JW, Fuller J, Patterson K, Blair R, Tabor A. Soy compared to casein meal replacement shakes with high energy restricted diets for obese women: randomized controlled trial. Metabolism 2006 56:280-8.

165. Teunissen-Beekman KFM, Dopheide J, Geleijnse JM, Bakker SJL, Brink EL, de Leeuw PW, et al. Differential effects of proteins and carbohydrates on postprandial blood. Br J Nutr. 2014 112:600-8.

166. Tielemans SMAJ, Kromhout D, Geleijnse JM. Associations of plant and animal protein intake with05-year changes in blood pressure: the Zutphen elderly study. Nutr Metab Cardiovasc Dis. 2014 24:1228-33.

167. Fekete AA, Givens DI, Lovegrove JA. The impact of milk proteins and peptides on blood pressure and vascular function: a review of evidence from human intervention studies. Nutr. Res. Rev. 2013 26:177-190

168. Haring B, Gronroos N, Nettleton JA, Wyler von Ballmoos MC, Selvin E, et al. . Dietary protein intake and coronary heart disease in a large community based cohort: Results from the Atherosclerosis Risk in Communities (ARIC) study. PLOS ONE 2014 9:e109552.

169. Bernstein AM, Sun Q, Hu FB, Stampfer MJ, Manson JE, Willet WC. Major dietary protein sources and thew risk of coronary heart disease in women. Circulation 2010 122:876-83.

170. Bernstein AM, Pan A, Rexrode KM, Stampfer M, Hu FB, Mozaffarian D, et al. . Dietary protein sources and the risk of stroke in men and women. Stroke 2012 43:637-44.

171. Pedersen AN, Kondrup J, Borsheim E. Health effects of protein intake in healthy adults: a systematic review. Food Nutr Res. 2013 57:21245.

172. Calvez J, Poupin N, Chesneau C, Lassale C, Tome D. Protein intake, calcium balance and health consequences. Eur J Clin Nutr. 2012 66:281-95.

173. Bonjour JP. Dietary protein: an essential nutrient for bone health. J Am Coll Nutr. 2005 24:526S-36S.

174. Westerterp KR. Weight loss and bone mineral content. Obes Res. 2002 10:559.

175. Møller G, Andersen JR, Ritz C, Silvestre MP, Navas-Carretero S, Jalo E, et al. . Higher protein intake is not associated with decreased kidney function in pre- diabetic older adults following a one-year interventiona preview sub- study. Nutrients 2018 10:54.

176. Tome D. Criteria and markers for protein quality assessment - a review. Br J Nutr. 2012 108(Suppl. 2):S222229.

177. Moughan PJ. Dietary protein for human health. Br J Nutr. 2012 108(Suppl. 2):S1-2.

178. Bray GA, Smith SR, de Jonge L, Xie H, Rood J, Martin CK, et al. . Most C. 2012. Effect of dietary protein content on weight gain, energy expenditure, and body composition during overeating: a randomized controlled trial. JAMA 307:47-55. 



\section{CHAPTER 5}

\section{Insulin Resistance, Weight and Behavioral Variables as Determinants of Brain Reactivity to Food Cues - a PREVIEW Study}

M. Drummen, E. Dorenbos, A.C.E.Vreugdenhil, A. Raben, M.S. Westerterp-Plantenga and T.C. Adam

In press:

American Journal of Clinical Nutrition (2018) 


\section{ABSTRACT}

\section{Background}

Obesity and type-2 diabetes have been linked to alterations in food reward processing, which may be linked to insulin resistance.

\section{Objective}

In this clinical study, we investigated the respective contribution of insulin resistance, anthropometry, and behavioral factors to brain reward activation in response to visual stimuli.

\section{Design}

Food reward-related brain reward activation was assessed with functional magnetic resonance imaging in 39 overweight/obese individuals with impaired fasting glucose and/or impaired glucose tolerance (22 women, 17 men; insulin sensitivity index (ISI): 2.7 \pm 1.3 ; body mass index (BMI): $32.3 \pm 3.7 \mathrm{~kg} / \mathrm{m}^{2}$; body-fat percentage: $40.5 \pm 7.9 \%$; fasting glucose: $6.3 \pm 0.6 \mathrm{mmol} / \mathrm{l}$ ). Food and non-food images were shown in a randomized block design. Brain activation (food vs nonfood images) was correlated with anthropometric and behavioral variables. Behavioral variables included eating behavior (TFEQ) and habitual physical activity (Baecke). Glucose and insulin concentrations, determined during an oral glucose challenge, were used to assess the homeostatic model assessment for insulin resistance (HOMA-IR) and Matsuda insulin sensitivity index (ISI).

\section{Results}

Food>non-food brain activation was positively associated HOMA-IR in the nucleus accumbens, right/left insula and right cingulate gyrus ( $p<0.005$, corrected for multiple comparisons). TFEQ factor 2 was positively related to food>non-food brain activation in the supramarginal gyrus $(p<0.005$, corrected for multiple comparisons). Habitual physical activity during leisure time was negatively associated with food $>$ non-food brain activation in multiple regions associated with the attention and reward network ( $p<0.005$, corrected for multiple comparisons).

\section{Conclusions}

Individuals with increased insulin resistance and emotional eating/disinhibition showed higher brain reactivity to food cues, which may imply changes in food preference and hyperphagia. Individuals with higher habitual physical activity showed less food reward related brain activation. 


\section{INTRODUCTION}

Insulin resistance is one of the most important factors linking obesity with chronic disease risk, including type-2 diabetes (T2D) and cardiovascular disease (1). While consequences of increased body fat and systemic insulin resistance have been investigated for the periphery, consideration of the brain as an insulin sensitive tissue is comparatively recent. Both, obesity and T2D were shown to be associated with altered brain signaling in areas relevant for food intake motivation and food reward (2-4). However, due to the frequent co-occurrence of both, it is difficult to discern whether their contribution to alterations in neural, cue-initiated responses is individual or synergistic in nature. Not only does insulin relay information of peripheral energy status for homeostatic control to the hypothalamus, insulin receptors also densely populate brain regions associated with motivated behaviors and reward processing (5). Furthermore, insulin is thought to play a role in brain reward regulation through its pivotal role for dopamine release and re-uptake (5). Uninhibited brain reward received from food intake may be one of the mechanisms underlying continued overeating in obese individuals. In healthy and lean participants studies utilizing intranasal insulin administration showed an attenuation of brain activation in response to food pictures (6) and reduced food intake (7). Two studies in children with overweight showed brain activation in response to food images to be inversely associated with either insulin sensitivity or waist circumference $(8,9)$. Those results corroborated studies suggesting the cooccurrence of peripheral and central insulin resistance, an idea further supported by studies utilizing magneto-encephalography (10).

Additionally, behavioral factors were shown to play a role in the modulation of brain reward signaling in people with obesity or T2D. Eating behavior (11) and physical activity (12) affect food reward, yet it is not clear whether their impact is direct or rather indirect through their relationship with either obesity or insulin resistance. In order to identify primary intervention targets, it is vital to discern the relative contribution of weight, insulin, and behavioral factors to the observed alterations in brain reward signaling, especially for people at risk for T2D. Almost all the insulin in the brain is derived from the periphery (13), posing peripheral insulin resistance as a particularly interesting target to tackle the mechanisms underlying altered brain responses in individuals at risk. Research participants from the PREVIEW intervention study deliver an ideal research population. The PREVIEW study is a multicentre study which aims to find the most effective lifestyle components for the prevention of T2D in overweight/ obese individuals with impaired fasting glucose (IFG) and/or impaired glucose tolerance (IGT). The aim of the current study was to investigate the respective association of insulin resistance, weight status, and behavioral factors with brain reward activation in response to visual food cues on a whole brain level and specifically for the nucleus accumbens, a central region of the dopaminergic reward system. Given the evidence so far it was our hypothesis that brain reward signaling would be primarily associated with insulin resistance, rather than weight status or behavioral variables. 


\section{SUBJECTS AND METHODS}

\section{Participants}

Forty participants were recruited from the cohort of the PREVIEW study (PREVIEW - Prevention of Diabetes through lifestyle intervention and population studies in Europe and around the world, EU $7^{\text {th }}$ Framework Programme, grant agreement no. 312057, www.previewstudy.com (14)) at Maastricht University. One participant lacked valid functional imaging data and was excluded from analysis (see TABLE 1 for participant characteristics). Inclusion criteria were: age 25-70 years, BMI $\geq 25 \mathrm{~kg} / \mathrm{m}^{2}$, fasting plasma glucose of $5.6-6.9 \mathrm{mmol} / \mathrm{l}$ and/or plasma glucose concentration of $7.8-11.0 \mathrm{mmol} / \mathrm{l}$ at $2 \mathrm{~h}$ after an oral glucose tolerance test (OGTT), and willingness to undergo MRI procedures. Exclusion criteria included T2D, left-handedness, claustrophobia and history of neurological disorders in addition to the general PREVIEW exclusion criteria (ClinicalTrials.gov NCT01777893). All participants gave written informed consent for participation. The study was approved by the Medical Ethical Committee of Maastricht University Medical Center and in accordance with guidelines of the Declaration of Helsinki.

TABLE 1. Participant characteristics

\begin{tabular}{lll}
\hline No. participants (female/male) & $39(17 / 22)$ & \\
Age (years) & $53 \pm 11.3$ & $25.0-68.0$ \\
BMI $\left(\mathrm{kg} / \mathrm{m}^{2}\right)$ & $32.3 \pm 3.7$ & $25.7-40.7$ \\
Fat mass $(\mathrm{kg})$ & $38.9 \pm 10.2$ & $18.5-59.8$ \\
Body-fat $(\%)$ & $40.5 \pm 7.9$ & $22.9-55.2$ \\
Fasting glucose $(\mathrm{mmol} / \mathrm{l})$ & $6.3 \pm 0.6$ & $5.4-8.3$ \\
Fasting insulin $(\mathrm{mU} / \mathrm{l})$ & $13.6 \pm 6.3$ & $1.1-30.0$ \\
HOMA-IR & $3.9 \pm 1.9$ & $0.3-9.2$ \\
ISI & $2.7 \pm 1.3$ & $0.9-5.8$ \\
ISI (log) & $0.38 \pm 0.22$ & $-0.03-0.76$ \\
Baecke work index & $2.6 \pm 0.8$ & $1.3-4.3$ \\
Baecke sport index & $2.6 \pm 0.7$ & $1.0-4.0$ \\
Baecke leisure index & $2.9 \pm 0.7$ & $1.5-4.4$ \\
TFEQ factor 1 & $8.5 \pm 4.7$ & $1.0-17.0$ \\
TFEQ factor 2 & $8.1 \pm 3.7$ & $2.0-15.0$ \\
TFEQ factor 3 & $5.6 \pm 3.5$ & $0.0-12.0$ \\
\hline
\end{tabular}

Notes: Data are mean \pm SD and range. HOMA-IR, homeostatic model assessment for insulin resistance; ISI, insulin sensitivity index; log, log transformed; TFEQ, three factor eating questionnaire

\section{Body weight and composition}

Body weight was measured using a calibrated scale (Life Measurement Corporation, Inc, Concord, (A, USA) and body composition was determined using Siri's equation based on body density measured via air-displacement plethysmography with the BodPod System (Life Measurement Corporation, Inc, Concord, CA, USA) (15). Height was measured using a wall-mounted stadiometer to the nearest $0.1 \mathrm{~cm}$ (Seca, model 222, Seca, Hamburg, Germany). 
OGTT

Participants underwent a 2 hour 75-gram OGTT after an overnight fast $>10$ hours. Blood samples to determine glucose and insulin concentrations were taken prior to and 30,60, 90 and 120 minutes after receiving the glucose load.

\section{Blood samples}

Blood samples were drawn from an antecubital vein and stored locally at $-80^{\circ} \mathrm{C}$. Samples were transported and analysed centrally at the National Institution for Health and Welfare in Helsinki, Finland. Plasma glucose was measured by enzymatic hexokinase method and insulin was measured using chemiluminescent microparticle immunoassay. The homeostatic model assessment for insulin resistance (HOMA-IR) was used to assess insulin resistance and was calculated as follows: fasting glucose $x$ fasting insulin / 22.5 (16). Insulin sensitivity was calculated with the Matsuda index: Insulin sensitivity index derived from OGTT (ISI) $=10,000 / \sqrt{ }$ (fasting glucose $x$ fasting insulin) $x$ (mean glucose $x$ mean insulin during OGTT) (17). Insulin data during the OGTT was missing for four participants. Therefore, all analyses with ISI were performed with 35 participants. HbA1c was measured using enzymatic assay. Laboratory measurements are performed on Architect ci8200 analyzer (Abbott Laboratories, Abbott Park, IL, USA).

\section{Brain imaging paradigm}

Participants arrived at the university after an overnight fast of $>10$ hours. They underwent functional magnetic resonance imaging to obtain blood oxygen level-dependent (BOLD) data. During scanning, nine blocks of ten images each were presented in a randomized order. Blocks contained high-calorie food, low-calorie food or non-food images. The food images were shown in a randomized order. Each participant viewed the same set of images. The images were selected from various Web sites and from the IAPS as it has been used in previous studies $(8,9,18,19)$. High-calorie images included items such as fries, mac-and-cheese, hamburgers, donuts etc. Lowcalorie images included items such as fruit salad, cucumbers, carrots, broccoli etc.

Food images were randomly chosen from sixty different images in order to avoid preference and learning effects. Images were shown for 2 seconds each. Between the blocks, a fixation cross was shown for 10 seconds. During the presentation participants received the instruction to focus on how much they liked the images.

\section{Image acquisition}

Scanning was performed on a 3 Tesla scanner (Magnetom, Siemens, Erlangen, Germany) using a 64-channel head coil. First, a T1 weighted scout scan was used to confirm the participant was correctly placed in the scanner. Functional runs were collected using a $\mathrm{T}^{*}$-weighted protocol $\left(\mathrm{TR}=2.0 \mathrm{~s}, \mathrm{TE}=30.0 \mathrm{~ms}\right.$, FOV $=216 \times 216$, matrix size $=72 \times 72$, voxel size, $\left.3 \times 3 \times 3 \mathrm{~mm}^{3}\right)$. Each volume consisted of 34 slices. The slice acquisition order was interleaved ascending. In each session, anatomical images were acquired with a high-resolution T1 weighted scan. 
Image processing

Functional data preprocessing included slice scan time correction, 3D motion correction temporal high-pas filtering with 4 cycles. Anatomical data was corrected for intensity inhomogeneities. To achieve brain normalization, the anatomical scan of each participant was transformed into Montreal Neurological Institute (MNI) space. After preprocessing, both functional and anatomical scans were aligned based on starting position and boundary-based registration. The resulting volume-time-courses were spatially smoothed by applying a Gaussian filter (FWHM=6) to increase signal-to-noise ratio. For each participant, food reward-related brain activation predictors for the three stimuli blocks (high-calorie food images, low-calorie food images and neutral images) were applied in generalized linear model (GLM) analyses and the hemodynamic-response was taken into account by adding a two gamma hemodynamic response function. Additionally, three-dimensional motion correction parameters were added as confounding predictors. The individual brain responses were subsequently used for whole brain analysis. To specifically investigate the activation in the nucleus accumbens, two spherical regions of interest (ROI) were drawn on the left and right nucleus accumbens (MNI coordinates $\pm 9,6,-4$ (20)). Beta values in these ROIs were calculated and extracted for each participant individually.

\section{Behavioral questionnaires}

Behavioral factors were assessed using validated questionnaires in native language. Eating Behavior was assessed using the Three Factor Eating Questionnaire (TFEQ), which consists of 51 questions (21). The three factors it measures are cognitive restraint (TFEQ factor 1), emotional eating and disinhibition (TFEQ factor 2) and feelings of hunger (TFEQ factor 3). Habitual physical activity was assessed using the Baecke questionnaire. It consists of 17 questions to measure physical activity during work, sport and leisure time (22).

\section{Statistical analysis}

Power calculations were based on a study by Jastreboff et al. (23) which reported a correlation coefficient of 0.52 between HOMA-IR and brain activation to food cues, yielding a minimum of 27 participants. Since in general no significant differences in brain activation during the high-calorie food images and low-calorie images were observed, food images were taken together and contrasted with the neutral images as a 'non-food' condition. Whole brain contrast map for food $>$ non-food is available as supplemental figure 2 . Whole brain correlation analyses was used to test the correlation between the food $>$ non-food activation and the different anthropometric and behavioral parameters. For the whole brain analyses, Monte Carlo simulations were performed in BrainVoyager to identify cluster extent thresholds. A cluster alpha of 0.005 was used to correct for multiple comparisons. Monte Carlo simulations were performed with 1000 iterations with an independent voxel threshold of $p<0.001$. For the ROI analysis in the nucleus accumbens, food $>$ non-food activation was averaged and extracted from the left and right ROI and used in pearson's correlation analyses to determine the relation with anthropometric and behavioral parameters. A $p<0.005$ was considered significant, to correct for multiple comparisons. Partial correlation analysis was used to determine the relationship between extracted brain activation in 
the significant clusters and ROIs with HOMA-IR or behavioral variables, adjusted for BMI and age. Data are expressed as mean \pm SD. Analyses were performed using BrainVoyager 20.6 (Brain Innovation B.V., Maastricht, The Netherlands) and SPSS 23 (IBM corp., Armonk NY, USA).

\section{RESULTS}

\section{Food reward-related brain activation and anthropometric or behavioral variables}

BMI was positively associated with HOMA-IR $(r=0.40 ; p=0.012)$ and inversely with ISI $(r=-0.43$; $p=0.009)$. HOMA-IR and ISI were negatively related $(r=-0.92 ; p<0.001)$. Activity in response to viewing food images was contrasted with non-food images and the association with anthropometric or behavioral parameters was assessed using whole brain analysis. Anthropometric parameters included BMI, body-fat percentage and HOMA-IR. Results showed a positive association between food $>$ non food activation and HOMA-IR in the right $(r=0.53)$ and left insula ( $r=0.55)$ and right cingulate gyrus ( $r=0.53$ ) (FIGURE 1) (TABLE 2). There were no significant associations between food $>$ non-food activation and BMI or body-fat percentage. After adjusting for BMI and age, the correlation coefficient between HOMA-IR and food>non-food activation remained significant (Table 2). Food $>$ non-food brain activation was positively related to TFEQ factor 2 (emotional eating and disinhibiton) in the right supramarginal gyrus $(r=0.55)$, which remained significant after adjusting for BMI and age (Table 2). Food $>$ non-food brain activation was not related to TFEQ factor 1 (cognitive restraint) or factor 3 (feelings of hunger). Food $>$ nonfood brain activation was negatively related to Baecke leisure index in multiple regions associated with reward, attention and memory. After adjusting for BMI and age, the correlation coefficients of these relationships were reduced (Table 2). Food $>$ non-food brain activation was positively related to Baecke work index $(r=0.53)$. This relationship disappeared after adjusting for BMI and age. Food $>$ non-food brain activation was not related to Baecke sport index.

Food reward-related brain activation in the nucleus accumbens and anthropometric and behavioral variables

Activation in the right nucleus accumbens was significantly associated with HOMA-IR ( $r=0.46$; $p=0.003$ ). While the association between HOMA-IR and food $>$ non-food activation in the right nucleus accumbens became non significant after correction for BMI and age $(r=0.33 ; p=0.046)$, activation in the left nucleus accumbens remained significantly associated with HOMA-IR $(r=0.47$; $\mathrm{p}=0.003$ ) after correction for BMI and age. Food $>$ non-food brain activation was not associated with the other variables. 

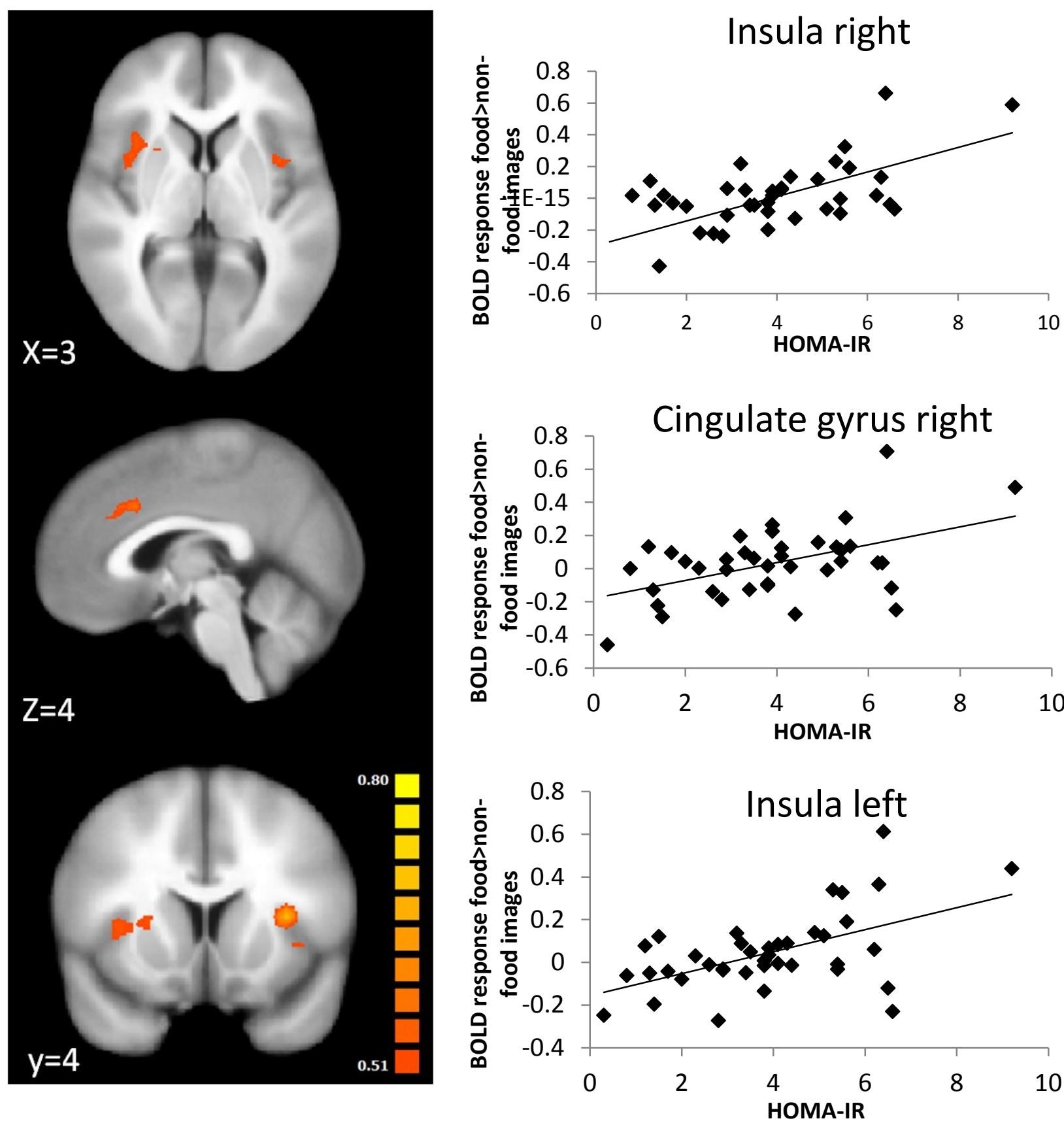

FIGURE 1. Whole brain contrast map. Brain regions with significant associations between food rewardrelated brain activation and HOMA-IR are shown in orange $(p<0.005$, corrected for muliple comparisons). Scatter plots of HOMA-IR and extracted food>non-food BOLD response are shown on the right. 
TABLE 2 Summary of whole brain analysis correlating food >non-food brain activation with anthropometric and behavioral variables

\begin{tabular}{|c|c|c|c|c|c|c|c|c|c|}
\hline Variable & $\begin{array}{l}\text { cluster threshold } \\
\left(\mathrm{mm}^{3}\right)\end{array}$ & AAL & $\mathbf{x}$ & $\mathbf{y}$ & $\mathbf{z}$ & $\begin{array}{l}\text { cluster size } \\
\left(\mathrm{mm}^{3}\right)\end{array}$ & $\mathbf{r}$ & $\mathbf{r}^{*}$ & $\mathbf{p}^{*}$ \\
\hline \multirow[t]{3}{*}{$H O M A-I R$} & 432 & Insula $\mathrm{R}$ & 40 & 15 & 0 & 1557 & 0.53 & 0.53 & $<0.001$ \\
\hline & & Middle Cingulate gyrus $\mathrm{R}$ & 3 & 22 & 33 & 478 & 0.53 & 0.46 & 0.004 \\
\hline & & Insula L & -36 & 9 & 5 & 1040 & 0.55 & 0.48 & 0.003 \\
\hline TFEQ factor 2 & 351 & supramarginal gyrus $\mathrm{R}$ & 58 & -32 & 45 & 841 & 0.55 & 0.56 & $<0.001$ \\
\hline \multirow[t]{7}{*}{ Baecke leisure index } & 513 & no label & 32 & -1 & 26 & 708 & -0.54 & -0.44 & 0.008 \\
\hline & & Thalamus R & 16 & -10 & 7 & 554 & -0.54 & -0.34 & 0.048 \\
\hline & & Middle cingulate gyrus L & -2 & -35 & 39 & 1934 & -0.55 & -0.33 & 0.050 \\
\hline & & Precuneus $\mathrm{R}$ & 2 & -53 & 25 & 1170 & -0.55 & -0.47 & 0.005 \\
\hline & & Putamen L & -26 & 1 & 8 & 557 & -0.55 & -0.29 & 0.094 \\
\hline & & no label & -35 & -46 & 17 & 771 & -0.54 & -0.43 & 0.010 \\
\hline & & Angular gyrus L & -38 & -54 & 35 & 910 & -0.55 & -0.29 & 0.091 \\
\hline Baecke work index & 378 & no label & 22 & 30 & 18 & 633 & 0.53 & 0.11 & 0.569 \\
\hline
\end{tabular}

Notes: Cluster extent threshold was determined by Monte Carlo simulation with a voxel threshold of $p<0.001$ and cluster alpha of 0.005 . Centre-of-gravity coordinates of each cluster are given in MNI space and the automated anatomical labeling atlas was consulted to obtain corresponding anatomical labels. Correlation coefficients $(r)$ present average correlation coefficients of the significant clusters determined with BrainVoyager. * adjusted for BMI and age

Abbreviations: $A A L$, automated anatomical labeling; HOMA-IR, homeostatic model assessment for insulin resistance; TFEQ, three-factor eating questionnaire;

$R$, right hemisphere; $L$, left hemisphere 


\section{DISCUSSION}

The present study investigated the respective association of body weight, insulin sensitivity and behavioral factors with brain activation contrasting food images to non-food images in overweight and obese individuals with IFG and/or IGT. Food reward-related brain activation was positively associated with insulin resistance during the anticipation of food reward, specifically in the nucleus accumbens, left/right insula and right cingulate gyrus, independently of BMI. High calorie food images were previously shown to increase activity in these regions that are known for playing a central role in food reward processing, and are connected through the dopaminergic pathway originating in the ventral tegmental area (24). Generally, but especially in people with IFG or IGT, disturbance of food reward processing may be an important accelerator for the transition to T2D through overeating. The catabolic action of insulin in the brain is an important signal to the homeostatic circuit, but also relevant to the termination of reward experience from pleasurable behaviors, including food intake. Taking the brakes off reward perception may consequentially support hyperphagia (25). Several studies have shown that diminished sensitivity of insulin receptors impairs inhibitory effects of insulin on brain signaling. Mechanistically, the close link between insulin and dopamine in the brain may explain the effect of insulin on reward perception. It has been shown that insulin sensitivity was positively associated with dopamine levels at the dopamine D2/3 receptor (26) and negatively related to dopamine D2/3 receptor availability in the ventral striatum (27). Insulin is thought to activate the PI3K/Akt/mTOR pathway stimulating the synthesis of the dopamine transporter for dopamine reuptake (28). Reduced reuptake of dopamine as a result of brain insulin resistance might lead to increased activation or prolonged action of synaptic dopamine (29), which in turn could lead to oversensitivity to food cues and subsequent hyperphagia. In line with this mechanism, Labouebé and colleagues showed that injection of insulin in the ventral tegmental area of mice led to a reduction in synaptic transmission of ventral tegmental area dopamine neurons (30). Blockage of the PI3k/Akt/mTOR pathway prevented this reduction. Central administration of insulin also led to decreased anticipatory activity and conditioned place preference (30). It should be noted that the interaction between insulin and dopamine is contentious and study results are quite diverse. Peripheral insulin administration had no effects on brain activation in healthy, presumably insulin sensitive, non-obese individuals in response to visual food cues (31).

Findings from our study are in accordance with other studies demonstrating positive associations between insulin resistance and neural activation in the mesolimbic reward system in overweight girls and obese individuals $(8,23)$. More support for the role of insulin resistance rather than weight status is given by studies demonstrating a robust effect on prefrontal cortex blood perfusion in lean, but not overweight/obese men, after elevating brain insulin concentrations through intranasal insulin administration (32). Changes were inversely related to insulin sensitivity, even after adjustment for BMI, with nasal insulin administration leading to a decrease in prefrontal blood flow in lean, but not in overweight and obese men (32). Studies that measured brain activation during a glucose challenge showed reduced activation in response to food pictures after glucose ingestion (33-35). The reduction in brain response to food cues was associated with increases in plasma insulin levels during the glucose challenge (33). However, this 
reduction in brain response was only seen in insulin-sensitive but not insulin-resistant participants $(34,35)$. Similar to our study, the degree of insulin resistance correlated positively with the BOLD response to food images in reward regions.

With respect to habitual physical activity and food reward-related brain signaling, we found an inverse relationship between habitual activity during leisure time and food-reward related brain activation in multiple regions associated with the attention network and reward network. Accordingly, another study suggested that brain activation to food pictures is affected by physical activity with physical exercise attenuating food reward-related brain activation (36). Furthermore, leisure-time physical activity, assessed with the Baecke questionnaire in a large cohort of adults, was also shown to be negatively associated with BMI and body fat and positively associated with eating fruits and vegetables (37). Based on the results it may be conceivable that habitual physical activity could potentially diminish anticipated food reward and lead to healthier eating habits.

Eating behavior and overeating is an important component in the association of obesity and T2D (38) and may come forward as a result to changes in food reward-related brain signaling (39). We found a positive association between food reward-related brain activation and emotional eating/disinhibiton in the right supramarginal gyrus. The supramarginal gyrus has been previously associated with reward, motivation and drug abuse $(40,41)$. A study in adolescents reported increased BOLD-response during inhibitions versus non-inhibition trials in the supramarginal gyrus and participants that showed highest activation also progressed to the highest levels of substance use within the next 18 months (40).

While our research participants presented with a fairly large range in BMI and insulin resistance, we did not include healthy participants or participants with T2D in this study. Since brain response in the nucleus accumbens to food images may not show a linear relation with insulin sensitivity (42) we cannot generalize the results for the whole population.

Furthermore, it is known that menstrual cycle and sex hormones influence reward-related brain activation (43-45). Since we did not collect data on markers of menopausal stage or menstrual stage, we were not able to take this into account. Another limitation poses the use of crosssectional data only. However, as part of the overall PREVIEW study, these observations will be followed by assessing effects of changes in body weight, insulin resistance and behavioral factors on food reward-related brain signaling, induced by an 8-weeks weight loss period followed by up to 3-years weight maintenance.

In conclusion, in participants with overweight/obesity and limited insulin sensitivity, insulin resistance was positively associated with brain reactivity to food cues in the nucleus accumbens, insula and cingulate gyrus and emotional eating/disinhibition was posivitely associated with brain reactivity to food cues in the supramarginal gyrus, which may lead to changes in food preference and hyperphagia. The results are especially relevant for individuals with increased risk for the development of T2D. The lifestyle factor physical activity was inversely associated with food reward related brain signaling, posing as a potentially protective factor to counteract the effects of insulin resistance on brain reactivity to food cues. In addition to the well known peripheral 
benefits of physical activity, the results corroborate an additional route for physical activity in the prevention of T2D and obesity.

\section{ACKNOWLEDGEMENTS}

We would like to thank all the PREVIEW participants and members of the PREVIEW team, coordinated by Anne Raben. We would like to thank Armin Heinecke for his expertise with Brainvoyager and Nuria Rosique Esteban for her extensive help with the practical work.

\section{FUNDING}

This study has received a grant from the EU $7^{\text {th }}$ Framework Programme grant \#312057 (FP7-KBBE2012.2.2-03).

\section{AUTHOR CONTRIBUTIONS}

The author's responsibilities were as follows: MD conducted the study, analysed the data and wrote the manuscript; ED assisted with the study; AV assisted with setup of the study and medical assistance; AR initiated and coordinated the PREVIEW study and reviewed the manuscript; MW-S designed and supervised the study and reviewed the manuscript; TA designed and supervised the study, supervised data analysis and reviewed the manuscript. 


\section{REFERENCES}

1. Reaven GM. Insulin resistance: the link between obesity and cardiovascular disease. Med Clin North Am 2011;95(5):875-92.

2. Stice E, Spoor S, Bohon C, Small DM. Relation of reward from food intake and anticipated food intake to obesity: a functional magnetic resonance imaging study. J Abnorm Psycho/2008;117(4):924-35.

3. Martens MJ, Born JM, Lemmens SG, Karhunen L, Heinecke A, Goebel R, Adam TC, Westerterp-Plantenga MS. Increased sensitivity to food cues in the fasted state and decreased inhibitory control in the satiated state in the overweight. Am J Clin Nutr 2013;97(3):471-9.

4. Chechlacz M, Rotshtein P, Klamer S, Porubska K, Higgs S, Booth D, Fritsche A, Preissl H, et al. Diabetes dietary management alters responses to food pictures in brain regions associated with motivation and emotion: a functional magnetic resonance imaging study. Diabetologia 2009;52(3):524-33.

5. Figlewicz DP, Evans SB, Murphy J, Hoen M, Baskin DG. Expression of receptors for insulin and leptin in the ventral tegmental area/substantia nigra (VTA/SN) of the rat. Brain Res 2003;964(1):107-15.

6. Guthoff $M$, Grichisch Y, Tschritter O, Veit R, Hallschmid M, Haring HU, Preissl H, Fritsche A. Insulin modulates food-related activity in the central nervous system. J Clin Endocrinol Metab 2010;95(2):748-55.

7. Jauch-Chara K, Friedrich A, Melchert UH, H GS-E, Hallschmid M, Oltmanns KM. Intranasal insulin suppresses food intake via enhancement of brain energy levels in humans. Diabetes 2012;61(9):2261-8.

8. Adam TC, Tsao S, Page KA, Hu H, Hasson RE, Goran MI. Insulin sensitivity and brain reward activation in overweight Hispanic girls: a pilot study. Pediatr Obes 2015;10(1):30-6.

9. Luo S, Romero A, Adam TC, Hu HH, Monterosso J, Page KA. Abdominal fat is associated with a greater brain reward response to high-calorie food cues in Hispanic women. Obesity 2013;21(10):2029-36.

10. Anthony K, Reed LJ, Dunn JT, Bingham E, Hopkins D, Marsden PK, Amiel SA. Attenuation of insulin-evoked responses in brain networks controlling appetite and reward in insulin resistance: the cerebral basis for impaired control of food intake in metabolic syndrome? Diabetes 2006;55(11):2986-92.

11. Born JM, Lemmens SG, Martens MJ, Formisano E, Goebel R, Westerterp-Plantenga MS. Differences between liking and wanting signals in the human brain and relations with cognitive dietary restraint and body mass index. Am J Clin Nutr 2011;94(2):392-403.

12. Horner KM, Finlayson G, Byrne NM, King NA. Food reward in active compared to inactive men: Roles for gastric emptying and body fat. Physiol Behav 2016;160:43-9.

13. Banks WA. The source of cerebral insulin. Eur J Pharmaco/ 2004;490(1-3):5-12.

14. Fogelholm M, Larsen TM, Westerterp-Plantenga M, Macdonald I, Martinez JA, Boyadjieva N, Poppitt S, Schlicht W, Stratton G, Sundvall J, et al. PREVIEW: Prevention of Diabetes through Lifestyle Intervention and Population Studies in Europe and around the World. Design, Methods, and Baseline Participant Description of an Adult Cohort Enrolled into a Three-Year Randomised Clinical Trial. Nutrients 2017;9(6).

15. Plasqui G, Soenen S, Westerterp-Plantenga MS, Westerterp KR. Measurement of longitudinal changes in body composition during weight loss and maintenance in overweight and obese subjects using airdisplacement plethysmography in comparison with the deuterium dilution technique. Inter J Obes 2005 2011;35(8):1124-30.

16. Matthews DR, Hosker JP, Rudenski AS, Naylor BA, Treacher DF, Turner RC. Homeostasis model assessment: insulin resistance and beta-cell function from fasting plasma glucose and insulin concentrations in man. Diabetologia 1985;28(7):412-9.

17. Matsuda $M$, DeFronzo RA. Insulin sensitivity indices obtained from oral glucose tolerance testing: comparison with the euglycemic insulin clamp. Diabetes Care 1999;22(9):1462-70.

18. Page KA, Seo D, Belfort-DeAguiar R, Lacadie C, Dzuira J, Sherwin RS, Sinha R. Circulating glucose levels modulate neural control of desire for high-calorie foods in humans. J Clin Invest 2011;121(10):4161-9.

19. Lang PJ. The emotion probe. Studies of motivation and attention. Am Psycho/1995;50(5):372-85.

20. Neto LL, Oliveira E, Correia F, Ferreira AG. The human nucleus accumbens: where is it? A stereotactic, anatomical and magnetic resonance imaging study. Neuromodulation 2008;11(1):13-22.

21. Stunkard AJ, Messick S. The three-factor eating questionnaire to measure dietary restraint, disinhibition and hunger. J Psychosom Res 1985;29(1):71-83.

22. Baecke JA, Burema J, Frijters JE. A short questionnaire for the measurement of habitual physical activity in epidemiological studies. Am J Clin Nutr 1982;36(5):936-42.

23. Jastreboff AM, Sinha R, Small DM, Sherwin RS, Potenza MN. Neural correlates of stress- and food cueinduced food craving in obesity: association with insulin levels. Diabetes Care 2013;36(2):394-402.

24. Koob GF, Volkow ND. Neurocircuitry of addiction. Neuropsychopharmacology 2010;35(1):217-38. 
25. Figlewicz DP. Adiposity signals and food reward: expanding the CNS roles of insulin and leptin. Am $J$ Physiol Regul Integr Comp Physiol2003;284(4):R882-92.

26. Caravaggio F, Borlido C, Hahn M, Feng Z, Fervaha G, Gerretsen P, Nakajima S, Plitman E, Chung JK, Iwata Y, et al. Reduced insulin sensitivity is related to less endogenous dopamine at D2/3 receptors in the ventral striatum of healthy nonobese humans. Int J Neuropsychopharmaco/ 2015;18(7):pyv014.

27. Dunn JP, Kessler RM, Feurer ID, Volkow ND, Patterson BW, Ansari MS, Li R, Marks-Shulman P, Abumrad NN. Relationship of dopamine type 2 receptor binding potential with fasting neuroendocrine hormones and insulin sensitivity in human obesity. Diabetes Care 2012;35(5):1105-11.

28. Carvelli L, Moron JA, Kahlig KM, Ferrer JV, Sen N, Lechleiter JD, Leeb-Lundberg LM, Merrill G, Lafer EM, Ballou LM, et al. PI 3-kinase regulation of dopamine uptake. J Neurochem 2002;81(4):859-69.

29. Mebel DM, Wong JC, Dong YJ, Borgland SL. Insulin in the ventral tegmental area reduces hedonic feeding and suppresses dopamine concentration via increased reuptake. Eur J Neuroscience 2012;36(3):2336-46.

30. Labouebe G, Liu S, Dias C, Zou H, Wong JC, Karunakaran S, Clee SM, Phillips AG, Boutrel B, Borgland SL. Insulin induces long-term depression of ventral tegmental area dopamine neurons via endocannabinoids. Nat Neurosci2013;16(3):300-8.

31. Belfort-DeAguiar R, Seo D, Naik S, Hwang J, Lacadie C, Schmidt C, Constable RT, Sinha R, Sherwin R. Food image-induced brain activation is not diminished by insulin infusion. Inter J Obes 2016;40(11):1679-86.

32. Kullmann S, Heni M, Veit R, Scheffler K, Machann J, Haring HU, Fritsche A, Preiss $H$. Selective insulin resistance in homeostatic and cognitive control brain areas in overweight and obese adults. Diabetes Care 2015;38(6):1044-50.

33. Kroemer NB, Krebs L, Kobiella A, Grimm O, Vollstadt-Klein S, Wolfensteller U, Kling R, Bidlingmaier M, Zimmermann US, Smolka MN. (Still) longing for food: insulin reactivity modulates response to food pictures. Hum Brain Mapp 2013;34(10):2367-80.

34. Van Vugt DA, Krzemien A, Alsaadi H, Frank TC, Reid RL. Glucose-induced inhibition of the appetitive brain response to visual food cues in polycystic ovary syndrome patients. Brain Res 2014;1558:44-56.

35. Alsaadi HM, Van Vugt DA. Insulin sensitivity affects corticolimbic brain responses to visual food cues in polycystic ovary syndrome patients. Hormone molecular biology and clinical investigation 2015;24(2):10115.

36. Cornier MA, Melanson EL, Salzberg AK, Bechtell JL, Tregellas JR. The effects of exercise on the neuronal response to food cues. Physiol Behav 2012;105(4):1028-34.

37. Oppert JM, Thomas F, Charles MA, Benetos A, Basdevant A, Simon C. Leisure-time and occupational physical activity in relation to cardiovascular risk factors and eating habits in French adults. Public Health Nutr 2006;9(6):746-54.

38. Mannucci E, Tesi F, Ricca V, Pierazzuoli E, Barciulli E, Moretti S, Di Bernardo M, Travaglini R, Carrara S, Zucchi T, et al. Eating behavior in obese patients with and without type 2 diabetes mellitus. Inter J Obes Relat Metab 2002;26(6):848-53.

39. Lemmens SG, Born JM, Rutters F, Schoffelen PF, Wouters L, Westerterp-Plantenga MS. Dietary restraint and control over "wanting" following consumption of "forbidden" food. Obesity (Silver Spring) 2010;18(10):1926-31.

40. Mahmood OM, Goldenberg D, Thayer R, Migliorini R, Simmons AN, Tapert SF. Adolescents' fMRI activation to a response inhibition task predicts future substance use. Addict Behav 2013;38(1):1435-41.

41. Yousuf M, Heldmann M, Gottlich M, Munte TF, Donamayor N. Neural processing of food and monetary rewards is modulated by metabolic state. Brain Imaging Behav 2017.

42. Kroemer NB, Sun X, Veldhuizen MG, Babbs AE, de Araujo IE, Small DM. Weighing the evidence: Variance in brain responses to milkshake receipt is predictive of eating behavior. NeuroImage 2016;128:273-83.

43. Macoveanu J, Henningsson S, Jensen P, Knudsen GM, Frokjaer VG, Siebner HR. Sex-Steroid Hormone Manipulation Reduces Brain Response to Reward. Neuropsychopharmacology 2016;41(4):1057-65.

44. Van Vugt DA. Brain imaging studies of appetite in the context of obesity and the menstrual cycle. Hum Reprod Update 2010;16(3):276-92.

45. Dreher JC, Schmidt PJ, Kohn P, Furman D, Rubinow D, Berman KF. Menstrual cycle phase modulates reward-related neural function in women. Proc Natl Acad Sci U S A 2007;104(7):2465-70. 
SUPPLEMENTAL FIGURE 1. Participant flowchart
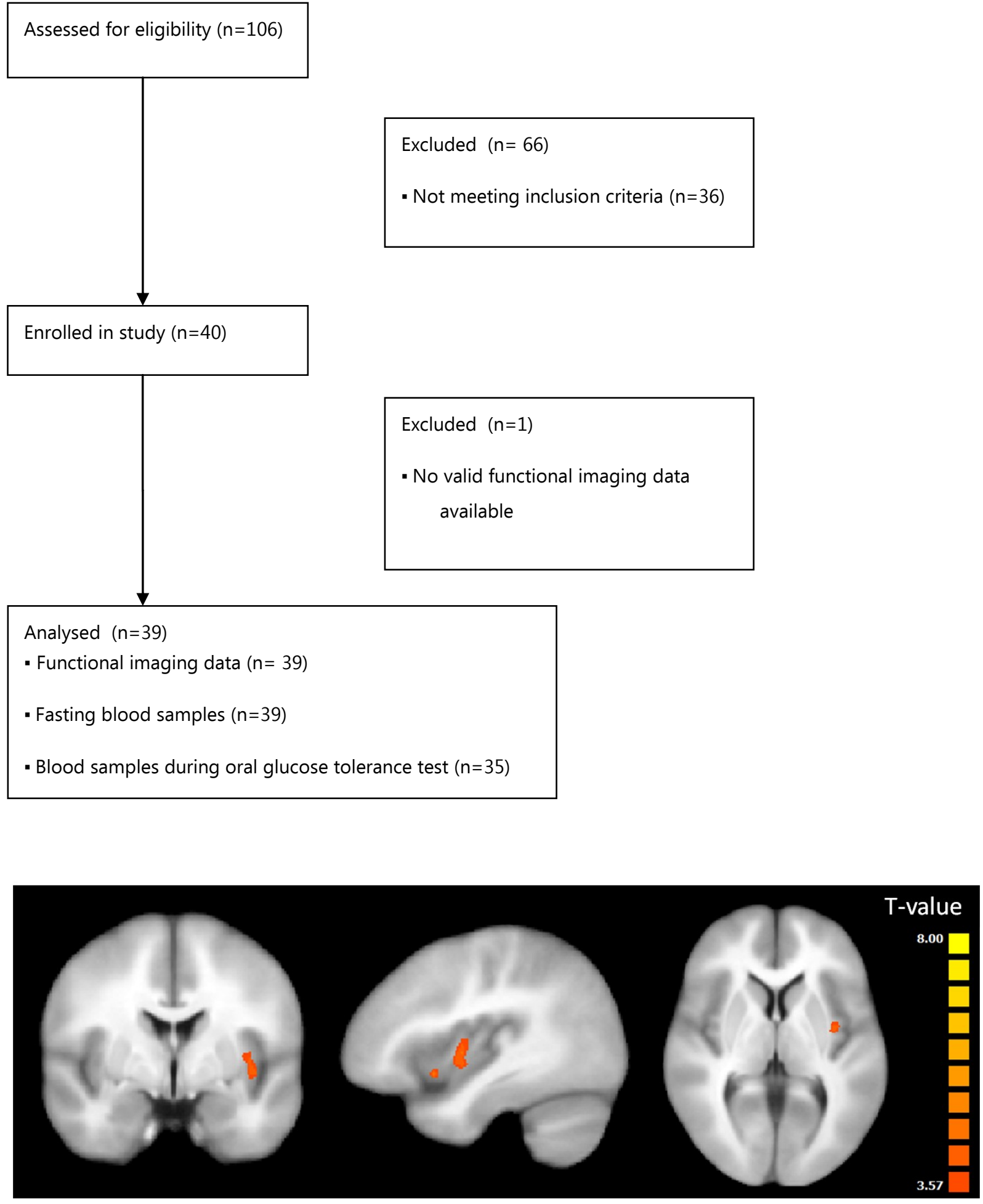

SUPPLEMENTAL FIGURE 2. Visual representation of neural response to food $>$ non-food images. Increased brain response to food images compared to non-food images is shown in orange $(T>3.57)$. 

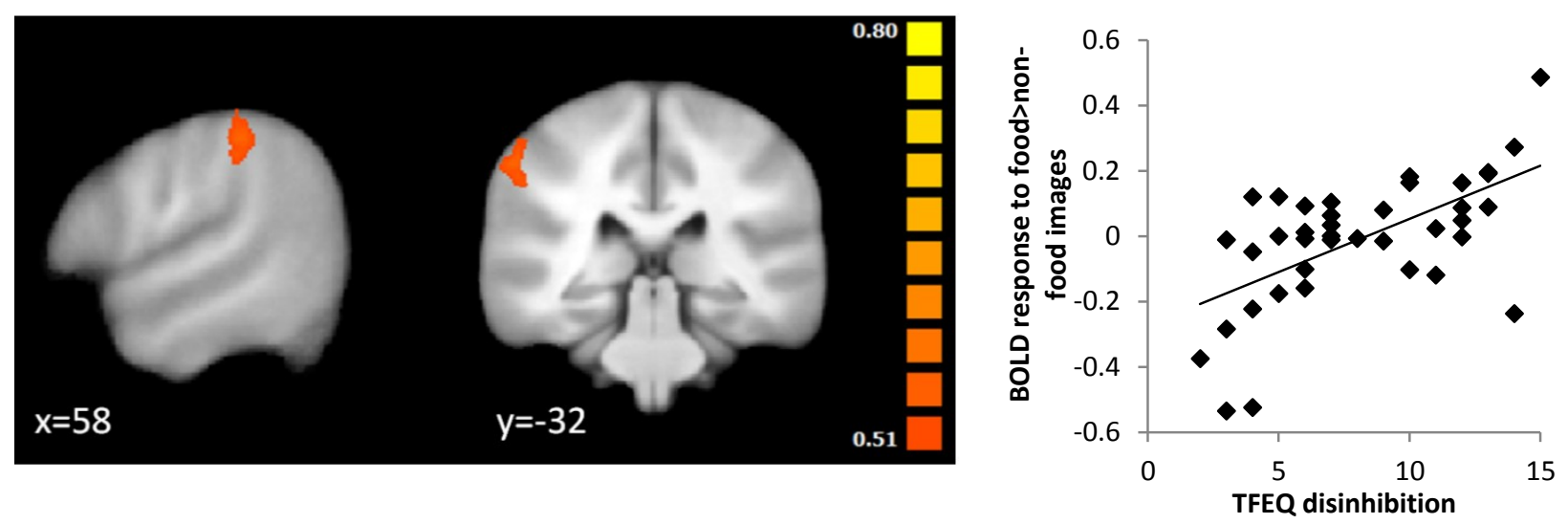

SUPPLEMENTAL FIGURE 3. Whole brain correlation map. Brain region with positive association between food reward-related brain activation and TFEQ disinhibition is shown in orange $(r=0.55$; $\mathrm{P}<0.005$, corrected for multiple comparisons). The scatter plot of TFEQ disinhibition and extracted food $>$ non-food BOLD response is shown on the right.

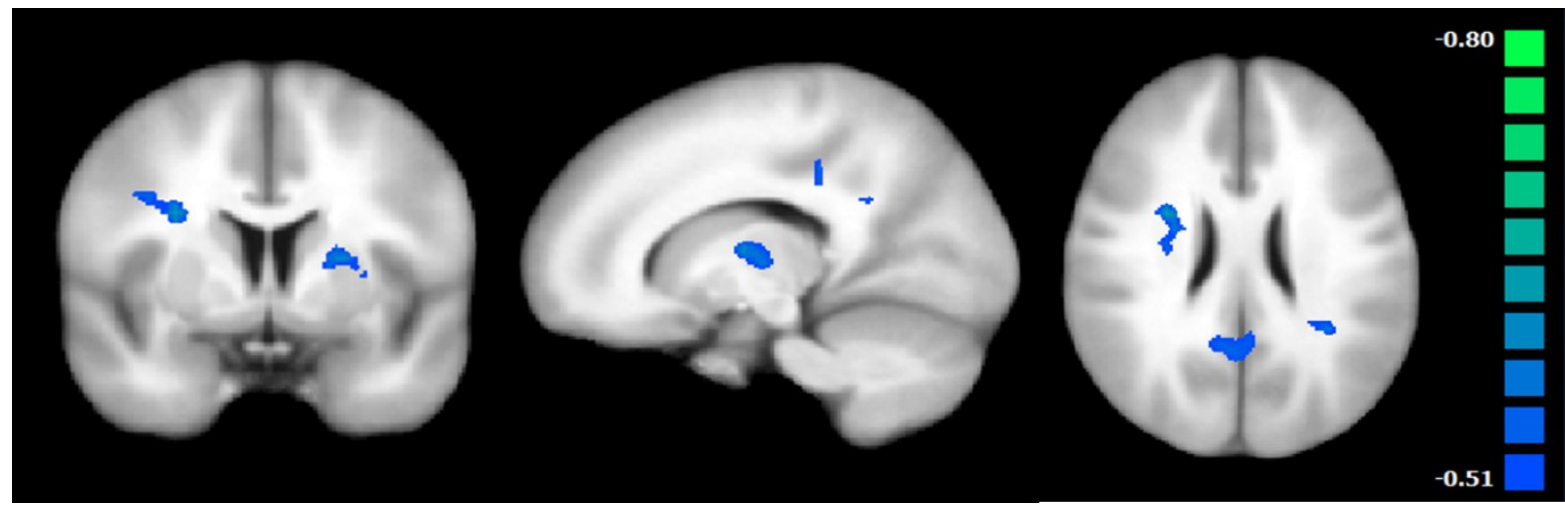

SUPPLEMENTAL FIGURE 4. Whole brain correlation map. Brain regions with significant inverse associations between food reward-related brain activation and Baecke leisure index are shown in blue ( $r=0.55 ; \mathrm{P}<0.005$, corrected for multiple comparisons).
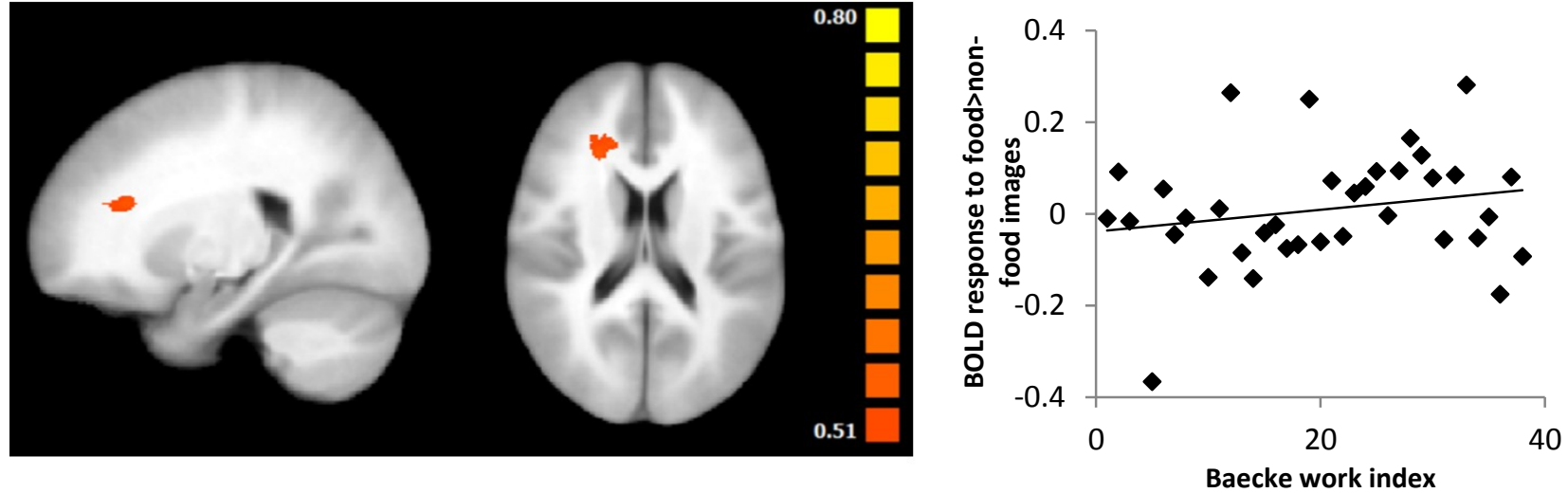

SUPPLEMENTAL FIGURE 5. Whole brain correlation map. Brain region with significant positive associations between food reward-related brain activation and Baecke sport index is shown in orange ( $r=0.55 ; \mathrm{P}<0.005$, corrected for multiple comparisons). 


\section{CHAPTER 6}

Men and women respond differently to rapid weight loss: Metabolic outcomes of a multi-centre intervention study after a low-energy diet in 2500 overweight individuals with pre-diabetes (PREVIEW)

P. Christensen, T. Meinert Larsen, M. Westerterp-Plantenga, I.Macdonald, J. Alfredo Martinez, S. Handjiev, S. Poppitt, S. Hansen, C. Ritz, A. Astrup, L. Pastor-Sanz, F. Sandø-Pedersen, K. H. Pietiläinen, J. Sundvall, M. Drummen, M. Taylor, S. NavasCarretero, T. Handjieva-Darlenska, S. Brodie, M. P. Silvestre, M. Huttunen-Lenz, J. Brand-Miller, M. Fogelholm and A. Raben

Published in:

Diabetes, Obesity and Metabolism (2018) 


\section{ABSTRACT}

\section{Aims}

The PREVIEW lifestyle intervention study is to date the largest, multinational study for type-2 diabetes prevention. We hypothesized that the initial, fixed low-energy diet (LED) would induce different metabolic outcomes in men vs women.

\section{Materials and methods}

All participants followed a LED [3.4 MJ/810 kcal/daily] for 8 weeks (Cambridge Weight Plan $®$ ). Participants were recruited from eight sites in Europe, Australia, and New Zealand. Those eligible for inclusion were overweight (BMI $\geq 25 \mathrm{~kg} / \mathrm{m}^{2}$ ) individuals with pre-diabetes according to ADA-criteria. Outcomes of interest included changes in insulin resistance, fat mass, fat-free mass and metabolic syndrome Z-score.

\section{Results}

In total, 2,224 (1,504 women; 720 men) individuals attended the baseline visit and 2,020 (90.8\%) completed the follow-up visit. Following the LED, weight loss was $16 \%$ greater in men than women (11.8\% vs $10.3 \%$ respectively) but improvements in insulin resistance were similar. HOMA-IR decreased by $1.50 \pm 0.15$ in men and $1.35 \pm 0.15$ in women (ns). After adjusting for differences in weight loss, men had larger reductions in metabolic syndrome Z-score, C-peptide, fat mass and heart rate, whilst women had larger reductions in HDL-cholesterol, fat free mass (FFM), hip circumference and pulse pressure. Following the LED, 35\% of the participants of both genders had reverted to normo-glycaemia.

\section{Conclusions:}

An 8-week LED induced different effects in women than men. These findings are clinically important and suggest gender-specific changes after weight loss. It is of importance to investigate whether the greater falls in FFM, hip circumference and HDL-cholesterol in women after rapid weight loss compromise weight loss maintenance and future cardiovascular health. 


\section{INTRODUCTION}

Type 2 diabetes mellitus is one of the fastest growing chronic diseases worldwide (1). We are aware of the major risk factors, including being overweight or obese, and know that achieving weight loss 'prevents diabetes' in the sense that onset of new cases is delayed. The most recent paper exploring the dose-response effect of weight loss shows that more than $4.3 \%$ weight loss is needed to prevent diabetes, for 3 years, in Japanese men (2). The PREVIEW intervention study (PREVention of diabetes through lifestyle Intervention and population studies in Europe and around the World; www.previewstudy.com) is to date the largest, multinational study which aims to prevent type 2 diabetes in overweight individuals with pre-diabetes. Diet and physical activity are utilized with changes being reinforced by behavior modification techniques (3). The study is an ongoing 3-year multicenter, 2-by-2 factorial, randomized controlled trial, in which eligible adult participants initially followed an 8-week low-energy diet (LED). The aim was to induce a weight loss of at least $8 \%$, in order to qualify for inclusion in the randomized intervention, where the focus is on long-term weight loss maintenance (4).

The majority of individuals who use weight loss programmes, including bariatric surgery, are women $(5,6)$. Investigating whether there are differences in outcomes between men and women is of importance in order to develop gender-specific treatment programmes, if required (6-12). Differences in outcomes after weight loss have been reported previously with men commonly losing more body weight and fat than women (13). This difference is mainly due to the concept of LED's. Thus, a fixed daily energy intake is provided to both genders, despite men and women having significantly different energy requirements due to men characteristically having a greater body mass. Notably however, during weight loss, men may mobilize more intra-abdominal fat than women, whereas women may lose more subcutaneous fat $(14,15)$. The greater reduction in intra-abdominal fat in men is accompanied by a more pronounced improvement in the metabolic risk profile. Therefore, greater improvement of risk factors in men is not only related to a greater negative energy balance, but also to a gender-specific effect $(16,17)$.

Of interest are the differences in glycaemia between overweight men and women. The prevalence of pre-diabetes has been reported to be significantly higher in men than in women (18). Impaired fasting glucose (IFG), which is indicative of hepatic insulin resistance (IR), is also more common in men (typically 1.5-3 times higher) (19). Conversely, the prevalence of impaired glucose tolerance (IGT), which is indicative of skeletal muscle IR, has been reported to be higher in women than men in almost all age groups (16).

In this study, we aimed to compare the effects of an 8 week LED-induced weight loss on metabolic outcomes in a large group of men and women. The study included data from adult participants aged 25-70 years who were enrolled into the PREVIEW diabetes prevention study. 


\section{MATERIALS AND METHODS}

Adult participants were recruited to the PREVIEW study between August 2013 and March 2015 from eight different intervention sites. The study sites were University of Copenhagen (UCPH), Denmark; University of Helsinki (HEL), Finland; University of Nottingham (UNOTT), United Kingdom; University of Maastricht (UM), The Netherlands; University of Navarra (UNAV), Spain; Medical University of Sofia (MU), Bulgaria; University of Auckland (UOA), New Zealand and University of Sydney (UNSYD), Australia. Overweight men and women with pre-diabetes were eligible for inclusion. Participants were recruited by advertisements in newspapers, newsletters, radio and television advertisements/interviews, and by contacting primary and occupational health care providers. Interested individuals were pre-screened for eligibility by using the Finnish Diabetes Risk Score $(20,21)$ as well as the inclusion and exclusion criteria listed in the Online Supplemental Materiel (Appendix 1). Potentially eligible participants were then invited to an information meeting, where written and oral information was provided. Before continuing to the laboratory screening session, written informed consent was obtained. Criteria for assessing pre-diabetes were those recommended by the American Diabetes Association (ADA) (22), namely: fasting venous plasma glucose concentration 5.6 - $6.9 \mathrm{mmol} / \mathrm{l}$ (IFG) and/or venous plasma glucose concentration of 7.8 - 11.0 $\mathrm{mmol} / \mathrm{l}$ at $2 \mathrm{~h}$ (IGT) after oral administration of $75 \mathrm{~g}$ glucose at an oral glucose tolerance test (OGTT), with fasting plasma glucose (FPG) less than $7.0 \mathrm{mmol} / \mathrm{l}$. $\mathrm{HbA}_{1 \mathrm{c}}$ was not used to determine eligibility. Other inclusion criteria for adult participants were 25-70 years of age and body mass index (BMI) $\geq$ $25 \mathrm{~kg} / \mathrm{m}^{2}$. Prior to screening and recruitment, the study protocol was approved by the Ethical Committees of the participating countries. The PREVIEW study is registered at clinicaltrials.gov with Identifier: [NCT01777893].

\section{Interventions}

The PREVIEW study comprises of two intervention phases. Phase 1 is an 8 week, weight loss phase using a formula LED (3.4 MJ/day) intended to induce weight loss of $\geq 8 \%$ in order to qualify for the next phase. The second phase of the study is an ongoing 148-week randomised lifestyle intervention which focuses on diet, physical activity and behaviour modification for weight loss maintenance. The LED was implemented by using a range of Cambridge Weight Plan ${ }^{\circledR}$ (Northants, UK) formula products. All intervention sites used the standard assortment from the Cambridge Weight Plan that was available in the United Kingdom, to ensure that the nutritional content of the sachets were identical. The sachets were provided to the participants without any charge and included soups, shakes and porridges. The participants were instructed to consume four sachets $(4 \times 40 \mathrm{~g})$ per day. Of these, 3 sachets were to be dissolved in milk $(3 \times 250 \mathrm{ml} \mathrm{low}$ fat milk = total $750 \mathrm{ml} / \mathrm{day})$ and 1 sachet in $250 \mathrm{ml}$ of water. The fat content of the milk was $\leq 0.5 \mathrm{~g} / 100 \mathrm{ml}$ and the energy content $\leq 170 \mathrm{~kJ}$ (40 kcal)/100 ml. Participants with a BMI $>40 \mathrm{~kg} / \mathrm{m}^{2}$ were encouraged to dissolve all 4 sachets in milk in order to increase the intake of protein. In total, the LED provided an estimated 3.4 $\mathrm{MJ} /$ day $(810 \mathrm{kcal} /$ day), $\sim 85 \mathrm{~g}$ of protein, $\sim 5 \mathrm{~g}$ of essential fatty acids and the daily requirement for vitamins and minerals $(23,24)$. 
The macronutrient composition was as follows: 43.7 total energy \% from protein, 41.2 total energy \% from carbohydrate and 15.1 total energy \% from fat. The fiber content of the LED was relatively low at $13.3 \mathrm{~g} /$ day. In order to avoid any gastrointestinal side effects, the participants were recommended to use psyllium fibers and to drink sufficient water to remain hydrated. In addition to the sachets and milk, the participants were permitted to consume $375 \mathrm{~g}$ of low-starch vegetables, such as tomatoes, cucumber and lettuce per day. Replacement of these additional foods by alternatives was not permitted. During the LED intervention, participants attended group visits at the intervention sites at weeks 2, 4, 6 and 8, where they were guided in the use of the LED by experienced dietitians or counsellors. Further information about the LED is available in the Online Supplemental Material (Appendix 2).

\section{Outcomes}

All outcomes were measured before and after the 8 weeks intervention at clinical investigation days (CIDs), which participants attended in the fasting state (10-12 hours). The main outcome of interest in this analysis was change in insulin resistance (IR) calculated by the Homeostasis Model for Assessment (HOMA). The equation used was (FSI * FPG)/22.5, where FSI is fasting serum insulin concentration ( $\mathrm{mU} / \mathrm{l})$ and $\mathrm{FPG}$ is fasting plasma glucose (mmol/l) (25). Other outcomes included were changes in FPG, hemoglobin A1c ( $\mathrm{HbA1c}$ ), fasting insulin, $\mathrm{C}$-peptide, total-, high density lipoprotein $(\mathrm{HDL})$ - and low density lipoprotein (LDL)-cholesterol, triglycerides (TG), C-reactive protein (CRP) and liver enzymes, alanine aminotransferase (ALT) and aspartate aminotransferase (AST).

The blood samples were drawn from the antecubital vein. Serum and whole blood samples were initially stored at $-80^{\circ} \mathrm{C}$ at the individual intervention sites, after which they were transported to a laboratory in Finland for central batch analyses (National Institute for Health and Welfare, Helsinki, Finland). Laboratory measurements were performed on Architect ci8200 integrated system (Abbott Laboratories, Abbott Park, IL, USA). The laboratory (T077) has been accredited by the Finnish Accreditation Service and fulfils the requirements of the standard SFS-EN ISO/IEC 17025:2005. The scope of accreditation covers all analyses except AST and C-Peptide. Other outcomes were change in body weight, measured in the fasting state, with an empty bladder and wearing underwear (or other light clothing). Two measurements were taken to the nearest $0.1 \mathrm{~kg}$ and the mean calculated. For measurement of height, the participants were required to remove shoes, and stand with their heels, buttocks and upper part of the back in contact with a wall-mounted stadiometer. Height was measured to the nearest $0.5 \mathrm{~cm}$ and the mean of two measurements was calculated. Waist-, hip- and thigh circumference were measured to the nearest $0.5 \mathrm{~cm}$ with a non-stretch tape with the participant standing. Two measurements were recorded and the mean was calculated. Waist circumference (WC) was measured midway between the bottom of the rib cage (last floating rib) and the top of the iliac crest, at the end of expiration. Hip circumference was measured at the widest point between the hips and buttocks, following the same directions as for the waist measurement. Mid-thigh circumference was measured on the right side of the body. The measuring tape was placed horizontally around the thigh at midway between the midpoint of the inguinal crease and the proximal border of the patella. 
Measurements of body composition were performed by different methods at the intervention sites (see Appendix 3). Fertile women were tested for pregnancy before DXA. The outcomes of interest were fat mass (FM), fat free mass (FFM), bone mineral content (BMC) and bone mineral density (BMD).

Systolic (SBP) and diastolic blood pressure (DBP) and heart rate were measured using a validated automatic device on the right arm after 5-10 min in a resting position. The measurements were performed three times with a 1 minute rest between each recording and mean value was reported. Pulse pressure was calculated by using the formula SBP minus DBP. Mean arterial pressure (MAP) was calculated by using the formula $0.42 \times \mathrm{SBP}+0.58 \times \mathrm{DBP}(26)$.

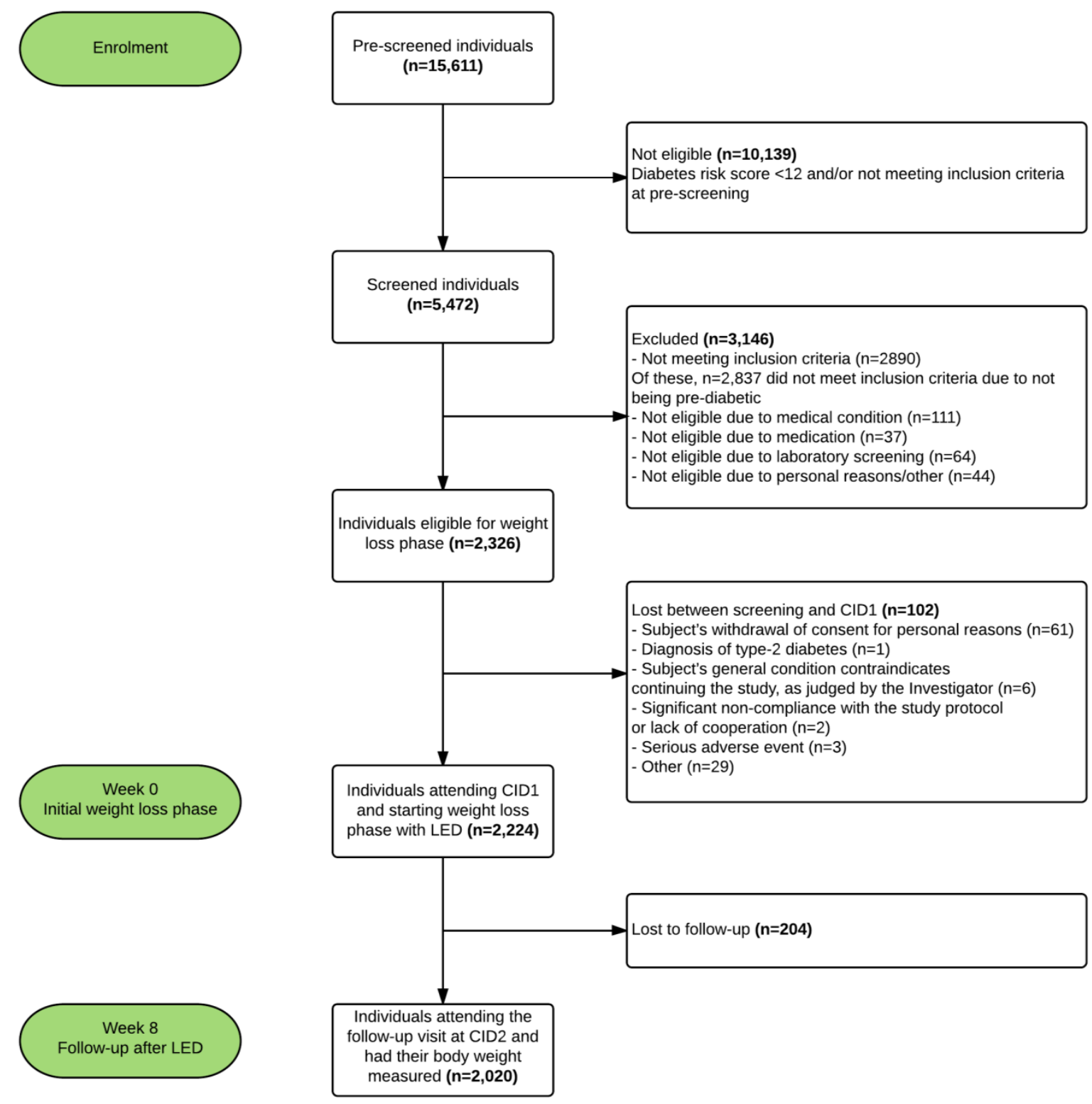

FIGURE 1. Trial flow chart. Pre-screening, screening, individuals starting initial weight-loss phase and follow-up of study participants. 
The metabolic syndrome (MS) was evaluated using a MS Z-score, which is a continuous score of the 5 MS variables as reported previously (27). Gender-specific Z-scores were used to account for variations in the criterion between men and women. The equations used were: MS Z-score = [(50$\mathrm{HDL}) / 14.1]+[(\mathrm{TG}-150) / 81.0]+[(\mathrm{FPG}-100) / 11.3]+[(\mathrm{WC}-88) / 9.0]+[(\mathrm{MAP}-100) / 9.1]$ for women, and Z-score $=[(40-H D L) / 9.0]+[(T G-150) / 81.0]+[(F P G-100) / 11.3]+[(W C-102) / 7.7]+[(M A P-100) / 9.1]$ for men (27).

At all visits to the intervention sites, the participants were asked whether they had experienced any adverse events. Any such adverse event (AE) was noted on a related AE form, which captured onset, end, intensity, causality, action taken and outcome of the AE.

\section{Statistical methods}

Descriptive characteristics at CID1 and CID2 are summarized as mean \pm SD. Differences between men and women were analyzed using a linear mixed model including intervention site as random effect. The estimate of mean difference at baseline is presented as mean \pm SEM. All analyses were carried out as complete-case analyses, (i.e., data from all participants that attended both baseline visit (CID1) and the visit at week 8 (CID2), independent of the amount of weight loss). Count data, such as number of participants dropping out or achieving a successful weight loss were analysed for group differences by simple $2 \times 2$ contingency tables and Chi-square. For continuous outcomes, the mean gender difference was estimated using ANCOVA-type linear mixed models, adjusting for fixed effects of baseline, age, and including centers as random effects. As the weight loss intervention provided $3.4 \mathrm{MJ} /$ day $(810 \mathrm{kcal} /$ day), we anticipated that men would experience a larger energy deficit than women during the intervention, and therefor lose more weight. In order to adjust for weight loss difference between men and women, the same ANCOVA-type linear model was applied for all outcome variables, whilst adjusting for weight loss percentage (\%) as well. All statistical analyses and calculations were performed with the statistical program " $R$ - version 3.3.2" and "RStudio - version 0.98.1028". A p-value of $<0.05$ was considered significant.

\section{RESULTS}

The flow of participants is shown in the Flow Chart FIGURE 1. A total of, 2,224 individuals $(1,504$ women; 720 men) participated in the baseline visit (CID1) and began the LED phase. The majority of participants described themselves as Caucasians $(1.949 ; 87.6 \%)$, whereas the remainder were Polynesians (92; 4.1\%), Asians (59; 2.7\%), Hispanics (44; 2.0\%) and Black (38; 1.7\%). A total of 42 (1.9\%) were classified as "other", where most were of mixed origin. On average, the age of the included individuals was $51.6 \pm 11.6$ years, body weight $100.1 \pm 21.4 \mathrm{~kg}$, BMI $35.4 \pm 6.6 \mathrm{~kg} / \mathrm{m}^{2}$ HOMA-IR $3.75 \pm 2.43$, and FPG $6.2 \pm 0.7 \mathrm{mmol} / \mathrm{L}$. Baseline characteristics are shown in TABLE 1.

Changes after the LED are shown in TABLE 2. A total of 2,020 participants attended the CID2 visit, with a dropout rate during the 8 weeks of 9.2\% (204 participants; 152 women; 52 men). The proportion of dropouts varied amongst the centers (UCPH: 2.5\%, HEL: 5.8\%, UM: 7.4\%, UNAV: 9.0\%, UNSYD: $10.1 \%$, MU: $12.1 \%$, UOA: $12.7 \%$, UNOTT: $14.4 \%)$. 
TABLE 1. Anthropometrical, metabolic and clinical characteristics of the participants at the baseline visit (CID1) and following 8 weeks (CID2).

\begin{tabular}{|c|c|c|c|c|c|c|c|c|}
\hline Variable & CID1 - all $(\mathrm{N}=2,224)$ & $\begin{array}{l}\text { CID1 - } \\
\text { women } \\
(\mathrm{N}=1,504)\end{array}$ & $\begin{array}{l}\text { CID1 - men } \\
(\mathrm{N}=720)\end{array}$ & $\begin{array}{l}\text { Mean difference } \\
\text { between men and } \\
\text { women }^{\text {a }}\end{array}$ & $\begin{array}{l}\text { CID2 - all } \\
(\mathrm{N}=2,020)\end{array}$ & $\begin{array}{l}\text { CID2 - } \\
\text { women } \\
(\mathrm{N}=1,352)\end{array}$ & $\begin{array}{l}\text { CID2 - men } \\
(\mathrm{N}=668)\end{array}$ & $\begin{array}{l}\text { Mean difference } \\
\text { between men anc } \\
\text { women }^{\text {a }}\end{array}$ \\
\hline Age, years & $51.6 \pm 11.6(25.0-70.0)$ & $51.0 \pm 11.6$ & $52.9 \pm 11.6$ & $1.1 \pm 0.5$ & - & - & - & - \\
\hline Weight, kg & $100.1 \pm 21.4(58.4-238.0)$ & $95.6 \pm 19.8$ & $109.4 \pm 21.6$ & $14.9 \pm 0.9 * \star *$ & $88.9 \pm 19.2$ & $85.2 \pm 17.5$ & $96.4 \pm 20.2$ & $12.3 \pm 0.8^{* * *}$ \\
\hline Height, $\mathrm{cm}$ & $168.0 \pm 9.4(139.0-198.0)$ & $163.5 \pm 6.7$ & $177.4 \pm 6.9$ & $13.7 \pm 2.9^{* \star *}$ & - & - & - & - \\
\hline $\mathrm{BMI}, \mathrm{kg} / \mathrm{m}^{2}$ & $35.4 \pm 6.6(24.7-77.3)$ & $35.7 \pm 6.7$ & $34.7 \pm 6.3$ & $-0.5 \pm 0.3$ & $31.4 \pm 6.0$ & $31.8 \pm 6.0$ & $30.6 \pm 5.9$ & $-0.8 \pm 0.3^{* *}$ \\
\hline \multicolumn{9}{|l|}{ Primary outcome } \\
\hline HOMA-IR & $3.75 \pm 2.43(0.23-31.37)$ & $3.5 \pm 2.2$ & $4.24 \pm 2.82$ & $0.73 \pm 0.11^{\text {***}}$ & $2.28 \pm 1.61$ & $2.26 \pm 1.45$ & $2.31 \pm 1.90$ & $0.12 \pm 0.08$ \\
\hline $\begin{array}{l}\text { Secondary outcomes } \\
\text { Metabolic syndrome } \\
\text { Z-score }^{c}\end{array}$ & $2.6 \pm 3.2(-7.5-18.2)$ & $\begin{array}{l}2.4 \pm 3.2 \\
(-7.5-18.2)\end{array}$ & $\begin{array}{l}2.9 \pm 3.3 \\
(-5.9-14.0)\end{array}$ & $0.5 \pm 0.1^{\star \star \star}$ & $0.1 \pm 3.1$ & $0.4 \pm 2.9$ & $-0.6 \pm 3.3$ & $-0.9 \pm 0.1^{* * *}$ \\
\hline Fasting glucose, $\mathrm{mmol} / \mathrm{L}$ & $6.2 \pm 0.7(3.4-13.6)$ & $6.1 \pm 0.7$ & $6.3 \pm 0.7$ & $0.2 \pm 0.03^{* * *}$ & $5.8 \pm 0.6$ & $5.7 \pm 0.6$ & $5.8 \pm 0.6$ & $0.1 \pm 0.03$ \\
\hline $\mathrm{HbA} 1 \mathrm{c}, \mathrm{mmol} / \mathrm{mol}$ & $36.7 \pm 4.1(23.0-79.0)$ & $36.7 \pm 3.9$ & $36.8 \pm 4.4$ & $0.2 \pm 0.2$ & $34.6 \pm 3.4$ & $34.7 \pm 3.3$ & $34.3 \pm 3.6$ & $-0.3 \pm 0.2$ \\
\hline $\mathrm{HbA} 1 \mathrm{c}, \%$ & $5.5 \pm 0.4(4.3-9.4)$ & $5.5 \pm 0.4$ & $5.5 \pm 0.4$ & $0.02 \pm 0.02$ & $5.3 \pm 0.3$ & $5.3 \pm 0.3$ & $5.3 \pm 0.3$ & $-0.03 \pm 0.01^{\star}$ \\
\hline Insulin, mU/L & $13.5 \pm 8.0(1.0-97.5)$ & $12.8 \pm 7.4$ & $14.8 \pm 8.9$ & $2.1 \pm 0.4^{\star \star \star}$ & $8.7 \pm 5.5$ & $8.7 \pm 5.0$ & $8.8 \pm 6.4$ & $0.3 \pm 0.3$ \\
\hline C-peptide, pmol/L & $923.6 \pm 349.3(177.0-3234.0)$ & $888.8 \pm 328.2$ & $996.3 \pm 379.7$ & $115.1 \pm 15.7^{\star \star \star}$ & $706.6 \pm 302.4$ & $713.4 \pm 290.1$ & $693.0 \pm 325.3$ & $-7.9 \pm 14.0$ \\
\hline Total Cholesterol, mmol/L & $5.2 \pm 1.0(2.0-10.3)$ & $5.3 \pm 1.0$ & $5.0 \pm 1.0$ & $-0.2 \pm 0.04^{\star * *}$ & $4.3 \pm 1.0$ & $4.4 \pm 0.9$ & $4.1 \pm 1.0$ & $-0.3 \pm 0.04^{\star * *}$ \\
\hline LDL Cholesterol, mmol/L & $3.2 \pm 0.8(0.7-7.2)$ & $3.3 \pm 0.8$ & $3.2 \pm 0.9$ & $-0.1 \pm 0.04^{\star *}$ & $2.6 \pm 0.8$ & $2.7 \pm 0.8$ & $2.5 \pm 0.8$ & $-0.2 \pm 0.04^{* * *}$ \\
\hline HDL Cholesterol, mmol/L & $1.3 \pm 0.3(0.6-2.6)$ & $1.3 \pm 0.3$ & $1.1 \pm 0.2$ & $-0.2 \pm 0.01^{* * *}$ & $1.2 \pm 0.2$ & $1.2 \pm 0.2$ & $1.1 \pm 0.2$ & $-0.1 \pm 0.01^{\star * \star}$ \\
\hline Triglycerides, mmol/L & $1.5 \pm 0.8(0.23-11.5)$ & $1.4 \pm 0.8$ & $1.6 \pm 0.8$ & $0.2 \pm 0.04^{* * *}$ & $1.1 \pm 0.5$ & $1.1 \pm 0.5$ & $1.1 \pm 0.7$ & $0.03 \pm 0.02$ \\
\hline C-reactive protein, $\mathrm{mg} / \mathrm{L}$ & $5.4 \pm 7.0(0.1-144.5)$ & $5.9 \pm 7.3$ & $4.3 \pm 6.2$ & $-1.4 \pm 0.3^{* \star \star}$ & $4.4 \pm 6.4$ & $4.5 \pm 6.0$ & $4.1 \pm 7.1$ & $-0.3 \pm 0.3$ \\
\hline ALT, U/L & $27.9 \pm 16.3(6.0-182.0)$ & $25.1 \pm 13.9$ & $33.8 \pm 19.2$ & $9.6 \pm 0.7^{\star \star *}$ & $35.7 \pm 26.9$ & $36.7 \pm 28.9$ & $33.6 \pm 22.1$ & $-3.3 \pm 1.3^{*}$ \\
\hline AST, U/L & $27.7 \pm 10.7(10.0-140.0)$ & $26.4 \pm 9.8$ & $30.5 \pm 11.9$ & $4.4 \pm 0.5^{* \star *}$ & $28.6 \pm 13.0$ & $28.5 \pm 14.2$ & $28.7 \pm 10.2$ & $0.01 \pm 0.6$ \\
\hline
\end{tabular}


TABLE 1. continued

\begin{tabular}{|c|c|c|c|c|c|c|c|c|}
\hline Variable & CID1 - all (N = 2,224) & $\begin{array}{l}\text { CID1 - women } \\
(\mathrm{N}=1,504)\end{array}$ & $\begin{array}{l}\text { CID1 - men } \\
(\mathrm{N}=720)\end{array}$ & $\begin{array}{l}\text { Mean difference } \\
\text { between men } \\
\text { and women }{ }^{a}\end{array}$ & $\begin{array}{l}\text { CID2 - all } \\
(\mathrm{N}=2,020)\end{array}$ & $\begin{array}{l}\text { CID2 - } \\
\text { women } \\
(\mathrm{N}=1,352)\end{array}$ & $\begin{array}{l}\text { CID2 - men } \\
(\mathrm{N}=668)\end{array}$ & $\begin{array}{l}\text { Mean difference } \\
\text { between men and } \\
\text { women }^{\text {a }}\end{array}$ \\
\hline \multicolumn{9}{|c|}{ Anthropometry, body composition and blood pressure } \\
\hline Waist circumference, cm & $110.4 \pm 14.7(71.0-210.0)$ & $107.5 \pm 14.0$ & $116.7 \pm 14.3$ & $9.8 \pm 0.6^{* * *}$ & $100.6 \pm 13.7$ & $98.2 \pm 13.0$ & $105.3 \pm 13.8$ & $7.5 \pm 0.6^{\star * *}$ \\
\hline Hip circumference, cm & $118.5 \pm 13.8(80.5-202.0)$ & $120.5 \pm 14.1$ & $114.2 \pm 12.1$ & $-5.5 \pm 0.6^{* * *}$ & $110.9 \pm 12.7$ & $112.7 \pm 13.0$ & $107.1 \pm 11.2$ & $-4.8 \pm 0.6^{\star * *}$ \\
\hline Thigh circumference, cm & $60.4 \pm 7.3(40.5-99.0)$ & $61.0 \pm 7.6$ & $59.1 \pm 6.6$ & $-1.8 \pm 0.3^{* * *}$ & $56.6 \pm 6.6$ & $57.1 \pm 6.9$ & $55.5 \pm 5.9$ & $-1.7 \pm 0.3^{* \star *}$ \\
\hline Fat free mass, kg & $56.5 \pm 12.0(32.8-138.4)$ & $50.8 \pm 7.7$ & $68.6 \pm 10.3$ & $18.7 \pm 0.4^{* \star \star}$ & $53.6 \pm 11.1$ & $48.1 \pm 6.9$ & $65.0 \pm 9.4$ & $17.7 \pm 0.4^{* * *}$ \\
\hline Fat mass, kg & $43.0 \pm 13.7(7.7-128.3)$ & $44.3 \pm 13.1$ & $40.3 \pm 14.4$ & $-3.7 \pm 0.6^{* * *}$ & $34.7 \pm 12.9$ & $36.7 \pm 12.2$ & $30.7 \pm 13.5$ & $-5.5 \pm 0.6^{\star * *}$ \\
\hline Fat \% & $43.3 \pm 7.6(11.1-61.3)$ & $46.4 \pm 5.8$ & $36.8 \pm 6.6$ & $-10.0 \pm 0.3^{* * *}$ & $39.3 \pm 9.0$ & $42.9 \pm 6.9$ & $31.7 \pm 8.0$ & $-11.4 \pm 0.3^{* * *}$ \\
\hline Bone mineral content, $\mathrm{g}$ & $2877 \pm 572(1442-5500)$ & $2631 \pm 399$ & $3424 \pm 518$ & $811 \pm 21^{\star \star *}$ & $2826 \pm 567$ & $2579 \pm 403$ & $3366 \pm 495$ & $793 \pm 23^{* * *}$ \\
\hline Bone mineral density, $\mathrm{g} / \mathrm{cm}^{2}$ & $1.3 \pm 0.1(0.9-1.7)$ & $1.2 \pm 0.1$ & $1.3 \pm 0.1$ & $0.09 \pm 0.007^{\star \star \star}$ & $1.3 \pm 0.1$ & $1.2 \pm 0.1$ & $1.3 \pm 0.1$ & $0.1 \pm 0.007^{\star \star *}$ \\
\hline $\mathrm{SBP}, \mathrm{mmHg}$ & $129.1 \pm 15.9$ (80.7- 85.3) & $127.1 \pm 16.0$ & $133.2 \pm 14.7$ & $6.0 \pm 0.7^{* * *}$ & $122.0 \pm 15.8$ & $120.8 \pm 15.7$ & $124.3 \pm 15.6$ & $3.4 \pm 0.7^{* \star *}$ \\
\hline $\mathrm{DBP}, \mathrm{mmHg}$ & $78.1 \pm 11.1(38.0-117.3)$ & $76.8 \pm 11.4$ & $80.9 \pm 9.9$ & $3.7 \pm 0.4^{\star \star *}$ & $75.0 \pm 9.9$ & $74.7 \pm 10.0$ & $75.5 \pm 9.6$ & $0.6 \pm 0.4$ \\
\hline Pulse pressure, mmHG & $50.9 \pm 12.4(19.0-100.3)$ & $50.3 \pm 12.8$ & $52.3 \pm 11.2$ & $2.3 \pm 0.5^{\star}$ & $47.0 \pm 11.4$ & $46.2 \pm 11.6$ & $48.8 \pm 10.8$ & $2.8 \pm 0.5^{\star \star \star}$ \\
\hline$M A P, m m H G^{d}$ & $99.5 \pm 11.8(56.6-137.1)$ & $97.9 \pm 12.0$ & $102.9 \pm 10.8$ & $4.6 \pm 0.5^{\text {***}}$ & $94.7 \pm 11.3$ & $94.0 \pm 11.3$ & $96.0 \pm 11.2$ & $1.8 \pm 0.5^{\star \star \star}$ \\
\hline Heart rate, bpm & $71.3 \pm 10.6(35.0-119.3)$ & $71.9 \pm 10.3$ & $70.0 \pm 11.0$ & $-1.3 \pm 0.5^{*}$ & $65.8 \pm 10.9$ & $66.9 \pm 10.6$ & $63.6 \pm 11.2$ & $-2.3 \pm 0.5^{\star \star \star}$ \\
\hline
\end{tabular}

Abbreviations: ALT, Alanine aminotransferase; AST, Aspartate aminotransferase; BMI, Body mass index; CID, Clinical investigation day; DBP, Diastolic blood pressure; HDL, High-density lipoprotein; HOMA-IR, Homeostasis model of assessment insulin resistance; LDL, Low-density lipoprotein; MAP, Mean arterial pressure; SBP, Systolic blood pressure; SD, Standard deviation. Data for all, men and women are presented as mean \pm SD (min - max).

${ }^{a}$ For difference between men and women the estimate is mean difference \pm SEM adjusted for site; ${ }^{*} P<0.05,{ }^{* *} P<0.01,{ }^{* *} P<0.001$.

${ }^{\mathrm{b}}$ The formula to calculate the HOMA-IR was: fasting insulin $(\mathrm{mU} / \mathrm{L})$ * fasting glucose (mmol/L) / 22.5 [25].

c The metabolic syndrome was calculated as a Z score [27].

${ }^{d}$ The formula used to calculate MAP was $0.42 \times$ SBP $+0.58 \times$ DBP (26). 
TABLE 2. Changes in Anthropometry, HOMA-IR and Blood Markers in Participants meeting at the Clinical Investigation Day after the LED (CID2).

\begin{tabular}{|c|c|c|c|c|c|c|c|c|}
\hline Variable & $\begin{array}{l}\mathrm{All}^{\mathrm{a}} \\
(\mathrm{N}=2,020)\end{array}$ & P-value ${ }^{a}$ & $\begin{array}{l}\text { Women }^{\mathrm{b}} \\
(\mathrm{N}=1,352)\end{array}$ & $\begin{array}{l}\text { Men }^{b} \\
(N=668)\end{array}$ & $\begin{array}{l}\text { Mean difference } \\
\text { between men } \\
\text { and women }\end{array}$ & $P$-value ${ }^{b}$ & $\begin{array}{l}\text { Mean difference } \\
\text { between men and } \\
\text { women }^{c}\end{array}$ & P-value \\
\hline \multicolumn{9}{|l|}{ Primary outcome } \\
\hline$\Delta$ Weight, kg & $-10.7 \pm 0.4$ & $<0.001$ & $-10.2 \pm 0.4$ & $-11.8 \pm 0.5$ & $-1.6 \pm 0.1$ & $<0.001$ & - & - \\
\hline Weight loss (\%) & $10.8 \pm 3.1$ & - & $10.3 \pm 2.8$ & $11.8 \pm 3.4$ & $1.3 \pm 0.1$ & $<0.001$ & - & - \\
\hline$\Delta \mathrm{HOMA}^{-\mathrm{IR}^{\mathrm{d}}}$ & $-1.42 \pm 0.15$ & $<0.001$ & $-1.35 \pm 0.15$ & $-1.50 \pm 0.15$ & $-0.15 \pm 0.06$ & n.s. & $0.01 \pm 0.06$ & n.s. \\
\hline \multicolumn{9}{|l|}{ Secondary outcomes } \\
\hline Metabolic syndrome Z-score & $-2.5 \pm 0.2$ & $<0.001$ & $-2.1 \pm 0.2$ & $-3.4 \pm 0.2$ & $-1.3 \pm 0.1$ & $<0.001$ & $-0.9 \pm 0.1$ & $<0.001$ \\
\hline$\Delta$ Fasting glucose, $\mathrm{mmol} / \mathrm{L}$ & $-0.44 \pm 0.07$ & $<0.001$ & $-0.42 \pm 0.07$ & $-0.46 \pm 0.07$ & $-0.04 \pm 0.02$ & n.s. & $0.02 \pm 0.02$ & n.s. \\
\hline$\Delta \mathrm{HbAlc}, \mathrm{mmol} / \mathrm{mol}$ & $-2.1 \pm 0.2$ & $<0.001$ & $-1.93 \pm 0.15$ & $-2.35 \pm 0.16$ & $-0.42 \pm 0.10$ & $<0.001$ & $-0.25 \pm 0.10$ & n.s. \\
\hline$\Delta \mathrm{HbAlc}, \%$ & $-0.19 \pm 0.02$ & $<0.001$ & $-0.17 \pm 0.01$ & $-0.22 \pm 0.01$ & $-0.05 \pm 0.01$ & $<0.001$ & $-0.03 \pm 0.01$ & $<0.05$ \\
\hline$\Delta$ Insulin, mU/L & $-4.51 \pm 0.44$ & $<0.001$ & $-4.28 \pm 0.44$ & $-4.83 \pm 0.46$ & $-0.55 \pm 0.21$ & $<0.05$ & $-0.03 \pm 0.21$ & n.s. \\
\hline$\Delta$ C-peptide, pmol/L & $-210.4 \pm 18.7$ & $<0.001$ & $-183.7 \pm 22.6$ & $-259.7 \pm 23.4$ & $-76.0 \pm 10.5$ & $<0.001$ & $-48.6 \pm 10.3$ & $<0.001$ \\
\hline$\Delta$ Total Cholesterol, $\mathrm{mmol} / \mathrm{L}$ & $-0.93 \pm 0.08$ & $<0.001$ & $-0.89 \pm 0.09$ & $-1.02 \pm 0.09$ & $-0.13 \pm 0.03$ & $<0.001$ & $-0.04 \pm 0.03$ & n.s. \\
\hline$\Delta \mathrm{LDL}$ Cholesterol, mmol/L & $-0.64 \pm 0.06$ & $<0.001$ & $-0.60 \pm 0.07$ & $-0.72 \pm 0.07$ & $-0.11 \pm 0.03$ & $<0.001$ & $-0.04 \pm 0.03$ & n.s. \\
\hline$\Delta \mathrm{HDL}$ Cholesterol, $\mathrm{mmol} / \mathrm{L}$ & $-0.12 \pm 0.02$ & $<0.001$ & $-0.12 \pm 0.02$ & $-0.10 \pm 0.02$ & $0.02 \pm 0.01$ & $<0.05$ & $0.03 \pm 0.01$ & $<0.01$ \\
\hline$\Delta$ Triglycerides, $\mathrm{mmol} / \mathrm{L}$ & $-0.40 \pm 0.04$ & $<0.001$ & $-0.39 \pm 0.04$ & $-0.42 \pm 0.04$ & $-0.02 \pm 0.02$ & n.s. & $0.02 \pm 0.02$ & n.s. \\
\hline$\Delta \mathrm{C}$-reactive protein, $\mathrm{mg} / \mathrm{L}$ & $-0.89 \pm 0.17$ & $<0.001$ & $-0.97 \pm 0.27$ & $-0.77 \pm 0.31$ & $0.20 \pm 0.29$ & n.s. & $0.38 \pm 0.29$ & n.s. \\
\hline$\Delta \mathrm{ALT}, \mathrm{U} / \mathrm{L}$ & $7.6 \pm 1.7$ & $<0.001$ & $10.0 \pm 2.3$ & $2.2 \pm 2.4$ & $-7.8 \pm 1.3$ & $<0.001$ & $-8.3 \pm 1.3$ & $<0.001$ \\
\hline$\triangle \mathrm{AST}, \mathrm{U} / \mathrm{L}$ & $1.0 \pm 0.6$ & n.s. & $1.5 \pm 0.7$ & $-0.1 \pm 0.8$ & $-1.6 \pm 0.6$ & $<0.05$ & $-1.8 \pm 0.6$ & $<0.05$ \\
\hline
\end{tabular}


TABLE 2. continued

\begin{tabular}{|c|c|c|c|c|c|c|c|c|}
\hline Variable & $\begin{array}{l}\text { All }^{\mathrm{a}} \\
(\mathrm{N}=2,020)\end{array}$ & P-value ${ }^{a}$ & $\begin{array}{l}\text { Women }^{\mathrm{b}} \\
(\mathrm{N}=1,352)\end{array}$ & $\begin{array}{l}\text { Men }^{b} \\
(N=668)\end{array}$ & $\begin{array}{l}\text { Mean difference } \\
\text { between men } \\
\text { and women }\end{array}$ & P-value ${ }^{b}$ & $\begin{array}{l}\text { Mean difference } \\
\text { between men and } \\
\text { women }^{c}\end{array}$ & P-value \\
\hline \multicolumn{9}{|c|}{ Anthropometry, body composition and blood pressure } \\
\hline$\Delta$ Waist circumference, $\mathrm{cm}$ & $-9.6 \pm 0.4$ & $<0.001$ & $-9.2 \pm 0.4$ & $-10.5 \pm 0.4$ & $-1.4 \pm 0.3$ & $<0.001$ & $-0.2 \pm 0.2$ & n.s. \\
\hline$\Delta$ Hip circumference, $\mathrm{cm}$ & $-7.1 \pm 0.3$ & $<0.001$ & $-7.1 \pm 0.2$ & $-7.2 \pm 0.3$ & $-0.04 \pm 0.2$ & n.s. & $0.7 \pm 0.2$ & $<0.001$ \\
\hline$\Delta$ Thigh circumference, $\mathrm{cm}$ & $-3.7 \pm 0.1$ & $<0.001$ & $-3.7 \pm 0.1$ & $-3.9 \pm 0.1$ & $-0.2 \pm 0.2$ & n.s. & $0.2 \pm 0.2$ & n.s. \\
\hline$\Delta$ Fat free mass, $\mathrm{kg}$ & $-2.74 \pm 0.37$ & $<0.001$ & $-3.17 \pm 0.38$ & $-1.90 \pm 0.40$ & $1.26 \pm 0.18$ & $<0.001$ & $1.58 \pm 0.17$ & $<0.001$ \\
\hline$\Delta$ Fat mass, kg & $-7.80 \pm 0.39$ & $<0.001$ & $-7.09 \pm 0.40$ & $-9.33 \pm 0.41$ & $-2.23 \pm 0.15$ & $<0.001$ & $-1.30 \pm 0.12$ & $<0.001$ \\
\hline$\Delta$ Fat $\%$ & $-3.9 \pm 0.5$ & $<0.001$ & $-3.7 \pm 0.4$ & $-4.3 \pm 0.4$ & $-0.6 \pm 0.2$ & $<0.01$ & $-0.2 \pm 0.2$ & n.s. \\
\hline$\Delta$ Bone mineral content, $\mathrm{g}$ & $-45.3 \pm 20.0$ & $<0.05$ & $-57.1 \pm 19.4$ & $-8.6 \pm 20.3$ & $48.4 \pm 9.3$ & $<0.001$ & $53.8 \pm 9.5$ & $<0.001$ \\
\hline$\Delta$ Bone mineral density, $\mathrm{g} / \mathrm{cm}^{2}$ & $0.004 \pm 0.005$ & n.s. & $0.001 \pm 0.004$ & $0.007 \pm 0.004$ & $0.006 \pm 0.002$ & $<0.05$ & $0.005 \pm 0.002$ & n.s. \\
\hline$\triangle \mathrm{SBP}, \mathrm{mmHg}$ & $-7.5 \pm 0.7$ & $<0.001$ & $-7.7 \pm 1.3$ & $-7.8 \pm 1.3$ & $-0.2 \pm 0.6$ & n.s. & $0.6 \pm 0.6$ & n.s. \\
\hline$\triangle \mathrm{DBP}, \mathrm{mmHg}$ & $-3.5 \pm 0.8$ & $<0.001$ & $-3.2 \pm 0.9$ & $-4.5 \pm 0.9$ & $-1.3 \pm 0.4$ & 0.001 & $-0.8 \pm 0.4$ & n.s. \\
\hline$\Delta$ Pulse pressure, $\mathrm{mmHG}$ & $-4.0 \pm 0.9$ & $<0.001$ & $-4.5 \pm 0.9$ & $-3.2 \pm 0.9$ & $1.4 \pm 0.4$ & $<0.01$ & $1.6 \pm 0.4$ & $<0.001$ \\
\hline$\Delta \mathrm{MAP}, \mathrm{mmHG}^{f}$ & $-5.2 \pm 0.6$ & $<0.001$ & $-5.1 \pm 0.9$ & $-5.9 \pm 1.0$ & $-0.8 \pm 0.4$ & n.s. & $-0.2 \pm 0.4$ & n.s. \\
\hline$\Delta$ Heart rate, bpm & $-5.4 \pm 0.8$ & $<0.001$ & $-4.9 \pm 1.1$ & $-6.3 \pm 1.1$ & $-1.4 \pm 0.4$ & $<0.001$ & $-1.1 \pm 0.4$ & $<0.05$ \\
\hline
\end{tabular}

Data are mean change \pm SEM. Abbreviations: CID, Clinical investigation day; HOMA-IR, Homeostasis model of assessment insulin resistance; BMI, Body mass index; LDL, Low-density lipoprotein; HDL, High-density lipoprotein; ALT, Alanine aminotransferase; AST, Aspartate aminotransferase; SBP, Systolic blood pressure; DBP, Diastolic blood pressure; MAP, Mean arterial pressure; SE, Standard error.

${ }^{a}$ The ANCOVA models includes adjustment for intervention site.

${ }^{\mathrm{b}}$ The ANCOVA models includes adjustment for site, age, gender and baseline.

'ANCOVA models included adjustment for site, age, gender, baseline and weight loss percentage.

${ }^{d}$ The formula to calculate the HOMA-IR was: fasting insulin(mU/L) * fasting glucose (mmol/L) / 22.5 [25]

${ }^{e}$ The metabolic syndrome was calculated as a Z score [27].

${ }^{f}$ The formula used to calculate MAP was $0.42 \times$ SBP $+0.58 \times$ DBP [26]. 
Proportionally, more women (10.1\%) than men (7.2\%) dropped out, leaving a risk difference of $2.9 \%$ points $(95 \%$ confidence interval $(\mathrm{CI}):-0.5$ to $-5.6 \%$ points, $\mathrm{P}=0.01) .1857$ (83.5\%) of the participants who began the LED phase, successfully achieved the target of $\geq 8 \%$ weight loss at 8 weeks. Fewer women (82\%) than men (86.5\%) achieved the target weight loss (difference of $4.5 \%$ points, $95 \%$ CI: $1.4 \%-7.7 \%$ points, $P=0.02$ ) The mean LED weight loss ( \pm SEM) in all participants was $10.7 \pm 0.4 \mathrm{~kg}(10.8 \% ; \mathrm{P}<0.001)$ with women losing $16 \%$ less weight than men $(10.2 \pm 0.4 \mathrm{~kg}$ (10.3\%) vs $11.8 \pm 0.5 \mathrm{~kg}(11.8 \%)$ respectively, $\mathrm{P}<0.001)$. On average, HOMA-IR decreased by 1.42 \pm 0.15 units $(P<0.001)$ in all participants and was similar in women to men $(1.35 \pm 0.15$ vs $1.50 \pm$ 0.15 respectively, $\mathrm{P}=$ n.s.). The overall change in the metabolic syndrome Z-score was $-2.5 \pm 0.2$ $(P<0.001)$, but the improvement was smaller in women than men $(-2.1 \pm 0.2$ vs $-3.4 \pm 0.2$ respectively) with a mean difference of $-1.3 \pm 0.1(P<0.001)$. The difference remained highly significant after adjusting for differences in weight loss $(\%)(P<0.001)$.

Of the 2,224 participants who completed the baseline visit, 1,429 participants (64.3\%) had isolated IFG, 283 participants (12.7\%) had isolated IGT, and 512 participants (23.0\%) had both IFG and IGT at the screening visit. Following the 8-week LED weight loss, 694 participants (35.8\%) had reverted to normo-glycaemia based on FPG alone. This number increased to $40.2 \%$ amongst participants who met the target weight loss (i.e. $\geq 8 \%$ of initial body weight).

Following the LED, fat free mass (FFM) decreased more in women than men (3.2 $\pm 0.4 \mathrm{~kg}$ vs $1.9 \pm$ $0.4 \mathrm{~kg}$ respectively (mean difference of $1.3 \pm 0.2 \mathrm{~kg}, \mathrm{P}<0.001$ ). Conversely, fat mass (FM) decreased less in women than men $(7.1 \pm 0.4 \mathrm{~kg}$ vs $9.3 \pm 0.4 \mathrm{~kg}$ respectively (mean difference of $2.2 \pm 0.2 \mathrm{~kg}, \mathrm{P}<0.001)$. For both outcomes, the difference in changes between women and men remained highly significant after adjusting for weight loss (\%).

A separate analysis of the changes in anthropometry, HOMA-IR and blood markers in the female participants in different age groups is shown in Appendix 5. The younger age group $(<45.9$ years) experienced statistically different changes in HOMA-IR, HbA1c, insulin, HDL-cholesterol, ALT, thigh circumference, $B M C, B M D$ and heart rate compared to the two older age groups (46-54 years and $>55$ years). Between the older age groups, changes in HbAlc, ALT, thigh circumference and BMD were statistically significantly different after the LED weight loss.

During the LED weight loss period, 961 adverse events were reported across all sites. Of these 10 events were reported as serious adverse events (SAE). However all SAE's were evaluated as unlikely to be related, or unrelated to the study intervention and the LED weight loss. As shown in TABLE 3, women reported significantly more adverse events than men. The main events were constipation, having a cold/influenza and muscular weakness and pain.

\section{DISCUSSION}

In this worldwide intervention study, participants lost an average of $11 \%$ of their body weight and showed significant improvements in insulin resistance (change in HOMA-IR $-1.4, \mathrm{P}<0.001$ ) after an 8 -week LED. There were differences in other metabolic outcomes by gender, in that men appeared to benefit more than women. Men lost significantly more body weight than women, and had larger reductions in the metabolic syndrome Z-score, C-peptide, FM and heart rate, even 
after adjusting for differences in weight loss (\%). In contrast, women had larger reductions in HDL-cholesterol, hip circumference, FFM and pulse pressure than men, again after adjustment for the differences in weight loss (\%). Since declines in HDL-cholesterol, BMC and lean mass are generally not supportive of long term health, it is of general interest whether rapid weight loss on a LED compromises the health of some women. Therefore it is of importance to investigate if the long-term effects of rapid weight loss are indeed more beneficial for men than women with regard to the prevention of both type-2 diabetes and cardiovascular disease.

TABLE 3. Adverse effects reported by the PREVIEW participants during and immediately after the weight loss period at the intervention sites.

\begin{tabular}{|c|c|c|c|c|}
\hline Symptoms & $\begin{array}{l}A / / \\
(n=2224)\end{array}$ & $\begin{array}{l}\text { Women } \\
(n=1504)\end{array}$ & Men $(n=720)$ & $\begin{array}{l}\text { Risk difference } \\
(95 \% \text { CI }) * P<0.05\end{array}$ \\
\hline Constipation & 169 (7.6\%) & 129 (8.6\%) & 40 (5.6\%) & $0.030 *(0.008 ; 0.052)$ \\
\hline Diarrhea & $34(1.5 \%)$ & 26 (1.7\%) & $8(1.1 \%)$ & $0.006(-0.004 ; 0.016)$ \\
\hline $\begin{array}{l}\text { Other gastrointestinal symptoms } \\
\text { including feeling nausea, having } \\
\text { pain, flatulence and vomiting }\end{array}$ & $84(3.8 \%)$ & $67(4.5 \%)$ & 17 (2.4\%) & $0.021^{*}(0.006 ; 0.036)$ \\
\hline Having a cold/influenza & 121 (5.4\%) & 85 (5.7\%) & $36(5.0 \%)$ & $0.007(-0.013 ; 0.026)$ \\
\hline Sore throat & $10(0.4 \%)$ & $6(0.4 \%)$ & $4(0.6 \%)$ & $-0.002(-0.008 ; 0.005)$ \\
\hline Dizziness & $44(2.0 \%)$ & $27(1.8 \%)$ & 17 (2.4\%) & $-0.006(-0.019 ; 0.007)$ \\
\hline Headaches and migraines & $66(3.0 \%)$ & $56(3.7 \%)$ & $10(1.4 \%)$ & $0.023 *(0.011 ; 0.036)$ \\
\hline Muscular weakness and pain & $113(5.0 \%)$ & 77 (5.1\%) & $36(5.0 \%)$ & $0.001(-0.018 ; 0.021)$ \\
\hline Allergic reaction & $8(0.4 \%)$ & $6(0.4 \%)$ & $2(0.3 \%)$ & $0.001(-0.004 ; 0.006)$ \\
\hline Hair loss & $19(0.9 \%)$ & $18(1.2 \%)$ & $1(0.1 \%)$ & $0.011 *(0.004 ; 0.017)$ \\
\hline $\begin{array}{l}\text { Changes in menstrual symptoms, } \\
\text {-cycle or postmenstrual symptoms }\end{array}$ & $15(0.7 \%)$ & $15(1.0 \%)$ & - & \\
\hline Various infections & $74(3.3 \%)$ & $61(4.1 \%)$ & $13(1.8 \%)$ & $0.023 *(0.009 ; 0.036)$ \\
\hline $\begin{array}{l}\text { Dry skin. eczema and other effects on } \\
\text { skin }\end{array}$ & $23(1.0 \%)$ & 17 (1.1\%) & $6(0.8 \%)$ & $\begin{array}{l}0.003(-0.006 ; 0.011) \\
-0.008^{*}(-0.015 ;-\end{array}$ \\
\hline Gout & $6(0.3 \%)$ & 0 (0.0\%) & $6(0.8 \%)$ & $0.002)$ \\
\hline Other & 175 (7.9\%) & $122(8.1 \%)$ & 53 (7.4\%) & $0.008(-0.016 ; 0.031)$ \\
\hline Total & 961 (43.2\%) & 712 (47.3\%) & 249 (34.6\%) & $0.128 *(0.085 ; 0.171)$ \\
\hline
\end{tabular}

Abbreviations: $\mathrm{CI}$, confidence interval. Data are presented as numbers and proportions. no. (\%); mean difference between women and men is estimated via the risk difference. *Analyzed using chi-square; $\mathrm{P}<0.05$.

Previous studies have reported that gender differences in metabolic outcomes occur because men mobilize more intra-abdominal fat than women during weight loss, and that this is accompanied by a more pronounced improvement in the metabolic risk profile $(12,14,15)$. In the present study, we found important differences when comparing outcomes between women and men, both before and after adjusting for the differences in weight loss (\%). This suggests intrinsic differences in how men and women adapt to dietary energy deficits.

Following the LED weight loss, the loss of FFM was on average $25 \%$ of total weight loss. Changes in FFM of this magnitude are considered normal during LED weight loss $(28,29)$. Interestingly, 
however, women lost twice as much FFM as men (31.4\% vs. $16.1 \%)$, which is striking as men had a larger energy deficit during LED-phase. It would be expected that the men would have a larger requirement for dietary protein as their FFM was much larger than that of the womens at baseline. From the most recent Joint FAO/WHO/UNU Expert Consultation on Human Energy Requirements (30), it is possible to estimate the daily energy requirement of an average male PREVIEW participant (body weight $109.4 \mathrm{~kg}$ ) with a low daily physical activity level (PAL: 1.45) as $13 \mathrm{MJ}$ $(3,086 \mathrm{kcal})$. In comparison, a female participant (body weight $95.6 \mathrm{~kg}$ ) with a similar activity level would have a daily energy requirement of only approximately $10 \mathrm{MJ}(2,353 \mathrm{kcal})$. However, despite this large difference in energy requirement, men managed to preserve more of their FFM during the LED than women. When looking at this from a compliance perspective, the daily provision of $3.4 \mathrm{MJ} /$ day from the LED would leave men with an energy deficit of $9.6 \mathrm{MJ} /$ day, and women with a $6.5 \mathrm{MJ} /$ day deficit. Following 8 weeks, these energy deficits should yield a weight loss of $18.3 \mathrm{~kg}$ for men and of $12.4 \mathrm{~kg}$ for women according to Westerterp et al (32). Considering the actual weight losses achieved of $11.8 \mathrm{~kg}$ for men and $10.2 \mathrm{~kg}$ for women, there is reason to believe that women were closer to their theoretically achievable weight loss (82.2\%) than men (64.5\%). If we then evaluate and make the reverse calculation of the achieved weight losses, it appears that the mean of the energy intake in men must have been $6.1 \mathrm{MJ} / \mathrm{d}$, and the mean energy intake of women must have been $4.55 \mathrm{MJ} / \mathrm{d}$. This suggests that women were more compliant with the diet than men. Similar observations were made by Camps SG et al (31). It would be interesting to investigate differences in compliance and adaptation to the LED-phase between men and women as it may help explain the differences found in this analysis.

Physical activity (PA) and exercise training are associated with numerous health benefits (33). In the PREVIEW study, we did not measure the level of physical activity during or immediately after the LED weight loss phase. Differences in the physical activity level between participants could have impacted on some of the results presented in this paper; however, the strict inclusion criterion (not high PA) have led to a narrower between-person variance in PA, which has decreased the likelihood that one could find an association between PA, weight loss and the related outcomes. The included participants were (more or less) physically inactive and no guidance on PA was given during the LED-phase. Although we do not have the direct evidence, it is unlikely that any major changes in PA occurred during the LED.

In the PREVIEW study different equipment was used to measure body composition at the intervention sites (see Appendix 3), however the same equipment was always used to measure the same participant during the intervention. There are many body composition methods available to estimate different body compartments $(34,35)$. The more practical and acceptable methods that are frequently used for the estimation of body composition include Dual-energy X-ray absorptiometry (DXA) and bioimpedance analysis (BIA). These were mostly used in the current study. The validity of DXA and BIA has been debated previously, where it is described that their accuracy can vary according to age, adiposity etc. $(34,36)$. In this study, using different equipment at the various sites may have introduced some variability in the data. However as the same equipment was always used for a participant, and adjustments were made for the site in the 
analyses, we believe that we have limited the bias to the greatest extent possible. However, not using the same equipment across all sites is a weakness of the trial.

Additionally, $87.6 \%$ of the study participants described themselves as Caucasians and the remaining participants were either Polynesians, Asians, Hispanics, Black or of mixed origin. Therefore, the ethnic diversity of the PREVIEW participants does not allow generalization of the results presented to all ethnic groups, but primarily to Caucasians.

The dropout rates during the LED were generally low, but varied across centers from $2.5 \%$ to $14.4 \%$. The lower drop-out rate in men might be explained by the greater, early success experienced by the men on the LED. There can be many reasons for the differences in drop-outs across sites. In some sites, the participants were not as familiar with using formula LEDs for weight loss as in other centers, so the cultural and social challenges varied. Differences in compliance and efficacy of a LED in different settings have also been reported in an earlier large-scale study (37).

As outlined in this discussion many aspects could have contributed to the gender-specific effects that we found. The regional fat distribution is indeed different between men and women, and as described earlier, men may mobilize more intra-abdominal fat than women, whereas women may lose more subcutaneous fat during weight loss $(14,15)$. However, our aim with these analyses was not to attempt to disentangle the various contributors to the gender-specific effect (i.e. the gender-specific hormones, behavior and compliance during the LED etc). Our aim was to assess the gender-specific effect as a whole. A future analysis of our data could explore what constitutes the gender-specific effects.

In the separate analysis investigating differences between the age groups within the female population, we found several significant findings. Whether these findings are clinically important or just statistically significant findings is hard to interpret.

Generally, weight loss is known to be associated with improvements in liver transaminases once weight stability has been achieved (39). However, our current study is consistent with the existing literature by showing that transient mild increases in liver enzymes can be observed in some individuals immediately after a LED period (39). The increments were significantly larger in the women than in the men. From previous studies it has been reported that the values return to normal within a few weeks (24). The consequences of the changes are believed to be benign if the enzyme elevation is transient (39).

An important strength of our study is the large sample size and the wide age span, in all sites, in Europe, Australia and New Zealand. In addition, criteria for identifying pre-diabetes were consistent from site to site as the ADA criteria (IFG $=5.6-6.9 \mathrm{mmol} / \mathrm{I})(22,40)$ were used. The range for identifying IFG according to the World Health Organization is narrower (6.1-6.9 $\mathrm{mmol} / \mathrm{l}$ ) (40). However, in the present study, following LED weight loss, more than $35 \%$ of the men and women with IFG at screening reverted to normo-glycaemia. A recent systematic review and metaanalysis concluded the risk of cardiovascular disease was increased in people with FPG as low as $5.6 \mathrm{mmol} / \mathrm{l}$. When considering participants with IFG, according to the WHO criteria (41) $(>6.1$ $\mathrm{mmol} / \mathrm{l}), \mathrm{n}=790), 442$ participants $(55.9 \%)$ were no longer classified with pre-diabetes after the 
LED weight loss. This number increased to $62.6 \%$, when including only those participants with a successful weight loss (i.e. $\geq 8 \%$ of initial body weight).

The results presented in this analysis only provide data on short-term changes. Indeed maintaining weight loss and the accompanying improvements is challenging $(42,43)$. Whether the PREVIEW participants are able to maintain the weight loss and achieved metabolic responses; and whether changes between genders persist in the long-term will be apparent once the trial is completed. However, the 8 week LED, in individuals with pre-diabetes, did results in the initial $10 \%$ weight loss needed to achieve major metabolic improvement in the first phase of a diabetes prevention programme.

\section{CONCLUSION}

In conclusion, an 8-week LED was accompanied by significant improvements in anthropometry, blood pressure and metabolic profile in overweight, women and men with pre-diabetes. Whilst HOMA-IR improved in all participants, (regardless of gender), men lost significantly more body weight than women, and had larger reductions in the metabolic syndrome Z-score, C-peptide and fat mass, even after adjusting for differences in weight loss (\%). In contrast, women had larger reductions in $\mathrm{HDL}$-cholesterol, fat free mass and BMC that could be considered undesirable. These findings are clinically important and suggest gender-specific changes in men and women after weight loss. It is of importance to investigate whether the greater reductions in FFM, hip circumference and HDL-cholesterol in women after a rapid weight loss is indeed beneficial or on the contrary might compromise weight loss maintenance and future optimal / good cardiovascular health. 


\section{ACKNOWLEDGEMENTS}

The following additional contributors assisted in conduct of the trial during recruitment, intervention and/or data collection. University of Copenhagen: Ulla Skovbæch Pedersen, Marianne Juhl Hansen, Bettina Belmann Mirasola, Maria Roed Andersen, Anne Wengler, Jane Jørgensen, Sofie Skov Frost, Eivind Bjørås, Grith Møller, Lone Vestergaard Nielsen. University of Helsinki: Elli Jalo, Saara Kettunen, Laura Korpipää, Tiia Kunnas, Heini Hyvärinen, Heikki Tikkanen, Sanna Ritola. University of Nottingham: Elizabeth Simpson, Shelley Archer, Natalie Bailey-Flitter, Nicky Gilbert, Laura Helm, Sally Maitland, Melanie Marshall, Theresa Mellor, Grace Miller, Seodhna Murphy, Vicky Newman, Amy Postles, Jakki Pritchard, Maria Papageorgiou, Cheryl Percival, Clare Randall, Sue Smith, Sarah Skirrow. University of Maastricht: Tanja Adam. Universidad de Navarra: Blanca Martinez de Morentin Aldabe, María Hernández Ruiz de Eguilaz, Salomé Pérez Diez, Rodrigo SanCristobal, Maria dels Angels Batlle, Laura Moreno-Galarraga, Alejandro Fernández-Montero, Marian Nuin, Javier Baquedano, Maria Eugenia Ursúa, Francisco Javier Martinez Jarauta, Pilar Buil, Lourdes Dorronsoro, Juana María Vizcay, Teodoro Durá-Travé, and all general practitioners and nurses from the Navarra Health Services who collaborated in recruitment of participants. Medical University of Sofia: Nadka Boyadjieva, Pavlina Gateva-Andreeva, Georgi Bogdanov, Galina Dobrevska. University of Auckland: Amy Liu, Lindsay Plank, Anne-Thea McGill, Madhavi Bollineni, Kelly Storey, Nicholas Gant, Jonathon Woodhead, Hannah Chisholm, Wonjoo Lee, Chelsea Cheah, Eric Hansen, Hacer Tekinkaya, Nadia Harvey. University of Sydney: Roslyn Muirhead, Kylie Simpson, Michele Whittle, Kirstine Bell. Lene Stevner, UCPH, assisted with advice on ethical issues, Good Clinical Practice and approval of the study protocol. Moreover, we would like to acknowledge all the additional people who have worked, and are currently working, for PREVIEW, including trainees, post-graduate and undergraduate students. Finally, a respectful thank you to all the study participants of PREVIEW.

\section{CONFLICT OF INTEREST}

All authors have completed the ICMJE uniform disclosure form and make the following declarations. P. C. received travel grants to attend scientific meetings from The Cambridge Weight Plan, UK, outside the submitted work. T. M. L. reports personal fees from Sense Kost, outside the submitted work. M. W.-P. has nothing to disclose. I. M. Has nothing to disclose. J. A. M. has nothing to disclose. S. H. has nothing to disclose. S. P. holds the Fonterra Chair in Human Nutrition at the University of Auckland. S. H. has nothing to disclose. C. R. has nothing to disclose. A. A. reports personal fees from Basic Research, USA; Beachbody, USA; BioCare Copenhagen, Denmark; Crossfit, USA; Danish Agriculture and Food Council; Dutch Beer Institute, The Netherlands; Feast Kitchen A/S, Denmark; Groupe Éthique et Santé, France; McCain Foods Limited, USA; Nestlé Research Center, Switzerland; Novo Nordisk, Denmark; Pfizer, Germany; Saniona, Denmark; SanofiAventis, Germany; S-Biotek, Denmark; Scandinavian Airlines System, Denmark; TetraPak, Sweden; Weight Watchers, USA; Zaluvida, Switzerland; Gelesis, USA; Personalized Weight Management Research Consortium ApS, Denmark and grants from Arla Foods, Denmark; Danish Dairy Research Council; Gelesis, USA; and Global Dairy Platform, outside the submitted work; has patents pending (University of Copenhagen, methods of inducing weight loss, treating obesity and preventing weight gain; licensee, Gelesis, USA) and (Biomarkers, predicting degree of 
weight loss (licensee Nestec SA, Switzerland); is coinventor of a number of other patents owned by the University in accordance with Danish law; receives royalties for the books "Verdens Bedste Kur"/Politikens Forlag, Denmark, 2012 (subsequently published in English as "World's Best Diet"/Penguin, Australia and "The Nordic Way"/Random House, USA), and "Spis dig slank efter dit blodsukker" (Eat according to your blood sugar and be slim)/Politikens Forlag, Denmark, 2017; is co-author of several books in the pipeline about personlized nutrition for weight loss; is co-owner and member of the board of the consultancy company Dentacom Aps, Denmark; is co-founder and co-owner and member of the board of UCPH spinouts Mobile Fitness A/S \& Flaxslim ApS. L. P.-S. has nothing to disclose. F. S.-P. has nothing to disclose. K. H. P. was supported by the Academy of Finland (grants 272376, 314383 and 266286), the Finnish Diabetes Research Foundation, Novo Nordisk Foundation and Helsinki University Hospital Government funds. M. D. has nothing to disclose. M. A. T. has nothing to disclose. S. N.-C. has nothing to disclose. T. H.-D. has nothing to disclose. S. B. has nothing to disclose. M. P. S. has nothing to disclose. M. H.-L. has nothing to disclose. J. B.-M. has nothing to disclose. M. F. has nothing to disclose. A. R. has nothing to disclose.

\section{AUTHOR CONTRIBUTIONS}

The PREVIEW project was designed by A. R., J. B.-M., M. W.-P., M. F., Wolfgang Schlicht (W.S.) and Edith Feskens (E.F.) The PREVIEW intervention study for adult participants was designed by $A$. R., M. F. and T. M. L. All co-authors contributed to implementation of the experimental trial and design of the protocol for intervention. It was the first author, P. C.'s idea to test the gender difference hypothesis reported in this paper. All authors contributed to analysis and interpretation of the data. P. C. drafted the manuscript. All authors contributed to critical revision of the manuscript for important intellectual content. The corresponding author, P.C., is the guarantor of this work and, as such, had full access to all the data in the study and takes responsibility for the integrity of the data and the accuracy of the data analysis. 


\section{REFERENCES}

1. WHO | Diabetes. World Health Organization; WHO [Internet]. 2016 Available at: http://www.who.int/mediacentre/factsheets/fs312/en/

2. Iwahashi $H$, Noguchi $M$, Okauchi $Y$, Morita $S$, Imagawa $A$, Shimomura I. Extent of weight reduction necessary for minimization of diabetes risk in Japanese men with visceral fat accumulation and glycated hemoglobin of 5.6-6.4\%. J Diabetes Investig. 2015;6:553-559.

3. Kahlert D, Unyi-Reicherz A, Stratton G, et al. PREVIEW behavior modification intervention toolbox (PREMIT): a study protocol for a psychological element of a multicenter project. Front Psychol. 2016;7:1136.

4. Fogelholm M, Larsen T, Westerterp-Plantenga M, et al. PREVIEW: Prevention of diabetes through lifestyle intervention and population studies in Europe and around the world. Design, methods, and baseline participant description of an adult cohort enrolled into a three-year randomised clinical trial. Nutrients. 2017;9:632.

5. Kennedy-Dalby A, Adam S, Ammori BJ, Syed AA. Weight loss and metabolic outcomes of bariatric surgery in men versus women - a matched comparative observational cohort study. Eur J Intern Med. 2014;25:922-925.

6. Bhogal MS, Langford R. Gender differences in weight loss; evidence from a NHS weight management service. Public Health. 2014;128:811-813.

7. Coles LT, Fletcher EA, Galbraith $C E$, Clifton PM. Patient freedom to choose a weight loss diet in the treatment of overweight and obesity: a randomized dietary intervention in type 2 diabetes and pre-diabetes. Int J Behav Nutr Phys Act. 2014;11:64.

8. Caudwell P, Gibbons C, Finlayson G, Näslund E, Blundell J. Exercise and weight loss. Exerc Sport Sci Rev. 2014;42:92-101.

9. Alberti KGMM, Eckel RH, Grundy SM, et al. Harmonizing the metabolic syndrome: a joint interim statement of the international diabetes federation task force on epidemiology and prevention; National Heart, Lung, and Blood Institute; American Heart Association; world heart federation; international atherosclerosis society; and International Association for the Study of obesity. Circulation. 2009;120:1640-1645.

10. Biro SM, Olson DL, Garren MJ, Gould JC. Diabetes remission and glycemic response to pre-bariatric surgery diet. J Surg Res. 2013;185:1-1855.

11. Buse JB, Caprio S, Cefalu WT, et al. How do we define cure of diabetes? Diabetes Care. 2009;32:2133-2135.

12. Handjieva-Darlenska T, Handjiev S, Larsen TM, et al. Initial weight loss on an 800-kcal diet as a predictor of weight loss success after 8 weeks: the diogenes study. Eur J Clin Nutr. 2010;64:994-999.

13. Williams RL, Wood LG, Collins CE, Callister R. Effectiveness of weight loss interventions - is there a difference between men and women: a systematic review. Obes Rev. 2015;16:171-186.

14. Wirth A, Steinmetz B. Gender differences in changes in subcutaneous and intra-abdominal fat during weight reduction: an ultrasound study. Obes Res. 1998;6:393-399.

15. Gasteyger C, Larsen TM, Vercruysse F, Pedersen D, Toubro S, Astrup A. Visceral fat loss induced by a low-calorie diet: a direct comparison between women and men. Diabetes Obes Metab. 2009;11:596-602.

16. Singh GM, Danaei G, Farzadfar F, et al. The age-specific quantitative effects of metabolic risk factors on cardiovascular diseases and diabetes: A pooled analysis. PLoS One. 2013;8:e65174.

17. Saudek CD. Can diabetes be cured?: potential biological and mechanical approaches. $J A M A$. 2009;301:1588-1590.

18. Cowie CC, Rust KF, Ford ES, et al. Full accounting of diabetes and pre-diabetes in the U.S. population in 1988-1994 and 2005-2006. Diabetes Care. 2009;32:287-294.

19. Unwin N, Shaw J, Zimmet P, Alberti KGMM. Impaired glucose tolerance and impaired fasting glycaemia: the current status on definition and intervention. Diabet Med. 2002;19:708-723.

20. Silventoinen $K$, Pankow J, Lindström J, Jousilahti $P, H u$ G, Tuomilehto J. The validity of the Finnish diabetes risk score for the prediction of the incidence of coronary heart disease and stroke, and total mortality. Eur $J$ Cardiovasc Prev Rehabil. 2005;12:451-458.

21. Lindström J, Louheranta A, Mannelin $M$, et al. The Finnish diabetes prevention study (DPS): lifestyle intervention and 3-year results on diet and physical activity. Diabetes Care. 2003;26:3230-3236.

22. American Diabetes Association. 2. Classification and diagnosis of diabetes. Diabetes Care. 2017;40:S11-S24.

23. Christensen $\mathrm{P}$, Bartels EM, Riecke BF, et al. Improved nutritional status and bone health after diet-induced weight loss in sedentary osteoarthritis patients: a prospective cohort study. Eur J Clin Nutr. 2012;66:504-509. 
24. Christensen P, Bliddal H, Riecke BF, Leeds AR, Astrup A, Christensen R. Comparison of a low-energy diet and a very low-energy diet in sedentary obese individuals: a pragmatic randomized controlled trial. Clin Obes. 2011;1:31-40.

25. Wallace TM, Levy JC, Matthews DR. Use and abuse of HOMA modeling. Diabetes Care. 2004;27:1487-1495.

26. Papaioannou TG, Protogerou AD, Vrachatis $D$, et al. Mean arterial pressure values calculated using seven different methods and their associations with target organ deterioration in a single-center study of 1878 individuals. Hypertens Res. 2016;39:640-647.

27. Johnson JL, Slentz CA, Houmard JA, et al. Exercise training amount and intensity effects on metabolic syndrome (from studies of a targeted risk reduction intervention through defined exercise). Am J Cardiol. 2007;100:1759-1766.

28. Larsen TM, Dalskov S-M, van Baak $M$, et al. Diets with high or low protein content and glycemic index for weight-loss maintenance. N Eng/J Med. 2010;363:2102-2113.

29. Lantz $\mathrm{H}$, Peltonen $\mathrm{M}$, Agren L, Torgerson JS. Intermittent versus on-demand use of a very low calorie diet: a randomized 2-year clinical trial. J Intern Med. 2003;253:463-471.

30. Human energy requirements: report of a joint FAO/ WHO/UNU Expert Consultation. Food Nutr Bull. 2005;26:166.

31. Camps SG, Verhoef SP, Westerterp KR. Weight loss, weight maintenance, and adaptive thermogenesis. Am J Clin Nutr. 2013;97:990-994.

32. Westerterp KR, Donkers JH, Fredrix EW, Boekhoudt P. Energy intake, physical activity and body weight: a simulation model. BrJ Nutr. 1995;73:337-347.

33. 33Haskell WL, Lee I-M, Pate RR, et al. Physical activity and public health. Med Sci Sport Exerc. 2007;39:1423-1434.

34. 34Wells JCK, Fewtrell MS. Measuring body composition. Arch Dis Child. 2005;91:612-617.

35. Wells JC, Fuller NJ, Dewit O, Fewtrell MS, Elia M, Cole TJ. Four-component model of body composition in children: density and hydration of fat-free mass and comparison with simpler models. Am J Clin Nutr. 1999;69:904-912.

36. Ferri-Morales $A$, Nascimento-Ferreira MV, Vlachopoulos $D$, et al. Agreement between standard body composition methods to estimate percentage of body fat in young male athletes. Pediatr Exerc Sci. 2018;30:402-410.

37. Papadaki A, Linardakis $M$, Plada $M$, et al. A multicentre weight loss study using a low-calorie diet over 8 weeks: regional differences in efficacy across eight European cities. Swiss Med Wkly. 2013;143:w13721.

38. Katsagoni CN, Georgoulis M, Papatheodoridis GV, Panagiotakos DB, Kontogianni MD. Effects of lifestyle interventions on clinical characteristics of patients with non-alcoholic fatty liver disease: a meta-analysis. Metabolism. 2017;68:119-132.

39. Gasteyger C, Larsen TM, Vercruysse F, Astrup A. Effect of a dietary-induced weight loss on liver enzymes in obese subjects. Am J Clin Nutr. 2008;87:1141-1147.

40. WHO. Definition and Diagnosis of Diabetes and Intermediate Hyperglycaemia. Geneva, Switzerland: WHO Document Production Services; 2006.

41. Huang Y, Cai X, Mai W, Li M, Hu Y. Association between prediabetes and risk of cardiovascular disease and all cause mortality: systematic review and meta-analysis. BMJ. 2016;355:i5953.

42. Christensen $\mathrm{P}$, Henriksen M, Bartels EM, et al. Long-term weight-loss maintenance in obese patients with knee osteoarthritis: a randomized trial. Am J Clin Nutr. 2017;106:755-763.

43. Kushner RF, Ryan DH. Assessment and lifestyle Management of Patients with Obesity. JAMA. 2014;312:943-952. 


\section{CHAPTER 7}

\section{Long-term effects of increased protein intake after weight loss on intrahepatic lipid content and implications for insulin sensitivity - a PREVIEW study}

M. Drummen, E. Dorenbos, A. Vreugdenhil, A. Raben, M. Fogelholm, M.S. WesterterpPlantenga and T. Adam

Published in:

American Journal of Physiology-Endocrinology and Metabolism (2018) 


\section{ABSTRACT}

Aims

To assess the effects of a weight maintenance period comprising two diets differing in protein intake, after weight loss, on intrahepatic lipid content and implications for insulin sensitivity.

\section{Materials and methods}

A total of 25 participants (BMI: $31.1 \pm 3.5 \mathrm{~kg} / \mathrm{m}^{2}$; intrahepatic lipid (IHL): $8.7 \pm 8.3 \%$; fasting glucose: 6.4 $\pm 0.6 \mathrm{mmol} / \mathrm{l} ;$ HOMA-IR: $3.7 \pm 1.6$; Matsuda index: $3.4 \pm 2.9$ ) started an 8-week low energy diet followed by a 2-year weight maintenance period with either high protein (HP) or medium protein (MP) dietary guidelines. At baseline, after 6 months and after 2 years, IHL, visceral adipose tissue (VAT) and subcutaneous adipose tissue (SAT) were determined by magnetic resonance spectroscopy/imaging. Glucose and insulin concentrations, determined during an oral glucose challenge, were used to assess the HOMA-IR and Matsuda insulin sensitivity index (ISI). Protein intake was measured with 24-h urinary nitrogen excretion.

\section{Results}

Protein intake, BMI, IHL, VAT, SAT, HOMA-IR and ISI did not change differently between the groups during the intervention. In the whole group, BMI, IHL, VAT, SAT, HOMA-IR, and ISI were favourably changed at 6 months and 2 years compared to baseline $(p<0.05)$. Mixed model analysis showed that independent of BMI, protein intake $\left(\mathrm{g} \cdot \mathrm{d}^{-1}\right)$ at 6 months was inversely related to IHL (coefficient:-0.04; $p<0.05$ ) and VAT (coefficient:-0.01; $p<0.05$ ). Overall, IHL was positively related to HOMA-IR (coefficient: $0.10 ; p<0.01$ ) and inversely related to ISI (coefficient: -0.17 ; $\mathrm{p}<0.01$ ), independent of BMI.

\section{Conclusion}

A 2-year medium- to high-protein energy restricted diet reduced IHL and VAT. Independently of changes in BMI, IHL was inversely related to insulin sensitivity. 


\section{INTRODUCTION}

The increase in obesity and type 2 diabetes is paralleled by an alarming increase in nonalcoholic fatty liver disease (NAFLD) with NAFLD being defined as intrahepatic lipid content exceeding $5 \%$ of liver weight (1). Reasons for intrahepatic lipid accumulation in NAFLD can be manifold, but most are associated with the metabolic consequences of excess body fat accumulation (2). Longterm excessive storage of free fatty acids (FFA) as triglycerides in subcutaneous adipose tissue depots eventually exceeds the functionally normal storage capacity of the subcutaneous adipose tissue depots, leading to spill over of FFA to other ectopic tissues, including the liver $(3,4)$.

Ectopic fat accumulation and increased de novo lipogenesis in individuals with NAFLD are associated with the development of systemic insulin resistance. The prevalence of NAFLD in the general population is estimated to be about 20-30\%, prevalence of NAFLD in type 2 diabetic individuals is estimated to be around 70\% (5). While NAFLD is often perceived as a pathway to insulin resistance (6), there is also evidence for the perspective of NAFLD being a consequence of adiposity induced metabolic dysfunction (7).

To elucidate the role of NAFLD for metabolic disease it is of particular interest to differentiate the role of intrahepatic lipid accumulation relative to other adipose tissue compartments for metabolic consequences. Even though hepatic fat has been associated with visceral fat accumulation (8), there is also research showing that their respective impact on metabolic risk may be independent (9). The latter perspective is supported by data showing no increase in metabolic dysfunction with concomitantly increased whole body adiposity, if the amount of liver fat was not affected (10). The specific importance for intrahepatic fat relative to visceral and subcutaneous fat for metabolic health finds further support in results showing that weight loss induced a decrease in liver fat content and the associated improvements in insulin sensitivity remained throughout a 2-year follow-up period, in spite of weight and fat mass regain (11). The role of weight loss as a primary intervention for NAFLD seems to be pivotal (12). The addition of physical activity to a dietary intervention was shown to further promote reductions in intrahepatic fat (13) and in people with and without NAFLD, exercise training lead to a reduction in intrahepatic fat (14).

While there is research assessing the effect of dietary fat and carbohydrate intake on liver fat accumulation (15), studies investigating the effect of protein intake are relatively sparse. Protein supplementation was shown to be associated with reduced hepatic fat in short-term studies (1618), but data on longer-term effects of increased protein intake is lacking.

The goal of the current study was to investigate long-term effects of weight maintenance with increased protein intake, after weight loss, on intrahepatic lipid content (IHL) and its implication for insulin sensitivity. Considering the evidence from short term studies we hypothesized that participants with higher protein intake during weight maintenance after weight loss would have reduced $\mathrm{IHL}$ and increased insulin sensitivity compared to participants with moderate protein intake during weight maintenance after weight loss. 


\section{RESEARCH DESIGN AND METHODS}

\section{Participants}

Twenty-five participants were recruited from the PREVIEW cohort at Maastricht University. The PREVIEW study (Prevention of Diabetes through lifestyle intervention and population studies in Europe and around the World, EU 7th Framework Programme, grant agreement no. 312057, ClinicalTrials.gov NCT01777893) has been initiated to find the most effective lifestyle (diet and physical activity) for the prevention of type 2 diabetes in overweight and obese participants with increased risk for type 2 diabetes (www.previewstudy.com) (19). Inclusion criteria were: age 25-70 years, BMI $>25 \mathrm{~kg} / \mathrm{m}^{2}$, pre-diabetes using the American Diabetes Association criteria (20): fasting plasma glucose of $5.6-6.9 \mathrm{mmol} / \mathrm{l}$ and/or plasma glucose concentration of $7.8-11.0 \mathrm{mmol} / \mathrm{l}$ at $2 \mathrm{~h}$ after an oral glucose tolerance test (OGTT) with fasting plasma glucose $<7.0 \mathrm{mmol} / \mathrm{l}$, and willingness to undergo MRI procedures. All participants provided written informed consent for participation. The study was approved by the Medical Research Ethics Committee of Maastricht University Medical Center and in accordance with guidelines of the Declaration of Helsinki.

\section{Study design}

The intervention consisted of two phases: a two-month period of rapid weight reduction using a low energy diet (LED), followed by a weight maintenance period with instructions to follow dietary guidelines in two groups, a moderate protein (MP) and high protein (HP) group. Measurements were performed at baseline, after 6 months and after 2 years after an overnight $>10 \mathrm{~h}$ fasting period. Measurements included body weight and anthropometrics, proton magnetic resonance spectroscopy $\left({ }^{1} \mathrm{H}-\mathrm{MRS}\right)$ for quantification of $\mathrm{IHL}$, MRI to determine subcutaneous and visceral adipose tissue, blood sampling before and during an OGTT. Prior to the investigation day, participants collected 24-hour urine to determine nitrogen excretion as a marker for protein intake.

\section{Weight loss period}

After the baseline measurements, participants started with an eight-week low energy LED period with the aim to lose at least $8 \%$ of their body weight. The LED provided 3.4 MJ (35-40 percentage of energy (En\%) protein, 45-50 En\% carbohydrate, 15-20 En\% fat) per day with four sachets of the Cambridge Weight Plan ${ }^{\circledR}, 3$ of which were dissolved in $250 \mathrm{~mL}$ low fat milk and one in $250 \mathrm{~mL}$ water. Additionally, energy-free drinks and $<400$ gram per day of non-starchy, low-carbohydrate vegetables (e.g. lettuce, asparagus, broccoli, celery, cucumber, mushrooms, radish, tomato, and watercress) were allowed.

\section{Weight maintenance period}

Participants were randomized into two dietary intervention groups at the start of the study. Participants received no information regarding their intervention group until after the LED phase. Both diets were consumed ad libitum with respect to energy, but with the instruction to maintain the achieved body weight. Additional weight loss was allowed. Dietary intervention groups comprised a moderate protein (MP) group with 15 En\% of energy from protein, 55 En\% of 
carbohydrates, 30 En\% of fat and a moderate dietary glycaemic index (GI) ( $\geq 56)$, and a high protein (HP) group with $25 \mathrm{En} \%$ of energy from protein, $45 \mathrm{En} \%$ of carbohydrates, $30 \mathrm{En} \%$ of fat, with a low dietary GI $(\leq 50)$. Participants were given examples of daily eating plans according to the macronutrient and GI requirements of the two intervention groups. Furthermore they received cooking books that were created for their dietary group. Participants were instructed about controlling portion sizes of specific food types in order to achieve the macronutrient and GI prescriptions, and in self-monitoring and adjustment of portion sizes in general, in order to maintain their body weight loss. They were encouraged to follow a regular meal pattern. More detailed information on the dietary guidelines and of the intervention groups has been reported before (19).

\section{Body weight and anthropometrics}

Body weight was measured using a calibrated scale (Life Measurement Corporation, Inc, Concord, (A, USA) and body composition was determined based on body density measured via airdisplacement plethysmography with the BodPod System (Life Measurement Corporation, Inc, Concord, CA, USA) (21), utilizing Siri's equation for body density (22). Height was measured using a wall-mounted stadiometer to the nearest $0.1 \mathrm{~cm}$ (Seca, model 222, Seca, Hamburg, Germany).

\section{Regional fat deposition; IHL, VAT, SAT}

IHL was quantified with $1 \mathrm{H}-\mathrm{MRS}$ on a 3.0-T whole-body scanner (Achieva 3Tx; Philips Healthcare, Best, The Netherlands) and a 32-element sense cardiac/torso coil. ${ }^{1} \mathrm{H}-\mathrm{MR}$ spectra were obtained from a $20 \times 20 \times 20 \mathrm{~mm}^{3}$ volume of interest (VOI) placed centrally in the right lobe of the liver by using point-resolved spectroscopy volume selection (PRESS) with a repetition time (TR) of 4000 $\mathrm{ms}$ and echo time (TE) of $32.5 \mathrm{~ms}$ and NSA $=64$. The water resonance was suppressed by using a chemical shift selective water suppression technique. Shimming was performed by using secondorder FASTMAP (fast, automatic shimming technique by mapping along projections)-based shimming. A water reference spectrum was acquired with NSA $=8$. Special care was taken to ensure that the VOI was placed at the same location during the two measurements.

The participants were instructed to breathe at a 4s-rhythm, which was monitored with a pressuresensitive sensor on the belly. Signals were acquired during the expired breathing phase. Spectra were analyzed using a MATLAB (version 7, The Mathworks Inc.) script, which phased and aligned all the spectra individually. Spectra with a full width at half maximum or peak height 1.5 SD above or below the mean of all acquired spectra were removed. Lipid-methylene $\left(\mathrm{CH}_{2}\right)$ and water peaks were fitted using a combination of Gaussian and Lorentzian line shape (50/50\%). $T_{2}$ relaxation times of $60 \mathrm{~ms}$ for the methylene peak and $26 \mathrm{~ms}$ for the water peak were used for quantification of $\operatorname{IHL}(23,24)$.

Visceral adipose tissue (VAT) and subcutaneous adipose tissue (SAT) were determined during the same scanning session as the IHL. T1-weighted TSE imaging at the L5 vertebral body was used to obtain a two-dimensional transversal image (Repetition time $=500 \mathrm{~ms}$ Echo time $=15 \mathrm{~ms}$ ). Images were analyzed using Osirix (version 3.9.2, Pixmea SARL, Switzerland). Regions of interest (ROI) were manually drawn following the skin and the abdominal wall. SAT was calculated by 
subtracting the area of the abdominal wall ROI from the area of the skin ROI. VAT was quantified within the abdominal wall ROI based on intensity segmentation, with a lower intensity threshold of 450 .

\section{Oral Glucose Tolerance Test}

Participants underwent a 2-hour 75-gram OGTT after an overnight fast $>10$ hours. Blood samples to determine glucose and insulin concentrations were taken prior to, as well as 30, 60, 90 and 120 minutes after receiving a glucose load.

\section{Blood samples and insulin sensitivity}

Blood samples were drawn from an antecubital vein and stored at $-80^{\circ} \mathrm{C}$. Samples were analysed at the National Institution for Health and Welfare in Helsinki, Finland. Plasma glucose was measured by enzymatic hexokinase method and insulin and C-peptide concentrations were measured using chemiluminescent microparticle immunoassay. Laboratory measurements are performed on Architect ci8200 analyzer (Abbott Laboratories, Abbott Park, IL, USA). The homeostatic model assessment (HOMA-IR) was used to assess insulin resistance and was calculated as follows: fasting glucose $x$ fasting insulin / 22.5 (25). Insulin sensitivity was calculated with the Matsuda index: Insulin sensitivity index derived from OGTT (ISI) $=10,000 / \sqrt{ }$ (fasting glucose $x$ fasting insulin) $x$ (mean glucose $x$ mean insulin during OGTT) (26).

\section{Urinary nitrogen}

Nitrogen excretion was measured from 24-hour urine collections, as a marker of protein intake. Urine was collected in $2 \mathrm{~L}$ urine bottles that contained $10 \mathrm{~mL} 4 \mathrm{M}$ hydrochloric acid to prevent nitrogen loss. Nitrogen concentration was measured with a nitrogen analyzer (CHO-O-Rapid; Hereaus) and multiplied with the total volume to determine nitrogen excretion per day. Nitrogen excretion per day was multiplied by 6.25 and divided by the body weight to determine daily oxidation per kilogram body weight.

\section{Physical activity}

Physical activity was assessed using the ActiSleep+ accelerometer (Actigraph LLC, Pensacola, FL). Participants wore the accelerometer for seven consecutive days on the right side of an elastic belt around the waist. Data was collected at 100 Hertz and aggregated to 60 second epochs. After removal of sleep episodes, average counts per minute (CPM) were calculated.

\section{Statistical analysis}

Data were expressed as mean \pm SD. Values of non-normally distributed variables were logarithmically transformed. Factorial ANOVA was used to assess differences between groups at baseline. Pearson's correlations were used to identify correlations between parameters at baseline. Two-way repeated measures ANOVA was used to test differences between groups and gender over time. Repeated-measures ANOVA was used to test differences over time for the whole group. Mixed model regression analysis was used to determine the relation between 
protein intake and regional fat deposition, physical activity and regional fat deposition and regional fat deposition and indices of insulin sensitivity, independent of BMI. Two-tailed $P$ values $<0.05$ were considered statistically significant. Statistical analyses were performed using the Statistical Package for the Social Sciences (SPSS, IBM Corp., IBM SPSS Statistics, V23, Armonk, NY, USA).

\section{RESULTS}

Characteristics of the two groups during the intervention period

Characteristics of the two intervention groups are presented in TABLE 1. Alanine aminotransferase (ALT) and aspartate aminotransferase (AST) were lower in the HP group compared to the MP group at baseline. No other parameters were significantly different between groups at baseline. There were no differences between the groups or between men and women regarding changes in regional fat deposition, anthropometry or blood parameters over time, throughout the intervention period.

\section{Nitrogen excretion and protein oxidation}

Protein intake, determined by nitrogen excretion $\left(\mathrm{g} \cdot \mathrm{d}^{-1}\right)$ and protein oxidation $\left(\mathrm{g} \cdot \mathrm{kg}^{-1} \cdot \mathrm{d}^{-1}\right)$ in the two groups are shown in TABLE 2. Nitrogen excretion and protein oxidation did not change differently between groups. Therefore, both groups were combined and further analysis was performed in the total group of participants.

Regional fat deposition, anthropometry, and blood parameters at baseline for all participants together

With respect to anthropometrics, baseline IHL $(r=0.55 ; p<0.01)$, VAT $(r=0.72 ; p<0.01)$ and SAT $(r=0.61 ; p<0.01)$ were positively related to BMI. Regarding indices of insulin sensitivity, IHL was positively associated with fasting concentrations of insulin $(r=0.48, p<0.05), C$-peptide $(r=0.50$, $p<0.05)$ and HOMA-IR $(r=0.58, p<0.01)$. Neither VAT nor SAT was related to indices of insulin sensitivity. Regarding liver enzymes, IHL was positively associated with ALT ( $r=0.69, p<0.01)$ and AST $(r=0.49, p<0.05)$. 
TABLE 1. Participant characteristics in the MP and HP group

\begin{tabular}{|c|c|c|c|c|c|c|c|c|c|}
\hline & \multicolumn{3}{|c|}{ Total group $(n=25)$} & \multicolumn{3}{|l|}{$M P(n=13)$} & \multicolumn{3}{|l|}{$H P(n=12)$} \\
\hline & Baseline & 6 months & 2 years & Baseline & 6 months & 2 years & Baseline & 6 months & 2 years \\
\hline Sex & $11 w / 13 m$ & & & $5 w / 7 m$ & & & $6 w / 6 m$ & & \\
\hline Age (yr) & $56.0 \pm 11.1$ & & & $54.3 \pm 13.1$ & & & $57.9 \pm 8.6$ & & \\
\hline Weight (kg) & $92.8 \pm 16.3$ & $81.4 \pm 13.0^{*}$ & $85.2 \pm 14.8^{\star} \#$ & $94.0 \pm 14.5$ & $81.9 \pm 10.5^{*}$ & $84.6 \pm 11.1^{\star} \#$ & $91.7 \pm 16.5$ & $80.9 \pm 15.7^{*}$ & $85.9 \pm 18.3^{\star} \#$ \\
\hline BMI $\left(\mathrm{kg} / \mathrm{m}^{2}\right)$ & $31.1 \pm 3.5$ & $27.4 \pm 3.63^{*}$ & $28.7 \pm 3.8^{\star} \#$ & $31.4 \pm 3.1$ & $27.5 \pm 2.4^{*}$ & $28.3 \pm 2.6^{\star} \#$ & $30.9 \pm 4.0$ & $27.3 \pm 4.0^{*}$ & $29.0 \pm 4.8^{\star} \#$ \\
\hline Body-fat (\%) & $41.0 \pm 6.5$ & $32.9 \pm 8.3^{*}$ & $37.2 \pm 8.5^{\star} \#$ & $41.3 \pm 7.3$ & $33.2 \pm 7.8^{*}$ & $36.5 \pm 8.5^{\star} \#$ & $40.6 \pm 6.0$ & $32.7 \pm 9.1^{*}$ & $37.8 \pm 8.9^{\star} \#$ \\
\hline IHL (\%) & $8.7 \pm 8.3$ & $2.4 \pm 3.0^{*}$ & $3.9 \pm 3.5^{\star} \#$ & $11.3 \pm 9.9$ & $3.0 \pm 3.2^{*}$ & $4.8 \pm 3.7^{*}$ & $5.8 \pm 5.1$ & $1.7 \pm 2.7^{\star}$ & $3.0 \pm 3.3^{*} \#$ \\
\hline IHL (log) & $0.68 \pm 0.56$ & $0.10 \pm 0.50^{*}$ & $0.34 \pm 0.57^{\star \#}$ & $0.83 \pm 0.57$ & $0.26 \pm 0.48^{*}$ & $0.46 \pm 0.56^{\star}$ & $0.52 \pm 0.54$ & $-0.09 \pm 0.49 *$ & $0.20 \pm 0.57^{\star} \#$ \\
\hline $\operatorname{SAT}\left(\mathrm{cm}^{2}\right)$ & $344.2 \pm 72.1$ & $271.4 \pm 86.2^{*}$ & $304.7 \pm 82.3^{\star} \#$ & $360.5 \pm 73.7$ & $285.0 \pm 99.3^{*}$ & $302.9 \pm 97.5^{\star}$ & $324.3 \pm 69.0$ & $254.8 \pm 68.9^{*}$ & $306.9 \pm 64.9 \#$ \\
\hline SAT (log) & $2.5 \pm 0.1$ & $2.4 \pm 0.1^{*}$ & $2.5 \pm 0.1^{\star} \#$ & $2.5 \pm 0.1$ & $2.4 \pm 0.2^{*}$ & $2.5 \pm 0.2^{*}$ & $2.5 \pm 0.1$ & $2.4 \pm 0.1^{*}$ & $2.5 \pm 0.1 \#$ \\
\hline $\operatorname{VAT}\left(\mathrm{cm}^{2}\right)$ & $311.8 \pm 79.4$ & $192.1 \pm 55.1^{*}$ & $229.4 \pm 93.7^{\star \#}$ & $316.4 \pm 74.9$ & $202.0 \pm 51.4^{*}$ & $228.1 \pm 85.1^{*}$ & $306.1 \pm 88.8$ & $180.0 \pm 60.0^{*}$ & $231.0 \pm 108.7 \#$ \\
\hline VAT (log) & $2.5 \pm 0.1$ & $2.3 \pm 0.1^{*}$ & $2.3 \pm 0.2^{\star} \#$ & $2.5 \pm 0.1$ & $2.3 \pm 0.1^{*}$ & $2.3 \pm 0.2^{*}$ & $2.5 \pm 0.1$ & $2.2 \pm 0.2^{*}$ & $2.3 \pm 0.2^{\star} \#$ \\
\hline Insulin (mU/l) & $13.4 \pm 5.6$ & $8.8 \pm 3.1^{*}$ & $9.5 \pm 3.5^{\star}$ & $14.8 \pm 6.0$ & $9.4 \pm 3.5^{*}$ & $10.4 \pm 3.7^{*}$ & $11.9 \pm 4.9$ & $8.1 \pm 2.6^{\star}$ & $8.6 \pm 3.2^{*}$ \\
\hline Glucose (mmol/l) & $6.4 \pm 0.6$ & $6.0 \pm 0.4^{*}$ & $6.0 \pm 0.5^{*}$ & $6.2 \pm 0.5$ & $5.9 \pm 0.3$ & $5.9 \pm 0.5$ & $6.6 \pm 0.6$ & $6.1 \pm 0.5^{*}$ & $6.1 \pm 0.5^{*}$ \\
\hline C-peptide (pmol/l) & $931.3 \pm 264.1$ & $645.6 \pm 136.5^{*}$ & $724.5 \pm 188.2^{\star} \#$ & $1010.4 \pm 264.6$ & $678.1 \pm 109.2^{*}$ & $755.1 \pm 154.4^{*}$ & $852.1 \pm 250.4$ & $613.2 \pm 157.7^{\star}$ & $693.9 \pm 66.4^{*}$ \\
\hline HOMA-IR & $3.7 \pm 1.6$ & $2.2 \pm 0.7^{*}$ & $2.4 \pm 0.8^{\star}$ & $4.1 \pm 1.7$ & $2.4 \pm 0.9 *$ & $2.7 \pm 0.9 *$ & $3.2 \pm 1.3$ & $2.0 \pm 0.4^{*}$ & $2.1 \pm 0.7^{*}$ \\
\hline HOMA-IR (log) & $0.5 \pm 0.2$ & $0.3 \pm 0.1^{*}$ & $0.4 \pm 0.2^{*}$ & $0.56 \pm 0.25$ & $0.36 \pm 0.15^{*}$ & $0.40 \pm 0.16^{*}$ & $0.48 \pm 0.19$ & $0.29 \pm 0.09^{*}$ & $0.30 \pm 0.15^{*}$ \\
\hline ISI & $3.4 \pm 2.9$ & $5.2 \pm 2.1^{*}$ & $4.8 \pm 2.1^{*}$ & $3.3 \pm 3.9$ & $4.7 \pm 2.3$ & $4.7 \pm 2.2$ & $3.5 \pm 1.4$ & $5.7 \pm 1.8^{\star}$ & $5.0 \pm 2.1^{*}$ \\
\hline ISI (I) & $0.44 \pm 0.26$ & $0.68 \pm 0.18^{*}$ & $0.65 \pm 0.19^{*}$ & $0.38 \pm 0.32$ & $0.63 \pm 0.22^{*}$ & $0.62 \pm 0.21^{*}$ & $0.51 \pm 0.19$ & $0.74 \pm 0.13^{*}$ & $0.67 \pm 0.17^{\star}$ \\
\hline HbA1c (\%) & $5.4 \pm 0.3$ & $5.2 \pm 0.3^{*}$ & $5.4 \pm 0.3 \#$ & $5.3 \pm 0.22$ & $5.1 \pm 0.2^{*}$ & $5.2 \pm 0.2 \#$ & $5.5 \pm 0.3$ & $5.3 \pm 0.3^{*}$ & $5.5 \pm 0.4 \#$ \\
\hline
\end{tabular}


TABLE 1. continued

\begin{tabular}{|c|c|c|c|c|c|c|c|c|c|}
\hline & \multicolumn{3}{|c|}{ Total group $(n=25)$} & \multicolumn{3}{|l|}{$M P(n=13)$} & \multicolumn{3}{|l|}{$H P(n=12)$} \\
\hline & Baseline & 6 months & 2 years & Baseline & 6 months & 2 years & Baseline & 6 months & 2 years \\
\hline ALT & $19.3 \pm 10.3$ & $13.9 \pm 3.8^{*}$ & $13.7 \pm 5.0^{*}$ & $23.3 \pm 11.2+$ & $13.9 \pm 3.4^{*}$ & $14.4 \pm 4.3^{*}$ & $15.4 \pm 7.9$ & $13.9 \pm 4.2$ & $13.1 \pm 5.8$ \\
\hline ALT (log) & $1.23 \pm 0.23$ & $1.13 \pm 0.12$ & $1.11 \pm 0.15^{\star}$ & $1.32 \pm 0.23+$ & $1.13 \pm 0.10^{*}$ & $1.14 \pm 0.12^{*}$ & $1.14 \pm 0.20$ & $1.12 \pm 0.14$ & $1.08 \pm 0.18$ \\
\hline AST & $28.9 \pm 9.2$ & $24.1 \pm 4.3^{*}$ & $23.9 \pm 3.4^{*}$ & $33.5 \pm 11.1^{+}$ & $24.7 \pm 2.9^{*}$ & $25.0 \pm 3.2^{*}$ & $24.2 \pm 2.7$ & $23.5 \pm 5.4$ & $22.7 \pm 3.4$ \\
\hline AST (log) & $1.44 \pm 0.13$ & $1.38 \pm 0.08^{*}$ & $1.37 \pm 0.06^{*}$ & $1.50 \pm 0.16^{\dagger}$ & $1.40 \pm 0.05^{*}$ & $1.39 \pm 0.06^{*}$ & $1.38 \pm 0.05$ & $1.36 \pm 0.10$ & $1.35 \pm 0.06$ \\
\hline CPM & $322.7 \pm 119.2$ & $361.1 \pm 152.3$ & $325.9 \pm 95.8$ & $361.0 \pm 132.1$ & $432.0 \pm 190.0$ & $336.3 \pm 112.4$ & $293.9 \pm 95.3$ & $308.0 \pm 67.7$ & $318.1 \pm 77.2$ \\
\hline $\mathrm{HDL}(\mathrm{mmol} / \mathrm{l})$ & $1.31 \pm 0.25$ & $1.43 \pm 0.31^{*}$ & $1.37 \pm 0.30 * \#$ & $1.31 \pm 0.3$ & $1.47 \pm 0.38^{\star}$ & $1.39 \pm 0.38$ & $1.32 \pm 0.18$ & $1.39 \pm 0.24$ & $1.35 \pm 0.19$ \\
\hline LDL (mmol/l) & $3.80 \pm 0.89$ & $3.45 \pm 0.86$ & $3.74 \pm 0.77 \#$ & $3.70 \pm 1.12$ & $3.49 \pm 0.95$ & $3.78 \pm 1.00 \#$ & $3.89 \pm 0.66$ & $3.42 \pm 0.80^{*}$ & $3.70 \pm 0.59 *$ \\
\hline $\mathrm{TG}(\mathrm{mmol} / \mathrm{l})$ & $1.43 \pm 0.69$ & $1.21 \pm 0.59 *$ & $1.40 \pm 1.09$ & $1.55 \pm 0.85$ & $1.27 \pm 0.66^{*}$ & $1.61 \pm 1.46$ & $1.30 \pm 0.49$ & $1.15 \pm 0.53$ & $1.19 \pm 0.54$ \\
\hline
\end{tabular}

Data are presented as mean \pm standard deviation. Baseline difference between groups were assessed by means of factorial ANOVA, $+P<0.05$. Differences over time between MP and HP were assessed by means of factorial repeated-measures ANOVA; none were found. Changes over time within groups were determined using repeated-measures ANOVA, * $P<0.05$ significantly different from baseline, $\# \mathrm{P}<0.05$, significantly different from 6 months. MP $=$ moderate protein; HP = high protein; IHL = intrahepatic lipid; VAT = visceral adipose tissue; SAT = subcutaneous adipose tissue; HOMA-IR = homeostatic model assessment for insulin resistance; ISI= insulin sensitivity index; $\mathrm{HbAlc}=$ glycated hemoglobin; $\mathrm{ALT}=$ alanine aminotransferase; $\mathrm{AST}=\mathrm{Aspartate}$ aminotransferase; $(\mathrm{log})=$ log-transformed; CPM =counts-per-minute; HDL = high-density lipoprotein; LDL= low-density lipoprotein; TG = triglyceride

TABLE 2. Protein oxidation was not different between the MP and HP group

\begin{tabular}{llll}
\hline$M P(n=13)$ & Baseline & 6 months & 2 years \\
\hline Nitrogen excretion $\left(\mathrm{g} \cdot \mathrm{d}^{-1}\right)$ & $12.3 \pm 4.0$ & $13.7 \pm 2.9$ & $14.5 \pm 4.6$ \\
Protein oxidation $\left(\mathrm{g} \cdot \mathrm{kg}^{-1} \cdot \mathrm{d}^{-1}\right)$ & $0.81 \pm 0.2$ & $1.03 \pm 0.2$ & $1.10 \pm 0.5$ \\
$H P(n=12)$ & & & $12.6 \pm 4.1$ \\
Nitrogen excretion $\left(\mathrm{g} \cdot \mathrm{d}^{-1}\right)$ & $12.8 \pm 5.2$ & $14.6 \pm 5.3$ & $0.95 \pm 0.3$ \\
Protein oxidation $\left(\mathrm{g} \cdot \mathrm{kg}^{-1} \cdot \mathrm{d}^{-1}\right)$ & $0.86 \pm 0.2$ & $1.12 \pm 0.3$ & \\
\hline
\end{tabular}

Data are presented as mean \pm standard deviation. Baseline difference between MP and HP groups were assessed by means of factorial ANOVA, $P<0.05$. Differences over time between MP and HP were assessed by means of two-way repeated-measures ANOVA; none were found. MP = moderate protein; HP = high protein 
Changes in regional fat deposition, anthropometry, activity and blood parameters during the intervention period

For the whole group, BMI, body-fat percentage (BF\%), IHL, VAT, SAT, and C-peptide were significantly lower at 6 months and 2 years compared to baseline (Table 1). BMI $(42.0 \pm 40.5 \%$ of amount lost), BF\% (71.2 $\pm 56.3 \%$ of amount lost), IHL $(24.0 \pm 72.0 \%$ of amount lost), VAT $(39.0 \pm 48.5 \%$ of amount lost) and SAT $(73.9 \pm 122.7 \%$ of amount lost) increased again from 6 months to 2 years. Activity (CPM) did not change during the intervention period. Glucose, insulin, HOMA-IR, ALT and AST were lower at 6 months and remained on that level during 2 years compared to baseline. ISI increased from baseline to 6 months and remained at that level during 2 years. $\mathrm{HbA1c}$ decreased from baseline to 6 months and increased again from 6 months to 2 years. HDL was significantly higher at 6 months and 2 years compared to baseline, and lower at 2 years compared to 6 months. LDL was significantly higher at 2 years compared to 6 months. Triglyceride concentration was significantly lower at 6 months compared to baseline. The number of participants with NAFLD, as defined by IHL exceeding $5 \%$, decreased from 15 participants at baseline to 3 participants at 6 months, and increased to 7 participants at 2 years.

Effect of protein intake assessed by urinary nitrogen and physical activity on regional fat deposition during the intervention period

The effect of nitrogen excretion on IHL, VAT or SAT during the intervention period, adjusted for BMI, was assessed using repeated measures mixed model regression analysis (TABLE 3). There was a significant time*nitrogen excretion effect throughout the whole study period $(p<0.001)$ for IHL and VAT, with a significant inverse relation between nitrogen excretion and IHL and VAT at 6 months but not at baseline or after two years. There was no significant effect of nitrogen excretion on SAT. There was no significant effect of physical activity (CPM) on IHL, VAT or SAT.

Effect of regional fat deposition on indices of insulin sensitivity and blood parameters during the intervention

There was an overall effect of IHL (\%, log transformed) on HOMA-IR (log transformed; estimate= 0.10; lower 95\% CI: 0.01; upper 95\% CI: 0.19; $p<0.05$ ), ISI (log transformed; estimate $=-0.16$, lower 95\% CI: -0.25 ; upper 95\% CI: -0.06 ; $\mathrm{p}<0.01$ ), and C-peptide (pmol/l; estimate $=102.2$, lower $95 \% \mathrm{CI}$ : 18.7; upper 95\% CI: 185.7; $\mathrm{p}<0.05)$, adjusted for BMI. There was no significant effect of IHL on fasting insulin or fasting glucose. There were no significant effects of VAT and SAT on indices of insulin sensitivity or blood parameters.

\section{DISCUSSION}

We assessed effects of increased daily protein intake from $0.82 \pm 0.2 \mathrm{~g} / \mathrm{kg}$ to $1.05 \pm 0.3 \mathrm{~g} / \mathrm{kg}$, on regional fat deposition and insulin sensitivity in men and women at risk for T2D, during a weight loss and weight maintenance intervention. We did not find differences in changes in regional fat deposition between the MP and HP group, which is most likely explained by the fact that groups did not differ in protein intake. Lack of a significant difference in protein intake at 6 months and 2 years between the two groups could in part be explained by a large dispersion of the data. The 
sub-group of 25 subjects did not have the power to result in two groups with statistically significant protein intakes. Nevertheless, in the whole group, protein intake at 6 months was inversely associated with $\mathrm{IHL}$, independent of BMI. Furthermore, the close relationship between IHL and insulin resistance was evidenced by the positive association between IHL and HOMA-IR at baseline as well as by the positive association between IHL and HOMA-IR and negative association between IHL and ISI during the intervention. There were no changes in activity (CPM) and CPM were not related IHL, VAT, SAT or indices of insulin sensitivity during the intervention.

TABLE 3. Effect of protein intake, determined by nitrogen excretion on IHL, VAT and SAT during the intervention

\begin{tabular}{llllll}
\hline Dependent variable & Time & Estimate & Lower 95\% CI & Upper 95\% CI & $p$ \\
\hline IHL & Baseline & -0.01 & -0.03 & 0.00 & 0.117 \\
& 6 months & -0.04 & -0.05 & -0.02 & 0.000 \\
& 2 years & 0.01 & -0.01 & 0.02 & 0.320 \\
VAT & Baseline & 0.00 & -0.01 & 0.01 & 0.560 \\
& 6 months & -0.01 & -0.02 & -0.00 & 0.001 \\
& 2 years & 0.00 & -0.00 & 0.02 & 0.153 \\
SAT & & & & & \\
& Baseline & -0.00 & -0.01 & 0.00 & 0.093 \\
& 6 months & 0.00 & -0.01 & 0.01 & 0.163 \\
& 2 years & -0.00 & -0.01 & 0.00 & 0.295 \\
\hline
\end{tabular}

Mixed modeling analysis was used to determine the effect of protein intake, determined by nitrogen excretion $\left(\mathrm{g} \cdot \mathrm{d}^{-1}\right)$, on IHL $\left(\%\right.$, log transformed), VAT $\left(\mathrm{mm}^{2}\right.$, log transformed) and SAT $\left(\mathrm{mm}^{2}\right.$, log transformed), adjusted for BMI. There was a significant time*nitrogen excretion effect $(p<0.001)$ in the models for IHL and VAT. IHL = intrahepatic lipid; VAT = visceral adipose tissue; SAT = subcutaneous adipose tissue

Diets with higher protein content have been shown to change body composition by sparing fat free mass and reducing fat mass, and to promote metabolic health, especially during weight maintenance after weight loss $(28,46)$. While evidence of long-term effects of protein intake on IHL is lacking, short-term hyper- and isocaloric studies with protein supplementation showed reductions of $\mathrm{IHL}$ in healthy participants, participants with obesity and participants with type 2 diabetes $(16-18$,$) . We found that protein intake at 6$ months was inversely associated with $\mathrm{IHL}$, independent of BMI. With regard to long-term metabolic impact, it is known that total amount of protein intake, rather than changes in protein intake is the significant factor to consider (29). Protein intake has also been shown to prevent lipid accumulation during weight (re)gain $(11,30$, 31) and hence may facilitate long-term metabolic benefits of weight loss, despite weight regain in at risk participants.

Rodent data have shown that increased protein intake leads to decreases in IHL due to downregulation of lipogenesis as well as increased hepatic lipid oxidation and utilization $(31,32)$. Another explanation for the effects of protein intake on IHL may be decreased carbohydrate or fat intake in exchange for increased protein intake. Both, increased carbohydrate, especially fructose, 
and increased fat intake have been linked to hepatic lipid accumulation in animals and humans (33), but mechanisms by which either may induce hepatic lipid accumulation may be different (34). In humans with overweight and obesity, a hypocaloric diet low in carbohydrates and a hypocaloric diet low in fat with equal protein content led to similar reductions in intrahepatic lipids (35).

The weight change induced by the 8 week weight loss and weight maintenance intervention led to reductions in regional fat deposition and $\mathrm{BF} \%$. This was accompanied by favorable changes in indices of insulin sensitivity and blood parameters. The number of participants with NAFLD decreased from 15 to 7 after 2 years, which is especially relevant in our study population with increased risk for the development of diabetes. NAFLD has been shown to be an independent risk factor for the development of type 2 diabetes, with studies reporting up to 5.5 higher risk ratio $(36,37)$. We found a positive association between changes in $\mathrm{IHL}$ and insulin resistance (HOMAIR) and a negative association with insulin sensitivity (ISI), independent of changes in BMI. Similar relations between IHL and hepatic, skeletal and adipose tissue insulin sensitivity have been reported, with insulin sensitivity being measured using a euglycemic-hyperinsulinemic clamp procedure $(38,39)$. Reductions in hepatic insulin resistance along with a reduction in IHL have been shown to occur within days while increases in whole body insulin sensitivity are less rapid (40). Many authors have shown the close relation between liver fat accumulation and insulin resistance and it is suggested that the two reciprocally aggravate each other $(41,42)$. Intrahepatic lipid impairs insulin signaling and disrupts inhibitory effect of insulin on gluconeogenesis and stimulatory effects on glycogen synthesis. Especially increased diacylglycerol concentrations in the liver has been associated with hepatic insulin resistance 43). Increased diacylglycerol has been shown to activate protein kinase $C \varepsilon$ which then reduces the phosphorylation of insulin receptor substrate-2. This impairs the activity of Akt2, leading to reduced glycogen synthesis and increased gluconeogenesis. In relation to this pathway, hepatic diaclyglycerol and protein kinase $C \varepsilon$ activity was shown to be the strongest predictor of insulin resistance in humans with obesity $(44,45)$.

Insulin resistance in adipose tissue leads to increased lipolysis, increasing non-esterified fatty acids in the circulation, which will be taken up by the liver (46). In accordance with those previous findings we found that IHL was positively related to fasting insulin and C-peptide concentrations at baseline and changes were also closely related to changes in C-peptide concentrations. The close link between increased $\mathrm{IHL}$ and hyperinsulinemia may be explained by reduced hepatic insulin clearance and/or increased pancreatic insulin secretion $(47,48)$. Hyperinsulinemia and increased $\mathrm{C}$-peptide have been postulated as both a consequence and cause of insulin resistance $(49,50)$.

To our knowledge, the present study is the first to assess long-term effects of weight loss and subsequent increased protein intake on IHL. Our study population consisted of people with overweight/obesity and IFG/IGT. The participants presented with increased and large ranges in IHL, BMI and insulin resistance. While our two groups did not statistically differ in protein intake, we were able to relate protein intake, measured by nitrogen excretion in the urine at 6 months of the intervention, with IHL. 
In conclusion, a 2 year relatively high- or medium protein energy restricted diet reduced IHL and VAT and increased insulin sensitivity. The reduction in IHL was inversely related to insulin sensitivity, independent of BMI. These findings stress the clinical implications and potential benefits of increased protein intake after weight loss for people with NAFLD at risk to develop diabetes.

\section{ACKNOWLEDGEMENTS}

We acknowledge the technicians at the department of Radiology for performing the MRI and ${ }^{1} \mathrm{H}-$ MRS measurements. We thank Dr. V. Schrauwen-Hinderling, Dr. L. Lindeboom and Dr. E. van Ewijk for assisting with the analysis of the ${ }^{1} \mathrm{H}$-MRS data. We also would like to thank all the PREVIEW participants and members of the PREVIEW team, coordinated by Anne Raben.

\section{AUTHOR CONTRIBUTION}

The author's responsibilities were as follows: Mathijs Drummen conducted the study, analysed the data and wrote the manuscript; Elke Dorenbos assisted with the study; Anita Vreugdenhil gave medical assistance and reviewed the manuscript; Anne Raben initiated and coordinated the PREVIEW study and reviewed the manuscript; Mikael Fogelholm coordinated the PREVIEW intervention and reviewed the manuscript; Tanja Adam supervised the study and reviewed the manuscript; Margriet Westerterp-Plantenga designed and supervised the study and reviewed the manuscript. Guarantor: Margriet Westerterp-Plantenga

\section{FUNDING}

This study has received a grant from the EU $7^{\text {th }}$ Framework Programme grant \#312057 (FP7-KBBE2012.2.2-03).

\section{CONFLICT OF INTEREST}

None of the authors have any conflict of interest. 


\section{REFERENCES}

1. Byrne CD, Targher G. NAFLD: a multisystem disease. J Hepatol. 2015;62(1 Suppl):S47-64.

2. Stefan N, Kantartzis K, Haring HU. Causes and metabolic consequences of Fatty liver. Endocr Rev. 2008;29(7):939-960.

3. Le KA, Ventura EE, Fisher JQ, et al. Ethnic differences in pancreatic fat accumulation and its relationship with other fat depots and inflammatory markers. Diabetes Care. 2011;34(2):485-490.

4. Savage DB, Semple RK, Chatterjee VK, Wales JK, Ross RJ, O'Rahilly S. A clinical approach to severe insulin resistance. Endocr Dev. 2007;11:122-132.

5. Firneisz G. Non-alcoholic fatty liver disease and type 2 diabetes mellitus: The liver disease of our age? World Journal of Gastroenterology: WJG. 2014;20(27):9072-9089.

6. Lonardo A, Ballestri S, Marchesini G, Angulo P, Loria P. Nonalcoholic fatty liver disease: a precursor of the metabolic syndrome. Dig Liver Dis. 2015;47(3):181-190.

7. Bugianesi $\mathrm{E}$, McCullough AJ, Marchesini G. Insulin resistance: a metabolic pathway to chronic liver disease. Hepatology. 2005;42(5):987-1000.

8. van der Poorten $\mathrm{D}$, Milner $\mathrm{KL}$, Hui J, et al. Visceral fat: a key mediator of steatohepatitis in metabolic liver disease. Hepatology. 2008;48(2):449-457.

9. Fabbrini $E$, Magkos $F$, Mohammed BS, et al. Intrahepatic fat, not visceral fat, is linked with metabolic complications of obesity. Proc Natl Acad Sci U S A. 2009;106(36):15430-15435.

10. Magkos F, Fabbrini E, Mohammed BS, Patterson BW, Klein S. Increased whole-body adiposity without a concomitant increase in liver fat is not associated with augmented metabolic dysfunction. Obesity (Silver Spring). 2010;18(8):1510-1515.

11. Haufe $\mathrm{S}$, Haas V, Utz W, et al. Long-lasting improvements in liver fat and metabolism despite body weight regain after dietary weight loss. Diabetes Care. 2013;36(11):3786-3792.

12. Marchesini G, Mazzella N, Forlani G. Weight Loss for a Healthy Liver. Gastroenterology. 2015;149(2):274278.

13. Goodpaster BH, Delany JP, Otto AD, et al. Effects of diet and physical activity interventions on weight loss and cardiometabolic risk factors in severely obese adults: a randomized trial. Jama. 2010;304(16):17951802.

14. Brouwers B, Schrauwen-Hinderling VB, Jelenik T, et al. Exercise training reduces intrahepatic lipid content in people with and people without nonalcoholic fatty liver. Am J Physiol Endoc Metab. 2018;314(2):E165-e173.

15. de Wit NJ, Afman LA, Mensink M, Muller M. Phenotyping the effect of diet on non-alcoholic fatty liver disease. J Hepatol. 2012;57(6):1370-1373.

16. Theytaz F, Noguchi Y, Egli L, et al. Effects of supplementation with essential amino acids on intrahepatic lipid concentrations during fructose overfeeding in humans. Am J Clin Nutr. 2012;96(5):1008-1016.

17. Bortolotti $\mathrm{M}$, Kreis $\mathrm{R}$, Debard $\mathrm{C}$, et al. High protein intake reduces intrahepatocellular lipid deposition in humans. Am J Clin Nutr. 2009;90(4):1002-1010.

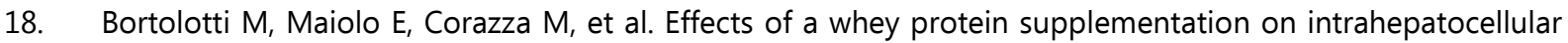
lipids in obese female patients. Clin Nutr. 2011;30(4):494-498.

19. Fogelholm M, Larsen TM, Westerterp-Plantenga $M$, et al. PREVIEW: Prevention of Diabetes through Lifestyle Intervention and Population Studies in Europe and around the World. Design, Methods, and Baseline Participant Description of an Adult Cohort Enrolled into a Three-Year Randomised Clinical Trial. Nutrients. 2017;9(6).

20. Mayer-Davis EJ, Sparks KC, Hirst K, et al. Dietary intake in the diabetes prevention program cohort: baseline and 1-year post randomization. Ann Epidemiol. 2004;14(10):763-772.

21. Plasqui G, Soenen S, Westerterp-Plantenga MS, Westerterp KR. Measurement of longitudinal changes in body composition during weight loss and maintenance in overweight and obese subjects using airdisplacement plethysmography in comparison with the deuterium dilution technique. Int J Obes (Lond). 2011;35(8):1124-1130.

22. Siri WE. Body composition from fluid spaces and density: analysis of methods. 1961. Nutrition. 1993;9(5):480-491; discussion 480, 492.

23. Guiu B, Loffroy R, Petit JM, et al. Mapping of liver fat with triple-echo gradient echo imaging: validation against 3.0-T proton MR spectroscopy. Eur Radiol. 2009;19(7):1786-1793.

24. Guiu B, Petit JM, Loffroy R, et al. Quantification of liver fat content: comparison of triple-echo chemical shift gradient-echo imaging and in vivo proton MR spectroscopy. Radiology. 2009;250(1):95-102. 
25. Matthews DR, Hosker JP, Rudenski AS, Naylor BA, Treacher DF, Turner RC. Homeostasis model assessment: insulin resistance and beta-cell function from fasting plasma glucose and insulin concentrations in man. Diabetologia. 1985;28(7):412-419.

26. Matsuda $M$, DeFronzo RA. Insulin sensitivity indices obtained from oral glucose tolerance testing: comparison with the euglycemic insulin clamp. Diabetes Care. 1999;22(9):1462-1470.

27. Westerterp-Plantenga MS, Lejeune MP, Nijs I, van Ooijen M, Kovacs EM. High protein intake sustains weight maintenance after body weight loss in humans. Int J Obes Relat Metab Disord. 2004;28(1):57-64.

28. Leidy HJ, Clifton PM, Astrup A, et al. The role of protein in weight loss and maintenance. Am J Clin Nutr. 2015.

29. Soenen S, Martens EA, Hochstenbach-Waelen A, Lemmens SG, Westerterp-Plantenga MS. Normal protein intake is required for body weight loss and weight maintenance, and elevated protein intake for additional preservation of resting energy expenditure and fat free mass. J Nutr. 2013;143(5):591-596.

30. Martens EA, Gatta-Cherifi B, Gonnissen HK, Westerterp-Plantenga MS. The potential of a high protein-low carbohydrate diet to preserve intrahepatic triglyceride content in healthy humans. PLoS One. 2014;9(10):e109617.

31. Schwarz J, Tome D, Baars A, Hooiveld GJ, Muller M. Dietary protein affects gene expression and prevents lipid accumulation in the liver in mice. PLoS One. 2012;7(10):e47303.

32. Margolis LM, Rivas DA, Ezzyat Y, et al. Calorie Restricted High Protein Diets Downregulate Lipogenesis and Lower Intrahepatic Triglyceride Concentrations in Male Rats. Nutrients. 2016;8(9).

33. Asrih M, Jornayvaz FR. Diets and nonalcoholic fatty liver disease: the good and the bad. Clin Nutr. 2014;33(2):186-190.

34. Wu W, Tsuchida H, Kato $\mathrm{T}$, et al. Fat and carbohydrate in western diet contribute differently to hepatic lipid accumulation. Biochem Biophys Res Commun. 2015;461(4):681-686.

35. Haufe $S$, Engeli $S$, Kast $P$, et al. Randomized comparison of reduced fat and reduced carbohydrate hypocaloric diets on intrahepatic fat in overweight and obese human subjects. Hepatology. 2011;53(5):1504-1514.

36. Ming J, Xu S, Gao B, et al. Non-alcoholic fatty liver disease predicts type 2 diabetes mellitus, but not prediabetes, in Xi'an, China: a five-year cohort study. Liver Int. 2015;35(11):2401-2407.

37. Kasturiratne $A$, Weerasinghe $S$, Dassanayake AS, et al. Influence of non-alcoholic fatty liver disease on the development of diabetes mellitus. J Gastroenterol Hepatol. 2013;28(1):142-147.

38. Korenblat KM, Fabbrini E, Mohammed BS, Klein S. Liver, muscle, and adipose tissue insulin action is directly related to intrahepatic triglyceride content in obese subjects. Gastroenterology. 2008;134(5):1369-1375.

39. Kusters $\mathrm{YH}$, Schalkwijk CG, Houben AJ, et al. Independent tissue contributors to obesity-associated insulin resistance. JCI Insight. 2017;2(13).

40. Kirk E, Reeds DN, Finck BN, Mayurranjan SM, Patterson BW, Klein S. Dietary fat and carbohydrates differentially alter insulin sensitivity during caloric restriction. Gastroenterology. 2009;136(5):1552-1560.

41. Valenti L, Bugianesi E, Pajvani U, Targher G. Nonalcoholic fatty liver disease: cause or consequence of type 2 diabetes? Liver Int. 2016;36(11):1563-1579.

42. Utzschneider KM, Kahn SE. Review: The role of insulin resistance in nonalcoholic fatty liver disease. J Clin Endocrinol Metab. 2006;91(12):4753-4761.

43. Perry RJ, Samuel VT, Petersen KF, Shulman GI. The role of hepatic lipids in hepatic insulin resistance and type 2 diabetes. Nature. 2014;510(7503):84-91.

44. Kumashiro N, Erion DM, Zhang D, et al. Cellular mechanism of insulin resistance in nonalcoholic fatty liver disease. Proc Natl Acad Sci U S A. 2011;108(39):16381-16385.

45. Magkos F, Su X, Bradley D, et al. Intrahepatic diacylglycerol content is associated with hepatic insulin resistance in obese subjects. Gastroenterology. 2012;142(7):1444-1446.e1442.

46. Samuel VT, Shulman GI. Mechanisms for insulin resistance: common threads and missing links. Cell. 2012;148(5):852-871.

47. Finucane FM, Sharp SJ, Hatunic $M$, et al. Liver fat accumulation is associated with reduced hepatic insulin extraction and beta cell dysfunction in healthy older individuals. Diabetol Metab Syndr. 2014;6(1):43.

48. Perseghin G, Caumo A, Lattuada G, et al. Elevated fasting plasma C-peptide occurs in non-diabetic individuals with fatty liver, irrespective of insulin resistance. Diabet Med. 2009;26(9):847-854.

49. Frank N, Tadros EM. Insulin dysregulation. Equine Vet J. 2014;46(1):103-112.

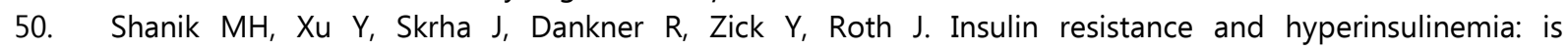
hyperinsulinemia the cart or the horse? Diabetes Care. 2008;31 Suppl 2:S262-268. 



\section{CHAPTER 8}

\section{Associations of brain reactivity to food cues with weight loss, protein intake and dietary restraint during the PREVIEW intervention}

M. Drummen, E. Dorenbos, A. Vreugdenhil, G. Stratton, A. Raben, M.S. WesterterpPlantenga and T. Adam

Published in:

Nutrients (2018) 


\section{ABSTRACT}

The objective was to assess the effects of a weight loss and subsequent weight maintenance period comprising two diets differing in protein intake, on brain reward reactivity to visual food cues. Brain reward reactivity was assessed with functional magnetic resonance imaging in 27 overweight/obese individuals with impaired fasting glucose and/or impaired glucose tolerance (HOMA-IR: $3.7 \pm 1.7$; BMI: $31.8 \pm 3.2 \mathrm{~kg} / \mathrm{m}^{2}$; fasting glucose: $6.4 \pm 0.6 \mathrm{mmol} / \mathrm{L}$ ) before and after an 8-week low energy diet followed by a 2-year weight maintenance period, with either high protein (HP) or medium protein (MP) dietary guidelines. Brain reactivity and possible relationships with protein intake, anthropometrics, insulin resistance and eating behaviour were assessed. Brain reactivity, BMI, HOMA-IR and protein intake did not change differently between the groups during the intervention. In the whole group, protein intake during weight maintenance was negatively related to changes in high calorie images $>$ low calorie images $(H>L)$ brain activation in the superior/middle frontal gyrus and the inferior temporal gyrus $(p<0.005$, corrected for multiple comparisons). $\mathrm{H}>\mathrm{L}$ brain activation was positively associated with changes in body weight and body-fat percentage and inversely associated with changes in dietary restraint in multiple reward, gustatory and processing regions $(p<0.005$, corrected for multiple comparisons). In conclusion, changes in food reward-related brain activation were inversely associated with protein intake and dietary restraint during weight maintenance after weight loss and positively associated with changes in body weight and body-fat percentage. 


\section{INTRODUCTION}

Overweight and obesity are established risk factors for the development of type 2 diabetes (T2D) (1) and insulin resistance (2). Both, obesity and T2D have been associated with neuronal alterations in areas associated with reward processing (3-5). Comparing obese and normal-weight individuals, functional neuroimaging studies have reported increased anticipatory brain activation in response to visual food cues in gustatory and reward regions (including the striatum, insula, amygdala, orbitofrontal cortex and hippocampus) (6). In response to food consumption however, obese individuals showed reduced activation of brain reward circuits compared to normal-weight individuals, suggesting decreased inhibitory control (4).

Along similar lines, patients with T2D showed increased brain activation in response to viewing food images in the insula, caudate and orbitofrontal cortex (5) and a lack of inhibition of hypothalamic neuronal activity after glucose ingestion (7) compared to healthy controls. Central insulin resistance was suggested to possibly play a role in the altered brain activation in both, obesity and T2D. In a study measuring cerebral blood flow, a blunted response in the prefrontal cortex was observed after intranasal insulin administration in obese men, which was inversely related to peripheral insulin sensitivity, independently of BMI (8). Further evidence comes from studies finding an inverse relationship between markers of peripheral insulin sensitivity and brain activation in response to food cues in brain reward regions $(9,10)$. In line with these findings, we previously reported positive associations between insulin resistance and reactivity to food cues in the insula, anterior cingulate gyrus and nucleus accumbens in overweight and obese individuals with impaired fasting glucose and/or impaired glucose tolerance (11). Given that insulin binds to receptors expressed on neurons in areas of reward processing (12), central insulin resistance may contribute to impaired reward signalling, and a reduction in insulin resistance may help to normalize the reward response.

One of the most potent strategies to reduce insulin resistance is body weight loss. It has been shown that food-cue reactivity of reward regions was also suppressed along with extended caloric restriction (13). Patients with T2D who underwent bariatric surgery showed decreased reward activation along with a normalization in glycaemic control, compared to T2D patients without surgery and impaired glycaemic control (14). Besides surgery, lifestyle intervention is a tool to reduce weight and increase insulin sensitivity. The intervention requires profound changes in eating behavior, but it remains unclear how changes in aspects of eating behavior, such as cognitive restraint, relate to changes in neuronal activation.

Considering the well established effect of protein on satiety, diet induced thermogenesis, and the preservation of fat free mass during weight loss, it seems to be the intuitive macronutrient in the nutritional component of a lifestyle intervention. While largely unknown, the beneficial effects of protein for weight loss and weight maintenance may in part be mediated through an effect on reward signalling (15). In the rat, brain signalling was reduced in the amygdala after infusion of an intragastric protein load (16). Human short-term studies also reported a reduction in brain activation to food cues and subsequent reductions in energy $(17,18)$ or changes in food preference (19) after protein ingestion. 
The aim of the current study was to investigate the effects of weight loss and subsequent weight maintenance with higher protein intake versus moderate protein intake on brain reward activity in response to visual food cues in participants of the PREVIEW study (Prevention of diabetes through lifestyle intervention in population studies in Europe and around the World). The PREVIEW study aims to find the most effective lifestyle for the prevention of T2D in overweight and obese participants with increased risk for type 2 diabetes (www.previewstudy.com). We hypothesized that participants with higher protein intake had reduced brain reactivity to food cues after 2 years compared to participants with moderate protein intake.

\section{MATERIALS AND METHODS}

\section{Participants}

Forty participants were recruited from the PREVIEW-cohort at Maastricht University and a total of twenty-seven participants completed both fMRI measurements. Inclusion criteria were: age 25-70 years, BMI $\geq 25 \mathrm{~kg} / \mathrm{m}^{2}$, fasting plasma glucose of $5.6-6.9 \mathrm{mmol} / \mathrm{l}$ and/or plasma glucose concentration of $7.8-11.0 \mathrm{mmol} / \mathrm{l}$ at $2 \mathrm{~h}$ after an oral glucose tolerance test (OGTT), and willingness to undergo MRI procedures. Exclusion criteria included T2D, left-handedness, claustrophobia and history of neurological disorders in addition to the general PREVIEW exclusion criteria (ClinicalTrials.gov NCT01777893). The study was approved by the Medical Research Ethics Committee of Maastricht University Medical Center and in accordance with guidelines of the Declaration of Helsinki. All participants provided written informed consent for participation.

Participants started with 8 weeks on a low energy diet (LED), followed by a weight maintenance period with instructions to follow dietary guidelines in two groups, a moderate protein (MP) and high protein (HP) group. Only participants that reached at least $8 \%$ weight loss with the LED were allowed to continue in the weight maintenance period. Five participants dropped-out during the LED period, seven participants were lost to follow-up during the weight maintenance period. One participant lacked valid functional imaging data and had to be excluded from analysis. After this, twelve participants completed the study in the MP group and fifteen in the HP group (Supplemental figure 1).

\section{Measurements}

Measurements included functional magnetic resonance imaging (fMRI), body composition, blood sampling before and during an oral glucose tolerance test (OGTT) and behavioral questionnaires. Prior to the investigation days, participants collected 24-hour to determine nitrogen excretion as a marker for protein intake. Accelerometers were worn for 7 days to calculate physical activity. At baseline and after 2 years, measurements were performed after an overnight $>10 \mathrm{~h}$ fasting period.

\section{Study design}

The LED provided 3.4 MJ (35-40 E\% protein, 45-50 E\% carbohydrate, 15-20 E\% fat) per day with four sachets of the Cambridge Weight Plan ${ }^{\circledR}, 3$ of which were dissolved in $250 \mathrm{~mL}$ low fat milk and one in $250 \mathrm{~mL}$ water. Additionally, energy-free drinks and < 400 gram per day of non-starchy, low- $\mathrm{CHO}$ vegetables were allowed. Participants were randomized into two dietary intervention 
groups at the start of the study, but received no information regarding their intervention group until after the LED phase. Dietary intervention groups comprised a moderate protein (MP) group with $15 / 55 / 30 \%$ of energy from protein/carbohydrate/fat and a moderate dietary glycaemic index (GI) ( $\geq 56)$, and a high protein (HP) group with $25 / 45 / 30 \%$ of energy from protein/carbohydrate/fat, with a low dietary GI $(\leq 50)$. Both diets were consumed ad libitum with respect to energy, but with the instruction to maintain the achieved body weight. Additional weight loss was allowed. Participants were given examples of daily eating plans according to the macronutrient and GI requirements of the two intervention groups. More detailed information on the dietary guidelines and of the intervention groups has been reported before (20).

\section{Brain imaging paradigm and acquisition}

Participants underwent functional magnetic resonance imaging to obtain blood-oxygen leveldependent (BOLD) data. Scanning was performed on a 3 Tesla scanner (Magnetom, Siemens, Erlangen, Germany) using a 64-channel head coil. Nine randomized blocks of ten images were presented during scanning and blocks contained images of high-calorie foods, low-calorie foods or non-food objects. Images were chosen from the International Affective Picture System (21) and various web sites, which has been described previously (11). High-calorie images included items such as fries, mac-and-cheese, hamburgers, donuts etc. Low-calorie images included items suchs as fruit salad, cucumbers, carrots, broccoli etc. Food images were randomly shown from sixty different images in order to avoid preference and learning effects. Images were shown for 2 seconds each. Between the blocks, a fixation cross was shown for 10 seconds. Participants received the instruction to focus on how much they liked the images. Functional runs were collected using a $T 2^{*}$-weighted protocol $(T R=2.0 \mathrm{~s}, \mathrm{TE}=30.0 \mathrm{~ms}$, $\mathrm{FOV}=216 \times 216$, matrix size $=72 \times 72$, voxel size, $3 \times 3 \times 3 \mathrm{~mm}^{3}$ ). Each volume consisted of 34 slices, acquired in interleaved ascending order. In each session, anatomical images were acquired with a high-resolution T1 weighted scan.

\section{Image processing}

Analysis of the fMRI data was performed with BrainVoyager 20.6 (Brain Innovation B.V, Maastricht, The Netherlands). Preprocessing of the functional images included slice scan time correction with cubic spline interpolation, 3D motion correction and temporal high-pas filtering with 4 cycles. Anatomical data was corrected for intensity inhomogeneities. The anatomical scan of each participant was transformed into Montreal Neurological Institute (MNI) space. After preprocessing, both functional and anatomical scans were aligned based on starting position and boundary-based registration. The volume-time-courses were spatially smoothed by applying a Gaussian filter (FWHM=6) to increase signal-to-noise ratio. For each participant, food rewardrelated brain activation predictors for the three stimuli blocks (high-calorie food images, lowcalorie food images and neutral images) were applied in Generalized Linear Model (GLM) analyses and the hemodynamic-response was taken into account by adding a Two Gamma Hemodynamic Response Function and movement parameters were modeled as confounding predictors. To investigate the two scan sessions dummy coding was applied with the BVA-Predictor Tool software (BVA-Predictor Tool, J.M. Born, Maastricht, The Netherlands). Region of interest (ROI) analysis was used to specifically investigate the activation in the right and left nucleus accumbens, 
the right anterior cingulate gyrus and right insula. Regions were selected based upon previous research, which identified food reward related brain activation in these regions to be correlated with insulin resistance (11). See supplemental figure 2 for a visualization of the ROIs.

\section{Body weight and composition}

Body weight was measured using a calibrated scale (Life Measurement Corporation, Inc, Concord, CA, USA) and body composition was determined using the BodPod System (Life Measurement Corporation, Inc, Concord, CA, USA) (22). Height was measured using a wall-mounted stadiometer to the nearest $0.1 \mathrm{~cm}$ (Seca, model 222, Seca, Hamburg, Germany).

\section{Blood samples and urinary nitrogen excretion}

Blood samples were taken to determine fasting glucose and insulin concentrations. The homeostatic model assessment for insulin resistance (HOMA-IR) was used to assess insulin resistance and was calculated as follows: fasting glucose $x$ fasting insulin / 22.5 (23). Blood samples were analysed at the National Institution for Health and Welfare in Helsinki, Finland. Plasma glucose was measured by enzymatic hexokinase method and insulin was measured using chemiluminescent microparticle immunoassay.

Nitrogen excretion was measured from 24-hour urine collections, as a marker of protein intake. Urine was collected in $2 \mathrm{~L}$ urine bottles that contained $10 \mathrm{~mL} 4 \mathrm{M}$ hydrochloric acid to prevent nitrogen loss. Nitrogen concentration was measured with a nitrogen analyzer (CHO-O-Rapid; Hereaus) and multiplied with the total volume to determine nitrogen excretion per day. Nitrogen excretion per day was multiplied by 6.25 and divided by the body weight to determine daily oxidation per kilogram body weight. 24-hour urine was collected at baseline, after 6 months, after 1 year and after 2 years. Averages of the 6 month, 1 year and 2 year samples were used as a representation of protein intake during the weight maintenance period.

\section{Physical activity}

Physical activity was assessed using the ActiSleep+ accelerometer (Actigraph LLC, Pensacola, FL). Participant wore the accelerometer for seven consecutive days on the right side of an elastic belt around the waist. Data was collected at $100 \mathrm{Hertz}$ and aggregated to 60 second epochs. After removal of sleep episodes, average counts per minute (CPM) were calculated.

\section{Eating behavior}

Eating Behavior was assessed using the Three Factor Eating Questionnaire (TFEQ), which consists of 51 questions (24). The three factors it measures are cognitive restraint (TFEQ factor 1), emotional eating and disinhibition (TFEQ factor 2) and feelings of hunger (TFEQ factor 3).

\section{Statistical analysis}

Data are expressed as mean \pm SD SPSS 23 (IBM corp., Armonk NY, USA). Variables were tested for normality and log-transformed if applicable. Factorial ANOVA was used to assess differences between groups at baseline. Two-way repeated measures ANOVA was used to test differences 
between groups over time. Repeated-measures ANOVA was used to test differences over time for the whole group. Two-tailed $P$ values $<0.05$ were considered statistically significant. For the fMRI data, contrasts of interest from single-subject analysis were tested in GLM analyses and then submitted to second-level whole brain random effect analysis to compare groups at baseline or changes between groups. Contrasts included food (high calorie images + low calorie images) versus non-food (neutral images) $(\mathrm{F}>\mathrm{nF})$ and high calorie images versus low calorie images $(\mathrm{H}>\mathrm{L})$. Whole brain correlation analyses was used to test the correlation between changes in $\mathrm{F}>\mathrm{nF}$ or $\mathrm{H}>\mathrm{L}$ reactivity and changes in anthropometric and behavioral parameters over the intervention period in the whole group of participants. Monte Carlo simulations were performed in BrainVoyager to identify cluster-extent thresholds with a cluster alpha of 0.005 , to correct for multiple comparisons. Simulations were performed with 1000 iterations and an independent voxel threshold of $p<0.001$. Regarding the ROI analysis, average parameter estimates within each ROI were extracted and exported to SPSS to compare differences between groups. Pearson's correlation analysis was used to determine the relation between brain reactivity within significant clusters or ROIs and anthropometric and behavioral parameters. Partial correlation analysis was used to determine the relationship between anthropometric and behavioral parameters and extracted brain activation in the significant clusters or ROIs adjusted for changes in BMI. There were no differences in changes in brain activation between men and women. A $p<0.005$ was considered significant to correct for multiple comparisons. Analyses were performed using BrainVoyager 20.6 (Brain Innovation B.V., Maastricht, The Netherlands) and the Statistical Package for the Social Sciences (SPSS, IBM Corp., IBM SPSS Statistics, V23, Armonk, NY, USA).

\section{RESULTS}

Characteristics of the participants in the two groups are shown in TABLE 1. Regarding anthropometrics, insulin resistance, protein intake and physical activity (CPM), no differences were observed at baseline, nor in changes during the intervention between the groups. All anthropometric parameters decreased significantly (see TABLE $\mathbf{1}$ ) in the whole group during the intervention period $(\mathrm{P}<0.001)$. Fasting insulin, glucose, c-peptide, HbAlc concentrations and HOMA-IR significantly decreased $(p<0.05)$. Physical activity $(C P M)$ did not significantly change during the intervention. During the intervention TFEQ restraint increased for the whole group. TFEQ hunger significantly decreased in the whole group of participants (TABLE $\mathbf{1}$ ).

\section{No differences in brain activity between MP and HP groups}

There were no differences in brain activation in response to viewing food versus non-food images $(\mathrm{F}>\mathrm{nF})$ or to high-calorie versus low-calorie images $(\mathrm{H}>\mathrm{L})$ between the groups at baseline. Differences in brain activation over the intervention period were compared between the two groups using whole brain analysis. There were no differences in changes for the contrasts $\mathrm{F}>\mathrm{nF}$ or $\mathrm{H}>\mathrm{L}$ between the groups. Furthermore, extracted brain activation in the a priori defined ROIs did not differently change between the groups for the contrasts $\mathrm{F}>\mathrm{nF}$ or $\mathrm{H}>\mathrm{L}$.

During the intervention, daily nitrogen excretion or daily protein intake were not different between the groups. Therefore, both groups were taken together for further analyses. In the whole group of participants, daily nitrogen excretion $(12.1 \pm 4.1 \mathrm{~g}$ to $13.8 \pm 4.4 \mathrm{~g})$ and daily protein 
intake $0.82 \pm 0.23 \mathrm{~g} / \mathrm{kg}$ to $1.04 \pm 0.25 \mathrm{~g} / \mathrm{kg}$ ) were increased at 2 years compared to baseline $(p<0.05)$. During the weight maintenance period, average daily nitrogen excretion was $14.2 \pm 3.9 \mathrm{~g}$ and average protein intake was $1.06 \pm 0.24 \mathrm{~g} / \mathrm{kg}$.

TABLE 1. Participant characteristics

\begin{tabular}{|c|c|c|c|c|c|c|}
\hline & $\begin{array}{l}\text { MP }(n=12) \\
\text { Baseline }\end{array}$ & 2 years & $\begin{array}{l}\text { HP }(n=15) \\
\text { Baseline }\end{array}$ & 2 years & $\begin{array}{l}\text { Total }(n=27) \\
\text { Baseline }\end{array}$ & 2 years \\
\hline Age & 54.7 (10.6) & & $52.7(10.3)$ & & $53.6(10.3)$ & \\
\hline Height & $1.74(0.1)$ & & $1.69(0.12)$ & & $1.71(0.12)$ & \\
\hline Weight $(\mathrm{kg})$ & $99.4(17.4)$ & $90.6(16.0)$ & 89.7 (15.4) & 81.9 (15.6) & $94.0(16.7)$ & $85.8(16.1)^{\star \star \star}$ \\
\hline $\operatorname{BMI}\left(\mathrm{kg} / \mathrm{m}^{<}\right)$ & $32.7(3.1)$ & $29.9(3.5)$ & $31.2(3.3)$ & $28.5(4.1)$ & $31.8(3.2)$ & $29.1(3.8)^{\star \star \star}$ \\
\hline FM & $40.9(8.8)$ & $33.9(12.0)$ & $35.8(8.7)$ & 29.7 (10.9) & $38.1(9.0)$ & $31.6(11.4)^{\star \star \star}$ \\
\hline Body-fat \% & $41.4(6.7)$ & $37.2(10.1)$ & $40.2(7.3)$ & $36.2(9.9)$ & 40.7 (6.9) & $36.6(9.8)^{\star \star \star}$ \\
\hline Insulin & $13.0(6.4)$ & $10.4(5.5)$ & $14.6(6.5)$ & $10.4(3.7)$ & $13.9(6.4)$ & $10.4(4.5)^{\star \star}$ \\
\hline Glucose & $6.4(0.8)$ & $6.0(0.7)$ & $6.3(0.5)$ & $5.9(0.4)$ & $6.4(0.6)$ & $5.9(0.5)^{\star \star}$ \\
\hline HOMA-IR & $3.7(1.9)$ & $2.8(1.8)$ & $4.2(2.1)$ & $2.7(1.1)$ & $4.0(2.0)$ & $2.8(1.4)^{\star}$ \\
\hline CPM & 302.4 (116.1) & $262.2(97.4)$ & $380.1(109.3)$ & 338.5 (116.8) & 345.2 (116.3) & 304.2 (112.6) \\
\hline TFEQ f1 & $7.7(4.4)$ & $13.6(2.8)$ & $8.9(4.8)$ & $13.1(3.5)$ & $8.3(4.5)$ & $13.3(3.1)^{\star \star \star}$ \\
\hline TFEQ f2 & $7.5(3.3)$ & $6.4(2.3)$ & $8.6(3.7)$ & $7.5(4.0)$ & $8.1(3.5)$ & $7.0(3.4)$ \\
\hline TFEQ f3 & $5.7(3.0)$ & $4.1(3.1)$ & $5.9(3.6)$ & $5.0(3.6)$ & $5.8(3.3)$ & $4.6(3.3)^{*}$ \\
\hline
\end{tabular}

Data are presented as mean \pm standard deviation. Differences over time between MP and HP were assessed by means of factorial repeated-measures ANOVA; none were found. Changes over time within groups were determined using repeated-measures ANOVA, * $p<0.05$, ** $p<0.01$, ${ }^{* *} p<0.001$. Abbreviations: $\mathrm{MP}=$ moderate protein group; $\mathrm{HP}=$ high protein group; $\mathrm{HOMA}-\mathrm{IR}=$ homeostatic model assessment for insulin resistance; CPM, counts per minute, TFEQ = Three factor eating questionnaire, $\mathrm{f} 1$ =factor 1 (cognitive restraint), f2=factor 2 (disinhibiton and emotional eating), $\mathrm{f} 3=$ factor 3 (feelings of hunger)

Whole brain analysis - relations between brain activation and BMI, body-fat percentage, HOMAIR, protein intake, activity or eating behavior

For the whole group, brain activation for the contrast food versus non-food images or highcalorie versus low-calorie images was not significantly different at 2 years compared to baseline, assessed with whole brain analyses. To determine whether changes in brain reactivity to food cues were associated with anthropometrics, insulin resistance, protein intake, activity or eating behavior whole brain analyses with changes in BMI, body-fat percentage, HOMA-IR, protein intake $(\mathrm{g} / \mathrm{kg})$, physical activity (CPM) or TFEQ scores added as covariates were performed for the whole group (TABLE 2) (SUPPLEMENTAL FIGURE 2-6).

\section{Food $>$ non-Food brain response}

Changes in body-fat percentage were negatively associated with changes in food versus nonfood images activation in the gyrus rectus and positively associated with changes in food versus non-food images activation in the left thalamus and left middle frontal gyrus. There were no significant clusters for changes in food versus non-food images activation and changes in other variables. 
TABLE 2. Summary of whole brain fMRI results

\begin{tabular}{|c|c|c|c|c|c|c|c|c|c|c|}
\hline Contrast & Variable & AAL & k & r & $r^{*}$ & $p^{*}$ & $x$ & y & z & Cluster extent \\
\hline \multirow[t]{4}{*}{$\Delta \mathrm{F}>\mathrm{nF}$} & \multirow[t]{4}{*}{$\Delta$ Body-fat $\%$} & gyrus rectus $L$ & \multirow[t]{4}{*}{540} & -0.66 & $-0.54^{*}$ & $0.005^{*}$ & -1 & 55 & -16 & 906 \\
\hline & & thalamus L & & 0.64 & $0.62^{*}$ & $0.001^{*}$ & -20 & -22 & 13 & 1010 \\
\hline & & no label (white matter L) & & -0.63 & $-0.72^{*}$ & $<0.001^{*}$ & -20 & -13 & 38 & 579 \\
\hline & & middle frontal gyrus L & & 0.63 & $0.65^{*}$ & $<0.001^{*}$ & -24 & 23 & 41 & 1314 \\
\hline \multirow[t]{17}{*}{$\Delta \mathrm{H}>\mathrm{L}$} & \multirow[t]{4}{*}{$\triangle \mathrm{BMI}$} & rolandic operculum $\mathrm{R}$ & \multirow[t]{4}{*}{621} & 0.66 & - & - & 55 & 0 & 9 & 688 \\
\hline & & inferior frontal gyrus $R$ & & 0.63 & - & - & 47 & 17 & 3 & 1807 \\
\hline & & middle frontal gyrus L & & 0.66 & - & - & -41 & 50 & 8 & 1610 \\
\hline & & rolandic operculum L & & 0.65 & - & - & -58 & -2 & 8 & 796 \\
\hline & \multirow[t]{6}{*}{$\Delta$ Body-fat $\%$} & angular gyrus R & \multirow[t]{6}{*}{675} & 0.65 & $0.71^{*}$ & $<0.001^{*}$ & 61 & -51 & 34 & 2881 \\
\hline & & middle temporal gyrus $\mathrm{R}$ & & 0.62 & $0.72^{*}$ & $<0.001^{*}$ & 48 & 1 & -25 & 893 \\
\hline & & putamen $\mathrm{R}$ & & 0.65 & $0.68^{*}$ & $<0.001^{*}$ & 31 & 6 & -1 & 11852 \\
\hline & & superior frontal gyrus L & & 0.65 & $0.65^{*}$ & $<0.001^{*}$ & -15 & 59 & 16 & 8828 \\
\hline & & superior occipital gyrus R & & 0.64 & $0.57^{*}$ & $0.003^{*}$ & 17 & -86 & 21 & 1269 \\
\hline & & insula L & & 0.65 & $0.71^{*}$ & $<0.001^{\star}$ & -40 & 14 & 2 & 8394 \\
\hline & \multirow{3}{*}{$\begin{array}{l}\text { WM protein } \\
\text { intake }(\mathrm{g} / \mathrm{kg})\end{array}$} & no label (white matter R) & \multirow[t]{3}{*}{405} & -0.63 & $-0.71^{*}$ & $<0.001^{*}$ & 20 & 4 & 49 & 4040 \\
\hline & & superior frontal gyrus L & & -0.64 & $-0.67^{*}$ & $<0.001^{*}$ & -16 & 9 & 59 & 2398 \\
\hline & & inferior temporal gyrus L & & -0.64 & $-0.72^{*}$ & $<0.001^{*}$ & -65 & -34 & -18 & 1062 \\
\hline & \multirow[t]{4}{*}{$\triangle$ TFEQ f1 } & superior temporal gyrus $\mathrm{R}$ & \multirow[t]{4}{*}{569} & -0.65 & -0.69 & $<0.001^{*}$ & 59 & -44 & 15 & 1835 \\
\hline & & precentral gyrus $\mathrm{R}$ & & -0.67 & -0.72 & $<0.001^{*}$ & 51 & 6 & 38 & 1127 \\
\hline & & superior occipital gyrus R & & -0.64 & -0.64 & $0.001^{*}$ & 28 & -79 & 23 & 601 \\
\hline & & superior occitipal gyrus L & & -0.66 & -0.80 & $<0.001^{*}$ & -21 & -79 & 33 & 1014 \\
\hline
\end{tabular}

Notes: Cluster extent threshold was determined by Monte Carlo simulation with a voxel threshold of $p<0.001$ and cluster alpha $<0.005$. Centre-of-gravity coordinates of each cluster are given in MNI space and the automated anatomical labeling atlas was consulted to obtain corresponding anatomical labels. ${ }^{*}$ corrected for $\triangle B M I$ Abbreviations: $k$, cluster threshold in $\mathrm{mm}^{3} ; A A L$, automated anatomical labeling; $F>n F$ food images versus non-food images; $\mathrm{H}>\mathrm{L}$ high calorie images versus low calorie images; $R$, right hemisphere; $L$, left hemisphere; TFEQ, three factor eating questionnaire, $f 1=$ factor 1 (cognitive restraint) 


\section{High-calorie > Low-calorie brain response}

Changes in BMI were positively related to changes in high-calorie versus low-calorie images brain activation in regions associated with reward and control (FIGURE 1) (rolandic operculum, inferior frontal gyrus, middle frontal gyrus). Changes in body-fat percentage were positively related to changes in $\mathrm{H}>\mathrm{L}$ brain activation in regions associated with visual processing, memory, reward and memory (middle temporal gyrus, angular gyrus, putamen, superior frontal gyrus, superior occipital gyrus, insula). Daily protein intake $(\mathrm{g} / \mathrm{kg})$ during weight maintenance was negatively related to high-calorie versus low-calorie images brain activation in the superior frontal gyrus and left inferior temporal gyrus (FIGURE 2). For high-calorie versus low-calorie images activation, changes in TFEQ dietary restraint (factor 1 ) were negatively associated with activation in the right superior temporal gyrus, the right precentral gyrus and the left and right superior occipital gyrus. There were no significant clusters for changes in high-calorie versus low-calorie brain activation and changes in HOMA-IR, CPM, TFEQ disinhibition or TFEQ hunger.
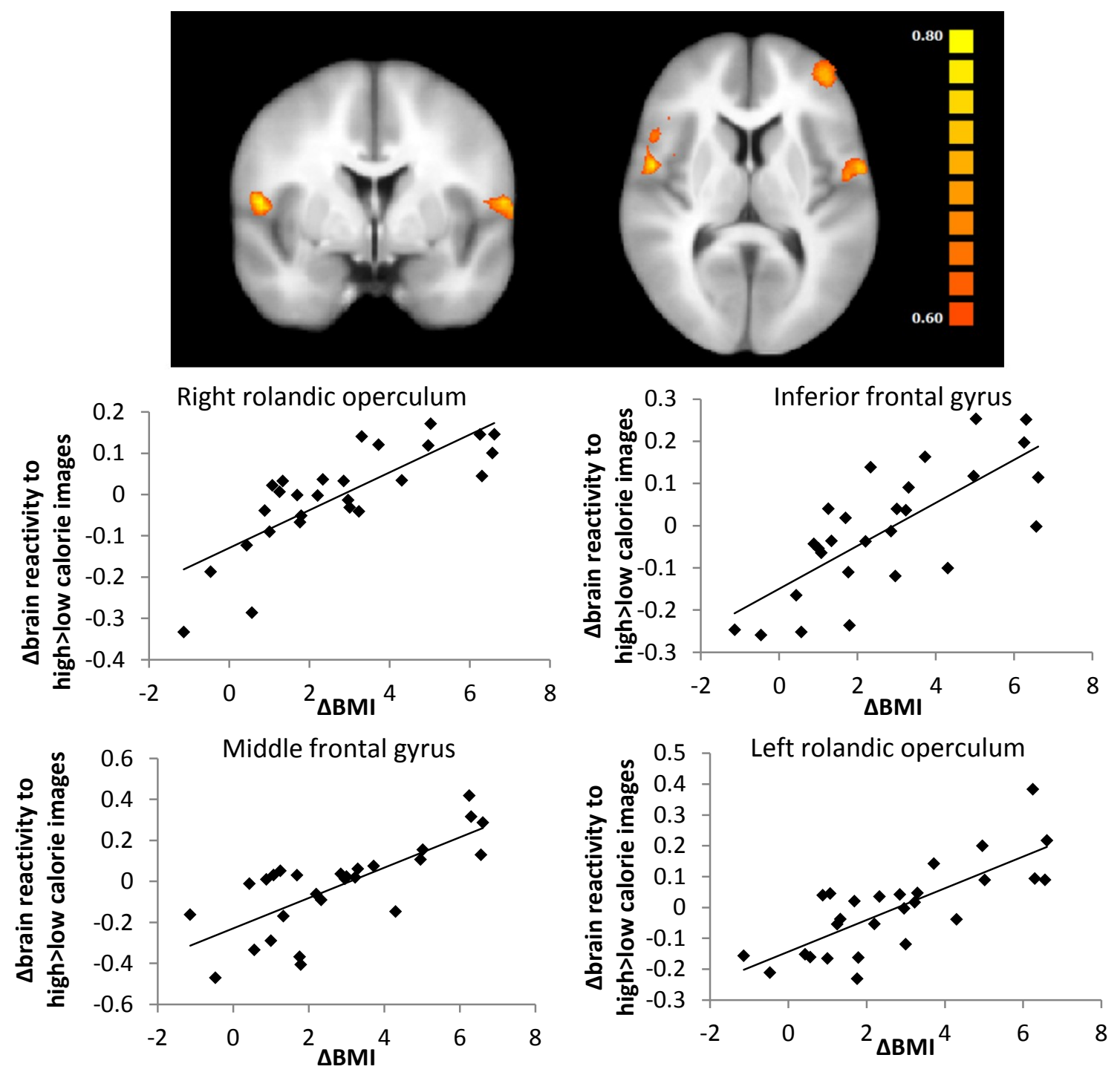

FIGURE 1. Whole brain contrast map of brain regions with significant associations between changes in high>low calorie images brain activation and changes in BMI. Positive associations are shown in orange ( $P<0.005$, corrected for multiple comparisons). Scatter plots of changes in BMI and changes in extracted high>low calorie images BOLD response are shown below. 

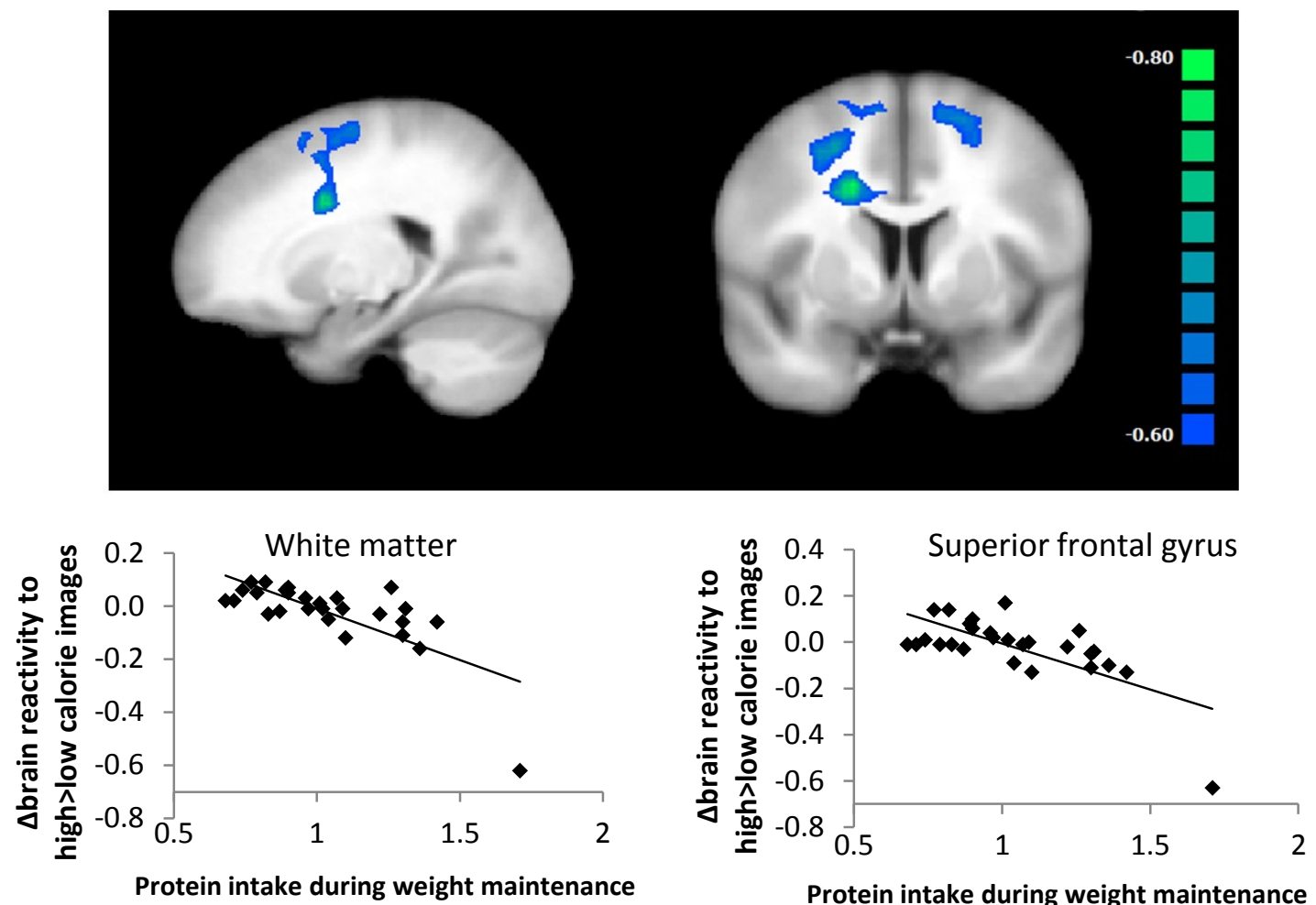

Protein intake during weight maintenance

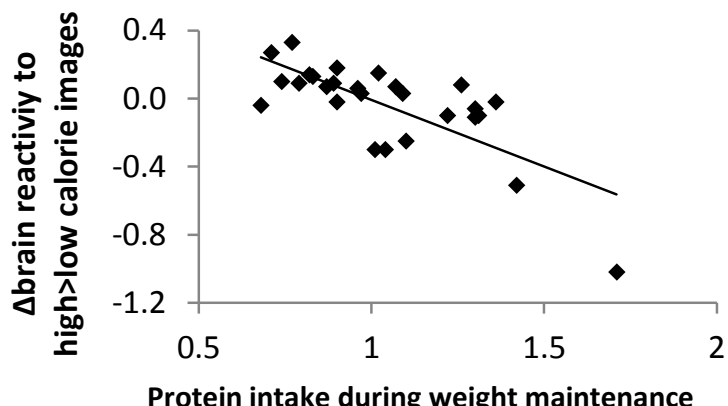

FIGURE 2. Whole brain contrast map of brain regions with significant inverse associations between changes in high>low calorie images brain activation and daily protein intake $(\mathrm{g} / \mathrm{kg})$ during weight maintenance. Inverse associations are shown in blue $(P<0.005$, corrected for multiple comparisons). Scatter plots of protein intake and changes in extracted high $>$ low calorie images BOLD response are shown below.

ROI analysis - relations between brain activation and BMI, fat mass, HOMA-IR, protein intake, activity or eating behavior

To specifically investigate the association in the a priori defined ROIs, average brain activation was extracted and associated with changes in BMI, fat mass, HOMA-IR, protein intake $(\mathrm{g} / \mathrm{kg})$, physical activity (CPM) or TFEQ scores.

\section{Food >non-food brain response}

Adjusted for changes in $\mathrm{BMI}$, changes in HOMA-IR were positively related to changes in $\mathrm{F}>\mathrm{nF}$ brain activation in the left nucleus accumbens $(r=0.60 ; p=0.001)$. Changes in $F>n F$ brain activation 
in the ROIs were not associated with changes in BMI, body-fat percentage, CPM, eating behavior or protein intake during weight maintenance.

High calorie > Low-calorie brain response

For the $\mathrm{H}>\mathrm{L}$ contrast, there was a positive association between changes in $B M I$ and brain activation in the right insula $(r=0.62 ; p=0.001)$ and right anterior cingulate $(r=0.58 ; p=0.002)$. Adjusted for changes in BMI, there were positive associations between changes in body-fat percentage and brain activation in the left insula $(r=0.71 ; p<0.001)$, the right $(r=0.54 ; p=0.005)$ and left nucleus accumbens $(r=0.58 ; p=0.002)$. Changes in CPM, TFEQ scores and protein intake during weight maintenance were not associated with changes in $\mathrm{H}>\mathrm{L}$ brain activation.

\section{DISCUSSION}

The aim of this study was to investigate the effects of weight loss and subsequent weight maintenance with relatively increased protein intake on brain reward activity in response to visual food in two groups of participants with overweight/obesity and IFG/IGT. There were no differences between the two protein groups in brain reactivity to food cues. However, we did not find differences in protein intake between the groups determined with urinary nitrogen excretion, implying the intervention was not successful in inducing the deliberate difference in protein intake between the groups.

Therefore, we applied post-hoc analyses on the whole group of participants to assess effects of protein intake on brain reactivity to food cues. Protein intake during the weight maintenance period in the whole group was negatively related to changes in brain activation contrasting highcalorie with low-calorie images in regions associated with frontal control (the superior frontal gyrus) and visual processing (the left inferior temporal gyrus). This is in line with evidence coming from short-term studies $(18,19)$. A high-protein breakfast was shown to further reduce hippocampal and parahippocampal reactivity to food cues compared to a normal-protein breakfast, measured in 20 overweight/obese girls in a randomized crossover study (18). Moreover, in 23 healthy women a 12-day low-protein diet compared to a high-protein diet led to an increased BOLD response in the orbitofrontal cortex and striatum in response to food cues (19). Based on our data, it is not possible to determine the causality of the relation between protein intake and brain reactivity to food cues, but multiple explanations have been postulated. Protein intake may influence brain signaling via changes in the neurotransmitter precursor availability. The amino acid tryptophan is the precursor for serotonin and tyrosine and phenylalanine are precursors for dopamine (25). Ingestion of protein increases the availability of these precursors, potentially resulting in higher neurotransmitter synthesis $(26,27)$. Furthermore, protein was shown to modulate food reward via activation of the vagus nerve, which projects to the nucleus tractus solitaries in the brain stem to relay satiety signals to the brain. Glutamate has shown to activate branches of the vagus nerve (28) and ingestion of glutamate led to activation of the amygdala, hippocampus and lateral hypothalamus in rats (29) while activation was fully suppressed after vagatomy. Indirectly, amino acids could also influence brain reward signaling through an increased release of anorectic hormones from the gut (15). It needs to be mentioned however, that in our particular study, the effects expected to be due to increased protein intake, could also 
be related to decreased carbohydrate or fat intake during the intervention (30). Increased protein intake during the dietary intervention may be part of a general change of a healthier lifestyle and other factors advocated in the PREVIEW intervention guidelines aiming at a generally healthier lifestyle could contribute to the results.

As expected, participants significantly reduced their body weight and fat mass during the intervention period. Changes in BMI were positively related to changes in brain reactivity to highcalorie compared to low-calorie images in the rolandic operculum, inferior frontal gyrus and middle frontal gyrus. Especially the inferior frontal gyrus and middle frontal gyrus have been implicated in dietary self-control $(31,32)$. The association with reactivity to high-calorie images versus low-calorie images is in line with studies reporting that activation in these regions modulates value-encoding regions when participants choose healthy over unhealthy foods (33). A positive relationship between brain response to food versus non-food cues in the anterior cingulate and BMI was also found in a study by Martens et al. (4). Furthermore, weight loss using a 6-month lifestyle intervention in overweight/obese individuals has previously shown to reduce brain activation to high-calorie images and cause a shift in relative activation favoring low-calorie versus high-calorie food cues in the putamen (34). Weight loss after bariatric surgery was shown to support reduced neuronal responses to food cues in multiple food reward regions $(14,35)$. In our study, changes in body fat percentage were positively related to changes in brain activation contrasting high-calorie with low-calorie images in various gustatory and frontal control regions, including the putamen and insula. This may be interesting in terms of linking eating behavior and body-fat mass (36). Higher cue reactivity in the putamen and insula has been associated with food cravings and may be a mechanism to match higher energy needs with increased adiposity $(10,37)$. Our findings are in line with a study that reported a positive association between brain activation to high-calorie food cues and abdominal fat in girls, independent of BMI (38). Suggested mechanisms through which fat mass may influence brain reward signaling are increased leptin concentrations or increased low-grade inflammation. Prior research reported a positive association between leptin concentrations and brain responses to high-calorie food versus nonfood cues in the putamen/caudate, insula and amygdala in lean and obese individuals $(39,40)$. Leptin injections were able to reduce weight loss-induced effects on neural activity to visual food cues in brain areas associated with regulatory, emotional and cognitive control of food intake (41). Adiposity-related inflammation has been suggested as another mechanism via which increased fat mass may moderate brain reward. Increased inflammation was shown to be related to reduced integrity and lower functional connectivity in food reward-related brain areas (42), but also to decreases in dopamine availability and release, leading to alterations in motivation and reward (43). Changes in body-fat percentage were positively associated with changes in reactivity to high-calorie images versus low calorie-images in the putamen and insula.

Region-of-interest analysis revealed that in our participants, changes in peripheral insulin resistance were positively related to changes in food versus non-food brain activation in the left nucleus accumbens. These results follow up on findings of a previous study in which we reported brain activation to food cues to be positively related to HOMA-IR (11). This observation is corroborating other studies reporting positive relations between markers of insulin resistance and 
brain reward signaling in different study populations (8-10). In the present study we used HOMAIR as a marker insulin resistance, but our results are also supported by studies investigating the effects of intranasal insulin administration on brain reward signaling (44). Intranasal insulin administration was shown to inhibit forward projections from the ventral tegmental area to the nucleus accumbens, and this was related to a reduction in food value, but these modulatory effects of insulin were not present in participants with increased insulin resistance (45). We found a significant relation between changes in insulin resistance and changes in brain reward signaling over a two year period, further illustrating the importance of reducing insulin resistance.

With regard to eating behavior, we found that changes in high versus low-calorie images were negatively associated with changes in dietary restraint in gustatory and visual processing regions. Dietary restraint increased during the intervention, which converges with studies reporting increased dietary restraint after caloric restriction $(46,47)$. This relation between dietary restrained and brain response to food images could be a possible mechanism via which dietary restraint leads to more healthy food habits $(48,49)$.

Our study is limited by the lack of difference in protein intake between the two intervention groups. Due to this, we cannot exclude that the lack of differences in changes in brain reactivity between the intervention groups may be due to type II errors. Therefore, post-hoc analyses were performed on the whole group to assess the relation between protein intake and brain reactivity to food cues. We acknowledge the need of replicating our results in long-term studies with provided dietary protein in order to achieve the goals of protein intake levels as indicated.

In conclusion, we found an association between the relatively increased intake of protein and a reduction in brain response to high-calorie food images compared to low-calorie food images in brain reward related regions in the total group of participants. Changes of anthropometric parameters, including body weight and body fat percentage during the intervention period, were positively associated with changes in brain responses to high-calorie versus low-calorie images. The reduction in insulin resistance throughout the intervention period was associated with a general reduction in the food reward response, evidenced by the positive association of brain activation contrasting food versus non-food images. Changes in dietary restraint were inversely associated with changes in brain response to high-calorie food images compared to low-calorie food images in gustatory and visual processing regions. 


\section{SUPPLEMENTARY MATERIAL}

The following are available online at www.mdpi.com/2072-6643/10/11/1771/s1, Figure S1: Participant flowchart, Figure S2: $A$ priori selected regions of interest, Figure S3: Whole brain contrast map of brain regions with significant associations between changes in food $>$ non-food brain activation and changes in body-fat percentage, Figure S4: Whole brain contrast map of brain regions with significant inverse associations between changes in food>non-food brain activation and changes in body-fat percentage, Figure S5: Whole brain contrast map of brain regions with significant associations between changes in high $>$ low calorie images brain activation and changes in body-fat percentage, Figure S6: Whole brain contrast map of brain region with significant inverse associations between changes in high>low calorie images brain activation and changes in TFEQ dietary restraint (factor 1)

\section{ACKNOWLEDGEMENTS}

We would like to thank all the PREVIEW participants and members of the PREVIEW consortium, coordinated by Anne Raben.

\section{FUNDING}

This study has received a grant from the EU $7^{\text {th }}$ Framework Programme grant \#312057 (FP7-KBBE2012.2.2-03).

\section{AUTHOR CONTRIBUTIONS}

Conceptualization, M.D., M.W-P, T.A..; methodology, M.D., T.A..; software, M.D., T.A., G.S..; formal analysis, M.D.; writing-original draft preparation, M.D..; writing-review and editing, M.D., E.D., A.V., G.S., A.R., M.W-P, T.A..; visualization, M.D..; supervision, M.W-P, T.A. 


\section{REFERENCES}

1. Vazquez G, Duval S, Jacobs DR, Jr., Silventoinen K. Comparison of body mass index, waist circumference, and waist/hip ratio in predicting incident diabetes: a meta-analysis. Epidemiol Rev. 2007;29:115-128.

2. Eckel $\mathrm{RH}$, Kahn SE, Ferrannini $\mathrm{E}$, et al. Obesity and type 2 diabetes: what can be unified and what needs to be individualized? Diabetes Care. 2011;34(6):1424-1430.

3. Stice E, Spoor S, Bohon C, Veldhuizen MG, Small DM. Relation of reward from food intake and anticipated food intake to obesity: a functional magnetic resonance imaging study. J Abnorm Psychol. 2008;117(4):924935.

4. Martens MJ, Born JM, Lemmens SG, et al. Increased sensitivity to food cues in the fasted state and decreased inhibitory control in the satiated state in the overweight. Am J Clin Nutr. 2013;97(3):471-479.

5. Chechlacz $\mathrm{M}$, Rotshtein $\mathrm{P}$, Klamer $\mathrm{S}$, et al. Diabetes dietary management alters responses to food pictures in brain regions associated with motivation and emotion: a functional magnetic resonance imaging study. Diabetologia. 2009;52(3):524-533.

6. Carnell S, Gibson C, Benson L, Ochner CN, Geliebter A. Neuroimaging and obesity: current knowledge and future directions. Obes Rev. 2012;13(1):43-56.

7. Vidarsdottir S, Smeets PA, Eichelsheim DL, et al. Glucose ingestion fails to inhibit hypothalamic neuronal activity in patients with type 2 diabetes. Diabetes. 2007;56(10):2547-2550.

8. Kullmann $\mathrm{S}$, Heni $\mathrm{M}$, Veit $\mathrm{R}$, et al. Selective insulin resistance in homeostatic and cognitive control brain areas in overweight and obese adults. Diabetes Care. 2015;38(6):1044-1050.

9. Adam TC, Tsao S, Page KA, Hu H, Hasson RE, Goran MI. Insulin sensitivity and brain reward activation in overweight Hispanic girls: a pilot study. Pediatr Obes. 2015;10(1):30-36.

10. Jastreboff AM, Sinha R, Lacadie C, Small DM, Sherwin RS, Potenza MN. Neural correlates of stress- and food cue-induced food craving in obesity: association with insulin levels. Diabetes Care. 2013;36(2):394402.

11. Drummen $\mathrm{M}$, Dorenbos $\mathrm{E}$, Vreugdenhil $\mathrm{AC}$, et al. Insulin Resistance, Weight and Behavioral Variables as Determinants of Brain Reactivity to Food Cues - a PREVIEW study. Am J CLin Nutr. 2018.

12. Figlewicz DP, Evans SB, Murphy J, Hoen M, Baskin DG. Expression of receptors for insulin and leptin in the ventral tegmental area/substantia nigra (VTA/SN) of the rat. Brain Res. 2003;964(1):107-115.

13. Behary P, Miras AD. Brain responses to food and weight loss. Exp Physiol. 2014;99(9):1121-1127.

14. Frank S, Heinze JM, Fritsche A, et al. Neuronal Food Reward Activity in Patients With Type 2 Diabetes With Improved Glycemic Control After Bariatric Surgery. Diabetes Care. 2016;39(8):1311-1317.

15. Journel M, Chaumontet C, Darcel N, Fromentin G, Tome D. Brain responses to high-protein diets. Adv Nutr. 2012;3(3):322-329.

16. Min DK, Tuor UI, Koopmans HS, Chelikani PK. Changes in differential functional magnetic resonance signals in the rodent brain elicited by mixed-nutrient or protein-enriched meals. Gastroenterology. 2011;141(5):1832-1841.

17. Li J, An R, Zhang Y, Li X, Wang S. Correlations of macronutrient-induced functional magnetic resonance imaging signal changes in human brain and gut hormone responses. Am J Clin Nutr. 2012;96(2):275-282.

18. Leidy HJ, Ortinau LC, Douglas SM, Hoertel HA. Beneficial effects of a higher-protein breakfast on the appetitive, hormonal, and neural signals controlling energy intake regulation in overweight/obese, "breakfast-skipping," late-adolescent girls. Am J Clin Nutr. 2013;97(4):677-688.

19. Griffioen-Roose S, Smeets PA, van den Heuvel E, Boesveldt S, Finlayson G, de Graaf C. Human protein status modulates brain reward responses to food cues. Am J Clin Nutr. 2014;100(1):113-122.

20. Fogelholm M, Larsen TM, Westerterp-Plantenga $M$, et al. PREVIEW: Prevention of Diabetes through Lifestyle Intervention and Population Studies in Europe and around the World. Design, Methods, and Baseline Participant Description of an Adult Cohort Enrolled into a Three-Year Randomised Clinical Trial. Nutrients. 2017;9(6).

21. Lang PJ. The emotion probe. Studies of motivation and attention. Am Psychol. 1995;50(5):372-385.

22. Plasqui G, Soenen S, Westerterp-Plantenga MS, Westerterp KR. Measurement of longitudinal changes in body composition during weight loss and maintenance in overweight and obese subjects using airdisplacement plethysmography in comparison with the deuterium dilution technique. Int J Obes (Lond). 2011;35(8):1124-1130.

23. Matthews DR, Hosker JP, Rudenski AS, Naylor BA, Treacher DF, Turner RC. Homeostasis model assessment: insulin resistance and beta-cell function from fasting plasma glucose and insulin concentrations in man. Diabetologia. 1985;28(7):412-419. 
24. Stunkard AJ, Messick S. The three-factor eating questionnaire to measure dietary restraint, disinhibition and hunger. J Psychosom Res. 1985;29(1):71-83.

25. Institute of Medicine Committee on Military Nutrition R. In: The Role of Protein and Amino Acids in Sustaining and Enhancing Performance. Washington (DC): National Academies Press (US)

26. Choi $\mathrm{S}$, Disilvio $\mathrm{B}$, Fernstrom MH, Fernstrom JD. Meal ingestion, amino acids and brain neurotransmitters: effects of dietary protein source on serotonin and catecholamine synthesis rates. Physio/ Behav. 2009;98(12):156-162.

27. Growdon JH, Cohen EL, Wurtman RJ. Effects of oral choline administration on serum and CSF choline levels in patients with Huntington's disease. J Neurochem. 1977;28(1):229-231.

28. Kondoh T, Mallick HN, Torii K. Activation of the gut-brain axis by dietary glutamate and physiologic significance in energy homeostasis. Am J Clin Nutr. 2009;90(3):832s-837s.

29. Uematsu A, Tsurugizawa T, Uneyama H, Torii K. Brain-gut communication via vagus nerve modulates conditioned flavor preference. EurJ Neurosci. 2010;31(6):1136-1143.

30. Avena NM, Rada P, Hoebel BG. Sugar and fat bingeing have notable differences in addictive-like behavior. $J$ Nutr. 2009;139(3):623-628.

31. Harris A, Hare T, Rangel A. Temporally dissociable mechanisms of self-control: early attentional filtering versus late value modulation. J Neurosci. 2013;33(48):18917-18931.

32. Neseliler S, Hu W, Larcher K, et al. Neurocognitive and Hormonal Correlates of Voluntary Weight Loss in Humans. Cell Metab. 2018.

33. Hare TA, Malmaud J, Rangel A. Focusing Attention on the Health Aspects of Foods Changes Value Signals in vmPFC and Improves Dietary Choice. The Journal of Neuroscience. 2011;31(30):11077-11087.

34. Deckersbach T, Das SK, Urban LE, et al. Pilot randomized trial demonstrating reversal of obesity-related abnormalities in reward system responsivity to food cues with a behavioral intervention. Nutr Diabetes. 2014;4:e129.

35. Ochner CN, Laferrere B, Afifi L, Atalayer D, Geliebter A, Teixeira J. Neural responsivity to food cues in fasted and fed states pre and post gastric bypass surgery. Neurosci Res. 2012;74(2):138-143.

36. O'Neill BV, Bullmore ET, Miller S, et al. The relationship between fat mass, eating behaviour and obesityrelated psychological traits in overweight and obese individuals. Appetite. 2012;59(3):656-661.

37. Murdaugh DL, Cox JE, Cook EW, 3rd, Weller RE. fMRI reactivity to high-calorie food pictures predicts shortand long-term outcome in a weight-loss program. Neuroimage. 2012;59(3):2709-2721.

38. Luo S, Romero A, Adam TC, Hu HH, Monterosso J, Page KA. Abdominal fat is associated with a greater brain reward response to high-calorie food cues in Hispanic women. Obesity (Silver Spring). 2013;21(10):2029-2036.

39. Jastreboff AM, Lacadie C, Seo D, et al. Leptin is associated with exaggerated brain reward and emotion responses to food images in adolescent obesity. Diabetes Care. 2014;37(11):3061-3068.

40. Grosshans M, Vollmert C, Vollstadt-Klein S, et al. Association of leptin with food cue-induced activation in human reward pathways. Arch Gen Psychiatry. 2012;69(5):529-537.

41. Rosenbaum M, Sy M, Pavlovich K, Leibel RL, Hirsch J. Leptin reverses weight loss-induced changes in regional neural activity responses to visual food stimuli. J Clin Invest. 2008;118(7):2583-2591.

42. Cazettes F, Cohen JI, Yau PL, Talbot H, Convit A. Obesity-mediated inflammation may damage the brain circuit that regulates food intake. Brain Res. 2011;1373:101-109.

43. Felger JC, Treadway MT. Inflammation Effects on Motivation and Motor Activity: Role of Dopamine. Neuropsychopharmacology. 2017;42(1):216-241.

44. Heni M, Kullmann S, Preissl H, Fritsche A, Haring HU. Impaired insulin action in the human brain: causes and metabolic consequences. Nat Rev Endocrinol. 2015;11(12):701-711.

45. Tiedemann LJ, Schmid SM, Hettel J, et al. Central insulin modulates food valuation via mesolimbic pathways. Nat Commun. 2017;8:16052.

46. Westerterp-Plantenga MS, Lejeune MP, Nijs I, van Ooijen M, Kovacs EM. High protein intake sustains weight maintenance after body weight loss in humans. Int J Obes Relat Metab Disord. 2004;28(1):57-64.

47. Westerterp-Plantenga MS, Kempen KP, Saris WH. Determinants of weight maintenance in women after diet-induced weight reduction. Int J Obes Relat Metab Disord. 1998;22(1):1-6.

48. Rideout CA, McLean JA, Barr SI. Women with high scores for cognitive dietary restraint choose foods lower in fat and energy. J Am Diet Assoc. 2004;104(7):1154-1157.

49. Moreira $P$, de Almeida MD, Sampaio D. Cognitive restraint is associated with higher intake of vegetables in a sample of university students. Eat Behav. 2005;6(3):229-237. 


\section{SUPPLEMENTAL FIGURE 1. Participant flowchart}

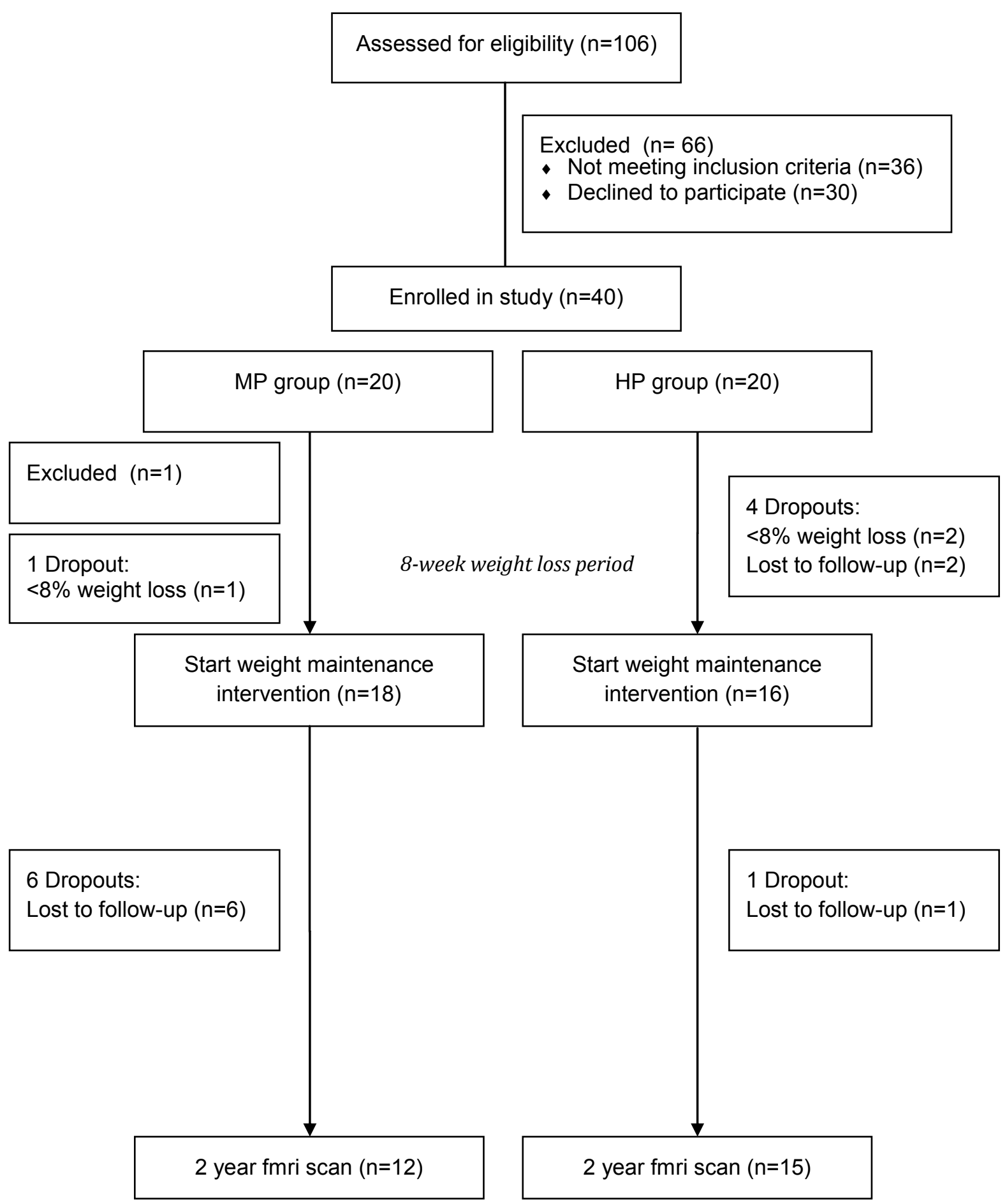




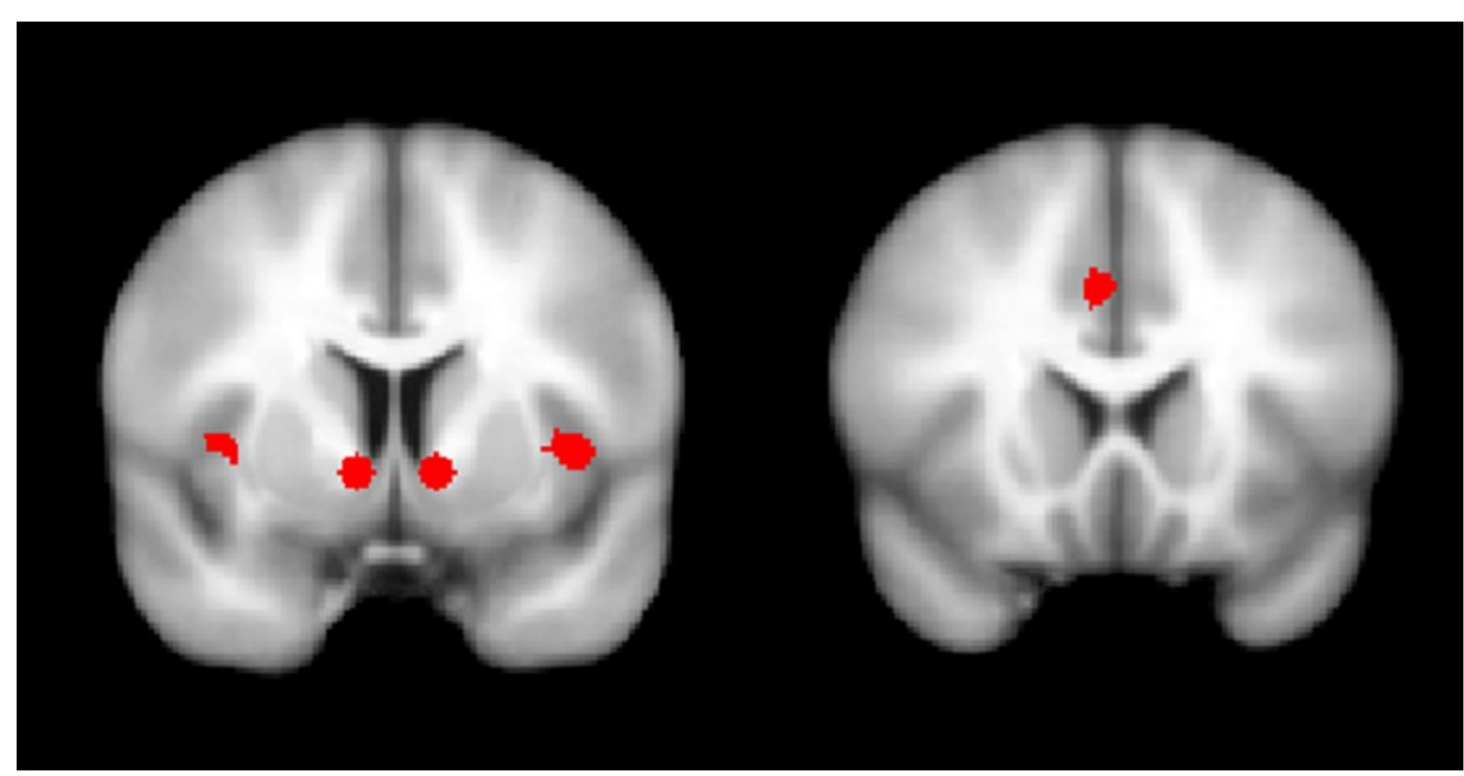

\section{SUPPLEMENTAL FIGURE 2. A priori selected regions of interest}

Regions were selected from Drummen et al. (2018; AJCN) based on significant associations brain reactivity to food cues and insulin resistance. ROIs included the right and left insular cortex, the left and right nucleus accumbens and the right anterior cingulate. 

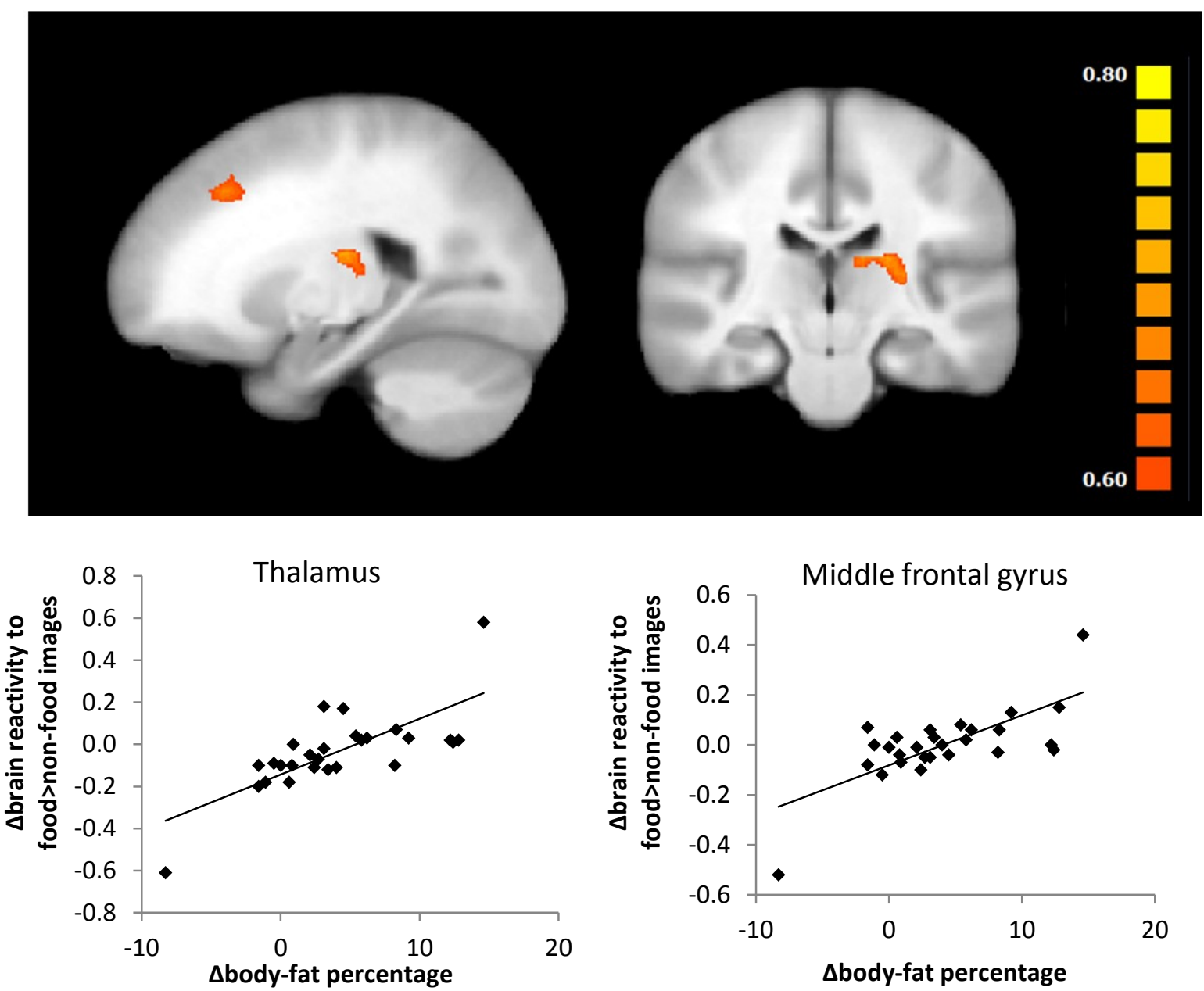

SUPPLEMENTAL FIGURE 3. Whole brain contrast map of brain regions with significant associations between changes in food $>$ non-food brain activation and changes in body-fat percentage. Positive associations are shown in orange ( $P<0.005$, corrected for multiple comparisons). Scatter plots of changes in body-fat percentage and changes in extracted food $>$ non-food BOLD response are shown below. 

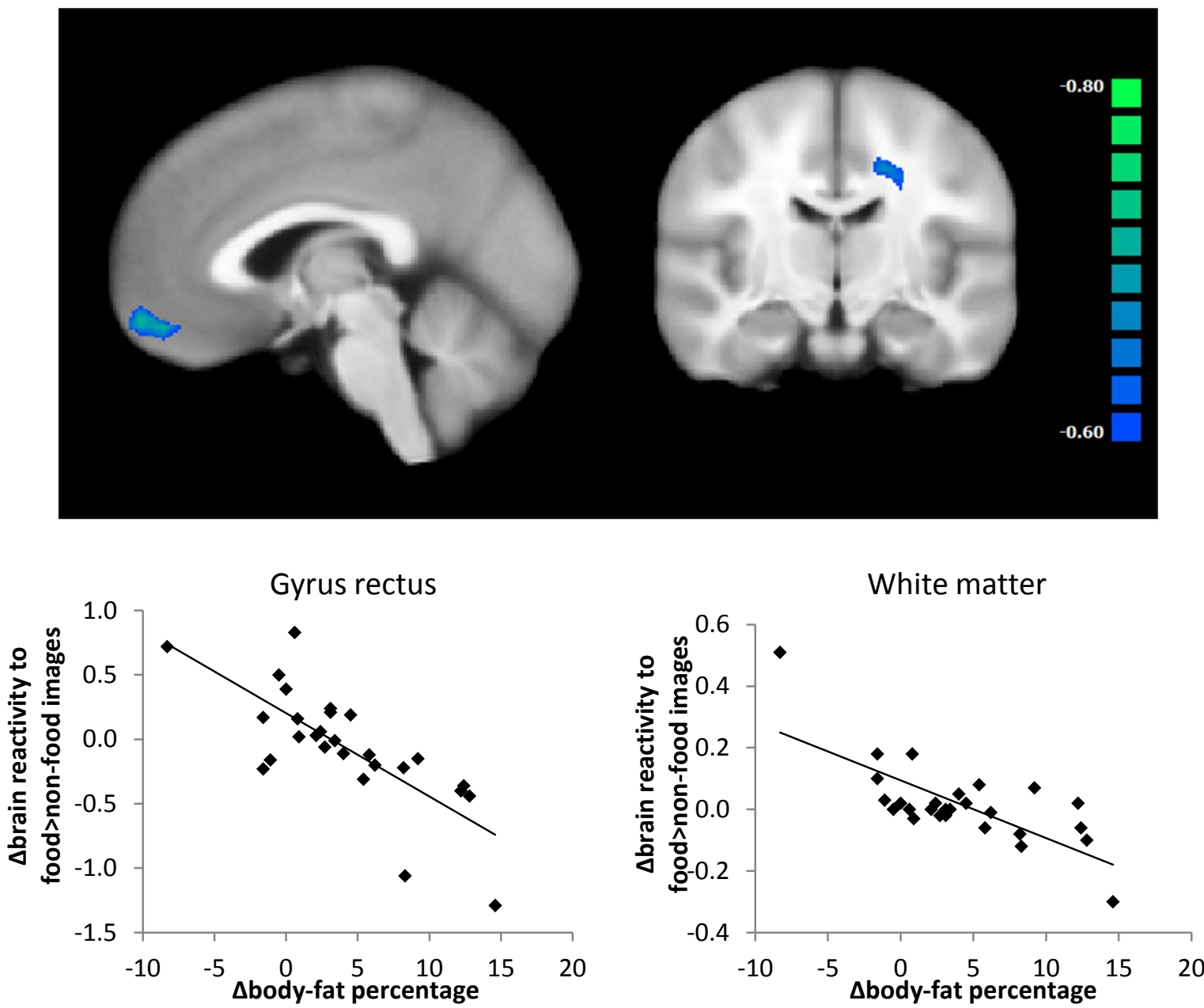

SUPPLEMENTAL FIGURE 4. Whole brain contrast map of brain regions with significant inverse associations between changes in food >non-food brain activation and changes in body-fat percentage. Inverse associations are shown in blue $(\mathrm{P}<0.005$, corrected for multiple comparisons). Scatter plots of changes in body-fat percentage and changes in extracted food $>$ non-food BOLD response are shown below. 

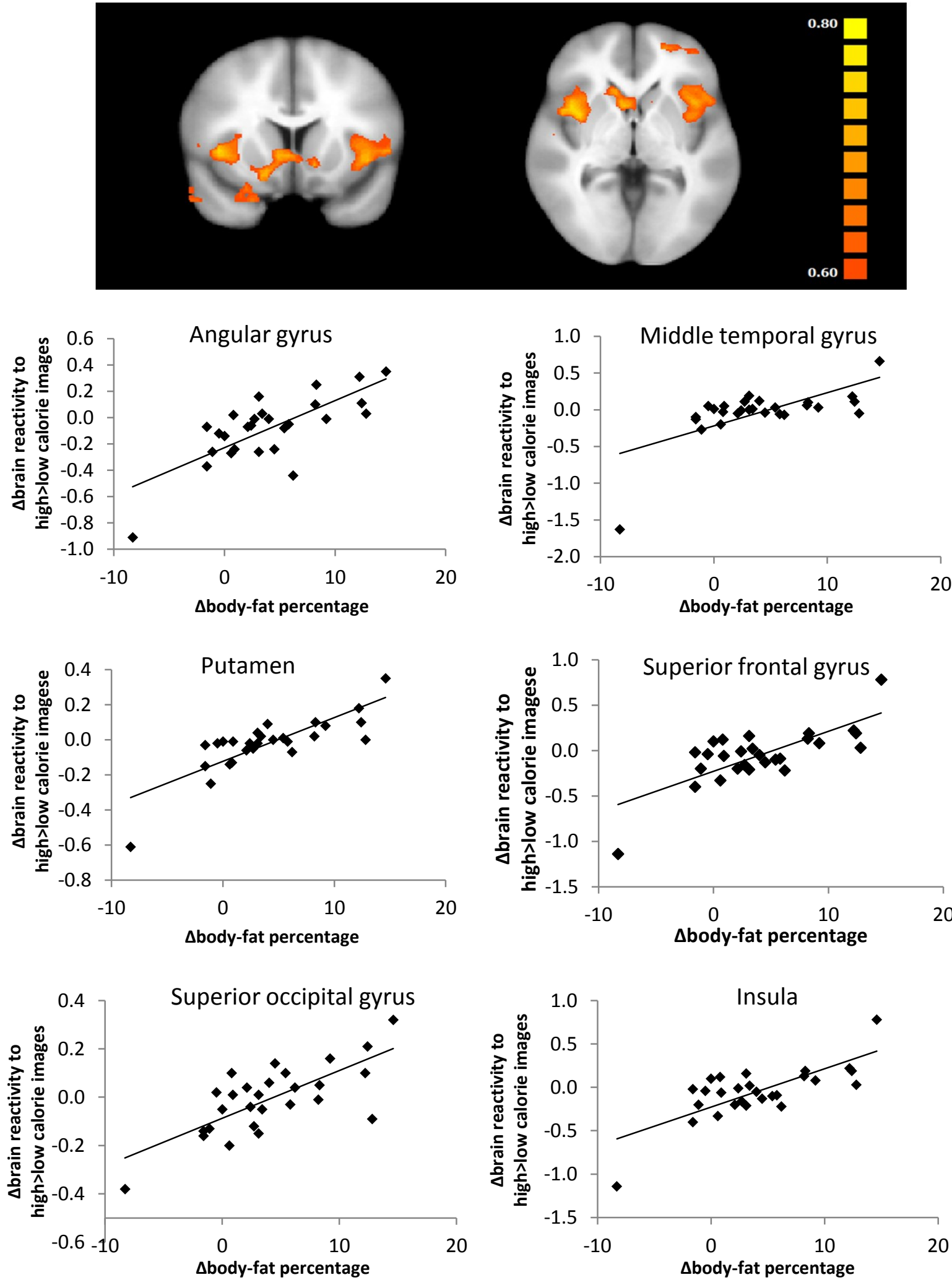

SUPPLEMENTAL FIGURE 5. Whole brain contrast map of brain regions with significant associations between changes in high>low calorie images brain activation and changes in body-fat percentage. Positive associations are shown in orange $(\mathrm{P}<0.005$, corrected for multiple comparisons). Scatter plots of changes in body-fat percentage and changes in extracted high>low calorie images BOLD response are shown below. 

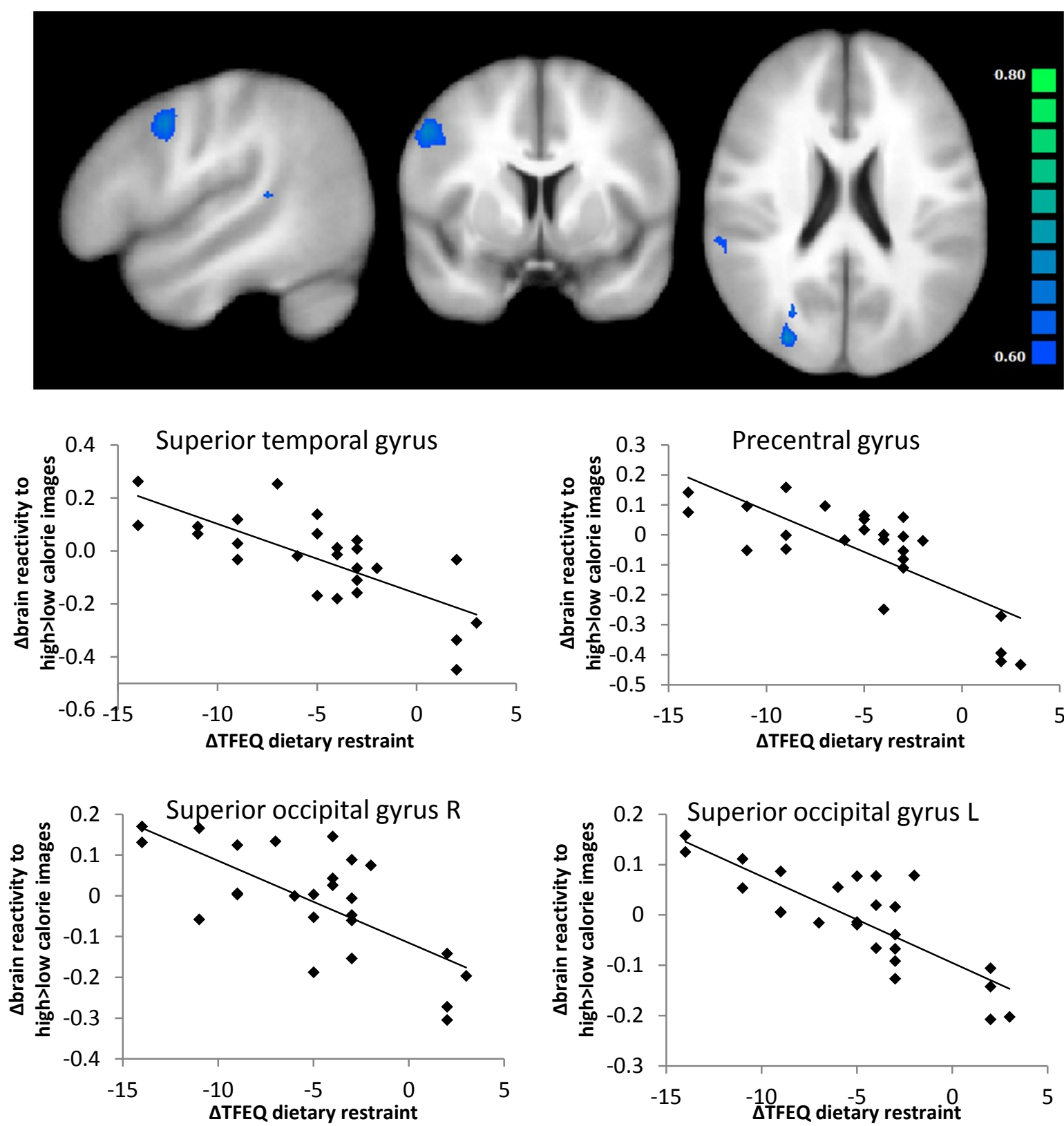

SUPPLEMENTAL FIGURE 6. Whole brain contrast map of brain region with significant inverse associations between changes in high>low calorie images brain activation and changes in TFEQ dietary restraint (factor 1 ). Inverse associations are shown in blue $(\mathrm{P}<0.005$, corrected for multiple comparisons). Scatter plot of changes in TFEQ dietary restraint and changes in extracted high>low calorie images BOLD response are shown below. 



\section{CHAPTER 9}

Grey brain matter volume and cortical thickness in the PREVIEW study

M. Drummen, A. Heinecke, E. Dorenbos, A. Vreugdenhil, A. Raben, M.S. WesterterpPlantenga and T. Adam 


\section{ABSTRACT}

\section{Introduction}

The effect of changes in body weight or insulin resistance on grey matter volume and cortical thickness change are unclear. The present observational study assessed effects of an 8-week weight loss period ( $\geq 8 \%$ of body weight), and a subsequent 22 -month weight maintenance period on grey matter volume and cortical thickness.

\section{Methods}

A total of 24 participants (12f/12m; age $52.8 \pm 10.6$ years) with overweight/obesity and prediabetes were recruited. T1-weighted magnetic resonance imaging was used to determine grey matter volume and cortical thickness at baseline, after the weight loss period and after a medium to high dietary protein weight maintenance period.

\section{Results}

At baseline, global grey matter volume was inversely associated with HOMA-IR, adjusted for sex and age $(r=-0.42 ; p=0.049)$. During the weight loss period participants decreased their BMI $\left(32.1 \pm 3.3\right.$ to $\left.28.1 \pm 2.8 \mathrm{~kg} / \mathrm{m}^{2}, p<0.01\right)$, body-fat $(41.6 \pm 6.4$ to $35.0 \pm 8.0 \%, p<0.01)$ and insulin resistance (HOMA-IR: $4.0 \pm 2.0$ to $1.8 \pm 0.9, p<0.01$ ). During the 22 -month weight maintenance period, these parameters gradually increased again (BMI: $29.3 \pm 3.8 \mathrm{~kg} / \mathrm{m}^{2}$; body-fat: $37.8 \pm 9.3 \%$; HOMA-IR: $2.9 \pm 1.4, p<0.01$ ). Global grey matter volume and cortical thickness did not change significantly during the weight loss or weight maintenance period. Changes in body weight, bodyfat percentage or insulin sensitivity were not associated with changes in global grey matter volume.

\section{Conclusion}

In conclusion, we confirmed that global grey brain matter volume was inversely associated with insulin resistance at baseline, yet an intervention yielding a decrease in insulin resistance did not lead to changes in global grey brain matter volume or cortical thickness. 


\section{INTRODUCTION}

Overweight and obesity and its related metabolic dysfunctions have been previously linked to altered grey matter volume and cortical thickness (1-5). While grey matter volume is a function of cortical surface area and cortical thickness, the latter has been posed as a more relevant marker of brain functioning than grey matter volume (6). Multiple studies have shown a relationship between grey matter volume and cortical thickness with body weight and insulin sensitivity, but findings have been inconsistent $(2,4,7-16)$. The results suggest that cortical thickness and grey matter volume are dynamic variables affected by different physiological parameters. Studies have reported longitudinal changes in cortical thickness and grey matter volume related to aging (17, 18), but it remains unclear if and how cortical thickness or grey matter volume change with changes in body weight or insulin resistance. Previously a higher BMI was shown to be a predictor of decline in temporal and occipital grey matter over the time period of 5 years (19) and other studies reported increases in cortical thickness after weight loss induced by bariatric surgery (20) and sleeve gastrectomy (21). In the current observational study, we investigated the effects of the PREVIEW intervention on cortical thickness and grey matter volume over the time period of two years, while the participants followed a weight loss and weight maintenance intervention program.

\section{DESIGN AND METHODS}

\section{Participants}

In total, twenty-four participants were assessed in this study. Participants were all part of the PREVIEW study (Prevention of Diabetes through lifestyle intervention and population studies in Europe and around the World, EU 7th Framework Programme, grant agreement no. 312057, ClinicalTrials.gov NCT01777893), which has been initiated to find the most effective lifestyle (diet and physical activity) for the prevention of type 2 diabetes in overweight and obese participants with increased risk for type 2 diabetes (www.previewstudy.com) (22). Inclusion criteria were: age 25-70 years, BMI $\geq 25 \mathrm{~kg} / \mathrm{m}^{2}$, fasting plasma glucose of $5.6-6.9 \mathrm{mmol} / \mathrm{l}$ and/or plasma glucose concentration of $7.8-11.0 \mathrm{mmol} / \mathrm{l}$ at $2 \mathrm{~h}$ after an oral glucose tolerance test (OGTT), and willingness to undergo MRI procedures. Exclusion criteria included T2D, left-handedness, claustrophobia and history of neurological disorders in addition to the general PREVIEW exclusion criteria (ClinicalTrials.gov NCT01777893). Forty participants of the PREVIEW study were recruited at Maastricht University to investigate to effects of the PREVIEW study on brain responsiveness to food cues, as was described previously (23). Of these participants, twenty-four participants completed magnetic resonance imaging (MRI) scans with sufficient quality of the anatomical images to be used in the current study. The study was approved by the Medical Research Ethics Committee of Maastricht University Medical Center and in accordance with guidelines of the Declaration of Helsinki. All participants provided written informed consent for participation.

\section{Study design}

All participants started with an 8-week weight loss period on a LED with the aim to lose at least $8 \%$ of their body weight. The LED provided 3.4 MJ (35-40 E\% protein, 45-50 E\% carbohydrate, 15- 
20 E\% fat) per day with four sachets of the Cambridge Weight Plan ${ }^{\circledR}, 3$ of which were dissolved in $250 \mathrm{~mL}$ low fat milk and one in $250 \mathrm{~mL}$ water. Additionally, energy-free drinks and $<400$ gram per day of non-starchy, low-CHO vegetables were allowed. The weight loss period was followed by a weight maintenance period with instructions to follow dietary guidelines with the instruction to maintain the achieved body weight. Additional weight loss was allowed. Dietary guidelines were provided in two groups, a moderate protein moderate glycaemic index group (MPMGI) and a high protein low glycaemic index (HPLGI) group. The MPMGI group received instructions to ingest 15/55/30 percentage of total energy intake from protein/carbohydrate/fat and focus on products/meals with a glycaemic index $\geq 56$. The HPLGI group received instructions to ingest 25/45/30 percentage of total energy intake from protein/carbohydrate/fat and focus on products/meals with a glycaemic index $\leq 50$. Participants were randomized at the start of the study and were notified of their group allocation after the LED period. More detailed information on the dietary guidelines and of the intervention groups has been reported before (22). At baseline, after weight loss and after 2 years, measurements were performed after an overnight $>10 \mathrm{~h}$ fasting period. Measurements included MRI, air displacement plethysmography to determine body composition and blood sampling to determine fasting glucose and fasting insulin.

\section{MRI acquisition}

Scanning was performed on a 3 Tesla scanner (Magnetom, Siemens, Erlangen, Germany). Highresolution T1-weighted structural volume was acquired with a MPRAGE sequence using the following parameters: matrix $256 \times 256 \mathrm{~mm}$, voxel resolution $1.0 \times 1.0 \times 1.0 \mathrm{~mm}, 1 \mathrm{~mm}$ slice thickness, no gap, flip angle $=9, T E=2.98 \mathrm{~ms}, \mathrm{TR}=2300 \mathrm{~ms}$.

\section{Image processing}

Preprocessing and analysis of the MRI data was performed with a combination of the "volBrain" online analysis pipeline (http://volbrain.upv.es) (24) and BrainVoyager version 20.6 (Brain Innovation B.V, Maastricht, The Netherlands). First, the data was processed within the volBrain pipeline, which included the following procedures: inhomogeneity correction, brain normalizations to MNI152 space, a second fine inhomogeneity correction, intensity standardization, intracranial cavity segmentation, tissue classification, hemisphere segmentation, cerebellum and subcortical structures segmentation. More details can be found in Manjon and Coupé (24). Using this pipeline, grey matter volume as percentage of intracranial cavity was obtained for the total brain and the left and right cerebrum. After running the volBrain pipeline, preprocessed and normalized anatomical images were imported into BrainVoyager for further data processing and analysis steps.

\section{Preparation for cortical thickness measurement}

First, an automatic brain peeling based on the voxel intensities within the data was applied. The peeled anatomy was converted from the original $1 \mathrm{~mm}$ data resolution into a $0.5 \mathrm{~mm}$ isovoxel representation. In a third step, the ventricles and subcortical regions were filled using a partially mask-based approach. Fourth, the cerebellum was removed automatically from the data. 
Following that, a tissue contrast enhancement procedure based on a sigma filter with a range of 5 was applied. The final preparation steps included an adaptive segmentation of the border between grey and white matter as well as a dilation to the CSF / pial surface. The resulting document included only two intensity levels for grey and white matter/subcortical regions. Cortical thickness was measured on the basis of this highly simplified representation of the data using LaPlace equations (25).

\section{Surface-based analysis}

In a second analysis path, the boundary between grey and white matter created for the calculation of cortical thickness values was used to create a highly detailed surface mesh representation for each hemisphere of each subject at each time point. The surface meshes were then normalized and aligned using the cortex-based alignment approach described in Fischl et al. (26) . Intra and Inter-subject alignment was performed using the specific curvature information available for each cortical hemisphere.

\section{Combination of volumetric thickness value and surface information}

Volumetric cortical thickness data was sampled into the corresponding surface meshes to create a cortical thickness surface map for each subject, hemisphere and time point. All these cortical thickness surface maps were aligned on the surface using the output of the aforementioned cortex-based alignment results, which allows a direct and fair comparison of cortical thickness at specific macroanatomical landmarks. All results were depicted on an average surface mesh representation created with the usage of the cortex-based alignment information. More information on the variability of cortical landmarks and its improvement via cortex-based alignment can be found in Frost and Goebel (27).

\section{Body weight and composition}

Body weight was measured using a calibrated scale (Life Measurement Corporation, Inc, Concord, CA, USA) and body composition was determined using the BodPod System (Life Measurement Corporation, Inc, Concord, CA, USA) (28). Height was measured using a wall-mounted stadiometer to the nearest $0.1 \mathrm{~cm}$ (Seca, model 222, Seca, Hamburg, Germany).

\section{Blood samples and insulin resistance}

Blood samples to determine glucose and insulin concentrations were taken in a fasted condition. Blood samples were analysed at the National Institution for Health and Welfare in Helsinki, Finland. The homeostatic model assessment for insulin resistance (HOMA-IR) was used to assess insulin resistance and was calculated as follows: fasting glucose $x$ fasting insulin / 22.5 (29). Plasma glucose was measured by enzymatic hexokinase method and insulin was measured using chemiluminescent microparticle immunoassay. 
Statistical analysis

Data are expressed as mean \pm SD SPSS 23 (IBM corp., Armonk NY, USA). Analyses were performed using BrainVoyager 20.6 (Brain Innovation B.V., Maastricht, The Netherlands) and the Statistical Package for the Social Sciences (SPSS, IBM Corp., IBM SPSS Statistics, V23, Armonk, NY, USA). Pearson's correlation analysis was used to determine the relation between average cortical thickness or grey matter volume and anthropometric parameters. Whole brain correlation analyses were used to determine the relation between regional cortical thickness and anthropometric variables. Repeated measures ANOVA and whole brain repeated measures ANOVA were used to assess differences during the intervention. Mixed model regression analysis was used to determine relationships of anthropometric variables and insulin resistance with GM or CT. For the whole brain analyses, Monte Carlo simulations were performed in BrainVoyager to identify cluster-extent thresholds with a cluster alpha of 0.05 . Simulations were performed with 1000 iterations and an independent voxel threshold of $p<0.001$. Since the participants were allocated to two different dietary intervention groups in the PREVIEW study, group effects were tested. There were no differences at baseline or different changes between the groups in any of the variables.

\section{RESULTS}

\section{Baseline relations with grey matter volume}

We found a negative association between age and grey matter volume $(r=-0.55 ; p=0.005)$ with grey matter volume being lower in men compared to women $(45.2 \pm 2.2 \%$ vs $48.2 \pm 2.0 \% ; p=0.002)$. After adjusting for age and gender, grey matter volume was inversely associated with HOMA-IR $(r=-0.42 ; p=0.049)$. There were no significant associations between grey matter volume and BMI or body-fat percentage.
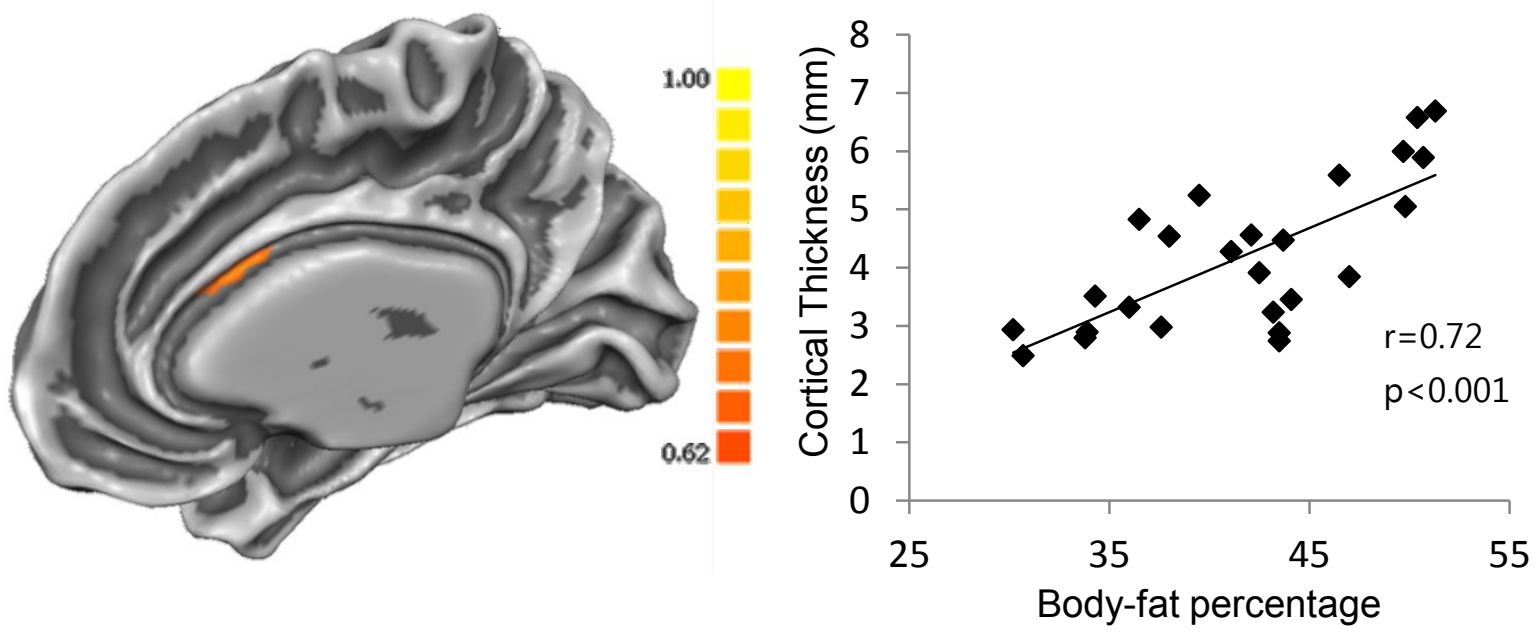

FIGURE 1. Association between cortical thickness and body-fat percentage. Monte Carlo simulations were used to determine minimal cluster size using an independent voxel threshold of $p<0.001$ and cluster alpha of $p<0.05$. Scatter plot of extracted average cortical thickness and body-fat percentage is shown on the right. 


\section{Baseline relations with cortical thickness}

There were no associations between average cortical thickness and age, BMI or HOMA-IR. Cortical thickness was not different between men and women. A positive association between average cortical thickness and body-fat percentage was found $(r=0.51 ; p=0.01)$, which changed into a trend after adjustment for age and gender $(r=0.40 ; p=0.065)$. Average cortical thickness was positively associated with average grey matter volume $(r=0.58 ; p=0.003)$. Regional cortical thickness, assessed with whole brain correlation analysis, was positively related to body-fat percentage in the right anterior cingulate $(r=0.72, p<0.05$ whole brain corrected) (FIGURE 1).

TABLE 1. Participant characteristics at baseline, after weight loss and after 2 years

\begin{tabular}{|c|c|c|c|c|c|c|c|c|c|}
\hline & \multicolumn{3}{|c|}{ baseline } & \multicolumn{3}{|c|}{ after weight loss } & \multicolumn{3}{|c|}{2 years } \\
\hline$N(f / m)$ & $24(12$ & & & & & & & & \\
\hline age (year) & 52.8 & \pm & 10.6 & & & & & & \\
\hline body-fat (\%) & 41.2 & \pm & 6.2 & 34.6 & \pm & $7.8^{*}$ & 37.3 & \pm & $9.1^{*} \#$ \\
\hline BMI $\left(\mathrm{m} / \mathrm{kg}^{2}\right)$ & 32.0 & \pm & 3.3 & 28.1 & \pm & $2.8^{*}$ & 29.2 & \pm & $3.9^{\star} \#$ \\
\hline fasting insulin (mU/l) & 13.9 & \pm & 6.7 & 7.4 & \pm & $2.7^{*}$ & 10.6 & \pm & $4.5^{\star} \#$ \\
\hline fasting glucose $(\mathrm{mmol} / \mathrm{l})$ & 6.3 & \pm & 0.6 & 5.8 & \pm & $0.5^{*}$ & 5.9 & \pm & $0.5^{*}$ \\
\hline HOMA-IR & 4.0 & \pm & 2.0 & 1.9 & \pm & $0.8^{*}$ & 2.8 & \pm & $1.5^{\star} \#$ \\
\hline $\mathrm{GM}\left(\mathrm{cm}^{3}\right)$ & 670.2 & \pm & 55.8 & 671.3 & \pm & 55.4 & 668.6 & \pm & 53.2 \\
\hline GM (\% intracranial volume) & 46.7 & \pm & 2.6 & 46.7 & \pm & 2.5 & 46.6 & \pm & 2.6 \\
\hline Cortical thickness $(\mathrm{mm})$ & 2.86 & \pm & 0.20 & 2.88 & \pm & 0.16 & 2.89 & \pm & 0.15 \\
\hline
\end{tabular}

Data are presented as mean \pm standard deviation. Changes over time were determined using repeated-measures ANOVA, * $P<0.05$ significantly different from baseline, $\# \mathrm{P}<0.05$, significantly different from after weight loss. $\mathrm{BMI}=$ body mass index; HOMA-IR $=$ homeostatic model assessment for insulin resistance; $G M=$ grey matter volume

\section{Changes during the intervention}

BMI, body-fat percentage and HOMA-IR were reduced after weight loss and 2 years compared to baseline and increased at 2 years compared to after weight loss (TABLE 1). There were no significant changes in grey matter volume or in average cortical thickness during the intervention. Regional cortical thickness assessed with whole brain repeated measures ANOVA, showed an effect in the right and left anterior cingulate. Cortical thickness in the right anterior cingulate was increased after weight loss compared to baseline and 2 years (FIGURE 2) $(p<0.001)$. Cortical thickness in the left anterior cingulate was reduced after weight loss compared to baseline and 2 years (FIGURE 3) $(p<0.001)$. Changes in cortical thickness of the right and left anterior cingulate were not associated. Changes in cortical thickness in the anterior cingulate of the left or right hemisphere were not associated to changes in BMI, body-fat percentage or HOMA-IR. 

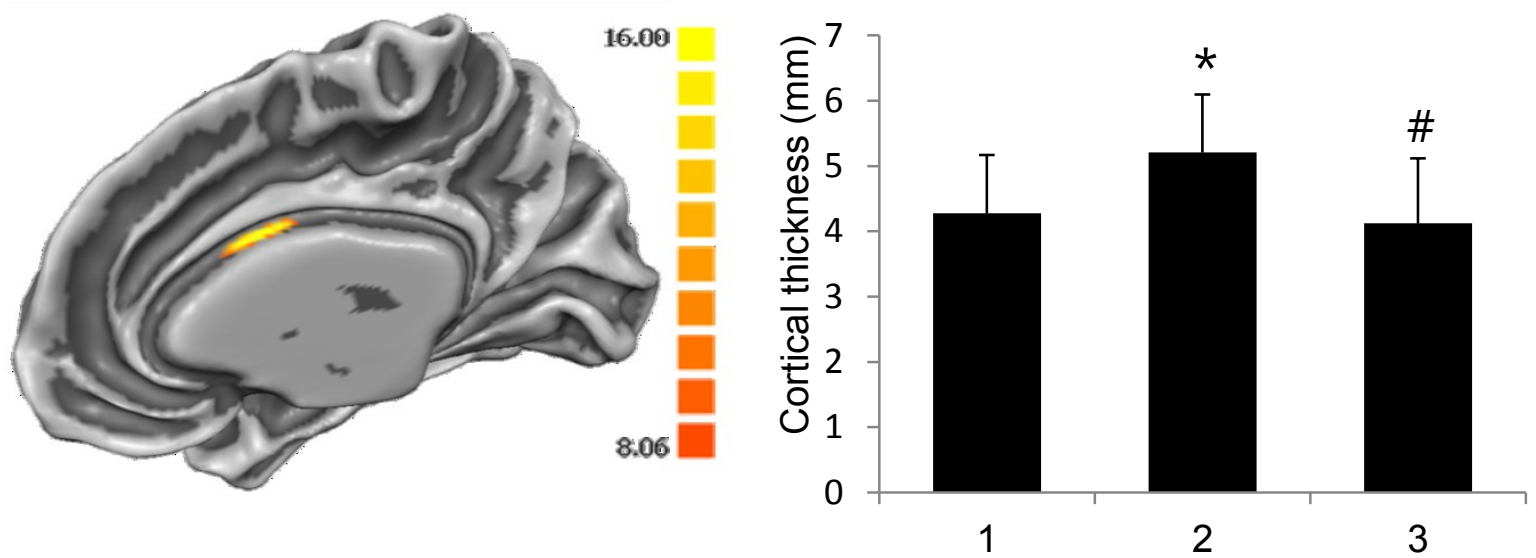

FIGURE 2. Significant effect on cortical thickness in the right anterior cingulate gyrus during the intervention, assessed with whole brain repeated measures ANOVA. Monte Carlo simulations were used to determine minimal cluster size using an independent voxel threshold of $p<0.001$ and cluster alpha of $p<0.05$. Bar graph of extracted average cortical thickness at baseline (1), after weight loss (2) and after 2 years (3) is shown on the right. Repeated measures ANOVA were used to assess differences between time points. ${ }^{*} P<0.05$ significantly different from baseline $\# \mathrm{P}<0.05$, significantly different from after weight loss
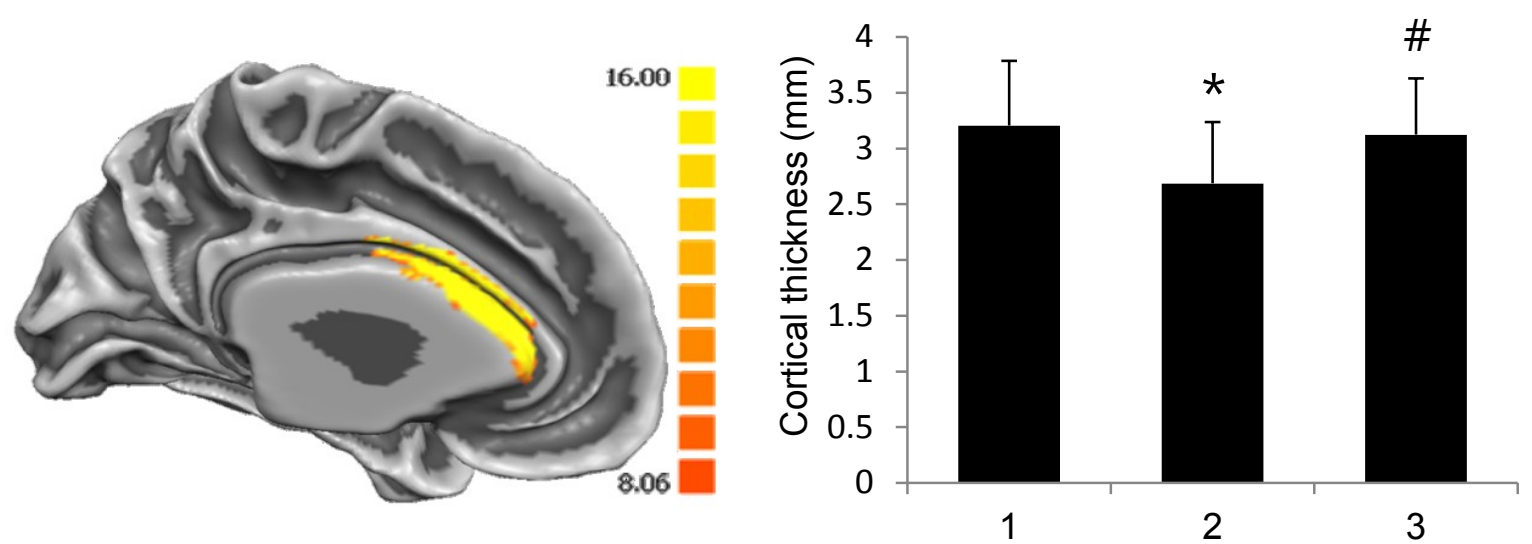

FIGURE 3. Significant effect on cortical thickness in the left anterior cingulate gyrus during the intervention, assessed with whole brain repeated measures ANOVA. Monte Carlo simulations were used to determine minimal cluster size using an independent voxel threshold of $p<0.001$ and cluster alpha of $p<0.05$. Bar graph of extracted average cortical thickness at baseline (1), after weight loss (2) and after 2 years (3) is shown on the right. Repeated measures ANOVA were used to assess differences between time points. ${ }^{*} P<0.05$ significantly different from baseline $\# \mathrm{P}<0.05$, significantly different from after weight loss

\section{DISCUSSION}

In this study, we investigated whether changes in body weight, body composition and insulin resistance were associated with structural brain changes, especially grey matter volume and cortical thickness. We found grey matter volume and cortical thickness unchanged, while body weight, body-fat percentage and insulin resistance were significantly reduced during a 2 year weight loss and weight maintenance period, we did see changes in cortical thickness in the right 
and left anterior cingulate gyrus after the weight loss period. These changes were in opposing directions and were not related to any of the anthropometric or blood parameters.

Multiple cross-sectional studies reported associations between grey matter or cortical thickness and adiposity, insulin resistance or $\operatorname{T2D}(2,4,7,8,11,12,15)$. Therefore, the intuitive next step seems to assess if grey matter or cortical thickness change along with weight loss and related metabolic changes. The participants in the current study significantly reduced their body weight, body-fat percentage and insulin resistance using a LED and showed slight regain in these parameters after 2 years in the PREVIEW intervention. However, these changes were not mirrored by changes in grey matter volume or cortical thickness. We also did not find baseline associations with grey matter or cortical thickness and body weight.

Multiple suggestions may be put forward to explain the lack of association between changes in grey matter volume or cortical thickness with changes in weight status, adiposity or insulin resistance. Due to too short a study period or too large inter individual variation in relation to intra-individual changes we may have not been able to pick up on changes in grey matter volume or cortical thickness. The latter may also explain why we did not find baseline associations between grey matter volume or cortical thickness and BMI. Studies with larger participant numbers and maybe even longer study periods are needed to assess the question in more detail. Another possibility may be that structural brain changes are unilaterally affected by increased body weight. It is thought that obesity-associated systemic inflammation leads to permanent neurodegeneration via increased brain oxidative stress and neuroinflammation (30-32). This may explain why BMI functions as a predictor for reduced grey matter volume (19). Contrarily, multiple studies suggested that cortical thinning can be reversed. Weight restoration led to increases in cortical thickness in patients with anorexia nervosa (33). This observation together with the demonstrated increase in cortical thickness after bariatric surgery $(20,21)$, suggests that there is an inverted u-shaped relationship between bodyweight and cortical thickness. Moreover, smoking cessation was able to reverse cortical thinning (34) and an exercise intervention increased cortical thickness and brain volume in brain tumor survivors (35). Whether cortical thinning and reductions in grey matter volume can be reversed by a lifestyle intervention to induce weight loss, still needs to be investigated.

While changes in body-fat percentage or HOMA-IR were not related to changes in grey matter volume or cortical thickness, they were associated at baseline. Similar to other studies, HOMA-IR was inversely associated with grey matter volume $(36,37)$, potentially playing a putative role for cognitive dysfunction and neurodegenerative diseases $(38,39)$. Body-fat percentage was positively associated to cortical thickness at baseline. This is in line with other studies $(9,40)$ and may be associated with increased adiponectin and leptin levels, which are suggested to be neuroprotective and anti-inflammatory $(41,42)$.

Opposing effects were found for changes in cortical thickness in the left and right anterior cingulate during the intervention. While the cortical thickness in the right anterior cingulate was increased after weight loss, but normalized after 2 years, it was reduced and normalized in the left anterior cingulate. These changes were not related to changes in body weight, body-fat 
percentage or insulin resistance. The anterior cingulate is an important relay station and plays a role in response inhibition. Inhibitory responses may be increased especially after a period of dieting, which may be why we found changes after the LED period. In a study investigating associations between structural measures and a go/no go response inhibition task it was found that cortical thickness was positively related to brain response inhibition in the right anterior cingulate gyrus (43). We did not relate structural measures to functional measures and hence cannot state whether changes in cortical thickness reflect changes in functionality.

In conclusion, we observed no relationship between grey matter volume or cortical thickness with weight loss, long-term weight maintenance, improvements in insulin resistance, and body-fat percentage. At baseline, insulin resistance was inversely related to grey matter volume while body-fat percentage was positively related to cortical thickness. However, the changes in insulin resistance or body-fat percentage induced by the PREVIEW intervention were not related to changes in grey matter volume or cortical thickness. It remains unclear, whether it is possible to reverse a loss of grey matter volume and cortical thickness by means of a weight loss intervention.

\section{ACKNOWLEDGEMENTS}

We would like to thank all the PREVIEW participants and members of the PREVIEW consortium, coordinated by Anne Raben.

\section{FUNDING}

This study has received a grant from the EU $7^{\text {th }}$ Framework Programme grant \#312057 (FP7-KBBE2012.2.2-03).

\section{AUTHOR CONTRIBUTIONS}

The author's responsibilities were as follows: Mathijs Drummen conducted the study, analysed the data and wrote the manuscript; Armin Heinecke performed processing and analyses of the brain data and reviewed the manuscript; Elke Dorenbos assisted with the study and reviewed the manuscript; Anita Vreugdenhil assisted with setup of the study and medical assistance and reviewed the manuscript; Anne Raben initiated and coordinated the PREVIEW study and reviewed the manuscript; Margriet Westerterp-Plantenga designed and supervised the study and reviewed the manuscript; Tanja Adam designed and supervised the study, supervised data analysis and reviewed the manuscript. 


\section{REFERENCES}

1. Pannacciulli N, Del Parigi A, Chen K, Le DS, Reiman EM, Tataranni PA. Brain abnormalities in human obesity: a voxel-based morphometric study. Neuroimage. 2006;31(4):1419-1425.

2. Medic N, Ziauddeen $\mathrm{H}$, Ersche $\mathrm{KD}$, et al. Increased body mass index is associated with specific regional alterations in brain structure. Int J Obes (Lond). 2016;40(7):1177-1182.

3. Ho AJ, Raji CA, Becker JT, et al. Obesity is linked with lower brain volume in 700 AD and MCI patients. Neurobiol Aging. 2010;31(8):1326-1339.

4. Coutinho AM, Coutu JP, Lindemer ER, Rosas HD, Rosen BR, Salat DH. Differential associations between systemic markers of disease and cortical thickness in healthy middle-aged and older adults. Neuroimage. 2017;146:19-27.

5. Schwarz NF, Nordstrom LK, Pagen LHG, et al. Differential associations of metabolic risk factors on cortical thickness in metabolic syndrome. Neuroimage Clin. 2018;17:98-108.

6. Winkler AM, Kochunov P, Blangero J, et al. Cortical thickness or grey matter volume? The importance of selecting the phenotype for imaging genetics studies. Neuroimage. 2010;53(3):1135-1146.

7. Taki Y, Kinomura S, Sato K, et al. Relationship between body mass index and gray matter volume in 1,428 healthy individuals. Obesity (Silver Spring). 2008;16(1):119-124.

8. Veit R, Kullmann $\mathrm{S}$, Heni $\mathrm{M}$, et al. Reduced cortical thickness associated with visceral fat and BMI. Neuroimage Clin. 2014;6:307-311.

9. Ronan L, Alexander-Bloch AF, Wagstyl K, et al. Obesity associated with increased brain age from midlife. Neurobiol Aging. 2016;47:63-70.

10. Gomez-Apo E, Garcia-Sierra A, Silva-Pereyra J, et al. A Postmortem Study of Frontal and Temporal Gyri Thickness and Cell Number in Human Obesity. Obesity (Silver Spring). 2018;26(1):94-102.

11. Kurth F, Levitt JG, Phillips OR, et al. Relationships between gray matter, body mass index, and waist circumference in healthy adults. Hum Brain Mapp. 2013;34(7):1737-1746.

12. Kennedy JT, Collins PF, Luciana M. Higher Adolescent Body Mass Index Is Associated with Lower Regional Gray and White Matter Volumes and Lower Levels of Positive Emotionality. Front Neurosci. 2016;10.

13. Yokum $\mathrm{S}, \mathrm{Ng} \mathrm{J}$, Stice E. Relation of regional gray and white matter volumes to current BMI and future increases in BMI: a prospective MRI study. Int J Obes (Lond). 2012;36(5):656-664.

14. Raji CA, Ho AJ, Parikshak NN, et al. Brain structure and obesity. Hum Brain Mapp. 2010;31(3):353-364.

15. Moran C, Beare R, Phan TG, Bruce DG, Callisaya ML, Srikanth V. Type 2 diabetes mellitus and biomarkers of neurodegeneration. Neurology. 2015;85(13):1123-1130.

16. Liu J, Liu T, Wang W, et al. Reduced Gray Matter Volume in Patients with Type 2 Diabetes Mellitus. Front Aging Neurosci. 2017;9.

17. Thambisetty M, Wan J, Carass A, An Y, Prince JL, Resnick SM. Longitudinal Changes in Cortical Thickness Associated with Normal Aging. Neuroimage. 2010;52(4):1215-1223.

18. Peters R. Ageing and the brain. Postgrad Med J. 2006;82(964):84-88.

19. Bobb JF, Schwartz BS, Davatzikos C, Caffo B. Cross-sectional and longitudinal association of body mass index and brain volume. Hum Brain Mapp. 2014;35(1):75-88.

20. Bohon C, Garcia LC, Morton JM. Changes in Cerebral Cortical Thickness Related to Weight Loss Following Bariatric Surgery. Obes Surg. 2018;28(8):2578-2582.

21. Liu L, Ji G, Li G, et al. Structural changes in brain regions involved in executive-control and self-referential processing after sleeve gastrectomy in obese patients. Brain Imaging Behav. 2018.

22. Fogelholm M, Larsen TM, Westerterp-Plantenga $M$, et al. PREVIEW: Prevention of Diabetes through Lifestyle Intervention and Population Studies in Europe and around the World. Design, Methods, and Baseline Participant Description of an Adult Cohort Enrolled into a Three-Year Randomised Clinical Trial. Nutrients. 2017;9(6).

23. Drummen M, Dorenbos E, Vreugdenhil AC, et al. Insulin Resistance, Weight and Behavioral Variables as Determinants of Brain Reactivity to Food Cues - a PREVIEW study. Am J CLin Nutr. 2018.

24. Manjón JV, Coupé P. volBrain: An Online MRI Brain Volumetry System. Front Neuroinform. 2016;10.

25. Jones $\mathrm{SE}$, Buchbinder BR, Aharon I. Three-dimensional mapping of cortical thickness using Laplace's equation. Hum Brain Mapp. 2000;11(1):12-32.

26. Fischl B, Sereno MI, Dale AM. Cortical surface-based analysis. II: Inflation, flattening, and a surface-based coordinate system. Neuroimage. 1999;9(2):195-207.

27. Frost MA, Goebel R. Measuring structural-functional correspondence: spatial variability of specialised brain regions after macro-anatomical alignment. Neuroimage. 2012;59(2):1369-1381. 
28. Plasqui G, Soenen S, Westerterp-Plantenga MS, Westerterp KR. Measurement of longitudinal changes in body composition during weight loss and maintenance in overweight and obese subjects using airdisplacement plethysmography in comparison with the deuterium dilution technique. Int J Obes (Lond). 2011;35(8):1124-1130.

29. Matthews DR, Hosker JP, Rudenski AS, Naylor BA, Treacher DF, Turner RC. Homeostasis model assessment: insulin resistance and beta-cell function from fasting plasma glucose and insulin concentrations in man. Diabetologia. 1985;28(7):412-419.

30. Sankowski R, Mader S, Valdes-Ferrer SI. Systemic inflammation and the brain: novel roles of genetic, molecular, and environmental cues as drivers of neurodegeneration. Front Cell Neurosci. 2015;9:28.

31. Cazettes F, Cohen JI, Yau PL, Talbot H, Convit A. Obesity-mediated inflammation may damage the brain circuit that regulates food intake. Brain Res. 2011;1373:101-109.

32. Zhang X, Dong F, Ren J, Driscoll MJ, Culver B. High dietary fat induces NADPH oxidase-associated oxidative stress and inflammation in rat cerebral cortex. Exp Neurol. 2005;191(2):318-325.

33. Bernardoni F, King JA, Geisler D, et al. Weight restoration therapy rapidly reverses cortical thinning in anorexia nervosa: A longitudinal study. Neuroimage. 2016;130:214-222.

34. Karama S, Ducharme S, Corley J, et al. Cigarette smoking and thinning of the brain's cortex. Mol Psychiatry. 2015;20(6):778-785.

35. Szulc-Lerch KU, Timmons BW, Bouffet E, et al. Repairing the brain with physical exercise: Cortical thickness and brain volume increases in long-term pediatric brain tumor survivors in response to a structured exercise intervention. Neuroimage Clin. 2018;18:972-985.

36. Benedict C, Brooks SJ, Kullberg J, et al. Impaired Insulin Sensitivity as Indexed by the HOMA Score Is Associated With Deficits in Verbal Fluency and Temporal Lobe Gray Matter Volume in the Elderly. Diabetes Care. 2012;35(3):488-494.

37. Benedict C, Brooks SJ, Kullberg J, et al. Impaired insulin sensitivity as indexed by the HOMA score is associated with deficits in verbal fluency and temporal lobe gray matter volume in the elderly. Diabetes Care. 2012;35(3):488-494.

38. Willette AA, Xu G, Johnson SC, et al. Insulin Resistance, Brain Atrophy, and Cognitive Performance in Late Middle-Aged Adults. Diabetes Care. 2013;36(2):443-449.

39. Kullmann $S$, Heni $M$, Hallschmid M, Fritsche A, Preissl H, Haring HU. Brain Insulin Resistance at the Crossroads of Metabolic and Cognitive Disorders in Humans. Physio/ Rev. 2016;96(4):1169-1209.

40. Kim HJ, Kim C, Jeon S, et al. Association of Body Fat Percentage and Waist-hip Ratio With Brain Cortical Thickness: A Study Among 1777 Cognitively Normal Subjects. Alzheimer Dis Assoc Disord. 2015;29(4):279286.

41. Song J, Lee JE. Adiponectin as a new paradigm for approaching Alzheimer's disease. Anat Cell Biol. 2013;46(4):229-234.

42. Davis C, Mudd J, Hawkins M. Neuroprotective effects of leptin in the context of obesity and metabolic disorders. Neurobiol Dis. 2014;72 Pt A:61-71.

43. Hegarty $C E$, Foland-Ross $L C$, Narr KL, et al. Anterior cingulate activation relates to local cortical thickness. Neuroreport. 2012;23(7):420-424. 
CHAPTER 10

General Discussion 
The research presented in this thesis focused on the effects of a lifestyle intervention, with special attention for the effects of protein intake on intrahepatic lipid content and the brain reward system. In participants with pre-diabetes, the three-year weight loss and weight maintenance PREVIEW intervention with four intervention arms aimed to prevent the development of T2D. The intervention arms during the weight maintenance phase differed in dietary and physical activity programs. All participants started with a low energy diet period of eight weeks during which differences in weight loss between men and women were investigated. Dietary programs during the weight maintenance period after the weight loss period differed regarding protein intake and glycemic index/glycemic load (GI/GL). This provided the opportunity to determine effects of weight loss and relatively increased protein intake with lower GI/GL on intrahepatic lipid content, brain reward activity and brain structure. Physical activity programs during the weight maintenance period differed regarding physical activity intensity and duration.

\section{Characterizing pre-diabetes}

Pre-diabetes has been used as a concept to characterize individuals at risk for developing diabetes. We recruited a large cohort of 2326 individuals with pre-diabetes to further characterize the differences but also the commonalities in this population. Different criteria to define prediabetes are currently in use $(1,2)$. In the PREVIEW-study, pre-diabetes was defined according to the ADA criteria of having: (i) impaired fasting glucose (IFG) with venous plasma glucose concentration of 5.6-6.9 mmol/I when fasted; and/or (ii) impaired glucose tolerance (IGT) with venous plasma glucose concentration of $7.8-11.0 \mathrm{mmol} / \mathrm{l}$ at 2 hours after a standard 75 gram oral glucose tolerance test (OGTT) and a fasting plasma glucose $<7.0 \mathrm{mmol} / \mathrm{l}$ (3). From the 2326 recruited participants, 1389 (62\%) had IFG, 506 (23\%) had IGT and 286 (13\%) had both IFG and IGT (CHAPTER 2) (4). More recently, the ADA has recommended using HbAlc as an additional standard for the diagnosis of pre-diabetes, with levels of $5.7 \%-6.4 \%$ defining a state of prediabetes. In PREVIEW, participants started with an $\mathrm{HbA1c}$ concentration of $5.5 \%$, suggesting that many of them did not meet this new pre-diabetes classification. This may pose a serious impact on the number of participants developing T2D during the PREVIEW intervention and therefore has to be taken into account when evaluating effects of the PREVIEW intervention groups on T2D incidence.

From previous studies it was reported that the annual incidence rate of diabetes was $4-6 \%$ for isolated IGT, 6-9\% for IFG and 15-19\% for combined IFG and IGT (5). The progression from being healthy to T2D manifestation is suggested to be a continuous process that starts years before hyperglycemia is present $(1,6)$. Initially, an increase in insulin resistance or loss of $\beta$-cell mass is compensated for by increased insulin secretion and increased $\beta$-cell mass, maintaining normoglycemia (7). Over time however, compensation fails and insulin secretion decreases. The progression in $\beta$-cell failure and dedifferentiation leads to relatively rapid rises in glucose levels and eventually to the manifestation of T2D. Based on this process, insulin resistance can be detected before hyperglycemia is present. Therefore, the assessment of insulin resistance is important in IFG, IGT and T2D, but has also been implicated as an important link between prediabetes and the development of dementia, renal failure and cancer (8-10). In the PREVIEW study, 
insulin resistance was assessed using the HOMA-IR, which is calculated using fasting glucose and insulin concentrations. The average HOMA-IR was 3.75 with a range of $0.23-31.37$. This indicates that insulin resistance was present in most individuals, but also emphasizes the heterogeneity of the population.

\section{Impaired fasting glucose versus impaired glucose tolerance}

Although IFG and IGT are both intermediates of the progression to T2D, the pathogenesis of the two is suggested to be different $(11,12)$. Epidemiological studies have demonstrated that individuals with IFG or IGT represent distinct populations and only partially overlap (13). This is further illustrated by the differences in blood glucose curves during an $\operatorname{OGTT}(12,13)$. Furthermore, it is suggested that IFG and IGT differ in their site of insulin resistance; IFG is associated with hepatic insulin resistance while IGT is more strongly associated with muscle insulin resistance (11).

\section{Pre-diabetes and physical activity}

Multiple lifestyle and heritable factors have been associated with the etiology of IFG or IGT. IFG seems more strongly related to heritable factors and smoking, while IGT may be more related to lifestyle factors like physical inactivity (11). We measured physical activity (PA) and sedentary time (ST) at baseline in 2326 adults with pre-diabetes using seven-day accelerometry (CHAPTER 3) (14).The purpose of this study was to quantify the relationship between objectively measured PA and ST with cardiometabolic health and risk of diabetes. We found distinct associations between fasting glucose and 2-hour glucose after glucose ingestion with parameters of PA in a large population with pre-diabetes. MVPA and total physical activity were inversely related to 2-hour glucose concentrations after glucose ingestion. HOMA-IR was positively associated with ST, but inversely associated with MVPA and total physical activity. Given that ST and MVPA are interchangeable components of a day depending on arbitrary thresholds, it is difficult to attribute effects to an increase in one variable or a decrease in the other. Replacing ST with light activity was shown to be related to reductions in HOMA-IR (15). In another study, both, replacing sitting with light-intensity walking and simple resistance activities reduced incremental area under the curve for glucose, insulin and c-peptide concentrations equally during consumption of standardized meals (16). Thus, while it remains unclear if the specific intensity of physical activity has effects on glucose or insulin sensitivity, the exchange of ST with PA seems pivotal to changes in cardiometabolic health and insulin resistance in individuals with pre-diabetes.

\section{Pre-diabetes and diet}

An 'unhealthy' diet has also been associated with disturbed glucose homeostasis and insulin resistance (11). Bagheri et al. reported that a healthy dietary pattern (characterized by high intake of vegetables, fruits, legumes, chicken, nuts, fish, etc.) was inversely associated, while an unhealthy dietary pattern (characterized by high intake of high-fat products, solid fats, soft drinks, red and processed meats, etc.) was positively associated with pre-diabetes risk, including fasting blood 
glucose and 2-hour glucose after glucose ingestion (17). These dietary patterns also corresponded with dietary patterns found to prevent T2D in meta-analyses $(18,19)$. Differences in macronutrient intake have also been related to changes in T2D risk, but all include some 'footnotes'. High-carbohydrate diets have been suggested to be detrimental for prevention and management of T2D (20), unless they are rich in fiber and with a low GI/GL $(21,22)$. Lowering GI/GL may reduce T2D risk via reductions in hyperglycemia, glucose concentration variability, hyperinsulinemia or free fatty acids $(23,24)$. However, it is not clear whether these effects persist after controlling for weight loss or dietary fiber intake (25-27). Regarding dietary fat intake, many studies reported increased insulin resistance with higher levels of total dietary fat intake (28). However, replacing short-chain fatty acids and trans fatty acids with mono- and polyunsaturated fatty acids was suggested to be beneficial for insulin sensitivity (29-31). Whether protein intake is related to prevention or development of T2D beyond the benefits for a negative energy balance, weight loss, and subsequent weight maintenance is still unclear and may depend on the source of protein (CHAPTER 4) (32). Total protein and animal protein is most likely associated with increased relative risk for T2D and plant protein with a decreased risk (33). Furthermore, red and processed meats were also reported to be risk factors for T2D and soy and dairy products were reported to be protective. Based on all these conditional statements of macronutrient intake effects on T2D prevention, a dietary lifestyle combining these conditional effects should be pursued for optimal results.

\section{Effects of a lifestyle intervention - Weight loss}

The PREVIEW study was directed to prevent diabetes by combining a weight loss period with a long-term intervention period focused on diet and physical activity. During the 8-week weight loss period with a LED, participants lost an average of $11 \%$ body weight and the average BMI after weight loss was $31.4 \mathrm{~kg} / \mathrm{m}^{2}$ (CHAPTER 6) (34). Therefore, most of the participants were still in the range of obesity which raises the question if the weight loss achieved was sufficient in terms of metabolic benefit. In previous studies, 5 to 10 percent weight loss was already sufficient for clinically relevant changes in health, suggesting the weight loss rate can be considered successful in our pre-diabetic population (35). Favorable changes were also evident in our participants including reductions in metabolic syndrome and 694 of the 2224 pre-diabetic participants reverting to normo-glycaemia based on fasting plasma glucose concentrations. Average HOMAIR decreased from 3.75 at baseline to 2.28 after weight loss. Based on an often used HOMA-IR threshold of $<2.5$, the body weight loss was enough to reduce insulin resistance to normal proportions (36-39).

It has to be noted that 204 (9.2\%) participants dropped-out during the weight loss period. Attrition is a common problem in weight loss studies and affects data collection quality, and inference. Moreover, the population of dropouts may represent an even more vulnerable population which is unable to respond to different treatment and prevention programs. On a positive note, the drop-out rate was lower compared to a similar weight loss period in the DioGenes study (40). This may be explained by the implementation of the PREMIT program, which was designed within the PREVIEW study to enhance behavioral change based on theory-driven 
and evidence-based approaches (41). In particular, we have shown that experiencing less discouragement for healthy eating by a supportive environment and perceiving fewer disadvantages of a healthy diet were positively associated with weight loss (42).

When comparing men and women during the weight loss period, we found greater weight loss and reductions in metabolic syndrome Z-scores in men compared to women, possibly indicating that men might have benefited more from an 8-week LED than women. This could have been explained by the fixed energy provided by the LED (3.4 MJ/d) for both, men and women. Based on the calculated baseline energy requirement using Westerterp et al. (43), the percentage energy intake of energy requirement during the LED was higher in men than in women, and therefore suggests women should have lost more weight.

Based on the accelerometry data, there were no differences in physical activity between men and women at baseline (CHAPTER 3) (14) and all participants received instructions to maintain the same level of physical activity during the weight loss period. We did not measure physical activity during weight loss and therefore cannot exclude that physical activity changed differently between men and women. Another explanation may be that men preserved their FFM better. Based on the calculations of Westerterp et al. (43), after the weight loss period men would have a body-fat percentage of $33.6 \%$ and women a body-fat percentage of $44.0 \%$. The actual body-fat percentages after the weight loss period were $31.7 \%$ and $42.9 \%$ in men and women respectively, indeed showing more preservation of FFM in men. A reason for this may be that the men had larger relative protein intake (CHAPTER 4) (32). During energy restriction it was shown that a daily protein intake of $0.8 \mathrm{~g} / \mathrm{kg}$ body weight was sufficient for weight loss, but a daily protein intake of $1.2 \mathrm{~g} / \mathrm{kg}$ body weight resulted in the preservation of FFM (44). The findings are in line with a study by Westerterp-Plantenga et al, which reported that relatively high protein intake led to increased energy expenditure, fat oxidation and protein anabolism in men versus increased satiety in women (45). The relative preservation of FFM may also explain the larger reductions in metabolic syndrome Z-scores in men compared to women even after adjusting for changes in body weight, since higher muscle mass has been inversely related to insulin resistance and metabolic syndrome $(46,47)$. The preservation of FFM is also necessary for weight maintenance after body weight loss, because FFM is the main determinant of basal energy expenditure.

\section{Weight maintenance}

The second phase of the PREVIEW-intervention was aimed at maintaining the lost body weight and participants were randomized to four intervention groups with differences in dietary programs and physical activity programs. For the studies presented in this thesis, we were especially interested in the long-term effects of the PREVIEW-intervention with the high protein versus moderate protein group on intrahepatic lipid content and brain reward activation. 
Due to its crucial role in glucose homeostasis, the liver is a central player in the development of insulin resistance, IFG, IGT and T2D. The liver is our first line of defense against hyperglycemia, taking up postprandial glucose to store as glycogen (48). Excess liver fat has been related with hepatic and skeletal muscle insulin resistance (49). Furthermore, intrahepatic lipid (IHL) content is progressively increased in individuals with normal glucose tolerance, isolated IFG, isolated IGT, IFG + IGT to T2D (50). When IHL exceeds $5 \%$ it is classified as non-alcoholic fatty liver disease, which has been shown to be an independent predictor for the development of T2D (51). We measured the amount of IHL in 25 individuals with pre-diabetes and found an average IHL content of $8.7 \%$ (CHAPTER 7) (52). Moreover, of these 25 individuals, 15 were classified as having NAFLD. The reduction in IHL was successfully established in the PREVIEW-intervention (CHAPTER 7). After 2 years, IHL were reduced compared to baseline and the number of individuals with NAFLD decreased from 15 to 7. Even though we did not see different changes in IHL between the two protein groups, we found that there was an effect of protein intake assessed with urinary nitrogen on IHL in the whole group of participants. Using mixed modeling analysis we found that protein intake at 6 months was inversely associated with IHL and this was independent of BMI. Increasing protein intake may lead to downregulation of lipogenesis and upregulation of hepatic lipid oxidation, lowering hepatic lipid content $(53,54)$. The relation between protein intake and IHL was not significant after 2 years. Protein-specific effects on IHL may be clouded by other factors attributable to a fading compliance to the general guidelines over time. This also directs that there may be a need for continuous application of the intervention guidelines.

Throughout the intervention IHL was positively associated with insulin resistance, independent of BMI. Furthermore, there were no relations between visceral adipose tissue (VAT) or subcutaneous adipose tissue (SAT) and insulin resistance. These findings are in line with Fabbrini et al. which reported that insulin sensitivity was lower in individuals with higher IHL matched on VAT, but was not different in individuals with higher VAT matched on IHL (55). We are not able to determine the causality between IHL and insulin resistance in our study. Causality between IHL and insulin resistance is often debated and there is evidence that both factors can be a consequence of the other. IHL may impair insulin signalling and affect glucose concentrations by reducing glycogen synthesis and increasing gluconeogenesis (56). On the other hand, insulin resistance in adipose tissue may lead to increased lipolysis and free fatty acids, resulting in increased lipid uptake in the liver (57). Importantly, the degree of insulin resistance is not necessarily similar in the three major insulin-sensitive tissues, liver, skeletal muscle and adipose tissue (58) and insulin resistance in these different tissues may have a different place and timing in the causal relation between insulin resistance and IHL accumulation. Based on our results, we postulate the hypothesis that increasing protein intake may indirectly increase insulin sensitivity via reductions in IHL. More research is needed to establish the exact mechanisms and causality of these relations. Moreover, in a previous study it was shown that IHL content was an independent predictor of non-response to a lifestyle intervention (59). Therefore, focusing on reducing IHL seems to be trivial within diabetes prevention interventions 
Another relevant component for the success of lifestyle interventions is the brain reward system, which plays a role in regulating ingestive behavior. The regulation of food intake and eating behavior is often divided into homeostatic and non-homeostatic or hedonic regulation (60), but is currently progressively viewed as a complex and highly interactive system unifying homeostasis, reward, cognition and emotion (61). It is apparent that physiological factors are able to act on the brain and vice versa. We investigated which factors were related to food-reward related brain activation in 39 individuals with pre-diabetes (CHAPTER 5). We observed that food-reward related brain activation was positively related to insulin resistance and emotional eating/disinhibition and inversely related to habitual physical activity. The relation between insulin resistance and brain activation in reward areas was also reported in other studies (62-64). Insulin is suggested to play a role in dopamine homeostasis by regulating dopamine release and dopamine transporter density and function (65). Disruption of this pathway has been shown to lead to hyperphagia and weight gain (66). We found changes in brain reward activation to be positively related with changes in insulin resistance during the 2-year weight loss and weight maintenance intervention, independent of BMI (CHAPTER 8). We specifically found this relation in the nucleus accumbens, insular cortex and anterior cingulate, which are all brain regions rich in dopaminergic neurons (67), pointing at the role of insulin for dopamine signalling. Furthermore, these regions have also been suggested to play an key role in addiction and eating disorders (6871). Based on our results in brain reactivity, individuals with pre-diabetes may be 'wired' for unhealthy eating and hyperphagia, snowballing the risk to develop T2D.

A main point of discussion remains whether central insulin resistance exists and subsequently if we can measure it. In favor of the existence of central insulin resistance are studies reporting that brain insulin levels are proportional to plasma insulin levels and that insulin is able to cross the blood-brain barrier (72-74). Furthermore, using intranasal insulin administration it was shown that a decrease in cerebral blood in response to insulin was only present in lean individuals, but not in overweight and obese individuals, and the decrease was related to insulin sensitivity (64). We also found food-reward related brain activation in the supramarginal gyrus to be positively related to emotional eating and disinhibition, measured by the three factor eating behavior questionnaire. The supramarginal gyrus has been implicated with reward, motivation and drug abuse. Disinhibition has previously been linked with obesity and high-energy intakes (75). It is not exactly clear how the relation between brain reward activity and emotion/disinhibition is established, but it further underlines the higher-order interplay of multiple brain pathways mentioned before (61). The inverse association between habitual physical activity and food-reward related brain activation is in line with previous work $(76,77)$ and since it is not possible to determine causality in our study, it has to be investigated whether increasing different types of physical activity and exercise are able to lead to long-term changes in brain activity and healthier eating habits. In that way, physical activity may be able to have secondary health benefits next to its primary effects on fitness and energy expenditure. 
In 27 participants, measurements of food-reward related brain activation were repeated after 2 years to assess effects of the intervention in the two protein groups (CHAPTER 8). We found no different changes in brain reactivity to food cues between the groups and no differences in brain reactivity to food cues comparing 2 years with baseline in the whole group of participants. However, in the whole group of participants we found an inverse association between protein intake assessed with urinary nitrogen during the weight maintenance period and changes in food reward-related brain activation, independent of BMI. Other studies have reported modulating effects of protein intake on brain activation to food cues $(78,79)$, but we found these effects after a 2 year period. This implies protein intake may have long-term benefits for eating behavior via changes in brain reward reactivity. Protein intake may influence brain activity via changes in neurotransmitter precursor availability or activation of the vagus nerve to relay satiety signals (8082). Effects of protein intake may also be caused by increased release of anorectic hormones (83). Changes in brain reactivity to high-calorie images versus low-calorie images were negatively related to changes in dietary restraint in multiple regions. This mechanism may be crucial for long-term body weight maintenance by enhancing compliance to dietary lifestyle. Diets high in protein intake may be difficult to maintain (CHAPTER 4) (84). Efforts to increase dietary restraint should be incorporated in lifestyle interventions to increase total efficacy. In the PREVIEW study, this issue was addressed by implementation of the PREMIT behavioral change toolbox.

\section{Grey matter volume and cortical thickness}

Next to brain activation, we also measured brain structure during the PREVIEW study to determine whether grey matter volume or cortical thickness would change during the intervention period along with changes in body weight or insulin resistance (CHAPTER 9). Previously reported associations between BMI or T2D and grey matter volume and cortical thickness included cross-sectional data only and it is unknown whether reversal of grey matter loss or cortical thinning is possible by reducing body weight or insulin resistance. We found that changes in body weight or insulin resistance were not mirrored by changes in grey matter volume or cortical thickness. It may be that the number of participants was too small to find small changes relative to the large inter individual variation. However, it may also be that the timing of these changes is very different and that changes in grey matter volume are gradual processes not responding to rapid changes in body weight or insulin resistance. Moreover, the relations between BMI/insulin resistance and grey matter volume/cortical thickness may have been induced via irreversible brain damage. In this light, Ronan et al. reported that obesity modulated age-related brain structural changes (85). More studies over a longer period and with larger number of participants are needed to shine light on these processes.

\section{Considerations}

It is necessary to consider that effects of protein intake may be indirectly caused by changes in carbohydrate or fat intake. Protein intake was assessed with urinary nitrogen, but biomarkers for carbohydrate or fat intake were not available. It was shown already that body-weight loss and weight-maintenance are associated with high-protein intake, independent of carbohydrate and 
fat-content of the diet and effects of a low-carbohydrate diet are depending on high-protein intake (86). Effects of protein intake on IHL content have been shown in mice with both low carbohydrate and low fat conditions (54). In favor of protein-specific effects on food reward related brain activation are studies showing reductions in brain activation after the ingestion of solely protein (78). Furthermore, the dietary programs that participants received did not only contain instructions to achieve high and moderate protein intake, but also instructions to consume low and moderate GI foods respectively. Therefore, it is possible that effects of protein intake are caused by correlated changes in GI and GL. Since we only have a biomarker of protein intake, we are unable to exclude this issue.

Another point of consideration is the lack of difference in protein intake between the two protein groups. While this may be a power issue of the subgroups that are reported in this thesis, it may also be a consequence of the study design. It seems that participants in the high protein group on average did not reach the amount of protein that was aimed for and participants in the moderate protein group ingested more than was aimed for. Reasons for this can be manifold, but it may be an effect of the PREMIT behavioral change toolbox and the general healthy guidelines of the PREVIEW study. Participants may have prioritized pursuing the guidelines for a general healthy lifestyle over the instructions aimed to yield group differences. This is underlined by the equal long-term beneficial changes of anthropometric and metabolic parameters in both intervention groups.

We did not find differences between men and women regarding changes in $\mathrm{IHL}$, brain reactivity or brain structure (CHAPTERS 7-9). This may be explained by the sample sizes in these substudies, as is also discussed in the respective chapters.

\section{Conclusions}

The heterogeneous PREVIEW cohort consisting of participants with overweight/obesity and prediabetes successfully achieved $8 \%$ body weight loss using the 8-week low energy diet and showed the relevance of the PREVIEW intervention especially for evaluating changes in insulin resistance and changes on organ level, like liver and brain.

In the participants, insulin resistance was reduced after 2 years of diet and exercise intervention accompanied by reductions in IHL and by reduced food reward related brain activation. The changes in brain reactivity were linked to increased control of eating behavior, adjusted for changes in BMI. More specifically and on group level, protein intake was related to reductions in IHL and changes in brain reward reactivity, demonstrating that higher protein intake has beneficial effects that supersede effects on body weight loss or body weight management.

\section{Future perspectives}

From the results presented in this thesis it becomes clear that pre-diabetes is not a simple physiological state, but rather a tool to captivate a vulnerable population. Future efforts to map 
differences and similarities within this heterogeneous population may help to elucidate underlying pathologies and find more effective treatment methods. For example, it will be relevant to investigate discrepancies between individuals with different markers of pre-diabetes such as isolated IFG or IGT.

In terms of treatment methods, we have underlined the relevance of weight loss in a population with pre-diabetes and increased body weight. The 8-week LED of the PREVIEW study was shown to be an effective method for reducing body weight in almost all participants. The weight loss was accompanied by significant reductions in body-fat percentage and insulin resistance, despite the average BMI still being in the obesity range after weight loss. It remains unclear whether additional weight loss would lead to even greater effects or to a prolongation of effects. Using post-hoc analyses this can be partly investigated within the PREVIEW-study, but future studies with longer duration are needed to clarify this issue.

The effects of the PREVIEW study on the incidence of T2D are not known yet, so this still needs to be analyzed and reported. We did find relevant changes in IHL considering the findings by other studies that IHL accumulation seems to be a pathological factor in many different conditions. Factors specifically reducing IHL should therefore be incorporated in lifestyle interventions. We reported the relevance of increased protein intake in this regard, but future studies should be aimed at finding other factors. Furthermore, there may be differential effects of protein from different sources or effects of specific amino acids. We also found protein intake during weight maintenance to be inversely associated with changes in brain reactivity to high calorie food cues. This may be part of the mechanism via which protein intake can help to lose weight or maintain weight loss, but may also be correlated to the adaptation to a healthier lifestyle in general. Future studies with intranasal administration of protein or specific amino acids may help to resolve whether protein or amino acids have direct affects on brain signalling. Furthermore, it will be necessary to assess whether the brain response to food cues is trainable, as has been shown in other study settings (87). This may be an additional tool to increase compliance to a healthy lifestyle. Similarly, future studies could be designed to disentangle effects of protein intake or effects of concomitant changes in other parameters like reductions in GI/GL.

Next to brain and liver, paying particular attention to other organs may contribute to an in depth understanding of the progression to T2D. For instance, the accumulation of lipids in different sites, e.g. the pancreas, may play independent roles for the development or worsening of insulin resistance. Other organs of interest, especially when evaluating effects on protein intake for T2D prevention, are the intestines and kidneys. The intestines are important for digestion and absorption of protein but are also considered important for food intake regulation via the gutbrain axis. Investigating the role of gut hormones secreted by the intestines (e.g. GLP-1, CCK) in response to protein and other foods may help unraveling the exact mechanisms of this regulation. Kidney disease is a common concomitant disease in T2D patients and there have been some concerns about whether high protein consumption leads to increased risk for kidney disease (88). In a sub-group of the PREVIEW study participants there were no indications of impaired kidney function after one year with higher protein intake (89). However, future studies 
are needed to determine whether higher protein diets have detrimental renal effects in populations with kidney problems or whether these effects occur after a longer period.

A central issue in large and lengthy lifestyle studies similar to the PREVIEW study is a reduction in compliance to the study guidelines. Based on the results presented in this thesis, protein intake or physical activity may hardly differ, or may differ in different directions between the intervention groups, suggesting participants followed a personal intervention instead of a group intervention. While this is closer to a real life situation than strictly controlled study designs, this also hampers the occurrence of group differences and inferences. Therefore, it will be crucial to include biomarkers of diet and physical activity in the final analyses next to group allocations. Future studies may also consider providing supplements like protein powder or guided physical activity sessions to increase differences between groups, especially when they are aimed at investigating physiological mechanisms. Another possible study design to investigate effects of a lifestyle intervention is to provide all participants with a range of dietary en physical activity instructions and retrospectively assign groups using biomarkers. This will permit the assessment of long-term responses to different instruction groups, but has the disadvantage that there is no randomization and is therefore prone to selection biases. Furthermore, intrinsic characteristics or physiological states may be responsible for the resulting groups, decreasing the generalizability.

Another concern of large intervention studies is the rate of attrition. Participants that drop-out may represent a distinct population and it will be interesting to determine which factors lead to attrition. This may help designing tailored interventions and enhancing the success of lifestyle interventions aimed at increasing health or preventing diseases. To achieve this, future studies should enhance efforts to follow-up participants that drop-out. 


\section{REFERENCES}

1. Tabák AG. Prediabetes: A high-risk state for developing. 2012;379(9833):2279-2290.

2. Buysschaert M, Bergman M. Definition of prediabetes. Med Clin North Am. 2011;95(2):289-297, vii.

3. 2. Classification and Diagnosis of Diabetes: <em >Standards of Medical Care in Diabetes-2018</em>. Diabetes Care. 2018;41(Supplement 1):S13-S27.

4. Fogelholm M, Larsen TM, Westerterp-Plantenga $M$, et al. PREVIEW: Prevention of Diabetes through Lifestyle Intervention and Population Studies in Europe and around the World. Design, Methods, and Baseline Participant Description of an Adult Cohort Enrolled into a Three-Year Randomised Clinical Trial. Nutrients. 2017;9(6).

5. Gerstein HC, Santaguida P, Raina P, et al. Annual incidence and relative risk of diabetes in people with various categories of dysglycemia: a systematic overview and meta-analysis of prospective studies. Diabetes Res Clin Pract. 2007;78(3):305-312.

6. Weir GC, Bonner-Weir S. Five stages of evolving beta-cell dysfunction during progression to diabetes. Diabetes. 2004;53 Suppl 3:S16-21.

7. Chen C, Cohrs CM, Stertmann J, Bozsak R, Speier S. Human beta cell mass and function in diabetes: Recent advances in knowledge and technologies to understand disease pathogenesis. Mol Metab. 2017;6(9):943957.

8. Nerpin E, Risérus U, Ingelsson E, et al. Insulin Sensitivity Measured With Euglycemic Clamp Is Independently Associated With Glomerular Filtration Rate in a Community-Based Cohort. Diabetes Care. 2008;31(8):15501555.

9. Baker LD, Cross DJ, Minoshima S, Belongia D, Watson GS, Craft S. Insulin resistance and Alzheimer-like reductions in regional cerebral glucose metabolism for cognitively normal adults with prediabetes or early type 2 diabetes. Arch Neurol. 2011;68(1):51-57.

10. Huang Y, Cai X, Qiu M, et al. Prediabetes and the risk of cancer: a meta-analysis. Diabetologia. 2014;57(11):2261-2269.

11. Færch K, Borch-Johnsen K, Holst JJ, Vaag A. Pathophysiology and aetiology of impaired fasting glycaemia and impaired glucose tolerance: does it matter for prevention and treatment of type 2 diabetes? Diabetologia. 2009;52(9):1714-1723.

12. Meyer C, Pimenta W, Woerle HJ, et al. Different mechanisms for impaired fasting glucose and impaired postprandial glucose tolerance in humans. Diabetes Care. 2006;29(8):1909-1914.

13. Abdul-Ghani MA, Tripathy $D$, DeFronzo RA. Contributions of $\beta$-Cell Dysfunction and Insulin Resistance to the Pathogenesis of Impaired Glucose Tolerance and Impaired Fasting Glucose. Diabetes Care. 2006;29(5):1130-1139.

14. Swindell N, Mackintosh K, McNarry M, et al. Objectively Measured Physical Activity and Sedentary Time Are Associated With Cardiometabolic Risk Factors in Adults With Prediabetes: The PREVIEW Study. Diabetes Care. 2018;41(3):562-569.

15. Duvivier B, Bolijn JE, Koster A, Schalkwijk CG, Savelberg H, Schaper NC. Reducing sitting time versus adding exercise: differential effects on biomarkers of endothelial dysfunction and metabolic risk. Sci Rep. 2018;8(1):8657.

16. Dempsey PC, Sacre JW, Larsen RN, et al. Interrupting prolonged sitting with brief bouts of light walking or simple resistance activities reduces resting blood pressure and plasma noradrenaline in type 2 diabetes. $J$ Hypertens. 2016;34(12):2376-2382.

17. Bagheri F, Siassi F, Koohdani F, et al. Healthy and unhealthy dietary patterns are related to pre-diabetes: a case-control study. Br J Nutr. 2016;116(5):874-881.

18. Esposito K, Kastorini CM, Panagiotakos DB, Giugliano D. Prevention of type 2 diabetes by dietary patterns: a systematic review of prospective studies and meta-analysis. Metab Syndr Relat Disord. 2010;8(6):471-476.

19. Jannasch F, Kroger J, Schulze MB. Dietary Patterns and Type 2 Diabetes: A Systematic Literature Review and Meta-Analysis of Prospective Studies. J Nutr. 2017;147(6):1174-1182.

20. Huntriss $R$, Campbell $M$, Bedwell $C$. The interpretation and effect of a low-carbohydrate diet in the management of type 2 diabetes: a systematic review and meta-analysis of randomised controlled trials. Eur J Clin Nutr. 2018;72(3):311-325.

21. Brand-Miller J, Hayne S, Petocz P, Colagiuri S. Low-glycemic index diets in the management of diabetes: a meta-analysis of randomized controlled trials. Diabetes Care. 2003;26(8):2261-2267.

22. Greenwood DC, Threapleton DE, Evans CEL, et al. Glycemic Index, Glycemic Load, Carbohydrates, and Type 2 Diabetes: Systematic review and dose-response meta-analysis of prospective studies. Diabetes Care. 2013;36(12):4166-4171. 
23. Aston LM. Glycaemic index and metabolic disease risk. Proc Nutr Soc. 2006;65(1):125-134.

24. Gellar L, Nansel TR. High and Low Glycemic Index Mixed Meals and Blood Glucose in Youth with Type 2 Diabetes or Impaired Glucose Tolerance. J Pediatr. 2009;154(3):455-458.

25. Sacks FM, Carey VJ, Anderson CAM, et al. Effects of High vs Low Glycemic Index of Dietary Carbohydrate on Cardiovascular Disease Risk Factors and Insulin Sensitivity: The OmniCarb Randomized Clinical Trial. Jama. 2014;312(23):2531-2541.

26. Goff LM, Cowland DE, Hooper L, Frost GS. Low glycaemic index diets and blood lipids: a systematic review and meta-analysis of randomised controlled trials. Nutr Metab Cardiovasc Dis. 2013;23(1):1-10.

27. Jebb SA, Lovegrove JA, Griffin BA, et al. Effect of changing the amount and type of fat and carbohydrate on insulin sensitivity and cardiovascular risk: the RISCK (Reading, Imperial, Surrey, Cambridge, and Kings) trial. Am J Clin Nutr. 2010;92(4):748-758.

28. Mayer-Davis EJ, Monaco JH, Hoen HM, et al. Dietary fat and insulin sensitivity in a triethnic population: the role of obesity. The Insulin Resistance Atherosclerosis Study (IRAS). Am J Clin Nutr. 1997;65(1):79-87.

29. Risérus U, Willett WC, Hu FB. Dietary fats and prevention of type 2 diabetes. Prog Lipid Res. 2009;48(1):4451.

30. van Dam RM, Willett WC, Rimm EB, Stampfer MJ, Hu FB. Dietary fat and meat intake in relation to risk of type 2 diabetes in men. Diabetes Care. 2002;25(3):417-424.

31. Harding $\mathrm{AH}$, Sargeant LA, Welch $\mathrm{A}$, et al. Fat consumption and $\mathrm{HbA}(1 \mathrm{c})$ levels: the EPIC-Norfolk study. Diabetes Care. 2001;24(11):1911-1916.

32. Drummen M, Tischmann L, Gatta-Cherifi B, Adam T, Westerterp-Plantenga M. Dietary Protein and Energy Balance in Relation to Obesity and Co-morbidities. Frontiers in Endocrinology. 2018;9:443.

33. Tian S, Xu Q, Jiang R, Han T, Sun C, Na L. Dietary Protein Consumption and the Risk of Type 2 Diabetes: A Systematic Review and Meta-Analysis of Cohort Studies. Nutrients. 2017;9(9).

34. Christensen $\mathrm{P}$, Meinert Larsen $\mathrm{T}$, Westerterp-Plantenga $\mathrm{M}$, et al. Men and women respond differently to rapid weight loss: Metabolic outcomes of a multi-centre intervention study after a low-energy diet in 2500 overweight, individuals with pre-diabetes (PREVIEW). Diabetes Obes Metab. 2018.

35. Blackburn G. Effect of degree of weight loss on health benefits. Obes Res. 1995;3 Suppl 2:211s-216s.

36. Salgado AL, Carvalho L, Oliveira AC, Santos VN, Vieira JG, Parise ER. Insulin resistance index (HOMA-IR) in the differentiation of patients with non-alcoholic fatty liver disease and healthy individuals. Arq Gastroenterol. 2010;47(2):165-169.

37. Owei I, Umekwe N, Provo C, Wan J, Dagogo-Jack S. Insulin-sensitive and insulin-resistant obese and nonobese phenotypes: role in prediction of incident pre-diabetes in a longitudinal biracial cohort. BMJ Open Diabetes Res Care. 2017;5(1):e000415.

38. Calori G, Lattuada G, Piemonti L, et al. Prevalence, metabolic features, and prognosis of metabolically healthy obese Italian individuals: the Cremona Study. Diabetes Care. 2011;34(1):210-215.

39. Kuk JL, Ardern CI. Are Metabolically Normal but Obese Individuals at Lower Risk for All-Cause Mortality? Diabetes Care. 2009;32(12):2297-2299.

40. Papadaki A, Linardakis $M$, Plada $M$, et al. A multicentre weight loss study using a low-calorie diet over 8 weeks: regional differences in efficacy across eight European cities. Swiss Med Wkly. 2013;143:w13721.

41. Kahlert D, Unyi-Reicherz A, Stratton G, et al. PREVIEW Behavior Modification Intervention Toolbox (PREMIT): A Study Protocol for a Psychological Element of a Multicenter Project. Front Psychol. 2016;7:1136.

42. Hansen S, Huttunen-Lenz M, Sluik D, et al. Demographic and Social-Cognitive Factors Associated with Weight Loss in Overweight, Pre-diabetic Participants of the PREVIEW Study. Int J Behav Med. 2018.

43. Westerterp KR, Donkers JHHLM, Fredrix EWHM, oekhoudt P. Energy intake, physical activity and body weight: a simulation model. British Journal of Nutrition. 1995;73(3):337-347.

44. Soenen S, Martens EA, Hochstenbach-Waelen A, Lemmens SG, Westerterp-Plantenga MS. Normal protein intake is required for body weight loss and weight maintenance, and elevated protein intake for additional preservation of resting energy expenditure and fat free mass. J Nutr. 2013;143(5):591-596.

45. Westerterp-Plantenga MS, Lejeune MP, Smeets AJ, Luscombe-Marsh ND. Sex differences in energy homeostatis following a diet relatively high in protein exchanged with carbohydrate, assessed in a respiration chamber in humans. Physiol Behav. 2009;97(3-4):414-419.

46. Srikanthan $P$, Karlamangla AS. Relative muscle mass is inversely associated with insulin resistance and prediabetes. Findings from the third National Health and Nutrition Examination Survey. J Clin Endocrinol Metab. 2011;96(9):2898-2903.

47. Atlantis E, Martin SA, Haren MT, Taylor AW, Wittert GA. Inverse associations between muscle mass, strength, and the metabolic syndrome. Metabolism. 2009;58(7):1013-1022. 
48. Moore MC, Coate KC, Winnick JJ, An Z, Cherrington AD. Regulation of Hepatic Glucose Uptake and Storage In Vivo. Adv Nutr. 2012;3(3):286-294.

49. Deivanayagam $S$, Mohammed BS, Vitola BE, et al. Nonalcoholic fatty liver disease is associated with hepatic and skeletal muscle insulin resistance in overweight adolescents. Am J Clin Nutr. 2008;88(2):257-262.

50. Borel AL, Nazare JA, Smith J, et al. Visceral, subcutaneous abdominal adiposity and liver fat content distribution in normal glucose tolerance, impaired fasting glucose and/or impaired glucose tolerance. Int $J$ Obes (Lond). 2015;39(3):495-501.

51. Zelber-Sagi S, Lotan R, Shibolet $O$, et al. Non-alcoholic fatty liver disease independently predicts prediabetes during a 7-year prospective follow-up. Liver International. 2013;33(9):1406-1412.

52. Drummen $\mathrm{M}$, Dorenbos $\mathrm{E}$, Vreugdenhil $\mathrm{AC}$, et al. Long-term effects of increased protein intake after weight loss on intrahepatic lipid content and implications for insulin sensitivity - a PREVIEW study. Am J Physiol Endocrinol Metab. 2018.

53. Margolis LM, Rivas DA, Ezzyat Y, et al. Calorie Restricted High Protein Diets Downregulate Lipogenesis and Lower Intrahepatic Triglyceride Concentrations in Male Rats. Nutrients. 2016;8(9).

54. Schwarz J, Tome D, Baars A, Hooiveld GJ, Muller M. Dietary protein affects gene expression and prevents lipid accumulation in the liver in mice. PLoS One. 2012;7(10):e47303.

55. Fabbrini E, Magkos F, Mohammed BS, et al. Intrahepatic fat, not visceral fat, is linked with metabolic complications of obesity. Proc Natl Acad Sci U S A. 2009;106(36):15430-15435.

56. Samuel VT, Shulman GI. The pathogenesis of insulin resistance: integrating signaling pathways and substrate flux. J Clin Invest. 2016;126(1):12-22.

57. Delarue J, Magnan C. Free fatty acids and insulin resistance. Curr Opin Clin Nutr Metab Care. 2007;10(2):142-148.

58. Honka MJ, Latva-Rasku A, Bucci M, et al. Insulin-stimulated glucose uptake in skeletal muscle, adipose tissue and liver: a positron emission tomography study. Eur J Endocrinol. 2018;178(5):523-531.

59. Schmid V, Wagner $R$, Sailer $C$, et al. Non-alcoholic fatty liver disease and impaired proinsulin conversion as newly identified predictors of the long-term non-response to a lifestyle intervention for diabetes prevention: results from the TULIP study. Diabetologia. 2017;60(12):2341-2351.

60. Berthoud HR. Homeostatic and non-homeostatic pathways involved in the control of food intake and energy balance. Obesity (Silver Spring). 2006;14 Suppl 5:197s-200s.

61. Berthoud HR, Münzberg H, Morrison CD. Blaming the brain for obesity: Integration of hedonic and homeostatic mechanisms. Gastroenterology. 2017;152(7):1728-1738.

62. Adam TC, Tsao S, Page KA, Hu H, Hasson RE, Goran MI. Insulin sensitivity and brain reward activation in overweight Hispanic girls: a pilot study. Pediatr Obes. 2015;10(1):30-36.

63. Jastreboff AM, Sinha R, Lacadie C, Small DM, Sherwin RS, Potenza MN. Neural correlates of stress- and food cue-induced food craving in obesity: association with insulin levels. Diabetes Care. 2013;36(2):394402.

64. Kullmann $S$, Heni $M$, Veit $R$, et al. Selective insulin resistance in homeostatic and cognitive control brain areas in overweight and obese adults. Diabetes Care. 2015;38(6):1044-1050.

65. Stouffer MA, Woods CA, Patel JC, et al. Insulin enhances striatal dopamine release by activating cholinergic interneurons and thereby signals reward. Nature Communications. 2015;6:8543.

66. Bruning JC, Gautam D, Burks DJ, et al. Role of brain insulin receptor in control of body weight and reproduction. Science. 2000;289(5487):2122-2125.

67. Figlewicz DP, Evans SB, Murphy J, Hoen M, Baskin DG. Expression of receptors for insulin and leptin in the ventral tegmental area/substantia nigra (VTA/SN) of the rat. Brain Res. 2003;964(1):107-115.

68. Salgado S, Kaplitt MG. The Nucleus Accumbens: A Comprehensive Review. Stereotact Funct Neurosurg. 2015;93(2):75-93.

69. Droutman V, Read S, Bechara A. Revisiting the role of the insula in addiction. Vol 192015.

70. Bär KJ, de la Cruz F, Berger S, Schultz CC, Wagner G. Structural and functional differences in the cingulate cortex relate to disease severity in anorexia nervosa. J Psychiatry Neurosci. 2015;40(4):269-279.

71. Naqvi $\mathrm{NH}$, Bechara $\mathrm{A}$. The insula and drug addiction: an interoceptive view of pleasure, urges, and decisionmaking. Brain Struct Funct. 2010;214(0):435-450.

72. Strubbe JH, Porte D, Jr., Woods SC. Insulin responses and glucose levels in plasma and cerebrospinal fluid during fasting and refeeding in the rat. Physiol Behav. 1988;44(2):205-208.

73. Banks WA, Kastin AJ. Differential permeability of the blood-brain barrier to two pancreatic peptides: insulin and amylin. Peptides. 1998;19(5):883-889.

74. Banks WA. The source of cerebral insulin. Eur J Pharmacol. 2004;490(1-3):5-12. 
75. Lindroos $A K$, Lissner $L$, Mathiassen $M E$, et al. Dietary intake in relation to restrained eating, disinhibition, and hunger in obese and nonobese Swedish women. Obes Res. 1997;5(3):175-182.

76. Cornier MA, Melanson EL, Salzberg AK, Bechtell JL, Tregellas JR. The effects of exercise on the neuronal response to food cues. Physiol Behav. 2012;105(4):1028-1034.

77. Killgore WD, Kipman M, Schwab ZJ, et al. Physical exercise and brain responses to images of high-calorie food. Neuroreport. 2013;24(17):962-967.

78. Leidy HJ, Ortinau LC, Douglas SM, Hoertel HA. Beneficial effects of a higher-protein breakfast on the appetitive, hormonal, and neural signals controlling energy intake regulation in overweight/obese, "breakfast-skipping," late-adolescent girls. Am J Clin Nutr. 2013;97(4):677-688.

79. Griffioen-Roose S, Smeets PA, van den Heuvel E, Boesveldt S, Finlayson G, de Graaf C. Human protein status modulates brain reward responses to food cues. Am J Clin Nutr. 2014;100(1):113-122.

80. Choi S, Disilvio B, Fernstrom MH, Fernstrom JD. Meal ingestion, amino acids and brain neurotransmitters: effects of dietary protein source on serotonin and catecholamine synthesis rates. Physiol Behav. 2009;98(12):156-162.

81. Growdon JH, Cohen EL, Wurtman RJ. Effects of oral choline administration on serum and CSF choline levels in patients with Huntington's disease. J Neurochem. 1977;28(1):229-231.

82. Kondoh T, Mallick HN, Torii K. Activation of the gut-brain axis by dietary glutamate and physiologic significance in energy homeostasis. Am J Clin Nutr. 2009;90(3):832s-837s.

83. Journel M, Chaumontet C, Darcel N, Fromentin G, Tome D. Brain responses to high-protein diets. Adv Nutr. 2012;3(3):322-329.

84. Leidy HJ, Clifton PM, Astrup A, et al. The role of protein in weight loss and maintenance. The American Journal of Clinical Nutrition. 2015;101(6):1320S-1329S.

85. Ronan L, Alexander-Bloch AF, Wagstyl K, et al. Obesity associated with increased brain age from midlife. Neurobiol Aging. 2016;47:63-70.

86. Soenen S, Bonomi AG, Lemmens SG, et al. Relatively high-protein or 'low-carb' energy-restricted diets for body weight loss and body weight maintenance? Physiol Behav. 2012;107(3):374-380.

87. Bryck RL, Fisher PA. Training the Brain: Practical Applications of Neural Plasticity From the Intersection of Cognitive Neuroscience, Developmental Psychology, and Prevention Science. Am Psychol. 2012;67(2):87100.

88. Marckmann $\mathrm{P}$, Osther $\mathrm{P}$, Pedersen $\mathrm{AN}$, Jespersen $\mathrm{B}$. High-protein diets and renal health. J Ren Nutr. 2015;25(1):1-5.

89. Moller G, Rikardt Andersen J, Ritz C, et al. Higher Protein Intake Is Not Associated with Decreased Kidney Function in Pre-Diabetic Older Adults Following a One-Year Intervention-A Preview Sub-Study. Nutrients. 2018;10(1). 

SUMMARY 
The increasing prevalence in type-2 diabetes (T2D) has also increased the surge for finding optimal T2D prevention and treatment strategies. Many of these strategies have been directed at reducing the risk factors obesity and insulin resistance, a precursor in the pathogenesis of T2D. In this perspective, the PREVIEW-study (Prevention of Diabetes through lifestyle intervention and population studies in Europe and around the World) was initiated. The PREVIEW-study is a multicentre trial, in which the impact of a high-protein, low-glycaemic index (GI) vs. moderate protein, moderate-GI diet in combination with moderate or high-intensity physical activity on the incidence of T2D are investigated in individuals with pre-diabetes (CHAPTER 2).

In total, 2326 participants who met the ADA pre-diabetes inclusion criteria were recruited. They presented with increased body weight and insulin resistance (CHAPTER 2). At baseline, we found multiple relationships that helped to characterize this population. Physical activity (PA) was positively associated and sedentary time (ST) was inversely associated with cardiometabolic health, including insulin resistance, within this population (CHAPTER 3). Therefore, replacing ST with PA may be a practical approach to improve cardiometabolic health. Furthermore, the participants were characterized by positive associations of insulin resistance with intrahepatic lipids (IHL) (CHAPTER 7) and with brain reactivity to food cues (CHAPTER 5). Moreover, reactivity to food cues was positively related to TFEQ disinhibition/emotional eating and inversely related to Baecke habitual physical activity during leisure time in multiple brain regions associated with the attention and reward network.

Taken together, these findings at the start of the PREVIEW study underlined the relevance of an intervention to prevent T2D in these participants but also showed that longitudinal measurements of $\mathrm{IHL}$ and brain reward activity along with the assessment of changes in body weight, body composition or insulin resistance were relevant to gain more insights in the underlying pathology.

The PREVIEW intervention started with an 8-week low energy diet (LED) to establish body weight loss. We showed that this was a suitable method to reach the contemplated $8 \%$ body weight loss, evidenced by an average weight loss of $11 \%$ (CHAPTER 6). The weight loss was higher in men than in women and this was accompanied by relatively larger reductions in metabolic syndrome scores. Still, more weight loss could have been achieved with full compliance to the LED based on a theoretically achievable weight loss of $14 \%$. The second phase of the PREVIEW intervention consisted of a 34-month lifestyle intervention aimed to maintain the lost body weight in four intervention groups, differing in physical activity and dietary guidelines. Dietary guidelines of the PREVIEW intervention consisted of two groups differing in protein intake and GI/GL. Increasing protein intake has been recommended to achieve weight loss and a daily protein intake of at least $0.8 \mathrm{~g} / \mathrm{kg}$ body weight was sufficient for weight maintenance after weight loss (CHAPTER 4). However, the additional value of a relatively high protein diet for T2D, cardiovascular diseases, non-alcoholic fatty liver disease remains inconclusive.

The lifestyle intervention led to long-term reductions in body weight and insulin resistance. Effects of the intervention on IHL were assessed in 25 participants using magnetic resonance spectroscopy (CHAPTER 7). Simultaneously, visceral adipose tissue (VAT) and subcutaneous adipose tissue (SAT) were determined using magnetic resonance imaging. IHL, VAT and SAT were 
reduced at 6 months and 2 years compared to baseline. We did not find different changes in $\mathrm{IHL}$, VAT or SAT between the two protein groups. We also did not find differences in protein intake assessed with urinary nitrogen excretion between the two groups. In the whole group of participants daily protein intake was inversely related to IHL at 6 months. Furthermore, IHL was positively related to insulin resistance throughout the intervention, independent of BMI. These findings suggest that protein intake may indirectly increase insulin sensitivity via reductions in $\mathrm{IHL}$ and focusing on reducing IHL may be crucial within diabetes prevention interventions.

We also determined brain reward activation in response to visual stimuli using functional magnetic resonance imaging in a sub-group of the PREVIEW participants and assessed possible relations with anthropometric, metabolic or behavioral parameters (CHAPTER 8). As mentioned before, at baseline, food-reward related brain activation was positively associated with HOMA-IR, TFEQ disinhibition/emotional eating and inversely associated with Baecke habitual physical activity during leisure time. The relationship between food-reward related brain activation and insulin resistance was further evidenced by the positive association between changes in food reward-related brain activation and changes in insulin resistance from baseline to 2 years. Furthermore, changes in food reward-related brain activation were positively associated with changes in BMI and body-fat percentage and inversely associated with changes in TFEQ dietary restraint scores and with protein intake during the weight maintenance period. These findings indicate that people with pre-diabetes and overweight/obesity may have increased risk for hyperphagia and 'unhealthy' eating behaviors due to altered food reward processing in the brain, while behavioral factors like physical activity, protein consumption, weight loss and cognitive restraint may counteract these alterations. Next to brain activation, we also measured brain structure to determine if grey matter volume or cortical thickness would change during the PREVIEW intervention along with changes in body weight or insulin resistance (CHAPTER 9). We found an inverse association between grey matter volume and insulin resistance at baseline, but the intervention did not lead to changes in global grey matter volume. Furthermore we did not find changes in cortical thickness along with weight loss and long-term weight maintenance.

In conclusion, the heterogeneous PREVIEW cohort successfully achieved $8 \%$ body weight loss using the 8-week low energy diet and showed the relevance of the PREVIEW intervention especially for evaluating changes in insulin sensitivity and its implications on organ level, like liver and brain. In the participants, insulin resistance was reduced after 2 years of diet and exercise intervention accompanied by reductions in $\mathrm{IHL}$ and by reduced food reward related brain activation. The changes in brain reactivity were linked to increased control of eating behavior, adjusted for changes in BMI. More specifically and on group level, protein intake was related to reductions in IHL and changes in brain reward activity, demonstrating beneficial effects that supersede effects on body weight loss or body weight management.

With these findings, we distinguished important aspects of a diabetes prevention program and future programs should incorporate efforts to reduce IHL and normalize brain signalling. Furthermore, mapping differences and similarities within the pre-diabetes population may contribute to better understanding of underlying pathologies and therefore may help to design tailored T2D prevention and treatment methods. 

SAMENVATTING 
De huidige toename van type 2 diabetes (T2D) vergt meer onderzoek naar mogelijke preventie of behandeling. Dergelijk onderzoek is vooral gericht op reductie van het lichaamsgewicht, en daarmee reductie van insulineresistentie. Deze twee factoren vormen de grootste risico's voor de ontwikkeling van T2D. In dit kader startte in 2013 het onderzoek naar "PREVentie van diabetes door leefstijlinterventie en populatie studies in Europa en in de Wereld", afgekort PREVIEW. Dit PREVIEW onderzoek bestaat uit een zogeheten multi-center studie waarin de effecten van twee verschillende eiwit-diëten in combinatie met lichamelijke activiteit op twee verschillende intensiteitsniveaus werden vergeleken. De diëten verschilden in relatief hoog of medium eiwitniveau, gecombineerd met producten van respectievelijk lage of medium glycaemische index (GI); de intensiteitsniveaus van lichamelijke activiteit waren zeer intensief of medium intensief. De belangrijkste vraagstelling van het onderzoek was welke leefstijl combinatie (Hoog-eiwit, laag GI, zeer intensieve activiteit; hoog-eiwit, laag GI, medium intensieve activiteit; medium-eiwit, medium GI, zeer intensieve activiteit; medium-eiwit, medium GI, medium intensieve activiteit) het sterkst de ontwikkeling van T2D binnen 3 jaar zou voorkomen.

De deelnemers werden zodanig geselecteerd dat zij aan de criteria voor 'prediabetes' voldeden; 2326 deelnemers werden aldus in 8 verschillende centra over de gehele wereld geselecteerd, waaronder de Universiteit Maastricht. Allen hadden overgewicht en een verhoogde insulineresistentie (HOOFDSTUK 2). Voor de start van de interventie werden enige mogelijke assocciaties onderzocht. Lichamelijke activiteit bleek positief, en sedentair gedrag negatief geassocieerd te zijn met een gezond metabolisme van hart en bloedvaten. Vervanging van sedentair door actief gedrag zou wellicht een gezond metabolisme kunnen bevorderen (HOOFDSTUK 3). Tevens werd een positief verband gevonden tussen insulineresistentie en vetstapeling in de lever (HOOFDSTUK 7). Ten slotte werd een negatief verband aangetoond tussen de reactie in beloningsgebieden van de hersenen bij het zien van voedselplaatjes en lichamelijke activiteit, hetgeen inhoudt dat bij meer lichamelijke activiteit de reactie in de desbetreffende hersengebieden minder sterk is, en daarmee de beheersing van de voedsel inname sterker is (HOOFDSTUK 5). Deze bevindingen voor de start van de interventie bevestigen ten aanzien van lichamelijke activiteit de relevantie van de interventie op zich, maar geven ook de noodzaak aan om specifieke effecten ten aanzien van voedselinname beheersing (in de hersenen) en levervetstapeling te onderzoeken.

Het eerste deel van de PREVIEW interventie bestond uit een 8 weken durend afvaldieet. Om daarna door te kunnen gaan dienden de deelnemers ten minste $8 \%$ van hun lichaamsgewicht te verliezen. Het gemiddelde gewichtsverlies van hen die dat bereikten, bleek $11 \%$ te zijn. Desondanks zou het gewichtsverlies zelfs $14 \%$ geweest kunnen zijn wanneer de deelnemers zich strikt aan het afvaldieet gehouden hadden. Mannen hadden een groter gewichtsverlies dan vrouwen, en daarmee een sterkere vermindering van hun zogeheten metabool syndroom (HOOFDSTUK 6). Hierna startte de 34 maanden durende leefstijlinterventie, met het doel het verkregen lichaamsgewicht te stabiliseren, en behouden. De eerder genoemde vier types leefstijlinterventie werden toegepast, en begeleid via specifieke groepsinstructies. De eiwit-diëten met een dagelijkse eiwit-inname van ten minste $0,8 \mathrm{~g} / \mathrm{kg}$ lichaamsgewicht zijn op basis van eerdere studies succesvol gebleken. Echter, of een hoog-eiwit dieet naast het effect van 
gewichtsbeheersing toegevoegde effecten heeft op T2D, cardiovasculaire ziektes of nietalcoholische leververvetting was tot nu toe niet bekend (HOOFDSTUK 4).

Na 6 maanden, en na 2 jaar, zijn de metingen van de leververvetting bij de desbetreffende deelnemers herhaald. Het lichaamsgewicht en de insulineresistentie van de deelnemers waren sterk afgenomen. Tevens bleek de leververvetting sterk te zijn afgenomen, alsook het buikvet en onderhuids vet. Tussen de twee eiwit-dieet groepen waren geen verschillen hierin ontstaan, maar deze dieet groepen bleken in de praktijk ook niet in eiwit-inname te verschillen. Wel was er na 6 maanden een negatieve associatie tussen eiwit-inname en vetstapeling in de lever, hetgeen impliceert dat degenen met een hogere eiwit-inname een geringere vetstapeling in de lever lieten zien. De reeds aanwezige positieve associatie tussen insulineresistentie en leververvetting bleef aanwezig, onafhankelijk van het lichaamsgewicht. De combinatie van deze waarnemingen suggereert dat de eiwit-inname een indirect effect op de insulineresistentie heeft, via verandering in leververvetting. Voorts duiden deze resultaten op het belang van vermindering van leververvetting, voor preventie van T2D (HOOFDSTUK 7).

De veranderingen in hersenactiviteit in de voedsel gerelateerde beloningsgebieden zijn beschreven in hoofdstuk 8. Na twee jaar bleken deze veranderingen in hersenactiviteit positief geassocieerd te zijn met veranderingen in insulineresistentie, hetgeen impliceert dat degenen met een sterkere reductie in insulineresistentie verminderde voedsel gerelateerde hersenactiviteit vertoonden, ofwel, een sterkere beheersing van hun voedselinname. Bovendien waren de veranderingen in hersenreactiviteit positief gerelateerd aan veranderingen in lichaamsgewicht en lichaamsvetpercentage en negatief gerelateerd aan de veranderingen in geremd eetgedrag en eiwit inname gedurende de gewichtsbehoudfase. Gewichtsvermindering, geremd eetgedrag, en een hogere eiwit-inname gaan dus samen met sterkere beheersing van de voedselinname (HOOFDSTUK 8). Naast hersenreactiviteit zijn de effecten van de PREVIEW interventie op het volume van de grijze hersenstof en de dikte van de hersenschors bepaald. Voor de interventie was er een negatieve relatie tussen het volume van de grijze hersenstof en insulineresistentie, maar tijdens de interventie traden geen veranderingen hierin op. Ook de dikte van de hersenschors veranderde niet (HOOFDSTUK 9).

De conclusie van dit proefschrift is dat de PREVIEW deelnemers met succes het afval-dieet gevolgd hebben, met meer dan $8 \%$ gewichtsverlies in de eerste 8 weken. Vervolgens leidde de PREVIEW interventie tot een significante vermindering in insulineresistentie na 2 jaar, tot verlaging van de mate van leververvetting, en tot sterkere beheersing van de voedselinname. Deze veranderingen in leververvetting en beheersing van de voedsel-inname hielden verband met de eiwit-inname na twee jaar, met de veranderingen in insulineresistentie, lichaamsgewicht en lichaamsvet, en verandering in geremd eetgedrag. De bevindingen wijzen op additionele effecten van eiwitinname, naast effecten op gewichtsverlies of gewichtsbehoud. 



\section{VALORISATION}




\section{SOCIETAL RELEVANCE}

Diabetes is one of the fastest growing chronic diseases worldwide and already 422 million people have diabetes according to the WHO. Every year, 1.6 million deaths are directly attributable to diabetes. Around $90 \%$ of all diabetes cases are made up by type-2 diabetes (T2D), which usually develops later in life. The development T2D has been associated with lifestyle and environmental factors and therefore the key for successful prevention of T2D may lie in changing these factors.

The PREVIEW study was initiated in 2013 with the aim to find the most effective lifestylecomponents (diet and physical activity) in the prevention of T2D. Furthermore, the study was set out to increase our knowledge on the relationship between lifestyle factors, health and wellbeing. The PREVIEW intervention was shown to be highly successful for long-term body weight loss and reductions in insulin resistance. The large number of participants benefitted directly from the intervention and our findings are especially relevant for the increasing number of people classified as having pre-diabetes. However, since we found beneficial effects on a variety of anthropometric, metabolic and behavioral parameters, it really indicates the importance of lifestyle intervention for improving health in a population with pre-diabetes.

In the first 8-weeks of the PREVIEW intervention participants started with a low-energy diet (LED) to achieve at least $8 \%$ weight loss. During this period, participants consumed a range of formula products of the Cambridge Weight Plan (Northants, UK). The average weight loss of the participants was $11 \%$, showing the success of the LED. Our results contribute to the evidence that a LED is a safe and suitable method to achieve weight loss and by presenting our findings at national and international meetings we hoped to stimulate the usage of LEDs in clinical settings.

It is evident that a better understanding of processes in specific organs and their role in diabetes development and prevention will help to develop new therapeutic or preventive methods for T2D. We were able to show effects of the intervention on intrahepatic lipids and brain reward reactivity using non-invasive imaging techniques.

Moreover, the close association of intrahepatic lipid accumulation and insulin resistance that we found throughout the intervention underlined the importance to address intrahepatic lipids in the prevention of T2D. Furthermore, with the increasing number of people presenting with liver diseases including non-alcoholic fatty liver disease, better strategies to reduce intrahepatic lipids are needed. We showed that sufficiently high protein intake after weight loss was associated with reduced intrahepatic lipids. This finding may contribute to developing optimal diet strategies to reduce intrahepatic lipids or prevent intrahepatic lipid accumulation.

We also found multiple factors interacting with brain reward reactivity. Increased body weight, body-fat percentage and insulin resistance was related to increased brain reactivity to food images, while increased protein intake during weight maintenance and dietary restraint was related to reduced brain reactivity to food images. These findings may suggest that people with increased body weight or insulin resistance are more sensitive for food cues in terms of anticipated reward and therefore overeat and have less control over their food intake. This is an important issue to address especially for long-term weight loss and interventions. Since we also 
found inverse relations between protein intake during the weight maintenance phase and changes in cognitive restraint and brain reactivity to food cues, these factors may be exploited to reduce the increased sensitivity to food cues and therefore increase compliance to a diet or intervention.

\section{ECONOMIC RELEVANCE}

According to the $\mathrm{WHO}, 2.5 \%$ to $15 \%$ of annual national health care budgets are direct healthcare costs of diabetes. Therefore, the prevention of T2D is also relevant from an economical aspect. PREVIEW will assess the costs, effectiveness and benefits of providing extended support, reinforcement and motivation to make lifestyle changes and maintain these in the longer term. This information will be relevant for future prevention programs and assigning clinical value to such designs. The research was funded by the $7^{\text {th }}$ Framework Programme of the European Commission, which also indicates the interest for the whole society.

The findings will also help in the debate of the validity and consequences of the 'pre-diabetes' classification. Especially since the pre-diabetes cut points were lowered by the American Diabetes Association, people have argued that the resulting rise in people with pre-diabetes exceed the capacity of health care systems. Moreover, the ranges in parameters like insulin resistance, body weight, age etc. of the population with pre-diabetes increased, leading to difficulties in the interpretation of interventions and outcomes.

\section{ACTIVITIES AND PRODUCTS}

Obviously, research alone will not lead to a reduction in the risk of diabetes. Therefore, an important part of the PREVIEW study was to facilitate the new knowledge from the project to all relevant stakeholders. This has been achieved in different ways and forms.

First of all we used the PREVIEW website (www.previewstudy.com), via which everyone had and still has easy access to the study information, newsletters and results/publications. Moreover, the website includes an e-learning module which has been specifically designed using the knowledge of the PREVIEW study and PREVIEW partners to educate the general public. The e-learning module contains study material to learn about diabetes, diet, physical activity and behavior change using an interactive format.

Furthermore, we developed and published the PREMIT toolbox, which is a theory-driven, evidence-based program to change physical activity and dietary behaviors people with prediabetes. This toolbox was designed for the PREVIEW study, but by publishing it we shared this knowledge for future interventions and treatment programs.

Other features of the project that by themselves or in combinations may lead to future practical applications include the cook books with recipes designed by Meyers Madhus to reach or limit a glycaemic index level and eating plans based on food unit systems. Moreover, information on glycaemic index values have been made available to national food databases so it can be reached by the general public. 


\section{TRANSLATION INTO PRACTICE}

A major strength of the PREVIEW study is the feasibility to translate the study and especially the intervention into practice. Results and conclusions can therefore be readily transferred to clinical interventions and treatment methods. The intervention was applied in free living conditions and dietary and physical activity guidelines were designed to be feasible for everyone without additional resources or personal counseling. Guidance was provided via group counseling sessions, which is a practical and economical way to reach a larger audience. Next to these practical issues, this type of research is pivotal to translate findings from animal work or smaller and controlled studies to daily life settings. 
ACKNOWLEDGEMENTS 
Dit proefschrift was nooit tot stand gekomen zonder de hulp van velen. Ik wil iedereen bedanken die op wat voor manier dan ook heeft geholpen. Merci!

Een speciaal woord van dank aan mijn promotieteam, dat mijn promotie heeft mogelijk gemaakt en waar ik ontzettend veel van heb mogen leren. Margriet, bedankt voor het vertrouwen, voor alle kansen en de vrijheid. En naast deze vrijheid ook voor de nodige doelgerichtheid en deadlines. Tanja, bedankt voor de dagelijkse begeleiding en hulp en voor het verbreden van mijn wetenschappelijke (en niet-wetenschappelijke) visie. Anita, bedankt voor de begeleiding en de hulp bij dit proefschrift.

Next, I would like to thank Prof. dr. Patrick Schrauwen, Prof. dr. Ad Masclee, Prof. dr. Rainer Goebel, Prof. dr. Daniel Tomé and Prof. dr. Hubert Preissl, the members of the reading committee, for their effort and time in reviewing my thesis.

Big thanks to the PREVIEW consortium/family and special thanks to our boss Anne for guiding us through this endeavor. I would like to thank everyone who has helped with the many screenings, test days and group meetings, including all the interns. Mandy, your help in the beginning of the study was indispensable and without you I wouldn't have managed to get through the first months. Nuria, you helped so much with the test days, brain scans, group meetings and much more. I still can't believe that you came to help even after your first experiences working with me... Elke, bedankt voor 'het ondergaan van hetzelfde PREVIEW lot' en succes met jouw afronding! Blandine, thanks for the practical help during your 'sabbatical' and it is awesome that you will take part in the defense committee. Big thanks to Armin, Hester, Lucas and Vera for your help with analyzing all the brain and liver data.

Natuurlijk ook een woord van dank aan de vele PREVIEW deelnemers die tot 3 jaar lang vrijwillig aan de studie hebben meegedaan. Zonder jullie was er niets om over te schrijven.

Rick, bedankt voor de hulp bij de PREVIEW studie en MRI metingen. En voor het zijn van de allerbeste eerste roomie! Ik wil ook de volgende kamergenoten Jakob, Carlijn en Lea bedanken voor de heerlijk rustige kamer en fijne sfeer. Speciaal woord van dank aan Lea voor de hulp met PREVIEW en ervoor te zorgen dat het aantal AIO's van Tanja werd verdubbeld. Guy en Emanuel, fijn dat jullie me willen ondersteunen als paranimfen. Bedankt voor de gezelligheid en ontspanning naast de werkzaamheden! Verder wil ik alle andere (ex-)collega's hartelijk danken voor de hulp en de fijne tijd. Aangezien ik hier vrij lang heb rondgelopen, zijn het ondertussen te veel namen om apart te vermelden. Om niemand te vergeten daarom een dikke merci aan jullie allemaal!

Alle vrienden en (sjoen)familie thuis wil ik bedanken voor de ontspanning, liefde en muziek in mijn leven. Pap, mam, Bente en Roy bedankt voor de onvoorwaardelijke steun. Zonder jullie had ik dit nooit kunnen bereiken.

Tot slot wil ik Rosanna bedanken. Bedankt voor je liefde, Italiaanse passie en emotie. Door jou vergat ik thuis meteen alle 'kleinigheden' van het werk... Jouw hulp gaat veel verder dan alleen dit proefschrift. 


\section{LIST OF PUBLICATIONS}


Drummen M, Dorenbos E, Vreugdenhil ACE, Raben A, Stratton G, Westerterp-Plantenga MS, Adam TC. Associations of brain reactivity to food cues with weight loss, protein intake and dietary restraint during the PREVIEW intervention. Nutrients. 2018 Nov 15; 10(11)

Huttunen-Lenz M, Hansen S, Christensen P, Meinert Larsen T, Sandø-Pedersen F, Drummen M, Adam TC, Macdonald IA, Taylor MA, Martinez JA, Navas-Carretero S, Handjiev S, Poppitt SD, Silvestre MP, Fogelholm M, Pietiläinen $\mathrm{KH}$, Brand-Miller J, Berendsen AA, Raben A, Schlicht W. PREVIEW studyinfluence of a behavior modification intervention (PREMIT) in over 2300 people with pre-diabetes: intention, self-efficacy and outcome expectancies during the early phase of a lifestyle intervention. Psychol Res Behav Manag. 2018 Sep 12; 11:383-394

Drummen M, Dorenbos E, Vreugdenhil ACE, Raben A, Westerterp-Plantenga MS, Adam TC. Insulin Resistance, Weight and Behavioral Variables as Determinants of Brain Reactivity to Food Cues - a PREVIEW Study. Am J Clin Nutr. In press

Hansen S, Huttunen-Lenz M, Sluik D, Brand-Miller J, Drummen M, Fogelholm M, Handjieva-Darlenska T, Macdonald I, Martinez AJ, Larsen TM, Poppitt S, Raben A, Schlicht W. Demographic and SocialCognitive Factors Associated with Weight Loss in Overweight, Pre-diabetic Participants of the PREVIEW Study. Int J Behav Med. 2018 Dec 25(6); 682-692

Drummen M, Dorenbos E, Vreugdenhil AC, Raben A, Fogelholm M, Westerterp-Plantenga MS, Adam T. Long-term effects of increased protein intake after weight loss on intrahepatic lipid content and implications for insulin sensitivity - a PREVIEW study. Am J Physiol Endocrinol Metab. 2018 315;5, E885891

Christensen P, Meinert Larsen T, Westerterp-Plantenga M, Macdonald I, Martinez JA, Handjiev S, Poppitt S, Hansen S, Ritz C, Astrup A, Pastor-Sanz L, Sandø-Pedersen F, Pietiläinen KH, Sundvall J, Drummen M, Taylor MA, Navas-Carretero S, Handjieva-Darlenska T, Brodie S, Silvestre MP, HuttunenLenz M, Brand-Miller J, Fogelholm M, Raben A. Men and women respond differently to rapid weight loss: Metabolic outcomes of a multi-centre intervention study after a low-energy diet in 2500 overweight, individuals with pre-diabetes (PREVIEW). Diabetes Obes Metab. 2018 Dec; 20(12):28402851

Drummen M, Tischmann L, Gatta-Cherifi B, Adam T, Westerterp-Plantenga M. Dietary Protein and Energy Balance in Relation to Obesity and Co-morbidities. Front Endocrinol (Lausanne). 2018 Aug 6;9:443 Review.

Dorenbos E, Drummen M, Rijks J, Adam T, Stouthart P, Alfredo Martínez J, Navas-Carretero S, Stratton G, Swindell N, Fogelholm M, Raben A, Westerterp-Plantenga M, Vreugdenhil A. PREVIEW (Prevention of Diabetes Through Lifestyle Intervention and Population Studies in Europe and Around the World) study in children aged 10 to 17 years: Design, methods and baseline results. Diabetes Obes Metab. 2018 May;20(5):1096-1101

Swindell N, Mackintosh K, McNarry M, Stephens JW, Sluik D, Fogelholm M, Drummen M, MacDonald I, Martinez JA, Handjieva-Darlenska T, Poppitt SD, Brand-Miller J, Larsen TM, Raben A, Stratton G. Objectively Measured Physical Activity and Sedentary Time Are Associated With Cardiometabolic Risk Factors in Adults With Prediabetes: The PREVIEW Study. Diabetes Care. 2018 Mar 41(3):562-569 
Fogelholm M, Larsen TM, Westerterp-Plantenga M, Macdonald I, Martinez JA, Boyadjieva N, Poppitt S, Schlicht W, Stratton G, Sundvall J, Lam T, Jalo E, Christensen P, Drummen M, Simpson E, NavasCarretero S, Handjieva-Darlenska T, Muirhead R, Silvestre MP, Kahlert D, Pastor-Sanz L, Brand-Miller J, Raben A.PREVIEW: Prevention of Diabetes through Lifestyle Intervention and Population Studies in Europe and around the World. Design, Methods, and Baseline Participant Description of an Adult Cohort Enrolled into a Three-Year Randomised Clinical Trial. Nutrients. 2017 Jun 20;9(6)

De Saint-Hubert M, Bauwens M, Deckers N, Drummen M, Douma K, Granton P, Hendrikx G, Kusters D, Bucerius J, Reutelingsperger CP, Mottaghy FM. In vivo molecular imaging of apoptosis and necrosis in atherosclerotic plaques using microSPECT-CT and microPET-CT imaging. Mol Imaging Biol. 2014 Apr;16(2):246-54

Gonnissen HK, Drummen M, Rosique Esteban N, Schoffelen PF, Westerterp-Plantenga MS. Overnight energy expenditure determined by whole-body indirect calorimetry does not differ during different sleep stages. Am J Clin Nutr. 2013 Oct;98(4):867-71

Drummen M, Heinecke A, Dorenbos E, Vreugdenhil ACE, Raben A, Westerterp-Plantenga MS, Adam TC. Grey matter volume and cortical thickness in the PREVIEW study.

- submitted -

Huttunen-Lenz M; Hansen S; Meinert Larsen T, Christensen P, Drummen M, Adam TC, Taylor M, Simpson L, Martinez JA, Navas-Carretero S, Handjieva-Darlenska T, Poppitt SD, Silvestre MP, Fogelholm M, Muirhead R, Brodie S, Raben A, Schlicht W. Supporting Lifestyle Changes in a Large International Intervention Study, the PREVIEW Study.

- submitted -

Swindell N, Hansen S, Mackintosh K, McNarry M, Stephens JW, Sluik D, Navas-Carreto S, Fogelholm M, Drummen M, MacDonald I, Martinez JA, Handjieva-Darlenska T, Poppitt SD, Brand-Miller J, Larsen TM, Raben A, Slicht W, Stratton G. Personal and psychosocial correlates of physical activity in adults with pre-diabetes from 8 countries: the PREVIEW study.

- in preparation . 


\section{ABOUT THE AUTHOR}

Mathijs Drummen was born on the 11th of April 1989 in Heerlen, the Netherlands. He obtained his Gymnasium diploma from the Porta Mosana College Maastricht in 2007. He continued his education with the bachelor study Biomedical Sciences at Maastricht University. During his bachelor studies, he obtained his Biology Teaching Degree at the Teachers Academy in Maastricht. In 2012, he started with the master Biomedical Sciences at Maastricht University during which he performed his first internship at the department of Nuclear Medicine at Maastricht University Medical Center and studied the staging of atherosclerosis by means of molecular imaging of cell death in mice. He performed his second internship at the department of Human Biology and studied long-term effects of dietary protein on body composition, energy expenditure and sleep architecture.

He graduated in 2013 and started his PhD at the department of Nutrition and Movement Sciences at Maastricht University under supervision of Prof. dr. Margriet Westerterp-Plantenga, dr. Tanja Adam and dr. Anita Vreugdenhil. The research conducted during this period is described in this PhD thesis entitled 'Prevention of Diabetes through Lifestyle Intervention - Liver fat and Brain - '. The performed studies were part of the PREVIEW-study, a large multicentre study aimed at finding optimal lifestyle strategies to prevent the development of type 2 diabetes in individuals with pre-diabetes. 